\title{
AREA ASSESSMENT OF A PEDESTRIAN WIND ENVIRONMENT USING POINT WIND SPEED MEASUREMENTS
}

\author{
BENJAMIN JAN KEPKA \\ SUPERVISED BY: \\ MICHAEL DONN (VICTORIA UNIVERSITY OF WELLINGTON) \\ PAUL CARPENTER (OPUS CENTRAL LABORATORIES) \\ THESIS SUBMITTED AS THE REQUIREMENT FOR COMPLETION OF THE \\ MASTER OF BUILDING SCIENCE
}

APRIL 2010 


\section{ABSTRACT}

This research has successfully produced a means of creating a reliable area measurement of a pedestrian level wind environment from a reasonable number of point wind speed measurements. To complete this aim a contouring script was developed through MATLAB. The script has the ability to read in series of point wind speed measurements coupled with cartesian co-ordinates and generate a reliable contour diagram.

The foundation for this research is a resource of over 150 wind tunnel tests conducted for code compliance in Wellington City. The District Plan in Wellington requires any building over $18.6 \mathrm{~m}$ in height to have a wind tunnel analysis conducted to assess the changes in wind speed with respect to pedestrian safety. Wellington compliance criteria require two forms of measurement to be conducted. Point measurements are taken to quantify wind speeds accurately, but are unable to efficiently assess large areas. Area measurement techniques are used to assess the comparative windiness of zones around the development site. Through examination of 3000 measured data points it has been demonstrated that the correlation between these two measurement techniques is relatively low. Until now, neither test alone has been sufficient to accurately quantify the impact of a new development on the pedestrian level wind environment as a whole.

Interpolation methods were used to generate pseudo measurements between points at which wind speeds were measured. A series of three building configurations were assessed using the MATLAB script to visualise the effect of increasing building height on pedestrian level winds. The building configurations assessed were: a uniformly distributed grid of 25 half cubes $(60 \mathrm{~m} \times 60 \mathrm{~m} \times 30 \mathrm{~m})$, central full cube $(60 \mathrm{~m} \times 60 \mathrm{~m} \times 60 \mathrm{~m})$, and, a central tall tower $(60 \mathrm{~m} \times 60 \mathrm{~m} \times 240 \mathrm{~m})$. Each building configuration was simulated through the contouring script and the resultant contours were assessed to ensure a realistic depiction of easily predictable wind flow patterns such as downwash and the corner effect.

The resolution of the output contours in any case is directly related to the number of point wind speed measurements used. It has been found that measurement points should be more densely located $(15 \mathrm{~m}$ in scale) around the site in question, and more sparsely located ( $30 \mathrm{~m}$ in scale) around the outer regions of the desired testing area. This is the most efficient method of generating contours for use in commercial pedestrian level wind laboratories. Mathematically generated contours have the potential to provide a more reliable output than those produced through current methods of area testing. 


\section{ACKNOWLEDGEMENTS}

I would like to thank and acknowledge the guidance offered by a number of individuals throughout this research. First and foremost, I would like to thank my primary supervisor Michael Donn. Mike is the reason I aspire to be in the building aerodynamics industry. He has provided countless opportunities to observe meetings and get involved in commercial projects around Wellington City. Without his support and creative academic insight this research would not have been possible.

I would also like to thank my secondary supervisor Paul Carpenter for his technical and practical advice during my work at Opus Central Laboratories. His help with the design of the MATLAB scripture was invaluable. Paul's guidance ensured the process was efficient and that the most practical solution was achieved. Without his guidance the project may never have been able to be completed. The post-work squash games will remain in my memory forever, for they were always a great battle!

Opus Central Laboratories played a major role in this research. I am extremely grateful for the financial support I received through the Enterprise Scholarship. Having the opportunity to gain priceless work experience by conducting pedestrian level building aerodynamics assessments was an amazing opportunity. Peter Cenek, and Neil Jamieson also played major roles, not only in conducting a number of the wind tunnel studies used throughout this research but, by providing positive thought provoking insights into the building aerodynamics industry.

My parents, Richard and Andrea, I would like to thank for all of the support they have given me throughout the writing of this thesis, without it my postgraduate research would not have been possible. To the administrative staff of Victoria University I thank you greatly for arranging the various scholarship procedures. My classmates Nick Smith and Jess Bennet provided a number of alternative insights and distractions that were essential in remaining positive throughout this research. I would finally like to thank Sam McQuilkan for his help with editing and his positive encouragement throughout my thesis writing.

To anyone who I have not mentioned (which I am sure there are many) I thank you greatly, for this research is not merely the work of one individual but the culmination of many great minds 


\section{CONTENTS}

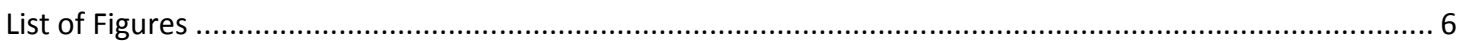

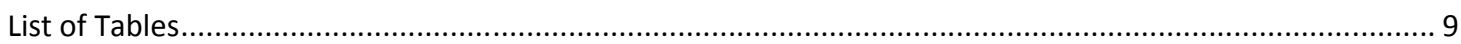

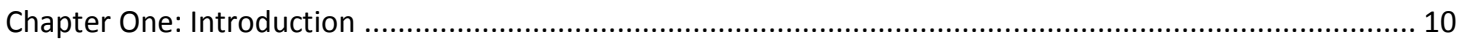

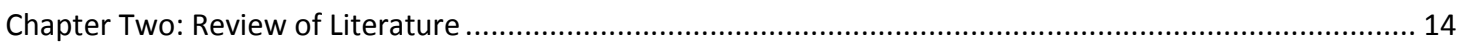

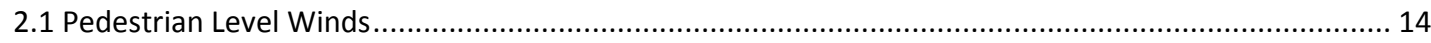

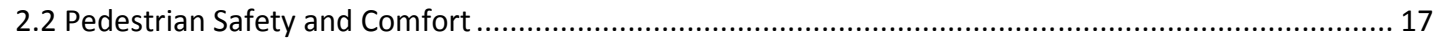

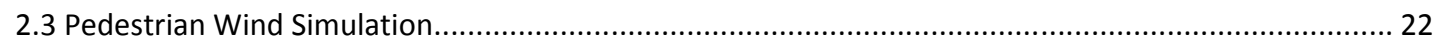

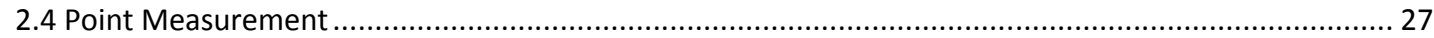

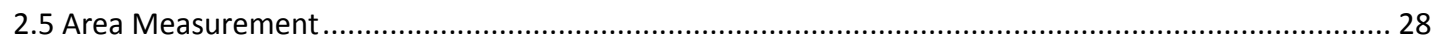

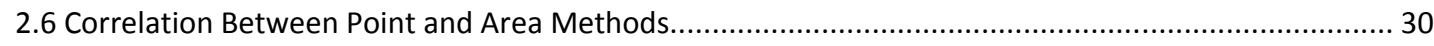

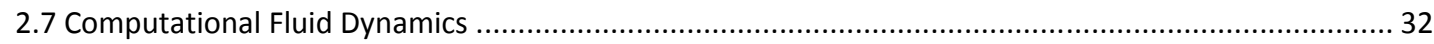

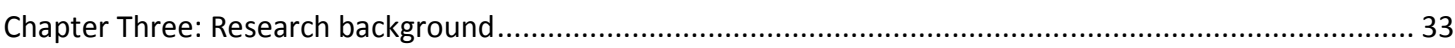

3.1.1 Relationship Between Measured Windspeed and Contour Level ............................................. 35

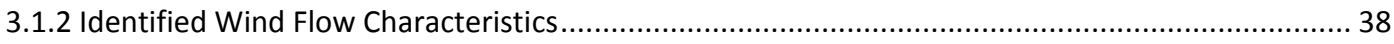

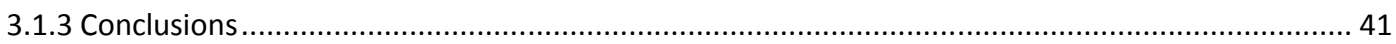

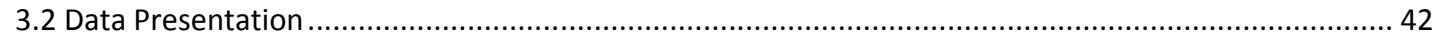

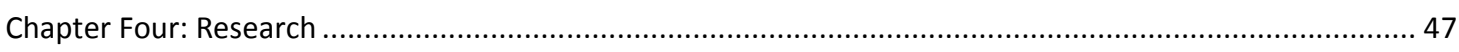

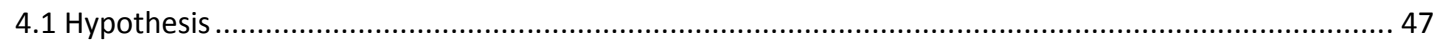

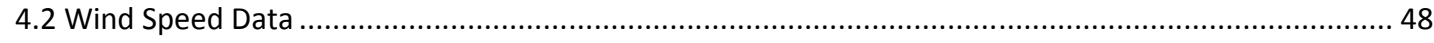

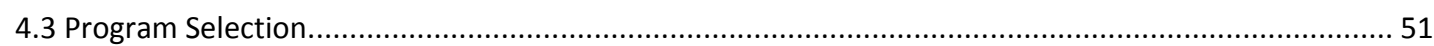

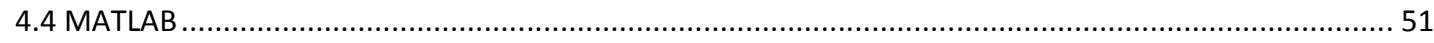

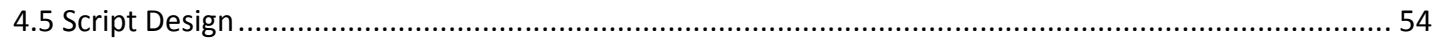

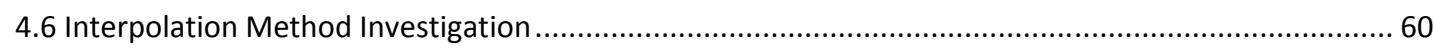

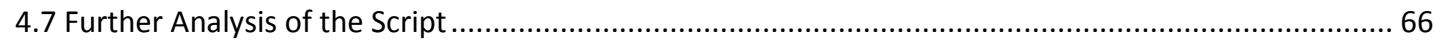

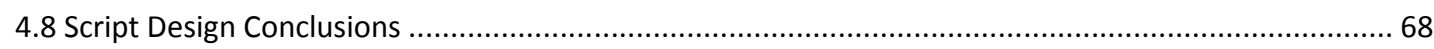

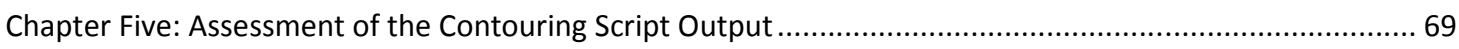




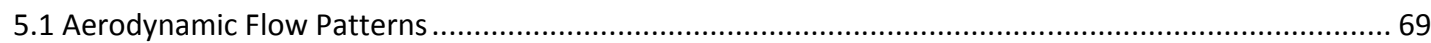

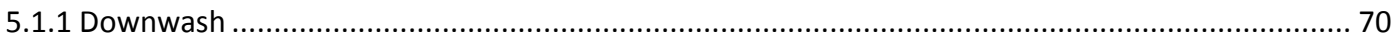

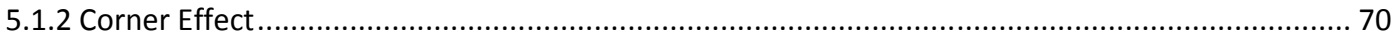

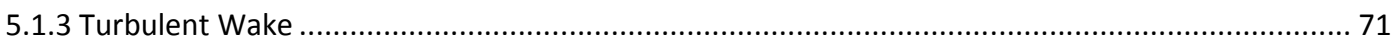

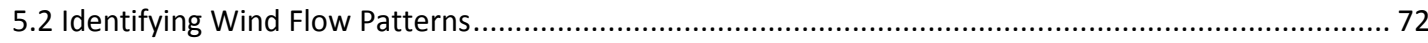

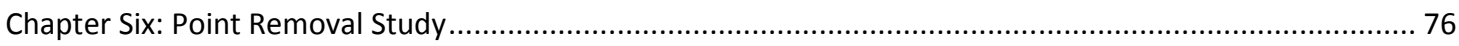

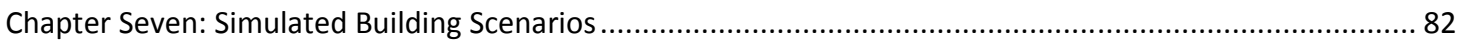

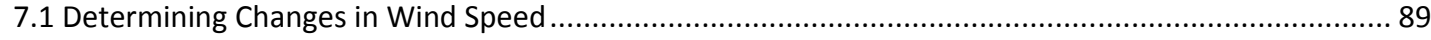

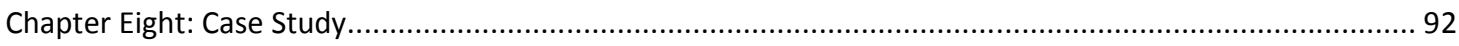

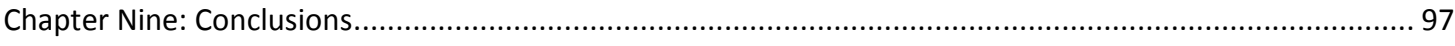

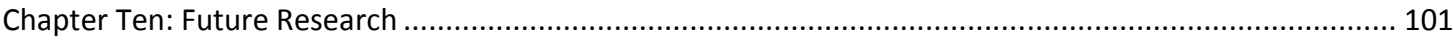

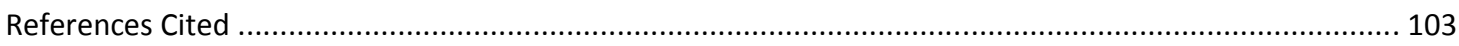

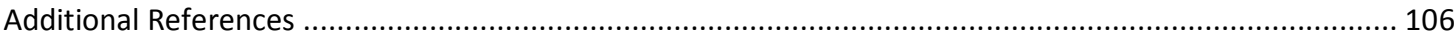

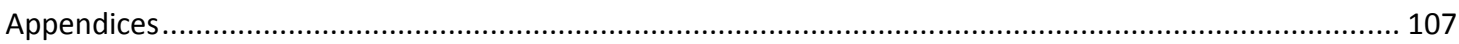

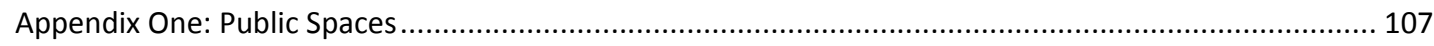

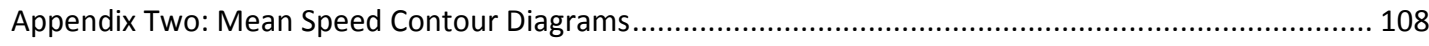

Appendix Three: Mean Change in Wind Speed Contour Diagrams................................................. 111

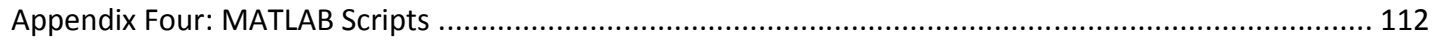

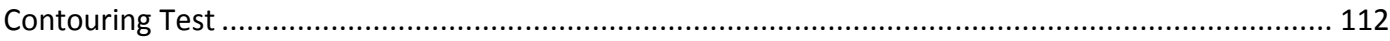

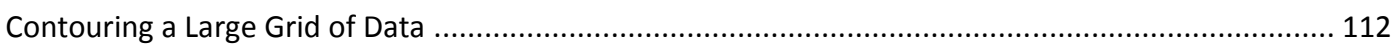

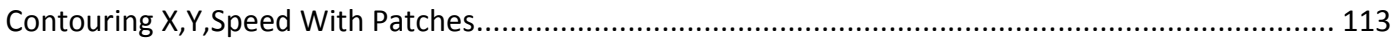

Contouring with Pseudo Measurements Manually Added .................................................... 115

Analysing Multiple Inlut Files Automatically ..................................................................... 117

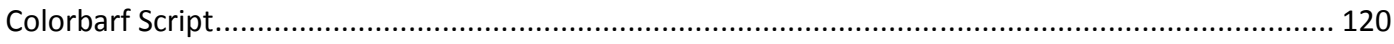

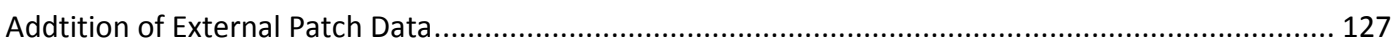

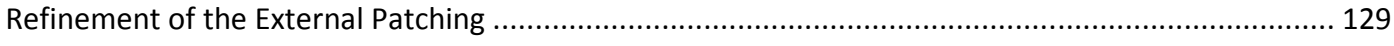

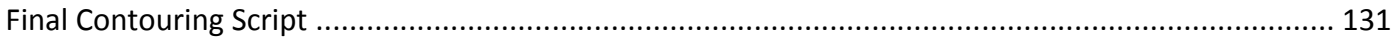

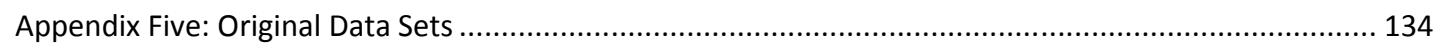


Area Assessment of a Pedestrian Wind Environment using Point Wind Speed Measurements

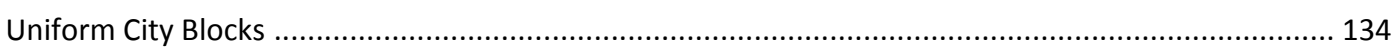

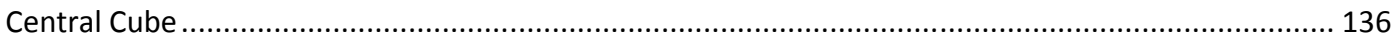

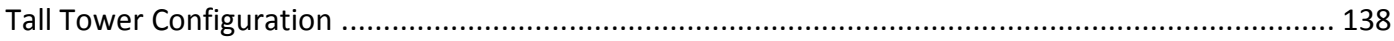

Appendix Six: Hot film anemometer calibration study ................................................................. 140 


\section{LIST OF FIGURES}

Figure 1: Hot film anemometer used to record point wind speed measurements. .................................. 0

Figure 2: Bran erosion test a common form of area measurement................................................ 0

Figure 3: Illustration of a rolling vortex formed by wind flowing over low rise building into a taller building. 15

Figure 4: Planetary boundary layer over various terrain categories................................................... 24

Figure 5: Example of a contour diagram produced as a result of erosion testing (area measurement).......... 26

Figure 6: Contour graph produced as a result of bran erosion testing. ................................................... 34

Figure 7: Locations at which hot film measurements were taken. ................................................. 0

Figure 8: Distribution of mean wind speed values at each windiness level. ........................................... 36

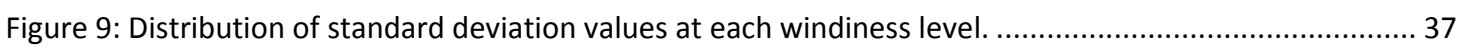

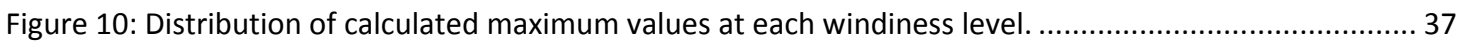

Figure 11: Plot depicting the distribution of identified flow characteristics. ...................................... 40

Figure 12: Contour graph produced as a result of bran erosion testing. ................................................. 43

Figure 13: An example of the way in which wind speed data is typically presented. ................................ 46

Figure 14: Sample of building grid showing measurement locations and measured speeds in $\mathrm{m} / \mathrm{s} . \ldots \ldots \ldots \ldots . . . .49$

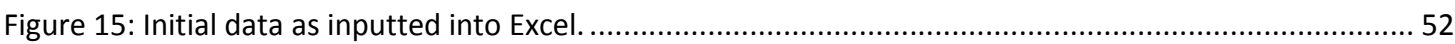

Figure 16: Initial contour output from MATLAB providing a proof of concept. .................................... 53

Figure 17: A three dimensional contour diagram drawn in MATLAB indicating slice planes that are drawn in two dimensional contours...

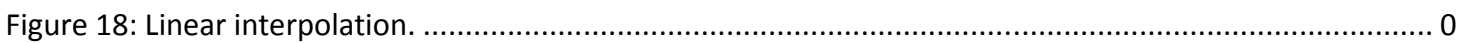

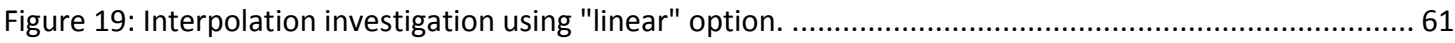

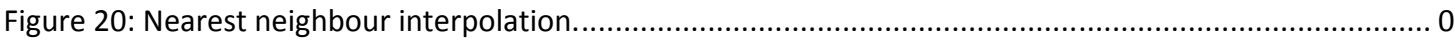

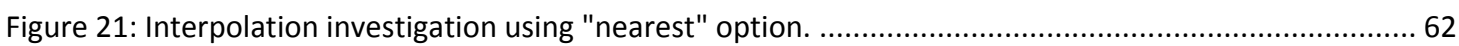

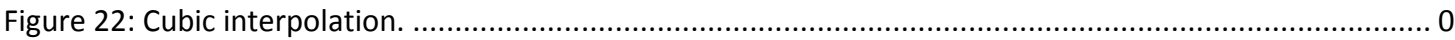

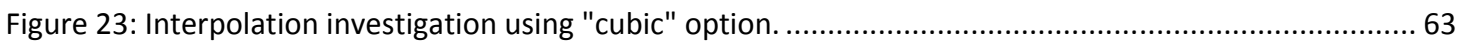

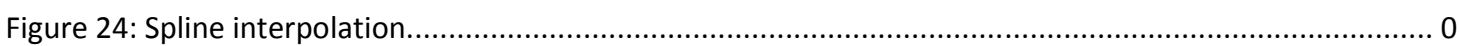

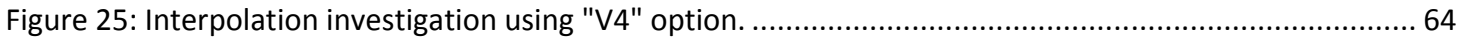

Figure 26: Resultant image with pseudo measurements generated for each point at a $1 \mathrm{~m}$ radius..............67

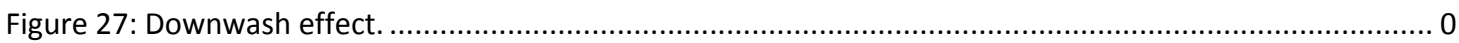

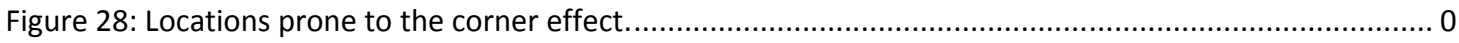


Figure 29: Turbulent wake effect. 0

Figure 30: Example of a contour diagram produced as a result of bran erosion testing. Areas of interest that have been noted are: downwash (red); corner effect (black) and turbulent wake (white).

Figure 31: Flow patterns of wind between low and high buildings. 0

Figure 32: Contour diagram produced as a result of the developed contouring script. Areas of interest that have been noted are: downwash (red); corner effect (black) and turbulent wake (white).

Figure 33: Original image with all points at $15 \mathrm{~m}$ intervals.

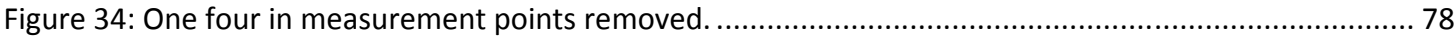

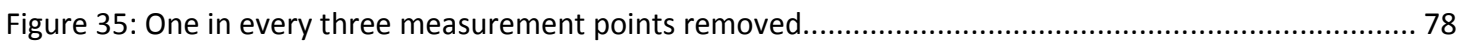

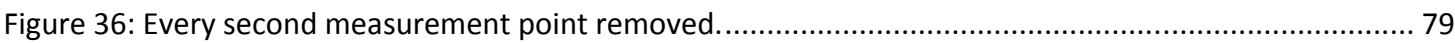

Figure 37: Retaining a high level of accuracy around the site (15m grid) while reducing surrounding areas to $30 \mathrm{~m}$ grid.

Figure 38: Contour diagram produced with a uniform distribution of buildings for gust wind speeds at a direction of $360^{\circ}$.

Figure 39: Contour diagram generated with a uniform distribution of buildings for gust wind speeds at a direction of $45^{\circ}$.

Figure 40: Contour diagram produced with a uniform distribution of buildings replacing the central half cube with a full cube, for gust wind speeds at a direction of $360^{\circ}$

Figure 41: Contour diagram produced with a uniform distribution of buildings replacing the central half cube with a full cube, for gust wind speeds at a direction of $45^{\circ}$

Figure 42: Contour diagram produced with a uniform distribution of buildings replacing the central half cube with a tall tower, for gust wind speeds at a direction of $360^{\circ}$.

Figure 43: Contour diagram produced with a uniform distribution of buildings replacing the central half cube with a tall tower, for gust wind speeds at a direction of $45^{\circ}$.

Figure 44: Change in wind speed between a grid of uniform half cubes and a central full cube, $360^{\circ}$ wind direction

Figure 45: Change in wind speed between a grid of uniform half cubes and a central full cube, $45^{\circ}$ wind direction.

Figure 46: Image depicting the measurement point locations used in the case study contour diagram.

Figure 47: Contours produced for the case study with the existing building configuration. Google Earth snapshot overlaid.

Figure 48: Contours produced for the case study with the new building configuration. Google Earth snapshot overlaid.

Figure 49: The difference between the existing and new wind speeds. Speeds have been added to the image to improve usability. Google Earth snapshot overlaid......

Figure 50: Contour diagram produced with a uniform distribution of buildings for mean wind speeds at a direction of $360^{\circ}$........... 
Figure 51: Contour diagram generated with a uniform distribution of buildings for mean wind speeds at a direction of $45^{\circ}$.

Figure 52: Contour diagram produced with a uniform distribution of buildings replacing the central half cube with a full cube, for mean wind speeds at a direction of $360^{\circ}$.

Figure 53: Contour diagram produced with a uniform distribution of buildings replacing the central half cube with a full cube, for mean wind speeds at a direction of $45^{\circ}$. 109

Figure 54: Contour diagram produced with a uniform distribution of buildings replacing the central half cube with a tall tower, for mean wind speeds at a direction of $360^{\circ}$.

Figure 55: Contour diagram produced with a uniform distribution of buildings replacing the central half cube with a tall tower, for mean wind speeds at a direction of $45^{\circ}$......

Figure 56: Original data for uniform city block configuration $360^{\circ}$ wind direction. Source: Jamieson et. al. (1992)

Figure 57: Original data for uniform city block configuration $45^{\circ}$ wind direction. Source: Jamieson et. al. (1992)

Figure 58: Original data for central cube configuration $360^{\circ}$ wind direction. Source: Jamieson et. al. (1992)136

Figure 59: Original data for central cube configuration $45^{\circ}$ wind direction. Source: Jamieson et. al. (1992). 137

Figure 60: Original data for central tall tower $360^{\circ}$ wind direction. Indicating change from uniform city blocks. Source: Jamieson et. al. (1992)

Figure 61: Original data for central tall tower $45^{\circ}$ wind direction. Indicating change from uniform city blocks.

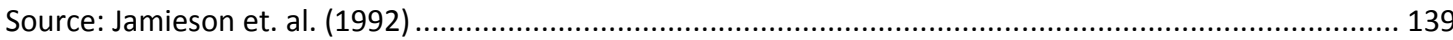

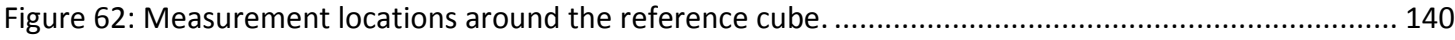

Figure 63: Analysis of the hot film orientation study. 141

Figure 64: Raw data for wind speeds taken around a reference cube with a vertically orientated anemometer.

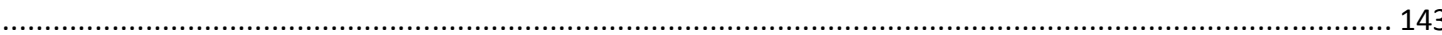

Figure 65: Raw data for wind speeds taken around a reference cube with a horizontally orientated anemometer 


\section{LIST OF TABLES}

Table 1: Modified Beaufort Scale representing mean wind speeds measured at $1.75 \mathrm{~m}$ height over land. Source: Aynsley, R. M. et al., (1977)

Table 2: Cumulative effect WCC wind regulations.

Table 3: Comfort wind rules applying to most popular public spaces promoting sedentary activity i.e. parks

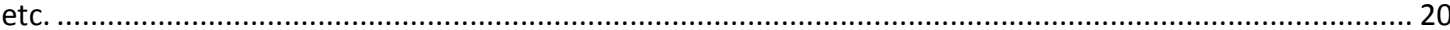

Table 4: Classification of the boundary layer roughness parameter. Source: Bottema, M. (1993).... 23

Table 5: Different building configurations analysed. 


\section{CHAPTER ONE: INTRODUCTION}

This research has aimed to produce a means of creating a reliable area measurement of a pedestrian level wind environment from a reasonable number of point wind speed measurements. To complete the research efficiently the primary aim has been divided into a number of individual objectives. The initial objective was to determine a suitable computer program with a number of interpolation methods available for contouring. Each interpolation method was assessed to determine the accuracy of the pseudo measurements generated with respect to the visualisation of potentially problematic aerodynamic flow characteristics. The accuracy of

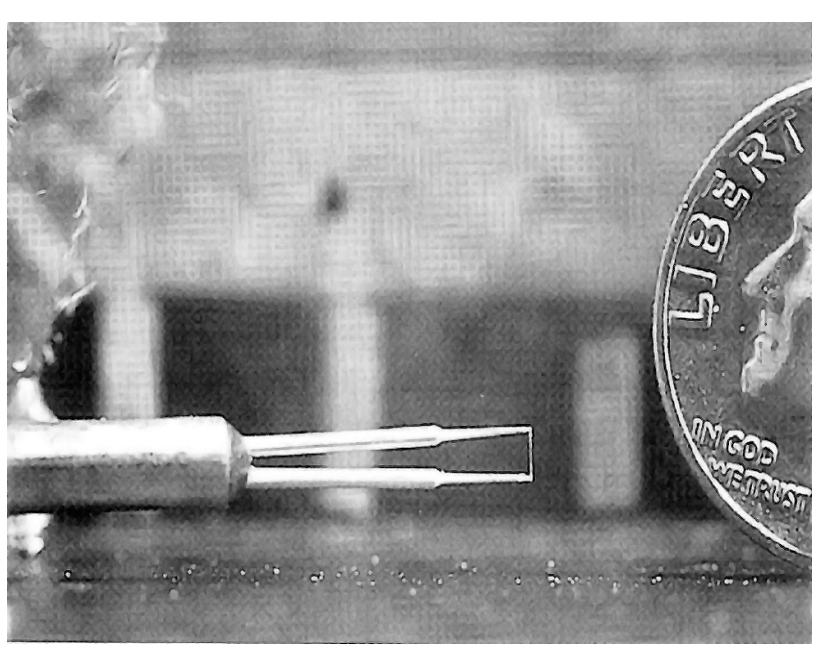

Figure 1: Hot film anemometer used to record point wind speed measurements. Image source: ASCE (2004)

the contours was assessed by using a series of simple building scenarios. The building scenarios tested had predictable wind flow patterns that were easy to identify and assess in the resultant contours. Flow patterns such as downwash and the corner effect are easily identifiable and should therefore be prominent in the generated contours. The minimum density of points will then be determined through a point removal study. Points are removed until the contours become too inaccurate for the flow patterns to be

identified. The resulting contour system was then assessed on a case study development to determine the further additions required to potentially implement the program for commercial use.

Current wind tunnel studies generally require two forms of measurement to be conducted in order to meet the requirements of local compliance criteria; point wind speed measurements (Figure 1) are coupled with area measurements (Figure 2) to provide an accurate understanding of the local wind environment.

Pedestrian level wind tunnel studies are completed in Boundary Layer Wind Tunnels (BLWT). Boundary Layer Wind Tunnels are used to simulate the turbulence that occurs naturally as wind flows across the varying 
surfaces of the earth. There are two methods of reporting measurements that have now become accepted measurement techniques used to assess the change in the wind environment as a result of a new

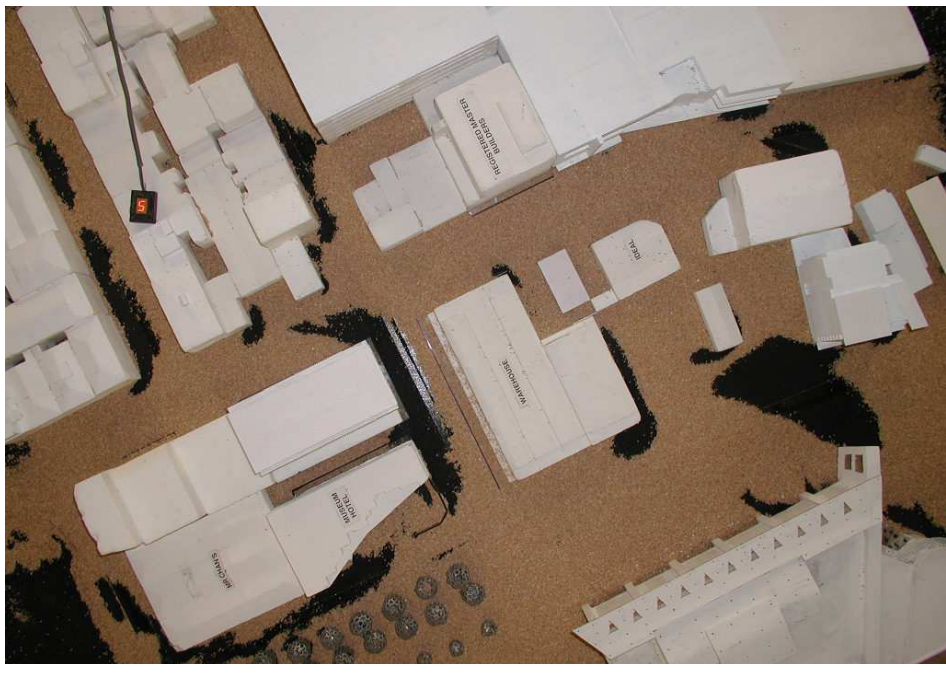

Figure 2: Bran erosion test a common form of area measurement. Image Source: Jamieson, N. (2005) development. Area measurement is used to assess the area as a whole. Point measurements are taken to quantify the changes in wind speed. Erosion testing is the most common area measurement technique used to assess the pedestrian level wind environment. Hot film (or wire) anemometry is the most common means of obtaining point wind speed measurements.

Background research conducted for this thesis compared over 3000 individual point wind speed measurements with measured erosion levels. The stage at which erosion occurred was matched with the corresponding wind speed measurement. All points analysed were located within commercial wind tunnel assessments conducted in a professional wind laboratory. The aim was to determine the level of consistency between the two forms of measurement. Results indicated that there is a low level of correlation between the two measurement techniques. Generally only $50 \%$ of the recorded mean wind speeds at each of the erosion levels derived from flow visualisation lay within a reasonable margin of error. ${ }^{1}$ These results suggest that it is extremely difficult to produce precise point wind speed predictions from an erosion study. This is due to the large number of potential inconsistencies present when conducting erosion tests (vertical wind flow, erosion material layering, model surface etc). However, measured point wind speeds are only applicable at the exact point in which the measurement is taken. Pedestrians predominantly move through spaces. Therefore, solely measuring the wind speed at a series of points is not a particularly reliable method of assessing the comfort or safety of an urban area. Neither test alone is able to quantify the pedestrian level

\footnotetext{
${ }^{1}$ See Chapter Three: Research Background.
} 
wind environment accurately as a whole. Creating an area measurement from a series of point wind speed measurements could potentially generate a much more reliable form of area measurement.

Erosion testing consists of covering the model surface in a fine layer of erosion material such as bran flakes. The wind tunnel speed is increased incrementally, allowing time at each speed increment for erosion to reach a stable conclusion. Photographs are taken after each stage of erosion. These photographs are then layered in order of wind tunnel speed from lowest (top) to highest (bottom). Erosion patterns are colour coded according to the stage in which erosion has occurred. The result of such a test is a contour diagram indicating the comparative windiness of various areas within the testing boundaries. Areas of high wind speed are identified when erosion occurs at lower wind tunnel speeds, and, conversely areas of low wind speed are eroded when there are higher reference wind tunnel speeds or are left un-eroded upon the completion of the test.

Point wind speeds are predominantly measured with hot wire anemometers. Hot wire anemometry is the most accurate form of measuring individual point wind speeds ${ }^{2}$. A hot wire anemometer consists of an extremely thin wire that is heated to a constant temperature. As wind flows past the wire the cooling effect is measured and converted to a wind speed. Point wind speed measurements are taken at a number of locations around the site in question. They are taken in fairly regular intervals along footpaths, entrances, building corners, pedestrian crossings and any other points of interest. Wind speeds are recorded for the existing building configuration and compared with speeds recorded for the new development.

Regulations within the Wellington City District Plan require both area and point measurement to be done as part of a full wind tunnel simulation of a new development ${ }^{3}$. The time taken to complete testing during full study is divided roughly evenly between the two methods. Erosion testing is typically done first to identify subsequent areas of interest that could require point wind speed measurement. Wind speed measurements

\footnotetext{
${ }^{2}$ Task Committee on Outdoor Human Comfort of the Aerodynamic Committee of the American Society of Civil Engineers, 'Outdoor Human Comfort and its Assessment: State of the Art', American Society of Civil Engineers, Virginia, 2004.

${ }^{3}$ Wellington City Council, (1984). Wellington City Proposed District Plan: Central Area Design Guide, Town Planning Department, Wellington City Council, Wellington.
} 
are generally presented in the form of a table. Measurement locations are given a reference figure and recorded alongside the associated wind speed. This can often be a difficult method to present results to clients as the wind speed measurements have to be matched to a location manually. The results from the flow visualisation studies are often of more interest to clients. Contour diagrams enable clients to instantly visualise problematic areas of wind speed.

The general focus of this research is to produce an area measurement from a reasonable number of point wind speed measurements. This is possible through the use of mathematical interpolation methods. Mathematical interpolation is a method of fitting a curve between measurement points on a graph. With a reasonable density of points it is possible to determine an effective interpolation method to generate pseudo measurements between the actual measured wind speeds on a three dimensional plane. The combination of wind speed measurements and pseudo measurements can then be displayed as a contour image similar to that produced through erosion testing. This can then be assessed similarly to a contour diagram produced as a result of erosion testing to determine areas of problematic wind speeds.

Producing an area measurement from a reasonable number of point wind speed measurements has a number of potential benefits. The time taken to complete a full wind tunnel test can be reduced, as only point wind speed measurements need to be taken. Although more measurement locations are required, the time taken to do this will be considerably less than that of completing a full erosion study. Contours generated through this method are derived from actual measured wind speeds. Wind speeds, therefore, can be drawn directly from the resulting contours. 


\section{CHAPTER TWO: REVIEW OF LITERATURE}

This chapter reviews and summarises literature used to provide a background of knowledge on pedestrian level building aerodynamics throughout this research. Initially a background on basic building aerodynamics was provided. The correlation between point wind speed measurements and area testing techniques was then analysed to determine their levels of continuity. Pedestrian comfort and safety was then investigated to identify the issues that must be analysed and predicted when conducting wind tunnel tests. Finally, current simulation techniques used throughout the building aerodynamics industry were analysed in detail.

\subsection{PEDESTRIAN LEVEL WINDS}

Developments in fluid mechanics have enabled building designers to better understand how buildings affect the pedestrian level wind environment. The different aerodynamic flow characteristics produced as a result of a new building development are directly related to the local environment surrounding the building. While downwash will occur with almost every exposed tall building, this effect can be reduced, or conversely, enhanced by the surrounding buildings. For example, a low-rise building on the windward side of a tall building will create a continuous rolling vortex travelling down the face of the tall building and up the face of the low rise building. This vortex is fed by the high speed wind travelling down the tall building. Thus, an extremely uncomfortable wind environment is created at ground level. Figure 3 illustrates this effect using smoke visualisation. Other anomalies such as the row effect are caused when a row of buildings are located at around $45^{\circ}$ to the prevailing winds. This causes winds to be drawn from above the buildings to pedestrian level and fed along the buildings in a spiral like fashion. There are many other anomalies such as the venturi and corridor effects that are explained in detail throughout building aerodynamics literature ${ }^{4}$.

\footnotetext{
${ }^{4}$ Cook, N. J. (1985) The Designer's Guide to Wind Loading of building Structures, Part 1, Buttersworths, London.
} 


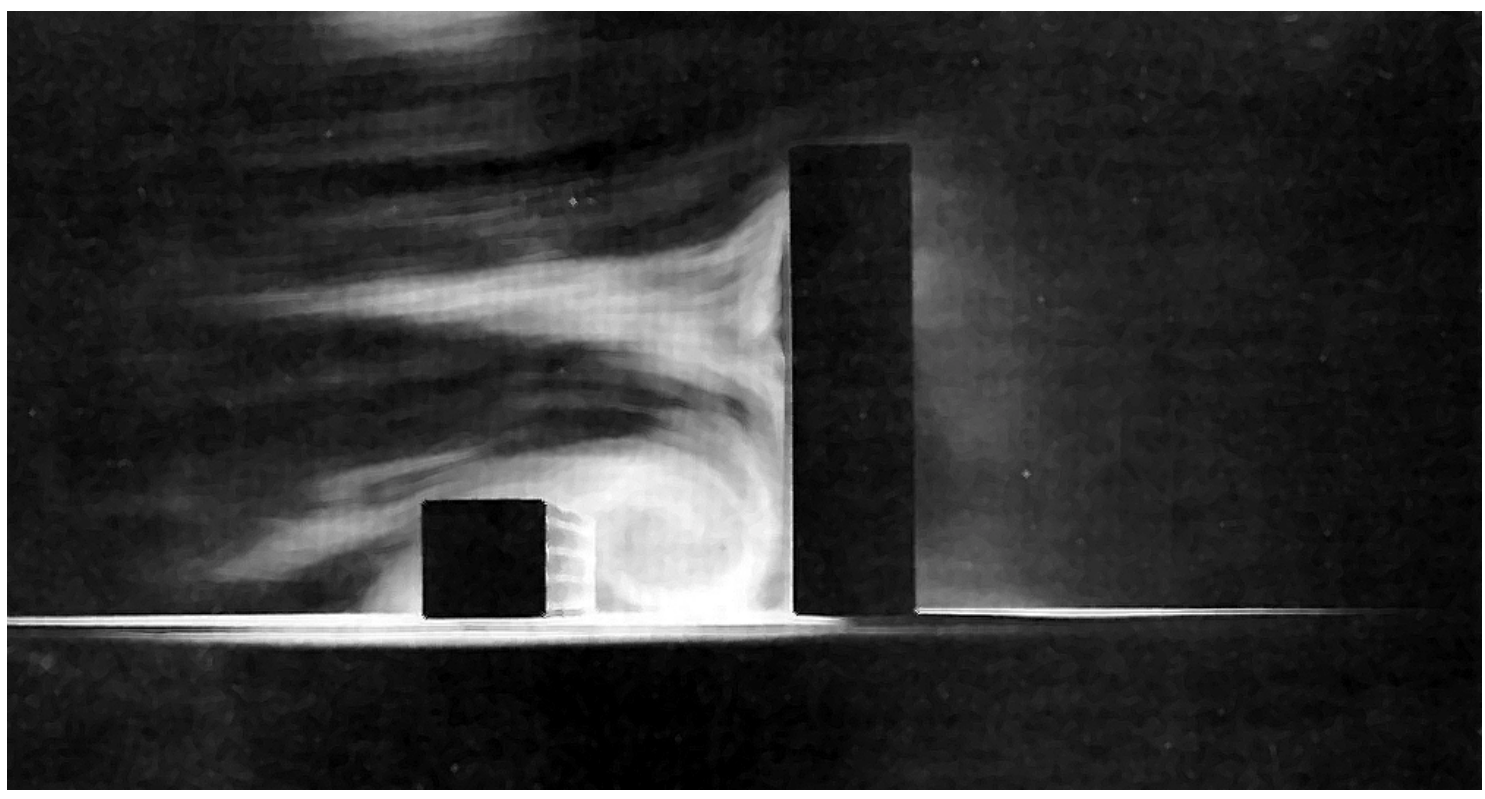

Figure 3: Illustration of a rolling vortex formed by wind flowing over low rise building into a taller building. Image Source: Blocken B, Carmeliet J. (2004)

Large increases in pedestrian wind speeds occur when a building is placed in a city with a considerable height difference between it and the surrounding buildings ${ }^{5}$. The higher up the windward face of a building, the higher the wind speed that is experienced. This creates a pressure gradient that increases in magnitude steadily up the windward face of the building ${ }^{6}$. The majority of the wind striking the centre of the windward face of a tall building will travel down to pedestrian level (downwash). This considerably worsens the pedestrian comfort. Further, it potentially reduces the safety of the surrounding wind environment, as high altitude high speed winds that previously would have passed high above the city are now flooding pedestrian level. However, the top third of the wind striking the windward face of a building carries enough momentum to travel above the building through the high pressure zone. This effect has been simulated through flow visualisation $^{789}$

\footnotetext{
${ }^{5}$ Penwarden, A. D. (1972) Wind environment around tall buildings, Building Research Station, Watford.

${ }^{6}$ Sexton, D. E. (1968) Building Aerodynamics, Building Research Station, Watford.

${ }^{7}$ Aynsley, R. M. et al. (1977) Architectural Aerodynamics: Environmental Wind Flows Around Buildings, Applied Science Publishers, London.

8 Penwarden, A. D. and Wise, A. F. E. (1975) Wind Environment around Tall Buildings, E7, Building Research Establishment, Watford.

9 Jackson, P. S. (1975) Testing the Aerodynamics of Buildings, NZIA Journal, (February).
} 
Since the advent of high rise buildings in around the 1950's city design has changed radically. This has led to developers attempting to achieve the maximum amount of floor area for a site, thus, buildings are built to the site boundaries and as high as modern engineering and local design laws will allow. These increasingly taller buildings are exposed to high altitude-high speed winds that would have previously passed over a city undisturbed. These winds are drawn down to pedestrian level creating an uncomfortable and potentially dangerous situation for pedestrians. Architects and developers have had to become conscious of this issue and modify building designs to address this potential hazard. 


\subsection{PEDESTRIAN SAFETY AND COMFORT}

Outdoor human comfort in the urban climate is defined by various factors, wind speed, air temperature, relative humidity, solar radiation, air quality, human activity, clothing level, age, etc ${ }^{10}$. It is not possible to achieve outdoor conditions that are comfortable $100 \%$ of the time. Therefore, comfort criteria have not only been developed to include values of wind speed but also to include a percentage of time in which the microclimate is within or exceeding the comfortable range. These comfort criteria are often developed for the mean population or, in some circumstances, for the most sensitive of the population ${ }^{11}$. Pedestrian comfort with regards to wind is divided into two categories: dynamic characteristics, or those related to pressure effects of the airflow (mechanical); and heat transfer effects concerning the transfer of heat between bodies and moving air (thermal) ${ }^{12}$.

The mechanical effects of wind can range from the feeling of a light breeze to people being blown over by strong gusts of wind. The effects of wind gusts on pedestrians were studied by Murakami et al in $1980^{13}$. The study was conducted in an industrial wind tunnel. Pedestrians' movements through a set of obstacles were observed and footstep irregularities were monitored. This showed that the footstep irregularities in a nonuniform wind flow were comparable to a steady wind flow 1.5 times stronger. The effects of different gust speeds on pedestrians have been studied in detail. A Ph.D thesis conducted by Bottema summarised the works of other researchers to state: a gust of $4 \mathrm{~m} / \mathrm{s}$ for $5 \mathrm{~s}$ causes hair to be disturbed and clothes to flap; a gust of $7 \mathrm{~m} / \mathrm{s}$ for $5 \mathrm{~s}$ can cause hair to be disarranged; a gust of $15 \mathrm{~m} / \mathrm{s}$ for $2 \mathrm{~s}$ can bring people out of balance and is dangerous to the elderly and the infirm; a gust of $20 \mathrm{~m} / \mathrm{s}$ can be dangerous even for young people; and a gust of $23 \mathrm{~m} / \mathrm{s}$ will blow people over ${ }^{14}$.

10 Arens, E. (1982) On Considering Pedestrian Winds During Building Design, International Workshop on Wind Tunnel Modelling and Techniques in Civil Engineering Applications, Maryland, USA, 8-26.

11 Soligo M., Irwin P., Williams C., Schuyler G. (1998). A comprehensive assessment of pedestrian comfort including thermal effects. Journal of wind engineering and industrial aerodynamics. 77\&78, 753-766.

12 Aynsley, R. M. et al. (1974) Effects of Airflow on Human Comfort, Building Science, 9, 91-94.

13 Murakami, S., Uehara, K. and Deguchi, K. (1980). Wind effects on pedestrians: new criteria based on outdoor observation of over (2000) persons, In: Cermak (Ed.) (1980), Proceedings of the 5th International Conference on Wind Engineering, Fort Collins, Colorado, pp. 277-288.

${ }^{14}$ Bottema, M. (1993). Wind climate and urban geometry, Ph.D. thesis, FAGO, Technical University of Eindhoven. 
A pedestrian's balance is affected by the gust component of the wind; the mean wind speed rarely has any effect. The effects of a steady wind on pedestrians has been summarised by Bottema (1993) in his aforementioned thesis. A continuous steady flow of wind gives a person time to adjust their balance to compensate and therefore is not an unsafe nor highly uncomfortable situation. This is the case for long gust durations, between 5 and 30 seconds. Gusts of a shorter duration than 5 seconds can have a large effect on a pedestrian's balance and can therefore be very dangerous, especially when high wind speeds occur ${ }^{15}$. In 1806 Admiral Beaufort developed a scale using nautical wind effects to determine wind speed. The Beaufort Scale used common appellations such as "hardly perceivable" or "very brisk" to estimate various wind speeds. Seen as a valuable resource at the time it has since been developed for use on land. The table has been replaced by much more scientific means of measuring wind speeds. However, it holds valuable information concerning the effects various wind speeds have on pedestrians (Table 1).

\begin{tabular}{|c|c|c|c|}
\hline Beaufort Number & & Wind speed (M/s) & Effects \\
\hline $\mathbf{0}$ & Calm & $0-0.1$ & \\
\hline 1 & Light air & $0.2-1$ & Calm; no noticeable wind \\
\hline 2 & Light breeze & $1.1-2.3$ & Wind felt on face \\
\hline 3 & Gentle breeze & $2.4-3.8$ & $\begin{array}{l}\text { Wind extends light flag } \\
\text { Hair is disturbed } \\
\text { Clothing flaps }\end{array}$ \\
\hline 4 & $\begin{array}{l}\text { Moderate } \\
\text { breeze }\end{array}$ & $3.9-5.5$ & $\begin{array}{c}\text { Raises dust, dry soil and loose paper } \\
\text { Hair Disarranged }\end{array}$ \\
\hline 5 & Fresh breeze & $5.6-7.5$ & $\begin{array}{l}\text { Force of wind felt on body } \\
\text { Drifting snow becomes airborne } \\
\text { Limit of agreeable wind on land }\end{array}$ \\
\hline 6 & Strong breeze & $7.6-9.7$ & $\begin{array}{c}\text { Umbrellas used with difficulty } \\
\text { Hair blown straight } \\
\text { Difficult to walk steadily } \\
\text { Wind noise unpleasant } \\
\text { Windborne snow above head height }\end{array}$ \\
\hline 7 & Near gale & $9.8-12.0$ & Inconvenience felt when walking \\
\hline 8 & Gale & $12.1-14.5$ & $\begin{array}{l}\text { Generally impedes progress } \\
\text { Great difficulty with balance in gusts }\end{array}$ \\
\hline 9 & Strong gale & $14.6-17.1$ & People blown over by gusts \\
\hline
\end{tabular}

Table 1: Modified Beaufort Scale representing mean wind speeds measured at 1.75m height over land. Source: Aynsley, R. M. et al., (1977)

\footnotetext{
15 Beranek, W.J., Van Koten, H., (1979) Visual Techniques for the Determination of Wind Environments, Journal of Wind Engineering and Industrial Aerodynamics (4) 295-306.
} 
Definitions concerning the thermal effects of wind on pedestrians are much more complex. Factors such as wind speed (mean and gust), air temperature, humidity, solar radiation, metabolism, exposure time, clothing level and moisture content of clothes etc. are included in the assessment of the heat transfer effects. These factors essentially determine the level of warmth a person would feel. However, levels of comfort differ between people. Different models have been created to assess the impact of both the mechanical and thermal characteristics of pedestrian comfort. A rather simple heat balance model was created in 1975 to assess the cooling effect of the wind taking into account the heat generated by human metabolism. The difference between the cooling effects of the wind and the heat produced by the body would determine the level of thermal discomfort ${ }^{16}$. This model did not include clothing levels, which have a significant impact on the perceived level of thermal discomfort. Including the thermal effects of wind in testing for the change in pedestrian comfort is very difficult. Therefore, most current methods for evaluating the pedestrian level wind environment predominantly focus on assessing the mechanical effects of wind.

Compliance criteria are designed to assess the level of pedestrian comfort and safety in a specific location. Initial criteria relied on wind speeds merely exceeding a threshold speed. A development with measured wind gusts in excess of $23 \mathrm{~m} / \mathrm{s}$ was required to take remedial action. However, this is not a realistic depiction of a site, for example, an area that has a gust of $23 \mathrm{~m} / \mathrm{s}$ occurring once per year may be deemed unsafe. New criteria states that remedial action is required if the mean wind speed exceeds $5 \mathrm{~m} / \mathrm{s}$ for over $20 \%$ of the year $^{17}$. This was based on the mean wind speed of $5 \mathrm{~m} / \mathrm{s}$ raising dirt and flapping clothes, perceived to be the onset of discomfort. However, as the level of discomfort felt by a pedestrian varies depending on a number of factors this single criterion was deemed inadequate. Wellington City Council District Plan Change $48^{18}$ presented a new set of wind criteria for the region. These criteria are broken into three categories: Safety, Cumulative Effect and Comfort.

\footnotetext{
${ }^{16}$ Vu T, Takashi A, Manabu I, Steve A. (1995) Characteristics of wind field in a street canyon. Journal of wind engineering and industrial aerodynamics $\mathbf{5 7}, 63-80$.

17 Penwarden, A. D. and Wise, A. F. E. (1975) Wind environment around buildings, Building Research Establishment Report, HMSO.

${ }^{18}$ Wellington City Council, (2007). Change 48: Central Area Review. Retrieved January 1, 2010, from Wellington City Council:

http://www.wellington.govt.nz/plans/district/planchanges/pdfs/change48/change48-pcd-chap13.pdf
} 
Safety: This safety guideline applies to all public spaces:

- The maximum gust speed shall not exceed $20 \mathrm{~m} / \mathrm{s}$. If the speed exceeds $20 \mathrm{~m} / \mathrm{s}$ with the proposed development, it must be reduced to $20 \mathrm{~m} / \mathrm{s}$ or below.

Cumulative Effect: This safety guideline applies to all public spaces: Any development must adhere to these proposed guidelines at all points of measurement (Table 2):

\begin{tabular}{|c|c|c|}
\hline Wind strength & $\frac{\text { Change in annual hours of }}{\text { occurrence }}$ & Requirements on the developer \\
\hline STRONG & $\begin{array}{c}\text { If hours that } 3.5 \mathrm{~m} / \mathrm{s} \text { is equalled } \\
\text { or exceeded increase by more } \\
\text { than } 170 \mathrm{hr} / \mathrm{yr} \text { (i.e. } 2 \% \text { of the } \\
\text { year) }\end{array}$ & $\begin{array}{c}\text { Reduce change in hours to a } \\
\text { maximum of } 170 \text { hours. }\end{array}$ \\
\hline MODERATE & $\begin{array}{c}\text { If hours that } 2.5 \mathrm{~m} / \mathrm{s} \text { is equalled } \\
\text { or exceeded increase by more } \\
\text { than } 170 \mathrm{hr} / \mathrm{yr} \text { (i.e. } 2 \% \text { of the } \\
\text { year) }\end{array}$ & $\begin{array}{c}\text { Reduce change in hours to a } \\
\text { maximum of } 170 \text { hours. }\end{array}$ \\
\hline
\end{tabular}

Table 2: Cumulative effect WCC wind regulations.

Comfort: This safety guideline applies to popular public spaces that promote sedentary activity (Table 3). Full list of areas in Wellington to which the comfort rule applies can be found in WCC district plan section 16.3.6.4 ${ }^{19}$ (see Appendix One).

\begin{tabular}{|c|c|c|}
\hline Comfort wind strength & $\begin{array}{c}\text { Annual hours of occurrence with } \\
\text { the development }\end{array}$ & Requirements on developer \\
\hline $\begin{array}{l}\text { Mean hourly wind speed }=2.5 \\
\mathrm{~m} / \mathrm{s}\end{array}$ & $\begin{array}{c}\text { If hours that } 2.5 \mathrm{~m} / \mathrm{s} \text { is equalled } \\
\text { or exceeded increase above } 1700 \\
\text { hours. }\end{array}$ & $\begin{array}{l}\text { If existing building exceeds } 1700 \\
\text { hours, then reduce number of } \\
\text { hours for proposed building to } \\
\text { existing levels. } \\
\text { If existing building is below } 1700 \\
\text { hours then reduce number of } \\
\text { hours for proposed building to } \\
\text { below } 1700 \text { hours. }\end{array}$ \\
\hline
\end{tabular}

Table 3: Comfort wind rules applying to most popular public spaces promoting sedentary activity i.e. parks etc.

\footnotetext{
19 Wellington City Council, 2007, Change 48: Central Area Review.

http://www.wellington.govt.nz/plans/district/planchanges/pdfs/change48/change48-pcd-chap13.pdf last accessed 2/1/2010.
} 
The compliance criterion for safety in Wellington is fairly straight forward and has not included an 'hours of occurrence' as wind speeds in excess of $20 \mathrm{~m} / \mathrm{s}$ are completely unacceptable for walking and therefore must be mitigated. This rule has remained unchanged since the advent of pedestrian wind criteria in Wellington in 1984. Previously there was a single comfort criterion stating wind speeds in excess of $15 \mathrm{~m} / \mathrm{s}$ were uncomfortable. This applied to all public spaces. New cumulative criteria are broken into separate categories as wind speeds that are comfortable for walking are not comfortable for long periods of sedentary activity. Inclusion of hours of occurrence within cumulative effect criteria enables more accurate depiction of pedestrian comfort across an entire year. The comfort criterion has been designed specifically for public urban spaces that promote sedentary activity such as parks, street malls and plazas. Areas such as these require more stringent criteria as pedestrians will occupy these spaces for longer durations of time while maintaining a very low metabolic rate. Therefore, developers have a large responsibility to ensure these areas remain comfortable. 


\subsection{PEDESTRIAN WIND SIMULATION}

Simulation of the pedestrian level wind environment is conducted in a boundary layer wind tunnel. The boundary layer can be thought of as the turbulent layer of wind that is directly influenced by the surface of the earth. Moisture, heat, air pollution and momentum are mixed by turbulence in this layer. The level of turbulence is proportional to the surface roughness of the earth, while the speed of the wind increases with height. The boundary layer is not constant; it varies throughout the day. Hotter daytime temperatures and low wind speeds may yield a boundary layer depth of around $1000 \mathrm{~m}$. Throughout the night the cooler temperatures provide more stable stratification and a suppression of turbulence. This can reduce the depth of the boundary layer to $100 \mathrm{~m}$ or less. Strong winds and cloudy conditions typically relate to a boundary layer depth of around $1000 \mathrm{~m}$ regardless of the time of day ${ }^{20}$.

Simulation parameters can vary between wind tunnels. However, the atmospheric effects such as temperature and humidity within the boundary layer are not generally simulated as the focus of a wind tunnel simulation is to assess the mechanical effects of wind on a pre-defined area. The depth of the simulated boundary layer is dependent on the terrain over which the wind is flowing. Different terrain types have differing levels of impact on the depth of the boundary layer. Terrains can be described by an aerodynamic roughness length $\left(z_{o}\right)$ and a displacement length $\left(z_{d}\right)$. The displacement length is the vertical displacement of the flow due to obstacles and wakes caused by obstacles. The aerodynamic roughness length is interpreted as the size of the eddies at the surface. These factors are influenced not merely by obstacle height but also by obstacle spacing and other factors. Therefore there are various roughness length classifications for common surface roughnesses ${ }^{21}$. See Table 4 for a detailed explanation of terrain categories.

\footnotetext{
${ }^{20}$ Aynsley, R. M. et al., (1977). Architectural Aerodynamics: Environmental Wind Flows Around Buildings, Applied Science Publishers, London.

${ }^{21}$ Bottema, M. (1993). Wind climate and urban geometry, Ph.D. thesis, FAGO, Technical University of Eindhoven.
} 


\begin{tabular}{|c|c|c|c|}
\hline No. & $\mathrm{Z}_{\mathrm{o}}$ (Metres) & & Landscape Description \\
\hline 1 & 0.0002 & Sea & $\begin{array}{l}\text { Open sea of lake (irrespective of wave size), tidal flat, snow } \\
\text { covered flat plain, featureless desert, tarmac, concrete, all } \\
\text { with a free fetch of several kilometres. }\end{array}$ \\
\hline 2 & 0.005 & Smooth & $\begin{array}{c}\text { Featureless land surface without any noticeable obstacles; } \\
\text { negligible vegetation: beaches, peak ice without large reaches, } \\
\text { morass, snow-covered or fallow open country. }\end{array}$ \\
\hline 3 & 0.03 & Open & $\begin{array}{l}\text { Level country with low vegetation (grass) and isolated } \\
\text { obstacles with separations of at least } 50 \text { obstacle heights } \\
(50 \mathrm{H}) \text { : grazing land without wind breaks, heather, moor, } \\
\text { tundra, runway of airports. }\end{array}$ \\
\hline 4 & 0.10 & Roughly open & $\begin{array}{l}\text { Cultivated area with regular cover of low crops, or moderately } \\
\text { open country with occasional obstacles (low hedges, single } \\
\text { rows of trees, isolated farms) at relative horizontal distances } \\
\text { of at least } 20 \mathrm{H} \text {. }\end{array}$ \\
\hline 5 & 0.25 & Rough & $\begin{array}{l}\text { Recently-developed 'young' landscape with high crops or } \\
\text { crops of varying height and scattered obstacles (dense } \\
\text { shelterbelts, vineyards) at relative distances of } 15 \mathrm{H} .\end{array}$ \\
\hline 6 & 0.50 & Very rough & $\begin{array}{l}\text { 'Old’ Cultivated landscape with many rather large obstacle } \\
\text { groups (farm buildings, clumps of forest) separated by open } \\
\text { spaces of about } 10 \mathrm{H} \text {. Also vegetation like bush land, orchards, } \\
\text { and young, densely planted forest (with small interspaces). } \\
\text { Dense low buildings: suburb. }\end{array}$ \\
\hline 7 & 1.0 & Closed & $\begin{array}{c}\text { Landscape totally and quire regularly covered with similar size } \\
\text { large obstacles with open spaces comparable to the obstacle } \\
\text { heights: mature regular forests, regularly built large town, } \\
\text { villages. }\end{array}$ \\
\hline 8 & $\geq 2.0$ & Chaotic & $\begin{array}{c}\text { Centres of large towns with a mixture of low-rise and high-rise } \\
\text { buildings (at least } 10 \text { storeys) Irregular forests with many } \\
\text { clearings. }\end{array}$ \\
\hline
\end{tabular}

Table 4: Classification of the boundary layer roughness parameter. Source: Bottema, M. (1993).

An artificial terrain is created in some boundary layer wind tunnels through the use of various wind gates, spires and a series of staggered blocks. These are generally arranged to produce a boundary layer according to a mathematical model. The Deaves and Harris model of 1982 for the structuring of strong winds is a generally accepted model for design purposes ${ }^{22}$. All wind tunnel simulations require a reference speed to be measured. A reference wind speed is taken to be the gradient wind speed above the boundary layer (see

22 Deaves, D. M., Harris, R. I. (1982). A note on the use of asymptotic similarity theory in neutral atmospheric boundary layers, Atmospheric Environment. 16, 1889-1893. 
Figure 4). The gradient wind figures (c) are representative of the percentage of the max wind speed above the boundary layer. The wind speeds measured around the model can then be divided by this reference speed producing a speed ratio. The speed ratio can then be compared to reference wind speeds taken at meteorological stations in the local area to produce a real world wind speed. As a result of this ratio there are no requirements for exact wind tunnel speeds as these are independent of the results. Reference speeds, however, must remain between $10-30 \mathrm{~m} / \mathrm{s}$ to maintain an accurate level of resolution in the results. This ensures a sufficient wind speed at ground level to simulate various aerodynamic anomalies such as downwash, row effect etc. Consequently, the changes in measured wind speeds are much larger, and therefore, easier to identify. These flow characteristics could easily be identified through collecting a number of point wind speed measurements around an area of interest.

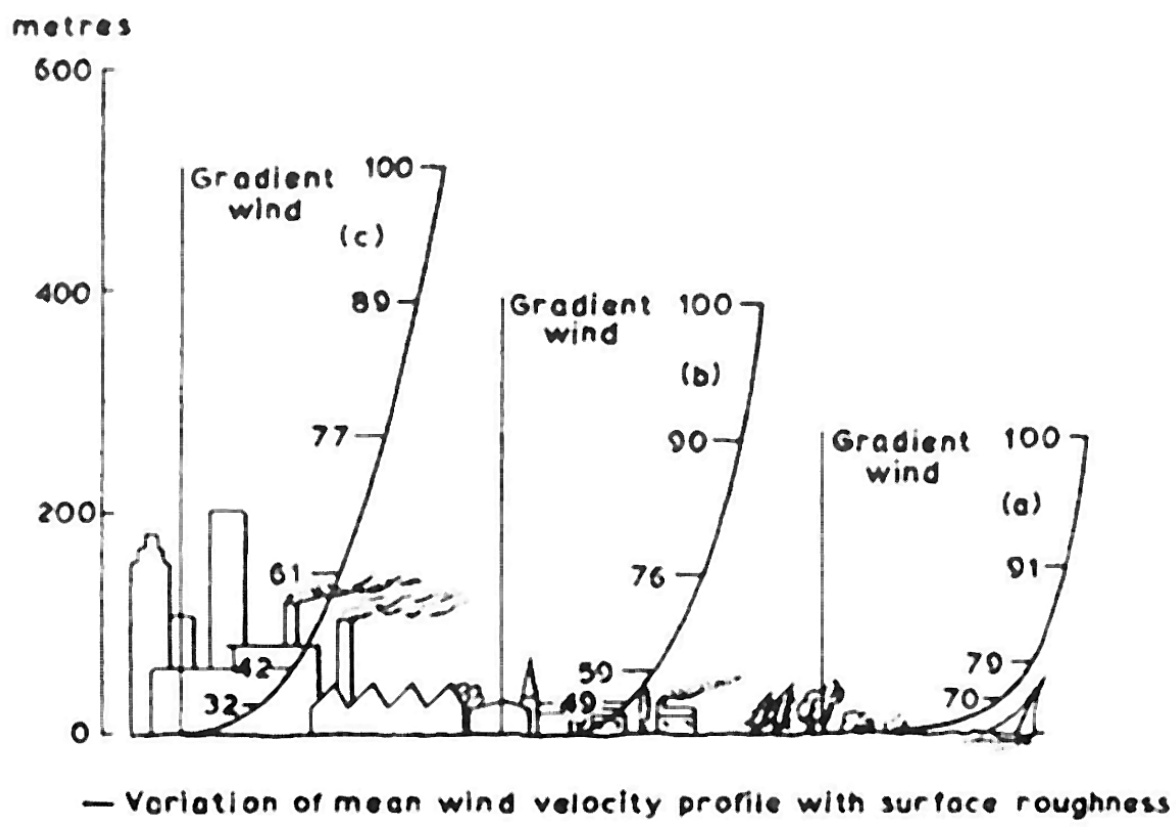

Figure 4: Planetary boundary layer over various terrain categories. Image source: ASCE (2004)

The normal requirements for a pedestrian wind analysis are to assess the mean, gust and root mean squared (rms) wind speeds at different locations around the area in question near ground level. However, as the required testing criteria are dictated by local governing bodies, results can vary between testing facilities. There are currently two different primary forms of measurement used to evaluate pedestrian level winds in a 
boundary layer wind tunnel ${ }^{23}$ : Point wind speed measurements and area measurements. It would be ideal to know the mean and peak wind speeds over an entire testing area, however, with current area testing techniques this is not practical. This would give the end user of the data a complete understanding of the pedestrian level wind environment. Point wind speed measurements are samples of the speed ratio taken at various locations around the development using extremely precise equipment. In order to achieve an overview of the entire location in question area measurement techniques are used. Area techniques can assess a large area simultaneously. However, this often comes with a sacrifice in measurement precision. Figure 5 shows an example of a contour diagram produced as a result of an erosion area test indicating areas and their relative windiness. There are numerous forms of each measurement. Each has advantages and disadvantages.

This research has aimed to combine the benefits of both area and point measurement into a single output. Point measurement techniques produce a more precise assessment of actual wind speeds ${ }^{24}$. Therefore if enough point wind speed measurements are collected it can be inferred that a picture of the pedestrian level wind environment could be produced. This picture has the potential to be more accurate than current area techniques as the contours produced are directly related to measured wind speeds. Determining the resolution of measurement points required to generate a reliable contour image is of primary importance. This thesis will focus on the most common form of each measurement: hot film anemometry (point measurement) and erosion method (area measurement).

${ }^{23}$ Task Committee on Outdoor Human Comfort of the Aerodynamic Committee of the American Society of Civil Engineers, 'Outdoor Human Comfort and its Assessment: State of the Art', American Society of Civil Engineers, Virginia, 2004.

${ }^{24}$ Livesey, F., Morrish, D., Mikitiuk, M., Isyumov, N., (1992). Enhanced Scout Tests to Evaluate Pedestrian Level Winds. Journal of Wind Engineering and Industrial Aerodynamics. (41-44) 2265-2276. 


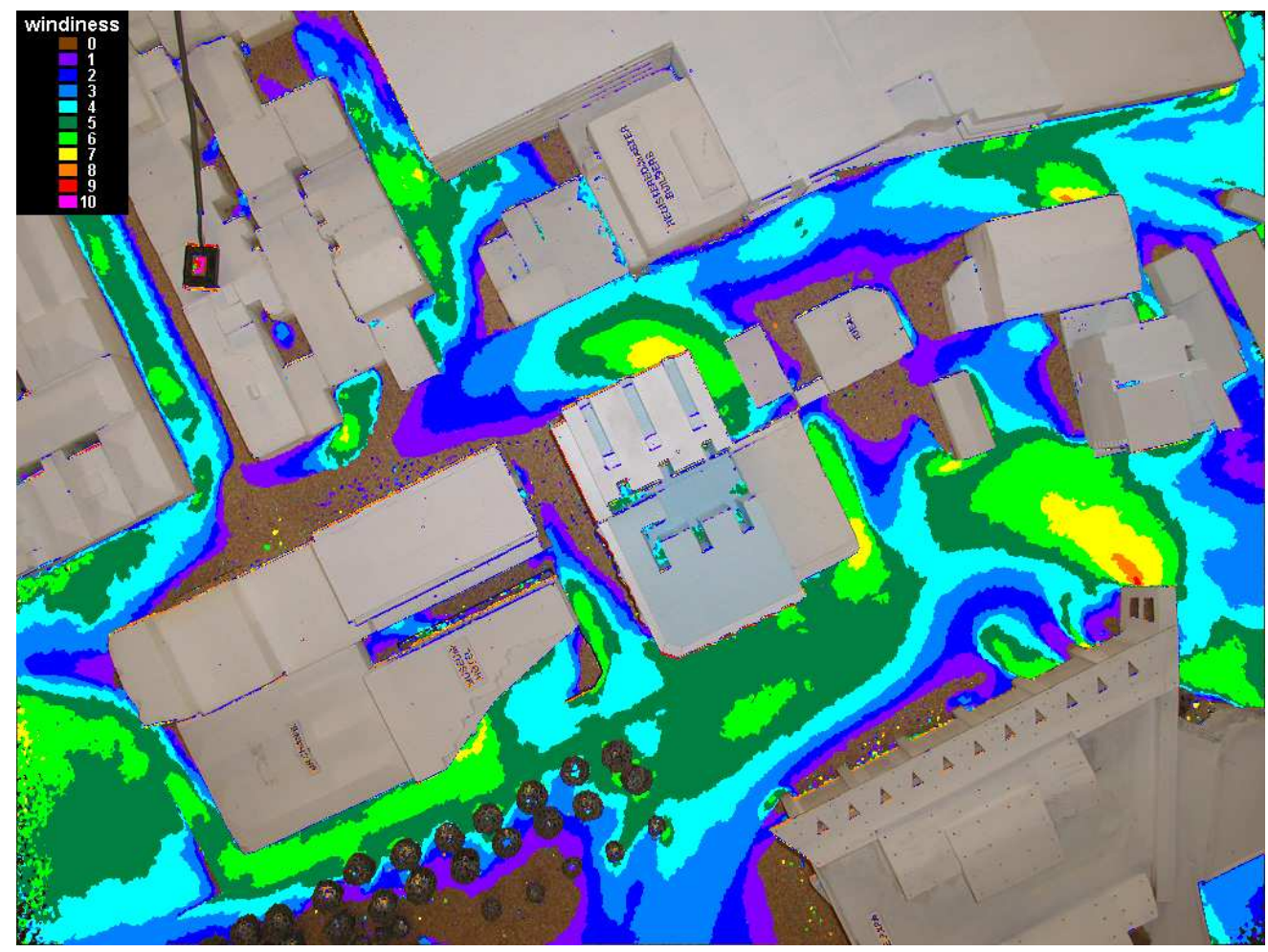

Figure 5: Example of a contour diagram produced as a result of erosion testing (area measurement). Image source: Jameson, N. (2005) 


\subsection{POINT MEASUREMENT}

Hot wire and hot film anemometers provide detailed information about certain aspects of the wind flow. The wind speed with respect to time and the reference wind speed (û) are known accurately. A root mean squared (rms) wind speed can then be calculated. When a mean wind speed measurement is relatively low compared to the levels of turbulence, the measurements are unreliable. This is due to the fact that air flow in an urban environment is highly turbulent, causing the local wind direction and speed to fluctuate relatively frequently. A hot film anemometer cannot measure the direction of the wind ${ }^{25}$.

Predominant wind directions for the area in question are tested. Hours in which the mean wind velocities exceed those specified by the local regulatory commission are also important to include in the report. The more wind speed data that can be obtained, the better. However, the commonly available methods of measurement only allow a limited number of point wind speed measurements to be conducted simultaneously. The method of wind speed measurement used is selected for accuracy, repeatability, stability, resolution and costs. The sensors must also have as minimal interference to the wind flow as possible $^{26}$.

The hot film anemometer is preferable to the hot wire for pedestrian level simulations as it has a slightly larger diameter and therefore is more robust, although proportionally less responsive. The hot wire anemometers typically have a frequency response of $10000 \mathrm{~Hz}$ when compared to a hot film, which has between $100-200 \mathrm{~Hz}$. However, $100 \mathrm{~Hz}$ is still sufficient to evaluate pedestrian level winds. A hot film anemometer consists of a very fine wire with a diameter typically $0.05 \mathrm{~mm}$. It is heated to a constant temperature by passing an electrical current through it. The frequency of the film (up to $200 \mathrm{~Hz}$ ) enables a wide wind speed range to be measured accurately. Air flowing around the wire produces a cooling effect, which when quantified can be converted to a wind speed.

\footnotetext{
25 Beranek, W.J., Van Koten, H., (1979) Visual Techniques for the Determination of Wind Environments, Journal of Wind Engineering and Industrial Aerodynamics (4) 295-306.

${ }^{26}$ Task Committee on Outdoor Human Comfort of the Aerodynamic Committee of the American Society of Civil Engineers, 'Outdoor Human Comfort and its Assessment: State of the Art', American Society of Civil Engineers, Virginia, 2004.
} 


\subsection{AREA MEASUREMENT}

There are a number of area measurements that can be used to assess a wide area simultaneously ${ }^{27}$. The most common of these methods is the erosion test. An erosion test is a convenient method of providing an overall indication of wind conditions at pedestrian level. This provides visual results which are particularly useful in situations where a large area needs to be analysed ${ }^{28}$.

A model of an area requiring pedestrian level wind analysis is placed in a boundary layer wind tunnel. The model is then covered with a uniformly spread layer of bran flakes. Bran flakes are generally used as they have been determined as the best erosion material ${ }^{29}$. An initial photograph is taken to ensure the even spread of bran throughout the model. The wind speed of the tunnel is then increased at pre-determined increments. At each increment the wind tunnel is left for a period of time (around 2 minutes) to ensure erosion has completed. The erosion patterns are photographed after each two minute interval. This technique allows erosion patterns created by wind flow throughout the model to be analysed. By overlaying the photographs taken at each increment, a contour image is produced which identifies how windy the areas of interest are. Figure 5 is an example of a contour diagram produced as a result of this form of area measurement. However, the initial onset of motion of the bran and the erosion patterns relate to fairly complex functions of the local field flow. This can make the calculation of threshold speed rather difficult. In 1990, Livesey studied materials (including bran) for use in the scour test and found the gust speed at which there is an initial onset of erosion is typically equal to the friction speed of the erosion material squared ${ }^{30}$. The erosion patterns are caused by the turbulent gusts rather than the mean wind speed, suggesting that erosion tests are indicative of pedestrian comfort as it is the turbulent gusts that cause uncomfortable conditions for pedestrians ${ }^{31}$.

\footnotetext{
27 Task Committee on Outdoor Human Comfort of the Aerodynamic Committee of the American Society of Civil Engineers, 'Outdoor Human Comfort and its Assessment: State of the Art', American Society of Civil Engineers, Virginia, 2004.

28 Livesey, F., Inculet, N., Isyumov, A.G., Davenport, A.G. (1990). A Sour Technique for the Evaluation of Pedestrian Level Wind Environment. Journal of Wing Engineering and Industrial Aerodynamics. (36) 779-789.

29 Eaddy, M., 1998, Pedestrian Level Wind Measurement using Computer Image Processing, ME Thesis, University of Auckland.

30 Livesey, F., Morrish, D., Mikitiuk, M., Isyumov, N., (1992). Enhanced Scout Tests to Evaluate Pedestrian Level Winds. Journal of Wind Engineering and Industrial Aerodynamics. (41-44) 2265-2276.

31 Beranek, W.J., Van Koten, H., (1979) Visual Techniques for the Determination of Wind Environments, Journal of Wind Engineering and Industrial Aerodynamics (4) 295-306.
} 
Conducting an erosion test allows large areas to be tested simultaneously which minimises the risk of neglecting to identify areas of importance. Also, the erosion test gives an understanding of the flow of wind throughout the space. Specific characteristics of the wind flow can be identified such as areas of down wash or corner effects. The building elements that cause these flow characteristics can then be directly identified. This allows suitable mitigating devices and their effects to be quantified. However, the erosion technique is fairly labour intensive. There have also been issues raised concerning the repeatability of the erosion tests, as there are a large number of factors that could influence the results, such as downwash, turbulence, model surface, tunnel gusts and layering of erosion material ${ }^{32}$.

32 Jamieson, N. (2005). Wind tunnel study of a proposed development for 233-245 Wakefield Street, Central Laboratories Report, 04-529871 


\subsection{CORRELATION BETWEEN POINT AND AREA METHODS}

Livesey et. al. ${ }^{33}$ and Durgin ${ }^{34}$ suggest that it is the instantaneous wind speed that causes the erosion particles to move rather than the mean speed. Livesey also states that if turbulence is present then the onset of particle motion will occur much earlier. This will also increase the rate of transport of each particle. Livesey et al. and Durgin have conducted boundary layer wind tunnel simulations comparing hot film anemometer measurements with erosion patterns. Rectangular blocks or a typical city block are usually used as the model in which comparisons between these two techniques are made. Assuming a normal distribution of wind speeds, the instantaneous gust speed can be calculated from the mean wind speed through the following formula:

$$
\mathrm{V}_{\text {gust }}=\mathrm{V}_{\text {mean }}+\left(\mathrm{g} \cdot \mathrm{V}_{\mathrm{rms}}\right)
$$

Where $V_{\text {gust }}$ is the instantaneous gust speed, $V_{\text {mean }}$ is the average wind speed and $V_{\text {rms }}$ is the root mean squared wind speed. The factor of $g$ is a constant determined through the frequency of occurrence of the resultant gust speed. This figure is generally between 1.0 and 4.0. The lower figures indicate gust speeds that are lower and more frequently occurring, and higher figures indicate less frequently occurring high wind speeds. In 1992 Livesey conducted a study of erosion materials and found the erosion patterns of bran to best relate to $\mathrm{g} \approx 1.1$. This is largely due to the aerodynamic properties of bran which indicate that it has a relatively low threshold of motion.

The characteristics of the hot film anemometer measurement technique are an important consideration when attempting to compare wind speeds from the erosion technique with anemometer data. The height at

33 Livesey, F., Inculet, N., Isyumov, A.G., Davenport, A.G. (1990). A Sour Technique for the Evaluation of Pedestrian Level Wind Environment. Journal of Wing Engineering and Industrial Aerodynamics.(36) 779-789.

34 Durgin, F.H. (1992) Pedestrian Level Wind Studies at the Wright Brother Facility, Journal of Wind Engineering and Industrial Aerodynamics. (41-44) 2253-2264. 
which the anemometer is set up is an important consideration. If it is set up at a height that is above the top layer of the bran, the two techniques will not be measuring the same wind and different results would therefore be expected. A hot film anemometer is generally set up with the wire strung vertically in order to measure the horizontal component of the wind. This is deemed the most important component of the wind as it is what affects pedestrians' safety. This is different to the erosion technique where both vertical and horizontal winds are measured simultaneously. The background research conducted for this thesis comparing over 3000 individual measurement point wind speed measurements with erosion levels suggested that erosion materials are disturbed much more easily by downward winds than by horizontal flow of wind. This often causes over erosion of the bran in areas where downwashes of wind are present ${ }^{35}$, potentially over estimating the level of discomfort felt by pedestrians.

There have been several investigations to determine the correlation between bran erosion and hot film anemometry. These are largely conducted by taking hot wire anemometer readings in areas in which erosion had occurred in a previous test. This allows a direct comparison between the two techniques. However the initial onset of motion of the bran and the erosion patterns relate to fairly complex functions of the local field flow. There is currently no definable relationship between the two methods of pedestrian level wind assessment. If there was a definable correlation between the two techniques, it would appear to be specific to a certain wind tunnel with a certain method of testing. "Wind speeds estimated from erosion patterns must be compared with speeds obtained from discrete wind speed measurements to determine the accuracy of the erosion technique" ${ }^{36}$.

${ }^{35}$ See Background Research Chapter Three.

36 Livesey, F., Inculet, N., Isyumov, A.G., Davenport, A.G. (1990). A Sour Technique for the Evaluation of Pedestrian Level Wind Environment. Journal of Wing Engineering and Industrial Aerodynamics.(36) 779-789. 


\subsection{COMPUTATIONAL FLUID DYNAMICS}

Computational Fluid Dynamics (CFD) is a form of fluid mechanics in which the flow of fluid through a space is solved with numerical methods and mathematical algorithms. There have been a number of CFD programs introduced into the market. Programs such as Ansys Fluent ${ }^{37}$ are primarily designed for engineering applications such as modelling fluid flow through engines, aircrafts and mechanical systems. However, Ansys Fluent can be modified to model airflow through an urban environment. Virtualwind ${ }^{38}$ is a much more recent introduction into the CFD software community. Purposely built for the simulation of pedestrian level aerodynamics, this piece of software is the first real step towards the eventual replacement of analogue wind tunnel testing.

Virtualwind is a powerful piece of software that is comparatively cheap and much easier to use than previous Computational Fluid Dynamics software. Geometry can easily be imported into Virtualwind through Google SketchUp. There are a wide range of output possibilities from the Virtualwind solver. Videos of wind flow across a space can be generated alongside spreadsheets of point wind speed measurements over time.

Virtualwind is still a number of years away from being a suitable tool for evaluating pedestrian level wind environments to determine compliance with regulations set by local governing bodies. It is, however, a powerful tool to simulate wind flow around buildings. CFD software such as Virtualwind has incredible value as an early design tool. If used throughout the design phase a number of different building shapes could be assessed easily and reasonably quickly. This would reduce the time taken (and thus cost) for a full wind tunnel simulation. It could be implemented in projects that do not require a full wind tunnel to improve the quality of adjacent outdoor areas. However, in its current state Virtualwind is not an accurate enough means of assessing compliance criteria with respect to wind speeds. Wind tunnel simulation will still be required for some years to come ${ }^{39}$.

\footnotetext{
37 ANSYS Inc. (n.d.). ANSYS FLUENT Flow Modeling Software. Retrieved March 09, 2010, from ANSYS: http://www.ansys.com/products/fluid-dynamics/fluent

${ }^{38}$ Virtualwind Inc. (n.d.). Value to Users. Retrieved March 8, 2010, from Virtualwind: http://www.virtualwind.com/about-virtualwind20/42-value-to-users

${ }^{39}$ Stathopoulos, T., (2002). The Numerical Wind Tunnel for Industrial Aerodynamics: Real or Virtual in the New Millennium? Wind \& Structures, 5, 193-208.
} 


\section{CHAPTER THREE: RESEARCH BACKGROUND}

Prior research conducted investigated the different pedestrian level wind evaluation techniques. Comparison of a very large number of point wind speed measurements with contour levels determined through area measurement was undertaken. The aim of this research was to determine the possibility of inferring relevant and accurate wind speeds solely through conducting bran erosion tests ${ }^{40}$. This research concluded there were very low levels of correlation between the two measurement techniques.

Wellington City Council has required a wind tunnel test of every new building proposal taller than four storeys in the CBD since the early 1980s. Because the city requires that these tests submit flow visualisations and anemometer readings, a large number of professional wind tunnel reports (most conducted by Opus Central Laboratories) are on file. These tests provided an efficient gathering of data for correlation studies, and made available a large quantity of data in which an array of different aerodynamic situations and locations could be tested.

Previous attempts to infer wind speeds from erosion tests (Beranek, ${ }^{41}$ Livesey $^{42}$ and Durgin ${ }^{43}$ ) use rectangular block/s or a typical city block for the model in which comparisons between the two techniques are made. A series of erosion measurements are made and compared with measured wind speeds. This research differed from these standardised approaches in three respects:

- It evaluated a comparatively large number of measured points and erosion tests.

- The data was extracted from many different wind tunnel simulations conducted with professional accuracy for code compliance. Each project report typically had two design situations, erosion tests for four wind directions; and hot film anemometer based wind speed measurements at 25+ positions.

\footnotetext{
40 This research was presented at the Australasian Wind Engineering Society Workshop in Hobart, Australia in December 2008.

${ }^{41}$ Beranek, W.J., Van Koten, H., (1979) Visual Techniques for the Determination of Wind Environments, Journal of Wind Engineering and Industrial Aerodynamics (4) 295-306.

42 Livesey, F., Inculet, N., Isyumov, A.G., Davenport, A.G. (1990). A Sour Technique for the Evaluation of Pedestrian Level Wind Environment. Journal of Wing Engineering and Industrial Aerodynamics.(36) 779-789.

43 Durgin, F.H., (1992) Pedestrian Level Wind Studies at the Wright Brothers Facility, Journal of Wind Engineering and Industrial Aerodynamics. (41-44) 2253-2264.
} 
- These tests included many different urban situations throughout Wellington City. None had standard heights of surrounding buildings, none were 'typical', and all were representative.

The 30 wind tunnel reports analysed, provided over 3000 individual points of comparison. The types of urban locations in which measurements were conducted vary considerably, thus assessing a broad spectrum of urban wind flow characteristics. Each report had a number of contour images produced as a result of bran erosion measurements. An example of a contour diagram is shown in Figure 6. The level of contouring (windiness) represents two minutes of erosion at a specific wind tunnel speed in a boundary layer wind tunnel. The wind tunnel speed is initially relatively low and is incrementally increased over a period of 20 minutes. The earlier erosion occurs, the higher the windiness level. A direct comparison was made between the windiness level present at points at which a hot film anemometer measurement was taken (see Figure 7).

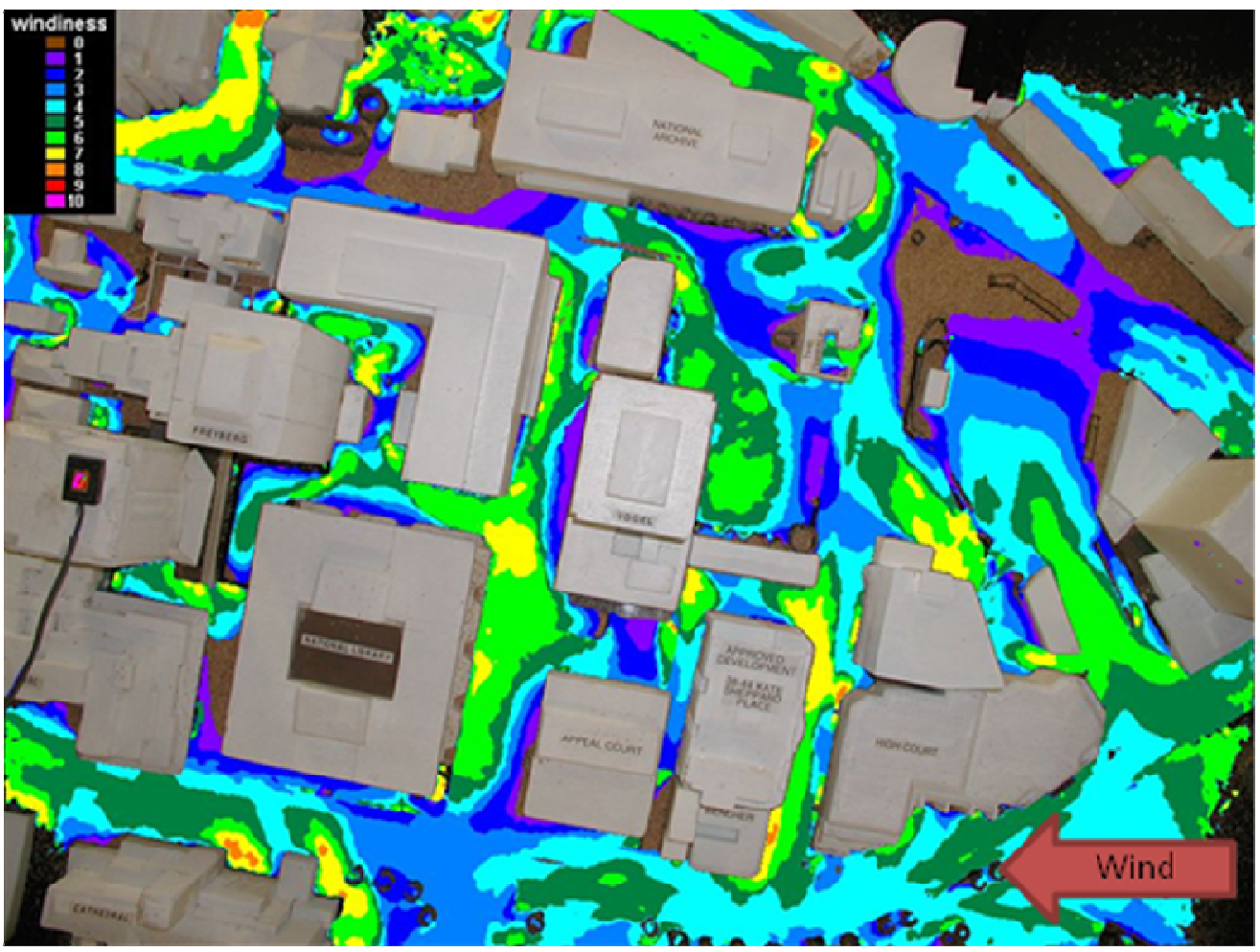

Figure 6: Contour graph produced as a result of bran erosion testing. Image source: Jamieson, N. (2004). 


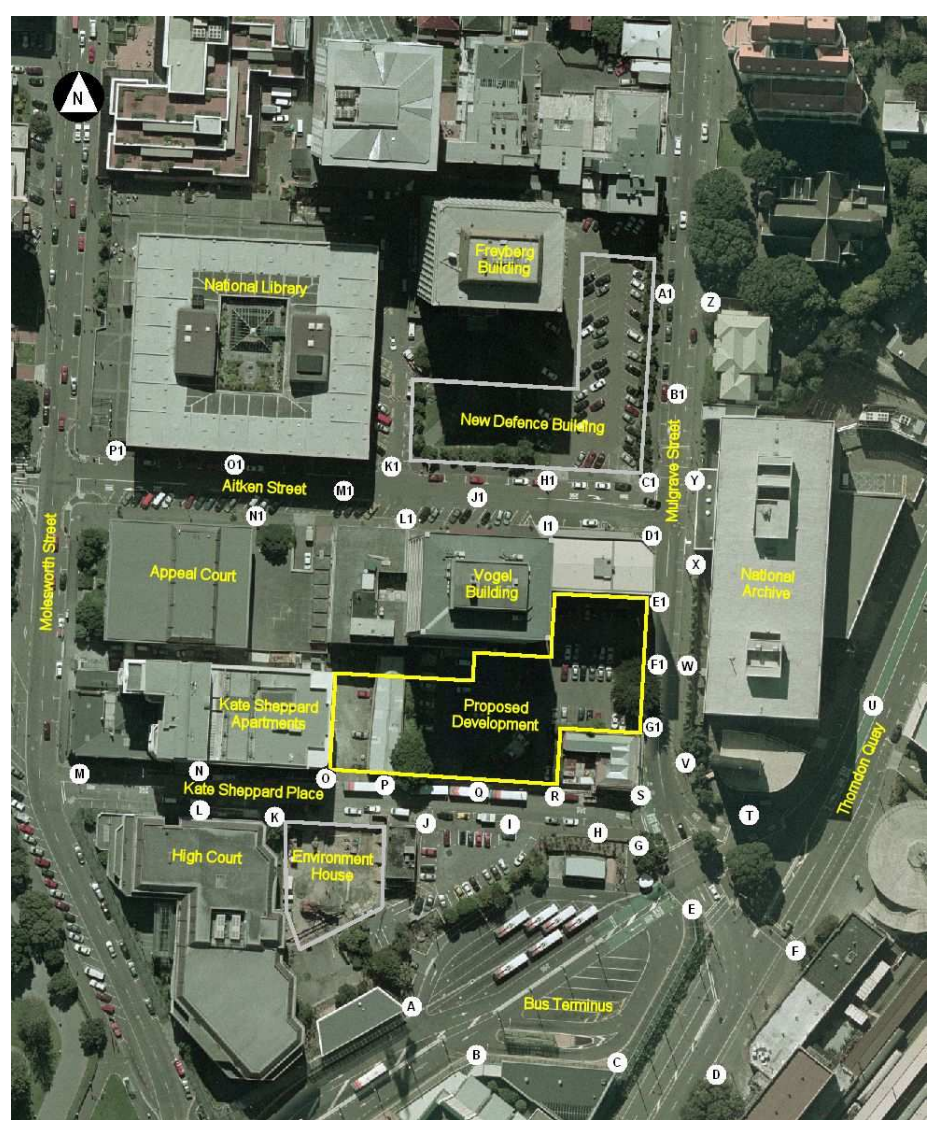

Figure 7: Locations at which hot film measurements were taken. Image source: Jamieson, N. (2004).

\subsubsection{RELATIONSHIP BETWEEN MEASURED WINDSPEED AND CONTOUR LEVEL}

The wind speeds were graphed against windiness level. The goal was to determine the spread of data at each of the windiness levels. In order for the data from erosion contour tests to replace the data from the wind speed measurements there must be a reasonably narrow distribution of data at each windiness level. Determination of how narrow is 'reasonably narrow' requires identification of an acceptable margin of error in decisions based upon this method. For the analysis the median wind speed at each level of windiness was determined and the spread of the data above and below this line was calculated. Opus Central laboratories currently assess wind speeds through hot film anemometer testing with a margin of error - a repeatability - of $1 \mathrm{~m} / \mathrm{s}$. Typical measured speeds are around $13 \mathrm{~m} / \mathrm{s}$. 
Measurements of wind speed were compared to the associated "windiness" level at each point. This would potentially identify the component of the wind that is being measured by the bran erosion tests. The components of wind speed that were analysed were mean, maximum, calculated maximum, standard deviation, and effective gust speed. The maximum speed is the maximum single gust speed measured at the individual point. The calculated maximum is calculated by $V_{\text {calmax }}=V_{\text {mean }}+3.7 V_{\text {rms }}$, where $V_{\text {mean }}$ is the mean speed, and $\mathrm{V}_{\mathrm{rms}}$ is the standard deviation. The factor 3.7 is the peak factor corresponding to a wind speed that is occurring less than $0.1 \%$ of the time. The effective gust is calculated by $V_{\text {eff }}=1.3\left(V_{\text {mean }}+2 V_{\text {rms }}\right)$. Effective gust is used as it is a combined measure of mean wind speed, turbulence and gusts.

Figure 8, Figure 9 and Figure 10 show respectively the distributions of the mean speed, standard deviation, and the calculated gust versus windiness value. There is a steadily increasing trend in all three results. That is, it is reassuring to note that the windiness level reported by the erosion tests increases as the overall measured wind speeds increase. Although this is the case overall, none of the components of measured wind speed that were compared to a windiness value produced a reasonable correlation. The calculated maximum showed the best correlation at 0.59 , while, the standard deviation showed the worst at 0.53 .

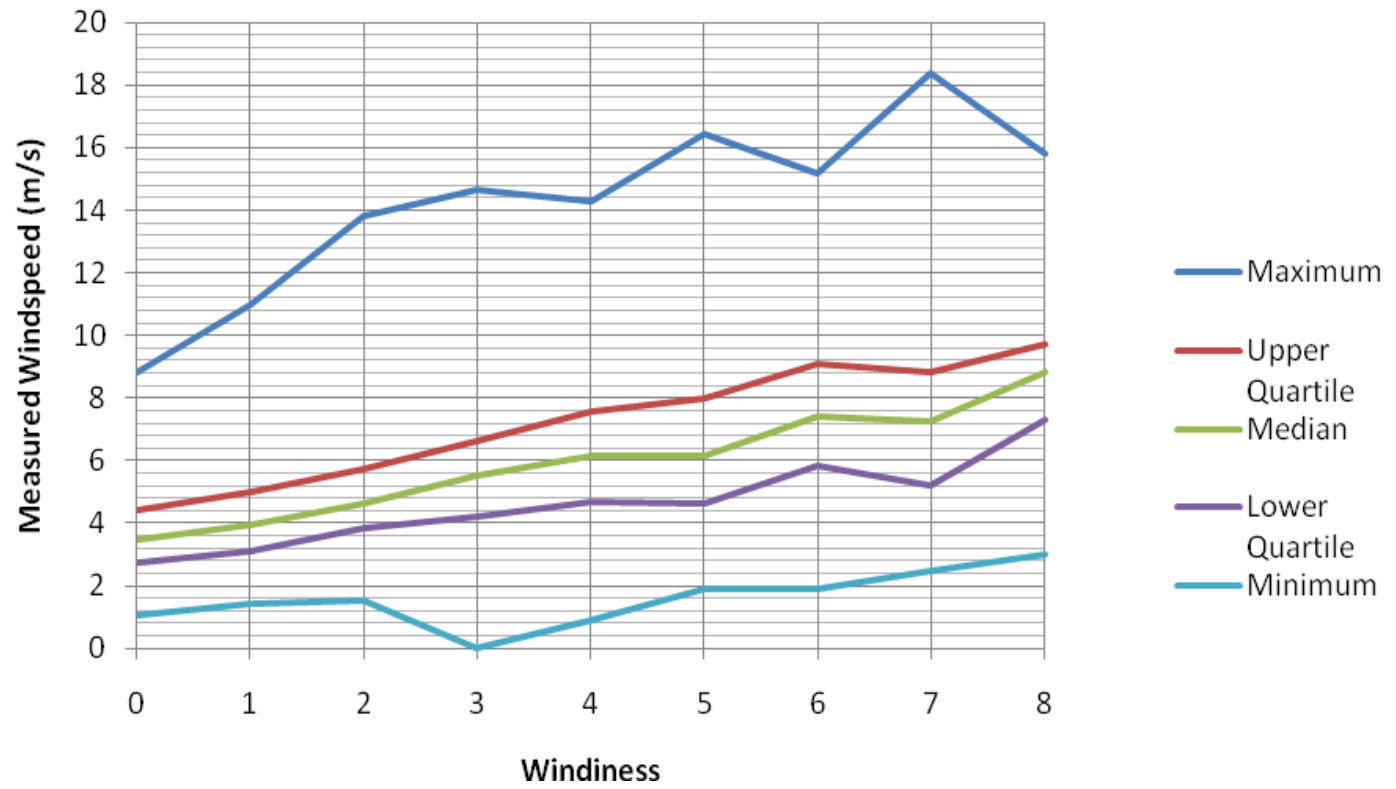

Figure 8: Distribution of mean wind speed values at each windiness level. 


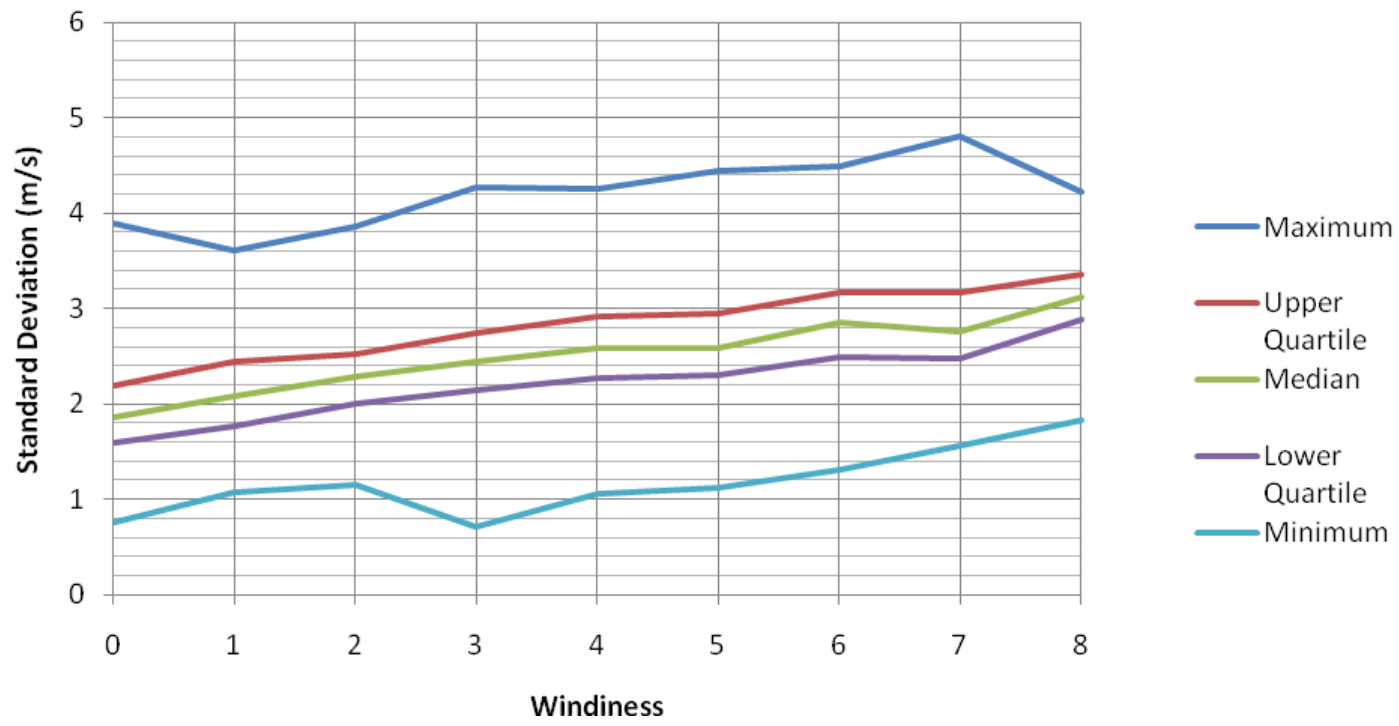

Figure 9: Distribution of standard deviation values at each windiness level.

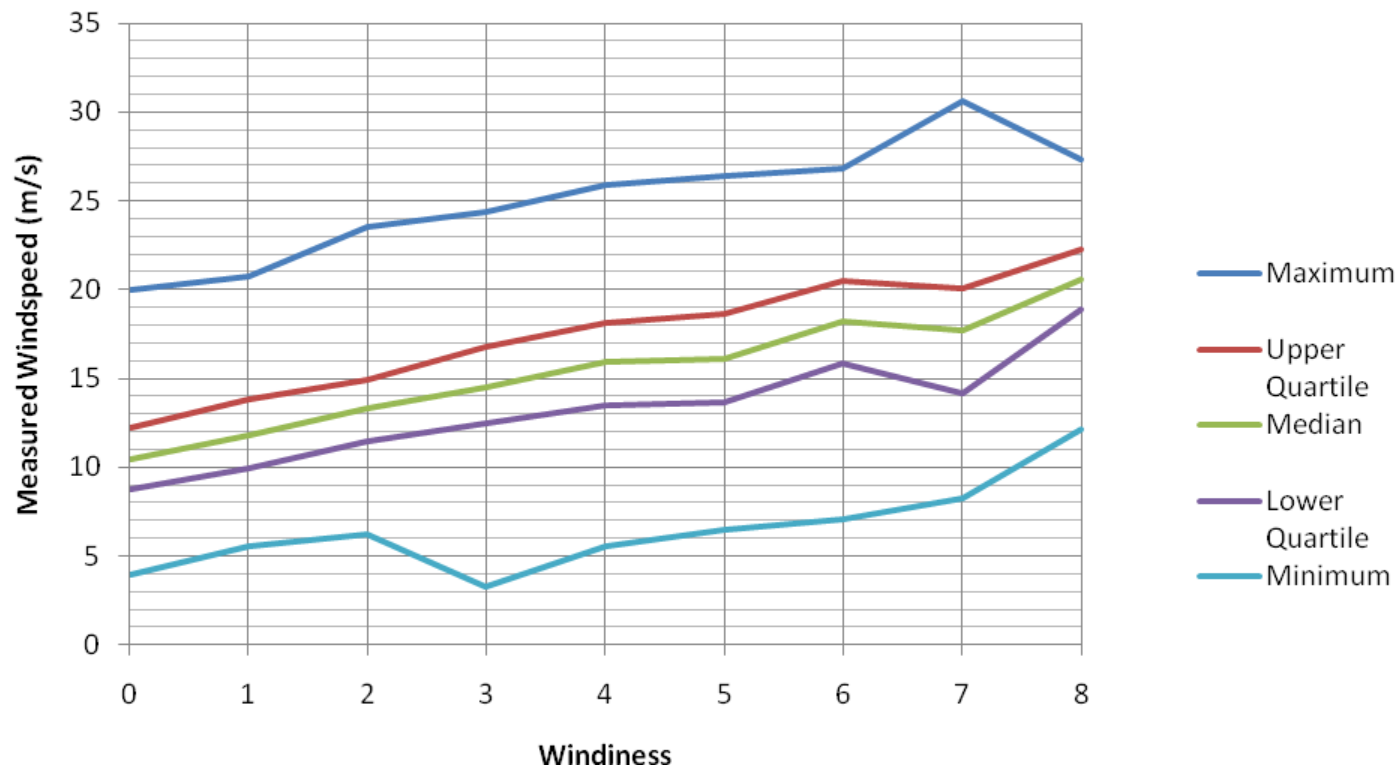

Figure 10: Distribution of calculated maximum values at each windiness level. 
Considering the calculated maximum data, for example, on average only $50 \%$ of the results lie within $\pm 2.5 \mathrm{~m} / \mathrm{s}$ of the median figure. The maximum and minimum are typically within $\pm 10 \mathrm{~m} / \mathrm{s}$ of the median. Compared to the base reading error for point wind speed data of $\pm 1 \mathrm{~m} / \mathrm{s}$, variation of the erosion windiness measurement is considerably high. All results are fairly consistent, as each graph depicts a similar yet proportional margin of error. It is apparent that the erosion technique can only be used to obtain an indication of the wind conditions. It is very difficult to measure a relevant and accurate wind speed solely through erosion testing.

\subsubsection{IDENTIFIED WIND FLOW CHARACTERISTICS}

Where a building is anomalous in a city, such as a tower which is taller than its surroundings, then significant wind effects at ground level can be expected. The range of different flow characteristics can affect the wind flows at street level in different ways. It was anticipated that these might affect the flow visualisations differently. Three specific flow characteristics were examined for their effect on the windiness level: downwash, open areas, and corner flow. Each had to be clearly defined as indicated below:

Downwash - Exposed windward building face perpendicular to the wind flow.

Open Areas - Exposed featureless terrain.

Corner Flow - Exposed windward corner of a building.

There were around 100 selected points associated with downwash, 100 associated with corner flow and 250 identified as open areas.

The goal was to examine whether the low levels of correlation between the measured wind speeds and the apparent windiness of a location could be a result of these flow characteristics. It is clear that the erosion test might be measuring a different component of the wind flow conditions compared to the hot film data ${ }^{44}$, as well as providing an indication of wind speed. Figure 11 plots these new studies. In summary, Figure 11 shows:

${ }^{44}$ See Chapter 2.6 for discussion. 
- The trend line associated with corner flows (blue) has a steep gradient. Indicating that where corner flows occur: low erosion levels are associated with low wind speeds, conversely, high wind speeds are associated with high levels of erosion. This suggests that corner flows are being measured proportionately through both forms of measurement.

- $\quad$ The trend line associated with downwash (red) has a comparatively flat gradient. Indicating that in areas of downwash there is no correlation between erosion technique and point speed measurements. There are two possible explanations for this: either a) hot film anemometry underestimates downwashes; b) bran erosion over exaggerates wind flow characteristic. Both effects may be concurrently operating. The vertical orientation of the hot film anemometer sensor has a tendency to measure more accurately the horizontal component of the wind. Downwash, flowing parallel to the sensor is less likely to be picked up than horizontal flow across the sensor. 'ASCE Outdoor Human Comfort and its Assessment: State of the Art' suggests vertical wind flow (downwash) tends to exaggerate the erosion ${ }^{45}$. This is because the bran is more easily disturbed by this vertical wind flow.

- In a calibration study (Appendix Six) wind speed measurements were taken around a standard cube with a hot film anemometer in both vertical and horizontal orientation. This showed that in areas where downwash was to be expected the horizontally orientated anemometer measured around an $18 \%$ increase in wind speed when compared to the vertically orientated anemometer. When this was compared to other locations around the cube where the primary component of the wind velocity vector was horizontal flow, the vertically orientated anemometer measured much higher wind speeds ( $18 \%$ to $50 \%$ increase) when compared to the horizontally oriented anemometer. This suggests that even in a vertical orientation the hot film anemometer measures the majority of the vertical component of the wind accurately. Therefore, the primary reason for the poor relationship between the erosion technique and point speed measurements in areas of downwash must be due to the over exaggeration of erosion patterns.

45 Task Committee on Outdoor Human Comfort of the Aerodynamic Committee of the American Society of Civil Engineers, 'ASCE Outdoor Human Comfort and its Assessment: State of the Art', American Society of Civil Engineers, Virginia, 2004. 
- The majority of results for open areas (green) lie at the low end of the windiness scale. This fact is not particularly well illustrated in this graph as the trend line is independent of the horizontal data distribution. It does show that higher than average wind speeds are being recorded at all windiness levels. Open areas in which high measured wind speeds are occurring appear to be under eroded. This is potentially due to the lack of turbulence in the wind flow to cause erosion. This anomaly is important, as the erosion technique could show very little erosion in areas in which unsafe wind speeds occur.

There are a number of obvious inconsistencies between the way in which both area and point measurement techniques quantify known flow characteristics. The two causing most concern are areas of downwash and open areas. The highlighting of these flow characteristics has not suggested a simple solution. It has suggested there is some level of consistency between wind speeds and windiness levels within each class of aerodynamic flow. But there is not sufficient evidence to be able to improve the correlation to the extent where reliable wind speed measurements could be drawn solely by conducting erosion tests.

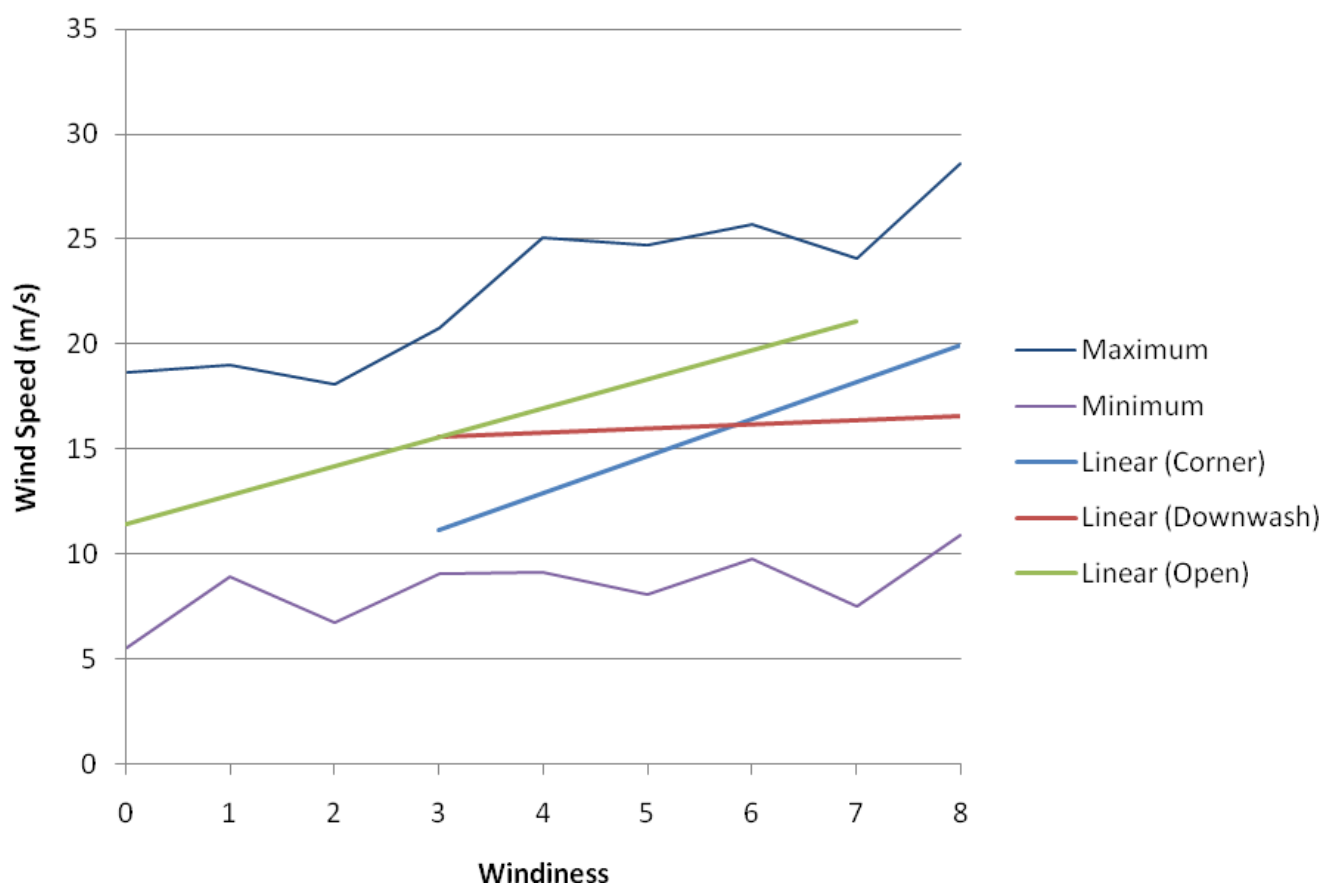

Figure 11: Plot depicting the distribution of identified flow characteristics. 
3.1.3 CONCLUSIONS

This analysis has shown that the erosion technique and the hot film anemometer measurements quantify various known wind flow characteristics differently.

It has shown that it is not possible to produce a precise prediction of a wind speed solely through conducting bran erosion tests. The correlation between the bran erosion windiness and the hot film wind speed is poor.

Generally only $50 \%$ of the recorded mean wind speeds at each of the windiness levels derived from flow visualisation lay within a reasonable margin of error.

The analysis has shown that erosion tests are indicative of broad flow effects, but not of localised predictions of wind speed. Point wind speed measurements are essential for a wind tunnel study seeking to publish predictions of risk of exceeding comfort or safety standards.

Vertical wind flow (downwash) tends to exaggerate the erosion of the bran. This is because the bran is more easily disturbed by this vertical wind flow when compared to horizontal wind flow.

Open areas in which high measured wind speeds occur are under eroded in the erosion tests. Recognising the effects of different flow features in the erosion tests is very important, as the erosion technique can show very little erosion in areas in which unsafe wind speeds occur.

These observations indicate that erosion testing is less consistent than point wind speed measurement. Point wind speed measurements tend to produce more reliable results. However, point measurements only quantify the wind speeds at individual points. The ability to generate an area assessment based on a reasonable number of point wind speed measurements could produce a more reliable form of area measurement and negate the need to conduct two forms of assessment. 


\subsection{DATA PRESENTATION}

In the case of architectural aerodynamics the accurate presentation of wind speed data is highly important. Results produced through a flow visualisation study are primarily represented through contour diagrams. Varying levels of contouring are directly associated with the comparative windiness scale. Areas with a higher windiness value are more susceptible to higher wind speeds than areas with lower windiness values (see Figure 12). This visual representation of flow visualisation data provides the end user with an easily understandable image in which areas of high wind speeds can be identified at a glance. Images such as these contour diagrams can be used in various mediums. Contour diagrams are a powerful medium for conveying flow visualisation. Therefore the question must be posed: can contour diagrams be used to convey point wind speed measurements?

A highly important part of a research study is the presentation of results to the intended audience. Printed mediums such as reports, journal articles and books are perhaps the most common methods of presenting research, each of which presents the research visually. At conferences nowadays research is almost solely presented through PowerPoint presentations, while photographic slides and overhead projector transparencies were commonplace for a number of years prior. The effective communication of information in a visual form whether it is text, tables, graphs, charts or diagrams, requires an understanding of three aspects of the data being presented:

- $\quad$ Legibility: can the data be clearly seen and easily read?

- $\quad$ Readability: is the information set out in a logical way so that its structure is clear and it can be easily scanned?

- Comprehensibility: does the data make sense to the audience for whom it is intended?

One important point to note is that data depicted in one form may not be suitable when presented through another medium. When data is presented in a journal for example, it is possible to identify important characteristics in detail through text, tables and illustrations. However, when data is presented in a PowerPoint presentation it must be limited to simple illustrations and small amounts of text to allow the 
audience to understand key points. The fine details and connections between data and text must be conveyed through the individual conducting the presentation ${ }^{46}$.

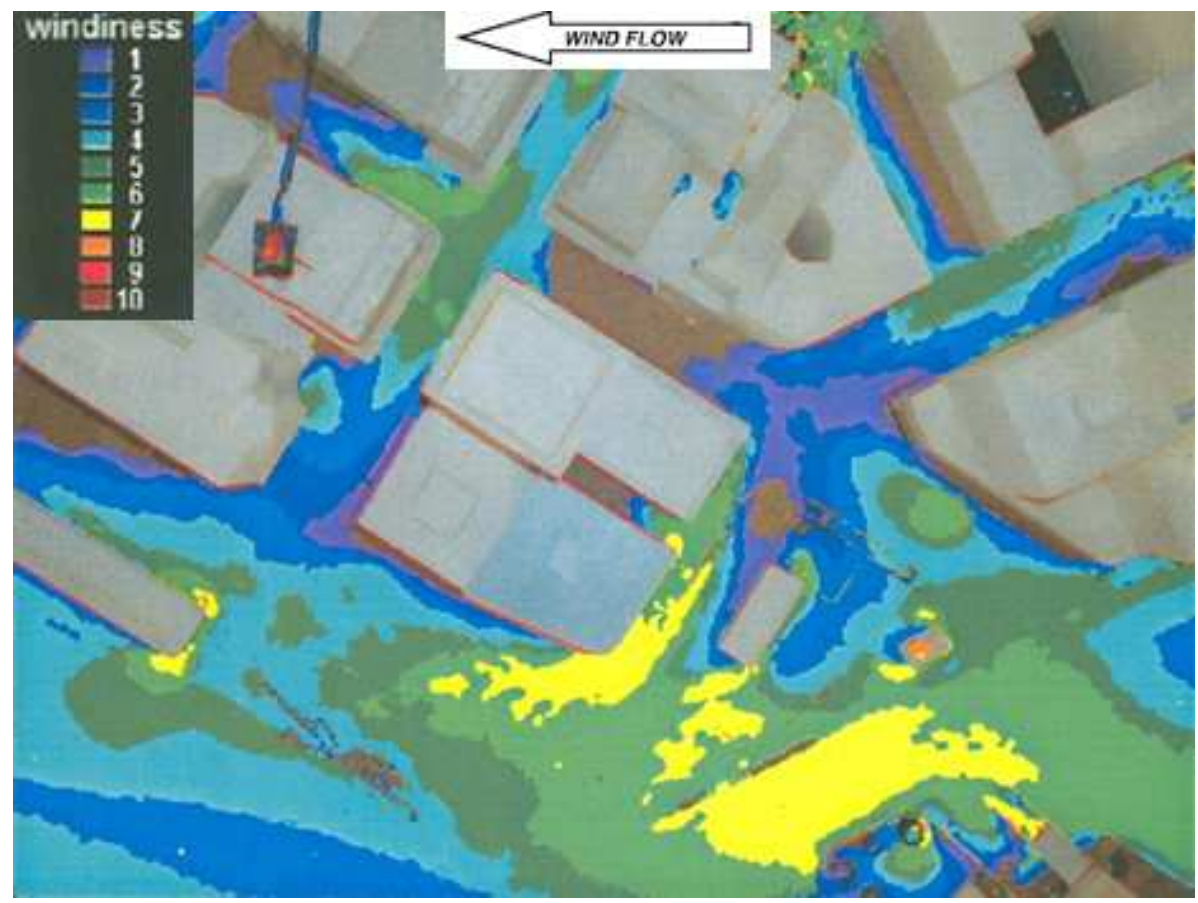

Figure 12: Contour graph produced as a result of bran erosion testing. Image source: Jamieson, N. (2004).

When data is presented pictorially, trends can be detected that we would otherwise be unable to recognise if it was presented in tabular form. This is especially true when large amounts of data are analysed. A graph can include:

- $\quad$ the range of measurements made;

- $\quad$ the uncertainty of each measurement;

- $\quad$ the existence or absence of a trend in the data gathered; and

- data points that do not follow the general trend exhibited by the majority of the data ${ }^{47}$.

\footnotetext{
46 Reynolds, L., Simmonds, D. (1981) Presentation of Data in Science, Martinus Nijhoff Publishers, London.

${ }^{47}$ Kirkup, L. (1994) Experimental Methods: An Introduction to the Analysis and Presentation of Data, John Wiley \& Sons, Queensland, Australia.
} 
Launor Carter conducted an experiment into the design of tables and graphs used for presenting numerical data in 1947. This suggested that information on precise numerical data can be obtained more rapidly and accurately from a table. Graphs are helpful where an interpretation between variables is important ${ }^{48}$. Any illustration of data must have a clear structure based on a defined set of priorities. Increased effectiveness is achieved when the priorities are simple rather than complex, as increased complexity in the presentation of data detracts from the core message that is intended to be conveyed.

Colour is a highly important aspect of data presentation. Research studies have proven that not only does colour improve the retention of data by the reader but effective colour treatment can improve reader interest in the content material ${ }^{49}$. In the case of the contour diagrams (see Figure 12) used to present flow visualisation data, colour, is essential. Colour is used to separate areas of different comparative windiness. This allows areas of low windiness to be associated with calmer colours such as blue or green, while, areas of relatively high windiness to be coloured with colours associated with danger such as yellow or red. This provides the reader with an instant recognition of what is occurring in various areas with little knowledge of building aerodynamics. Providing an instant recognition and understanding allows a much less detailed explanation and is therefore a more powerful way of conveying scientific data ${ }^{50}$.

Measured wind speed data is typically presented in a table (see Figure 13). This table compares the measured wind for the existing building configuration with the wind speeds measured after the building configuration has changed. A number of points located in and around the primary site are measured to attempt to quantify the change in measured wind speeds as a result in the change of the building configuration. In order to determine the effectiveness of this form of data communication, three key aspects of visual data presentation can be applied to this table:

\footnotetext{
${ }^{48}$ Carter, L., (1947) An experiment on the design of tables and graphs used for presenting numerical data. Journal of Applied Psychology, 31, 640-650.

${ }^{49}$ Dwyer, F., (1976) The effect of IQ level on the instructional effectiveness of black and white and colour illustrations. Audio Visual Communications Review. 24, 49-62.

${ }^{50}$ Reynolds, L., Simmonds, D. (1981) Presentation of Data in Science, Martinus Nijhoff Publishers, London.
} 
- Legibility: The data is highly legible in this form. As it is a change numerical value it is easy to see why this is the most legible form of presenting measured wind speed data;

- $\quad$ Readability: The information is set out in a logical way. However if the reader were to scan this table alone they would have difficulty drawing any firm conclusions; and

- Comprehensibility: At a glance a table such as this would make little sense. This table requires the report reader to change pages between the image identifying measurement locations and this list of measured wind speeds.

Upon assessing this form of presenting wind speed measurement it is obvious that the tabular form is merely the most legible way in which to present the wind speed data. A detailed explanation of point locations and wind speeds is required to ensure the reader is able to understand the information. Placing the data on individual lines like this it implies that each point has the same significance. If 3 points are $5-10 \mathrm{~m}$ apart they are likely to all change in the same manner but are only representative of a small area. Whereas, if 3 points at $30 \mathrm{~m}$ intervals all change a similar amount it is indicative of a much larger change in the pedestrian level wind environment. Can measured wind speed data be presented in a way that increases both the readability and comprehensibility of the data? In order to attempt a solution to this question, the variables in this data must be identified. There are two primary variables used in the presentation of wind speed data; location, and measured wind speed. A flow visualisation test assesses the variables of location, and relative windiness of an area. The major difference being that in a flow visualisation test, a large area is analysed simultaneously, while wind speed measurements are taken for a series of individual points.

The two primary variables that need to be conveyed to the reader within wind speed data (speed and location) can be analysed with respect to the effectiveness in which they are presented. Wind speeds consist solely of numerical data. One of the most effective ways in which to present and identify changes in numerical data is in tabular form. This allows the reader to identify changes in wind speed at a glance. When analysing the presentation of measurement locations in tabular form, problems arise. It is however, very difficult to convey a location to a reader at a glance without having a reference map available. This is why tables of this sort generally use a key, which, when referring to a reference map will reveal the locations in which 
measurements are taken. This requires the reader to take extra measures in order to fully understand the data. If wind speed data could be presented within a map of the surrounding area it would make conveying information about the location in which wind speeds have been measured much easier.

Table 1: Net Effective Gust Speeds, $V_{\text {net }}(\mathrm{m} / \mathrm{s})$

Notes: $\mathrm{Exg}=$ with existing buildings, $\mathrm{New}=$ with proposed development.

$\Delta=$ increase of $2 \mathrm{~m} / \mathrm{s}$ or more over existing wind conditions

$\nabla=$ decrease of $2 \mathrm{~m} / \mathrm{s}$ or more over existing wind conditions

\begin{tabular}{|c|c|c|c|c|c|c|}
\hline \multirow[t]{2}{*}{ Location } & \multicolumn{3}{|c|}{ Northerly winds } & \multicolumn{3}{|c|}{ Southerly winds } \\
\hline & Exg & & New & Exg & & New \\
\hline $\mathrm{A}$ & 17 & $\Delta$ & 19 & 7 & $\Delta$ & 12 \\
\hline B & 14 & $\mathbf{A}$ & 17 & 7 & & 8 \\
\hline C & 15 & $\mathbf{A}$ & 17 & 7 & & 8 \\
\hline $\mathrm{D}$ & 13 & & 13 & 7 & $\nabla$ & 5 \\
\hline $\mathrm{E}$ & 29 & & 29 & 19 & & 20 \\
\hline $\mathrm{F}$ & 12 & & 12 & 19 & & 19 \\
\hline G & 9 & $\mathbf{A}$ & 12 & 21 & $\nabla$ & 18 \\
\hline $\mathrm{H}$ & 13 & $\mathbf{A}$ & 16 & 16 & & 15 \\
\hline I & 14 & $\nabla$ & 12 & 17 & & 17 \\
\hline J & 9 & & 8 & 13 & & 13 \\
\hline $\mathrm{K}$ & 15 & $\nabla$ & 13 & 13 & & 13 \\
\hline $\mathrm{L}$ & 20 & & 20 & 15 & & 14 \\
\hline $\mathbf{M}$ & 21 & & 22 & 14 & & 14 \\
\hline $\mathbf{N}$ & 24 & $\mathbf{A}$ & 26 & 16 & & 17 \\
\hline 0 & 27 & & 27 & 20 & & 20 \\
\hline $\mathbf{P}$ & 24 & & 25 & 22 & & 22 \\
\hline$Q$ & 25 & & 26 & 20 & & 21 \\
\hline $\mathbf{R}$ & 25 & & 26 & 18 & & 19 \\
\hline$S$ & 29 & & 28 & 20 & & 21 \\
\hline $\mathrm{T}$ & 25 & & 24 & 20 & & 21 \\
\hline $\mathrm{U}$ & 11 & & 12 & 11 & $\Delta$ & 19 \\
\hline $\mathrm{V}$ & 14 & & 14 & 9 & 4 & 11 \\
\hline W & 14 & & 14 & 10 & $\nabla$ & 8 \\
\hline$x$ & 19 & & 19 & 11 & & 12 \\
\hline$Y$ & 27 & & 27 & 14 & 秀 & 16 \\
\hline $\mathrm{Z}$ & 28 & & 27 & 16 & $\Delta$ & 19 \\
\hline $\mathbf{A} 1$ & 26 & & 26 & 18 & & 19 \\
\hline $\mathrm{B} 1$ & 29 & & 29 & 18 & & 19 \\
\hline
\end{tabular}

Figure 13: An example of the way in which wind speed data is typically presented. Image source: Jamieson, N. (2004). 


\section{CHAPTER FOUR: RESEARCH}

This chapter discusses the research process established to ensure reliable outcomes from this thesis. The initial research question was to determine whether it is possible to produce an area measurement of a pedestrian wind environment based upon a reasonable number of point wind speed measurements. Most common area testing techniques in building aerodynamics produce a contour diagram which represents the comparative "windiness" of certain locations around site. These are typically created by over-laying a series of photographs taken at various stages of an erosion wind tunnel study.

A comparison of erosion contour diagrams and point wind speeds concluded that there were low levels of correlation between the two measurement techniques ${ }^{51}$. Drawing relevant wind speeds from contours produced as a result of erosion testing is an unreliable process. Producing a contour diagram from a series of point wind speed measurements carries all the benefits of an area test while improving the level of accuracy in the output as they would directly relate to measured wind speeds. Contour diagrams would also be a vast improvement over the common presentation of point wind speed measurement techniques. This consists of columns of data representing location and recorded speeds, which can be rather difficult to present to clients of new developments as it is not initially evident where potentially troublesome locations of wind speed are located.

\subsection{HYPOTHESIS}

It is possible to produce an area measurement of a pedestrian wind environment based upon a reasonable number of point wind speed measurements.

\footnotetext{
${ }^{51}$ Refer to Chapter 3: Background Research.
} 


\subsection{WIND SPEED DATA}

Mathematically generating contours requires a number of wind speed measurements to be taken. In developing the contouring script, the more measurement points available the higher the quality of output able to be produced. The use of accurate data is also imperative. For the basis of this study it was initially important that the data be in a grid like fashion and have a range of different building configurations. Opus Central Laboratories conducted a study in 1992 to assess the impact of architectural detailing on pedestrian level wind speeds around city buildings ${ }^{52}$. In this study, both mean and gust wind speeds were measured around the streets for a range of different building shapes in a simplified representative city model. Different designs included towers with and without podiums, carparking buildings, and the use of fences at street level. Two wind directions were examined for each building variation: $360^{\circ}$ and $45^{\circ}$. The representative city model is a 1:300 scale 5 block by 5 block grid of uniform city blocks $60 \mathrm{~m} \times 60 \mathrm{~m} \times 30 \mathrm{~m}$ high with streets $30 \mathrm{~m}$ wide. The central building within the 5 by 5 grid was chosen to be the reference building.

The Opus Central Laboratories wind tunnel is an open circuit type, with a $2.74 \mathrm{~m}$ wide by $1.22 \mathrm{~m}$ high test section and approximately $30 \mathrm{~m}$ upwind fetch. Fences and roughness elements were set up to simulate a wind flow similar to that of suburban terrain. Turbulence and speed profiles within this tunnel are carefully designed to match the terrain category $3\left(Z_{0}=0.2 \mathrm{~m}\right)$ based on the work of Deaves and Harris ${ }^{53}$.

Wind speed measurements were taken with a hot film anemometer at a scale height of $2 \mathrm{~m}$ at various locations around each test building. Measurement points were located in the centre of the streets and at a scale distance of $1.5 \mathrm{~m}$ from the buildings. For each building configuration, measurements were taken for both 360 and 45 degree wind directions. The wind speed at each location was measured for two minutes at a sampling rate of $500 \mathrm{~Hz}$. Figure 14 shows wind speed measurement locations for a sample area of the 5 by 5 grid.

\footnotetext{
52 Jamieson, N.J., Carpenter, P., Cenek, P. D. (1992). The Effect of Architectural Detailing on Pedestrian Level Wind Speeds. Journal of wind engineering and industrial aerodynamics. 41-44, 2301-2312.

53 Deaves, D. M., Harris, R. I. (1978). A Mathematical Model of the Structure of Strong Winds, CIRIA Report 76.
} 


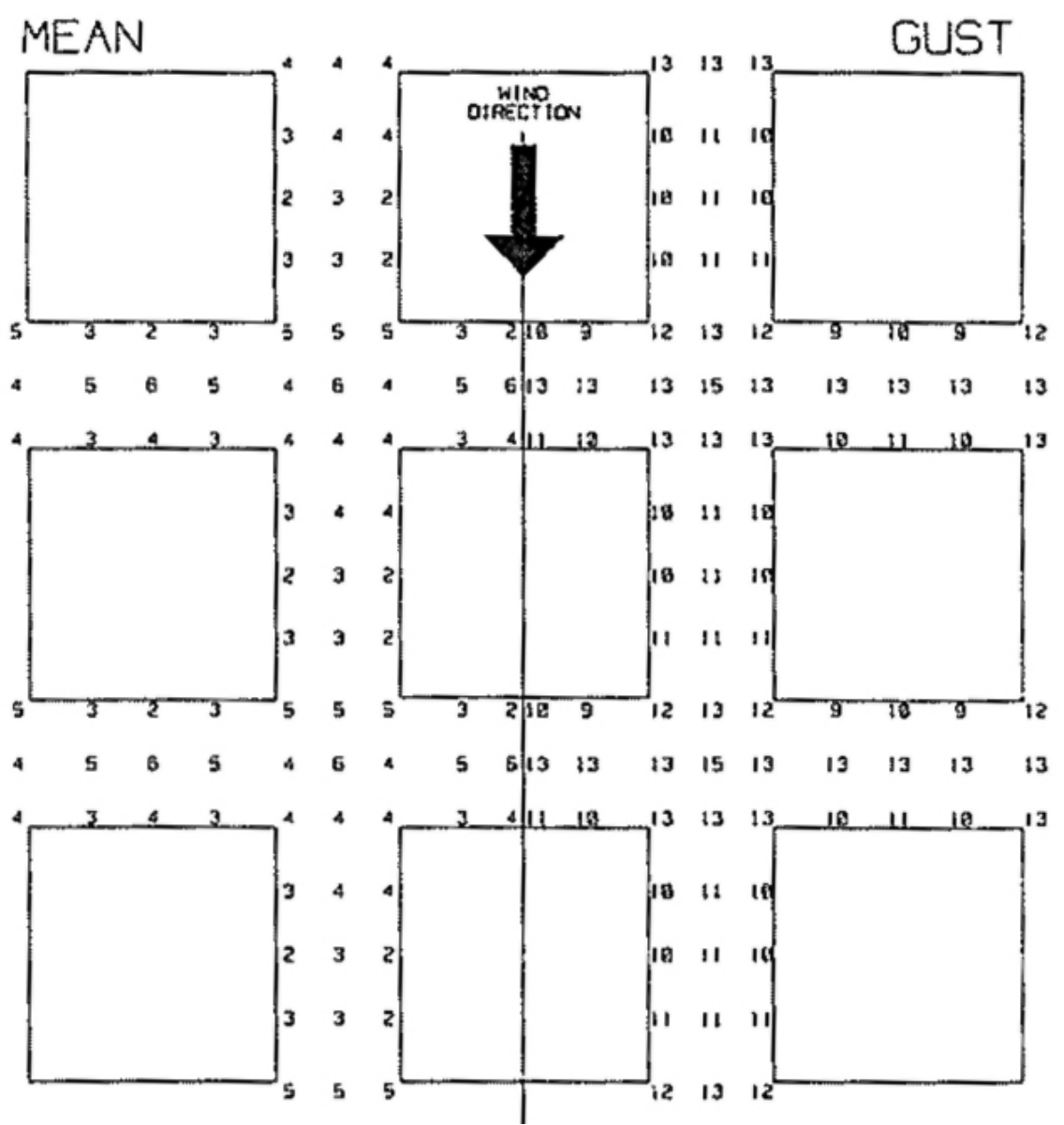

Figure 14: Sample of building grid showing measurement locations and measured speeds in $\mathrm{m} / \mathrm{s}$. Image Source: Jamieson, N., et al. (1992).

The wind speed data was only available in printed type format - no digital copies of the data existed. Each data set is symmetrical, thus, only certain areas of points were measured with the intention of the reader understanding that the remainder of the measurements can be extrapolated from the provided data. However, for this study each set of data would need to be complete. The data was manually extrapolated along these lines of symmetry. Missing measurement points were assumed from areas of a similar nature ensuring lines of symmetry or reflection remained accurate. 
Data sets were chosen to show the progressive impact of building height on the pedestrian wind environment. These consisted of:

- Uniform 5 by 5 grid of half cubes: The uniform grid of half cubes is the base model from which comparisons can be made. All cubes are $60 \mathrm{~m} \times 60 \mathrm{~m} \times 30 \mathrm{~m}$ tall in scale.

- Cube reference (centre) building: The reference cube consists of the base array of half cubes with the central building being a full cube. This reference cube is $60 \mathrm{~m} \times 60 \mathrm{~m} \times 60 \mathrm{~m}$ high in scale. By analysing this arrangement an insight can be obtained into how a medium rise building would affect an area of relatively low uniform building height.

- Tall tower reference building: The tall tower data set consists of a uniform grid of half cubes surrounding a tall tower on a square platform. The platform is a half cube and the tall tower is $30 \mathrm{~m} \times 30 \mathrm{~m} \times 240 \mathrm{~m}$ in scale. In total there have been 12 data sets analysed.

The different data sets that were selected for analysis with the contouring script are listed in Table 5:

\begin{tabular}{|ccc|}
\hline Uniform 5 by 5 Grid & Cubic Reference Building & $\begin{array}{c}\text { Tall Tower Reference } \\
\text { Building }\end{array}$ \\
\hline $360^{\circ}$ mean & $360^{\circ}$ mean & $360^{\circ}$ mean \\
\hline $360^{\circ}$ gust & $360^{\circ}$ gust & $360^{\circ}$ gust \\
\hline $45^{\circ}$ mean & $45^{\circ}$ mean mean \\
\hline $45^{\circ}$ gust & $45^{\circ}$ gust & $45^{\circ}$ gust \\
\hline
\end{tabular}

Table 5: Different building configurations analysed. 


\subsection{PROGRAM SELECTION}

In order to process large quantities of wind speed measurements a powerful contouring program was required. In general terms, contouring is predominantly associated with mapping and meteorology. Therefore, the majority of programs available for contouring are purpose built around these fields. The initial concept was to determine how an existing contouring program could be applied in a manner appropriate for this study. There are a number of small, contouring programs available. These are, however, somewhat limited in the scope of the inputs/outputs. This research required a program to: input data from an excel spreadsheet, have a powerful contouring function and variable interpolation methods; and the output needed to be accessible for manipulation. These programs did not meet these criteria. Upon an internet search of contouring programs, one program yielded a much more diverse array of results. The program was called MATLAB. It appeared to have a powerful contouring function that was extremely flexible in the range of possible inputs/outputs.

\subsection{MATLAB}

MATLAB is a high-level scientific and engineering programming environment which provides many useful capabilities for plotting and visualizing data and has an extensive library of built-in functions for data manipulation. MATLAB allows matrix manipulation, plotting of functions and data, implementation of algorithms, creation of user interfaces, and interfacing with programs in other languages ${ }^{54}$. Functions of primary importance to this study were the ability to manipulate matrices of data and the various contouring functions available.

\footnotetext{
${ }^{54}$ The Mathworks (n.d.). MATLAB 7.10 - Product Description. Retrieved March 8, 2010, from The Mathworks: http://www.mathworks.com/products/matlab/description1.html
} 
There are numerous formats for which data can be inputted into MATLAB. Initially the data had to be digitised as it was from an older journal article and was solely in print form. This was done by creating a 31 by 31 cell grid in Microsoft Excel and placing the numbers into this spreadsheet leaving empty coloured cells where the cubes were present. In this form the data could be manipulated to ensure symmetry and accuracy. Each data set has recorded measurements for 360 and 45 degrees and data on both the peak and mean wind speeds. This provided a total of 12 different data sets for which this analysis was conducted. The development of a MATLAB script with these simple cases would allow accuracy in the script itself while also identifying anomalies that may need further analysis. Figure 15 shows an example of initial (full) data as initially inputted into excel. This study would eventually require three columns of data to be read into MATLAB, wind speed and the co-ordinates of each point in both the $\mathrm{x}$ and $\mathrm{y}$ directions.

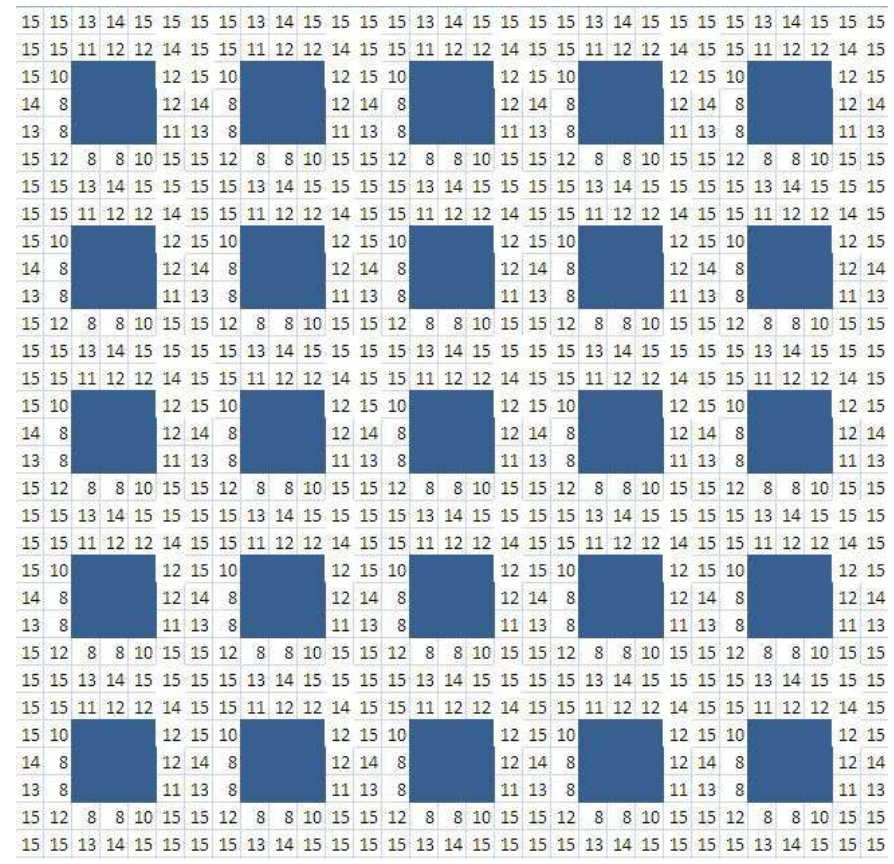

Figure 15: Initial data as inputted into Excel.

With this direct translation from print form to a digital matrix of numbers a simple study was conducted using the base MATLAB filled contour function in order to provide a proof of concept. MATLAB is able to read in Excel data. The grid of measurements (Figure 15), therefore, was read in as the matrix of points. Figure 16 shows the output created as a result of this. This would prove that MATLAB has the capacity to produce 
relevant contours for a series of point wind speed measurements. However, there are a large number of errors in the image that would need to be systematically improved upon. Of primary importance was the addition of locational data. In the current form the contour image has no co-ordinate system to locate measurement points. To have a practical application, a co-ordinate system of data entry would have to be implemented. This would involve combining wind speed data with co-ordinates in three columns ( $x, y$, speed). A co-ordinate system would allow freedom in measurement point location and provide a practical application for this script.

Wind speed measurements were taken in the centre of the streets and $1.5 \mathrm{~m}$ (scale) away from the buildings. Therefore, all points were associated with a co-ordinate corresponding to the location on both the $\mathrm{x}$ and $\mathrm{y}$ axis. Beginning with $(0,0,15)$ in the lower left corner the co-ordinates progressed incrementally along the $x$ axis before moving upwards along the y axis. The typical distance between points was $15 \mathrm{~m}$. By inputting the data in these columns it would allow points to be easily added and subtracted without the need to rely on a regular grid of measurements.

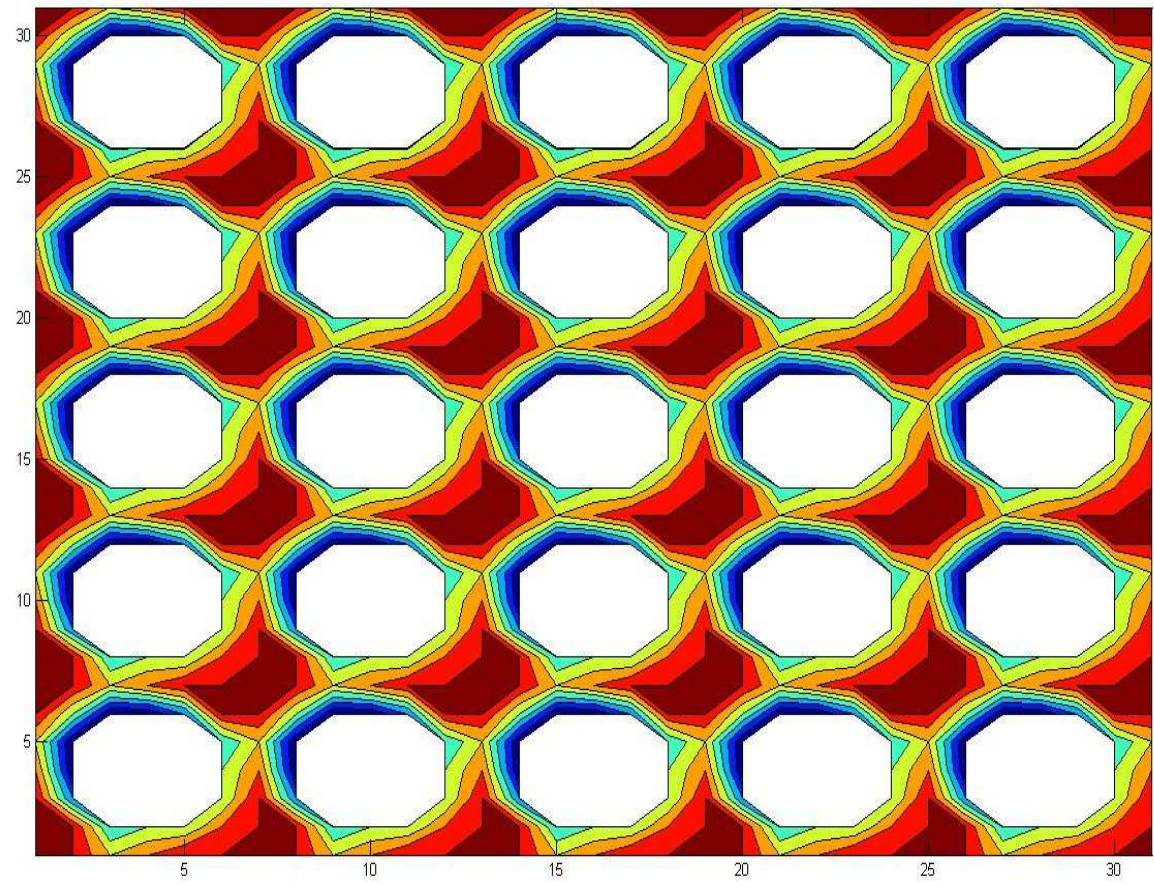

Figure 16: Initial contour output from MATLAB providing a proof of concept. 


\subsection{SCRIPT DESIGN}

In order to use MATLAB efficiently the process by which it draws contours must first be understood. Firstly a matrix of data is required. This matrix of data is what the inbuilt function will draw contours from. Most matrices of data inputted will represent an irregular array of data that is sampled at various locations. Therefore, pseudo measurements may need to be created through one or a combination of interpolation methods to fill in the gaps in the matrix. There are a number of methods available in MATLAB to interpolate data into vectors, grids and triangulated tessellations. Through careful modification of various parameters within these interpolation methods, the raw data can be modelled in a way that reflects assumptions of the desired output. Different interpolation methods are analysed in the following chapter. MATLAB then determine which contour levels to draw. If the levels of contours are not defined, it will automatically determine them. No more than 20 contour levels will be created based on the range of the data inputted.

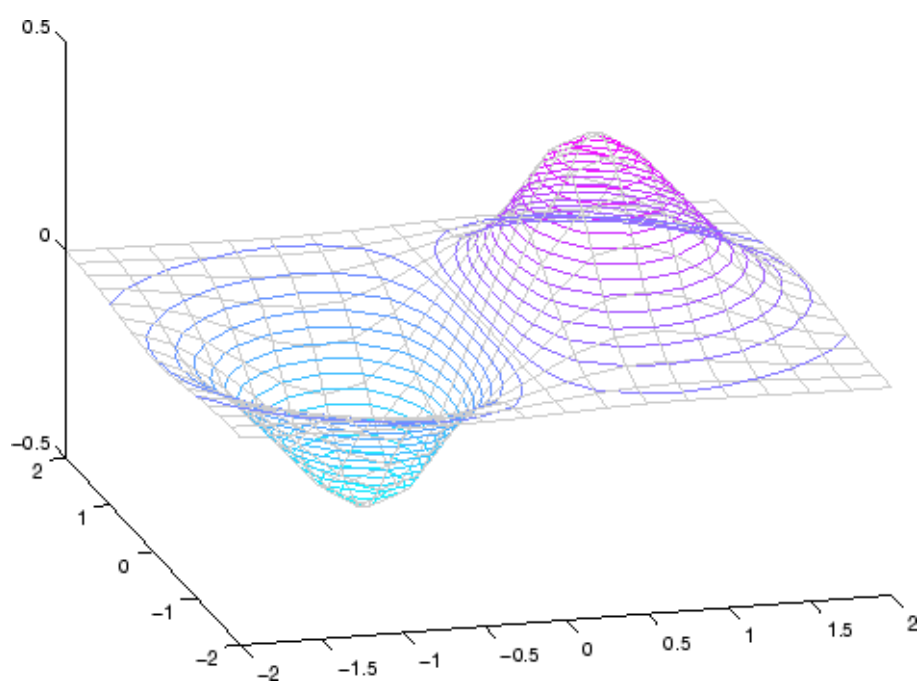

Figure 17: A three dimensional contour diagram drawn in MATLAB indicating slice planes that are drawn in two dimensional contours.
Specific cases such as this research, require a regular grid of possible measurement locations. A grid such as this does not require data to be inputted regularly. It merely creates a base on which to locate the data. If a standardised grid is not defined MATLAB will automatically define one based on the matrix of data that is inputted. Once MATLAB has a matrix of data, the contours can be drawn. A

matrix of data is then drawn in as a three-dimensional surface plot. The level of accuracy within the surface plot drawn depends on the quality of raw data and the interpolation method used. Defined contour levels are then isolated and indicated on the surface plot. Contours are then drawn essentially as horizontal twodimensional slices through the three-dimensional surface at the pre-defined levels (see Figure 17). 
A MATLAB script is an external file that contains a sequence of statements. This type of file contains blocks of MATLAB commands written in programming language. The development of an efficient and accurate script was essential to improving the quality of the output. Once the contouring process was understood the initial image was reviewed and critiqued in order to determine areas that may need further development. Over time these were systematically improved and the script was built upon. Obvious initial major issues that needed to be addressed were:

- $\quad$ there is a lack of locational data from which speeds were associated;

- $\quad$ gaps of data (i.e. where buildings are located) needed to be addressed;

- $\quad$ buildings should be displayed on the graphs;

- $\quad$ there is no key to associate wind speeds with a colour;

- $\quad$ various interpolation methods need to be investigated.

The locational data was added to the contouring process through the aforementioned process of changing the format in which the data was read into MATLAB. The data was converted into three columns representing the co-ordinate along the $x$ axis, the co-ordinate along the $y$ axis, and the measured wind speed at this location ( $x$, $y$, speed). By having the data in this form, different points could be added or subtracted without affecting the layout of the grid. The script was then initiated by a command to read in the three columns of data. Each column of data was then defined as $\mathrm{x}, \mathrm{y}$ or speed in order for the program to recognise it and allow it to be further analysed. Simply doing this, however, did not improve the aesthetic quality of the output image. The only significant change occurred in the legends. The legend now read 450 which corresponded to the measurement locations.

The next major issue to be addressed was the areas within the contouring diagram where the buildings are located. MATLAB associates them with areas of empty space. Other alternative entries were attempted such as changing the measurement locations underneath the buildings to read zero. The reasoning for this was that underneath the building at these locations the wind speed was in fact zero. However, after processing the script with this modification there were a number of obvious issues. The contouring program was concluding that areas now labelled zero were part of the area to be contoured and as a result areas around 
the buildings were now associated with relatively low wind speeds. This would present a major issue with respect to the accuracy of the contours produced. It became evident that these areas in which the buildings were located could not be associated with nothing nor could they be associated with any numerical value as this would skew the results. These areas were simply not associated with wind speeds. This forced MATLAB to attempt to contour around these areas.

In order for MATLAB to process an accurate contour function a regular grid must be defined in order for the measurement points to be located accurately. Initially this was left undefined which resulted in the poor quality image shown in Figure 16. The careful definition of a grid to locate measurement points upon was essential in this case as accurate interpolation cannot occur on undefined grids. Nor was there a possibility to define a grid with parts missing as the interpolation methods described later need a continuous surface to extrapolate points along. Therefore, two possibilities were presented at this point:

- Leave the grid undefined which would produce crudely drawn contours (i.e. incapable of using interpolation methods). However areas where buildings are located would be absent from the diagram and thus contouring would not continue over this space; or

- Define a regular grid on which the measurement locations can be defined. This option would require one continuous surface to be defined and thus, areas where the buildings were located would have no measurements. This would cause contouring to continue across this space resulting potential minor inaccuracies especially around building edges.

These options seemed to promote the obvious choice to define a regular grid to place the measurements on. Although this would not provide an ideal level of accuracy in contouring around the buildings, the contours would be of a much higher quality. This would allow the use of an interpolation method to determine pseudo measurements in between the plotted wind speeds. A very fine grid, defined with minimum distance of $0.5 \mathrm{~m}$, was used as this allows freedom in the location of measurements. A finer grid could be used if required. However, contour generation time is increased proportionately. 
Determining how best to illustrate how the buildings should be displayed on the contour image was the next issue to resolve. As the defined grid would not allow blank areas to be simulated where the buildings were located, this had to be done in a further step. Research through the MATLAB user manuals led to the solution of placing "patches" over the image where the buildings are located. Although not ideal, it seemed the high wind speeds around the edges of the buildings were being accurately illustrated and this would merely cover the continued contour extrapolation over the blank spaces. In order to draw patches the building locations had to be defined. Co-ordinates of the 25 buildings throughout the $450 \mathrm{~m}$ by $450 \mathrm{~m}$ grid were noted. To generate the patches, the $x$ co-ordinates of each point around the edge of the patch were defined, followed by the y co-ordinates. For example, the first patch was written as: patch([15,75,75,15],[15,15,75,75]). The first square bracket contains $\mathrm{x}$ co-ordinates that are then paired with the corresponding $\mathrm{y}$ co-ordinates in the second square bracket. The points define each square beginning with the lower left hand point of $(15,15)$ and moving counter clockwise around the square to the upper left hand point of $(15,75)$.

This step created a further 25 lines of code written into the script to define these patches. This then presented another issue to resolve. To ensure a future usefulness in this program, varying patches of buildings would have to be created. With the script at its current state only this specific 5 by 5 grid of buildings could be patched. If further patches were required the script would have to be altered. The eventual goal of this script is to use it for commercial wind studies. Various patches would therefore have to be created for varying building configurations. To achieve this step a further script entitled "patches" was created and within this code are the co-ordinates of the various patches. In doing this it would enable the contour processing script to remain separate from the patches. Therefore, future studies could create patches resembling the shapes of surrounding buildings and overlay them onto the image. This presents the potential to create a point and click type graphical user interface (GUI) in which to define the edges of patches. This could greatly reduce the amount of time taken to define an irregular building layout.

The next step in producing an accurate contouring script was the formation of a legend to associate the contours produced with the corresponding measured wind speeds. This critical piece of the diagram would provide what existing flow visualisation contour images do not: a direct correlation between contours and 
measured wind speeds. To do this MATLAB has a number of colour bar functions that vary in the number of steps, and thus colours. However, in this research it is important to ensure the results from one study can be comparable to another. The colour bar must therefore have a fixed number of steps, each of which should associate a colour to a certain speed. This was done by using a separate colour bar script. Using an external script to control this separate from the contouring script would allow the colour bar to be modified to suit individual commercial wind studies.

MATLAB is a highly diverse program, and as a result there are a large number of third party scripts developed by individuals to suit a number of purposes. Upon searching the MATLAB file exchange ${ }^{55}$ it became apparent that Blair Greenan of the Bedford Institute of Oceanography had created an external script to control various aspects of the colour bar ${ }^{56}$. This script is used to fix the data processed within the original script to individual colours. By default MATLAB will draw a colour bar with fixed colours and then assign the range of data to the various colours. This would present immense difficulties when comparing two images of a similar nature. However, the "colorbarf" script allowed colours to be assigned individually to a specific data range, or in this case, an individual data point. The range of the data is then determined directly from the data being analysed and allocated their specific colours. If higher (or lower) speeds are recorded in a subsequent study the same colours will not be associated to different wind speeds. Additional colours will be added to the colour bar, thereby allowing an easy comparison between various studies.

At this stage the script was running reasonably well for individual studies. An Excel file could now be automatically read in with three columns of data in the form of $x$ co-ordinate, y co-ordinate and wind speed. The data was then fitted to a regular grid from which the contours could be produced. Patches were then overlaid for the areas in which buildings were located. Creating an external patch script allowed modifications to easily be made, which ensure flexibility for future use. A colour bar was then added to the right hand side of the graph to associate colours with actual measured wind speeds. This also was processed through a

\footnotetext{
${ }^{55}$ Greenan, B,. (2001). MATLAB Central: colorbarf. Retrieved March 11, 2010, from MATLAB Central: http://www.mathworks.com/matlabcentral/fileexchange/1135-colorbarf

${ }^{56}$ See Appendix Four for details of colorbarf script.
} 
separate script allowing for flexibility in processing the data. To ensure accuracy and aesthetic quality in the output, the different interpolation methods available through MATLAB were now assessed. 


\subsection{INTERPOLATION METHOD INVESTIGATION}

Producing an accurate contour diagram without any form of interpolation of data would require an extremely large number of measurements. Even with a large number of points the resultant contours would be jagged and not an ideal representation of an area measurement technique. An assumed minimum distribution of points required for this would be approximately $0.5 \mathrm{~m}$ or the width of a person's shoulder (in scale). This method for assessing the pedestrian wind environment should theoretically assess each location in which a pedestrian could be located. However, the aim of this research is to determine a practical means of obtaining an area measurement from a series of point wind speed measurements. Measuring hundreds or even thousands of speeds for each wind direction is not practical. Therefore, with careful selection of a mathematical interpolation method, an accurate contour diagram could be produced with a comparatively low number of measurement points.

MATLAB has a large number of interpolation methods available for various forms of data. For the purpose of this research interpolation methods that focussed on grids of data are of primary importance as this is how the data is configured. The griddata function was used as a primary command to configure the measured data and locate it on a template grid. Within the griddata function there are a number of interpolation methods that can be used to fit the data to the template surface. Different interpolation methods available were:

- $\quad$ Linear: Triangle based linear interpolation (default function);

- $\quad$ Cubic: Triangle based cubic interpolation;

- $\quad$ Nearest: Nearest neighbour interpolation; and

- V4: MATLAB specific spline interpolation.

In order to determine the most efficient method of interpolation for the purpose of this research each option was investigated with an identical dataset. The images were compared and assessed with respect to their accuracy. Accurate images would contain smooth well defined contours that could identify potentially problematic wind flow characteristics. Contours such as these would provide a better level of understanding for the end user. 


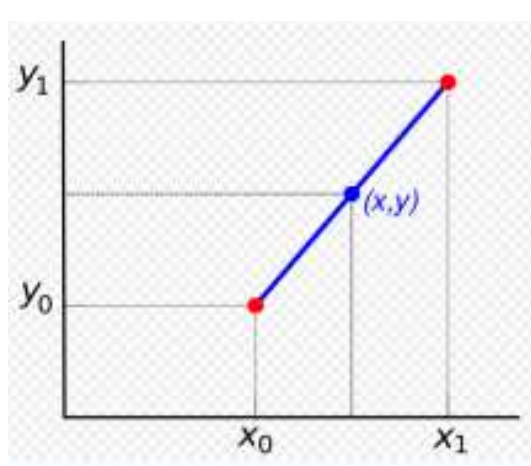

Figure 18: Linear interpolation.

The linear interpolation option was run first. Linear interpolation draws straight lines between measurement points, thus, assuming a linear relationship between the two measurements. The contours produced as a result of this form of interpolation are particularly sharp. Areas in which no speeds are defined (i.e. areas where building are situated) cause irregular calculations and as a result produce the strange irregularities in the contour image (Figure 19). Linear interpolation is not an accurate representation of wind related contouring.

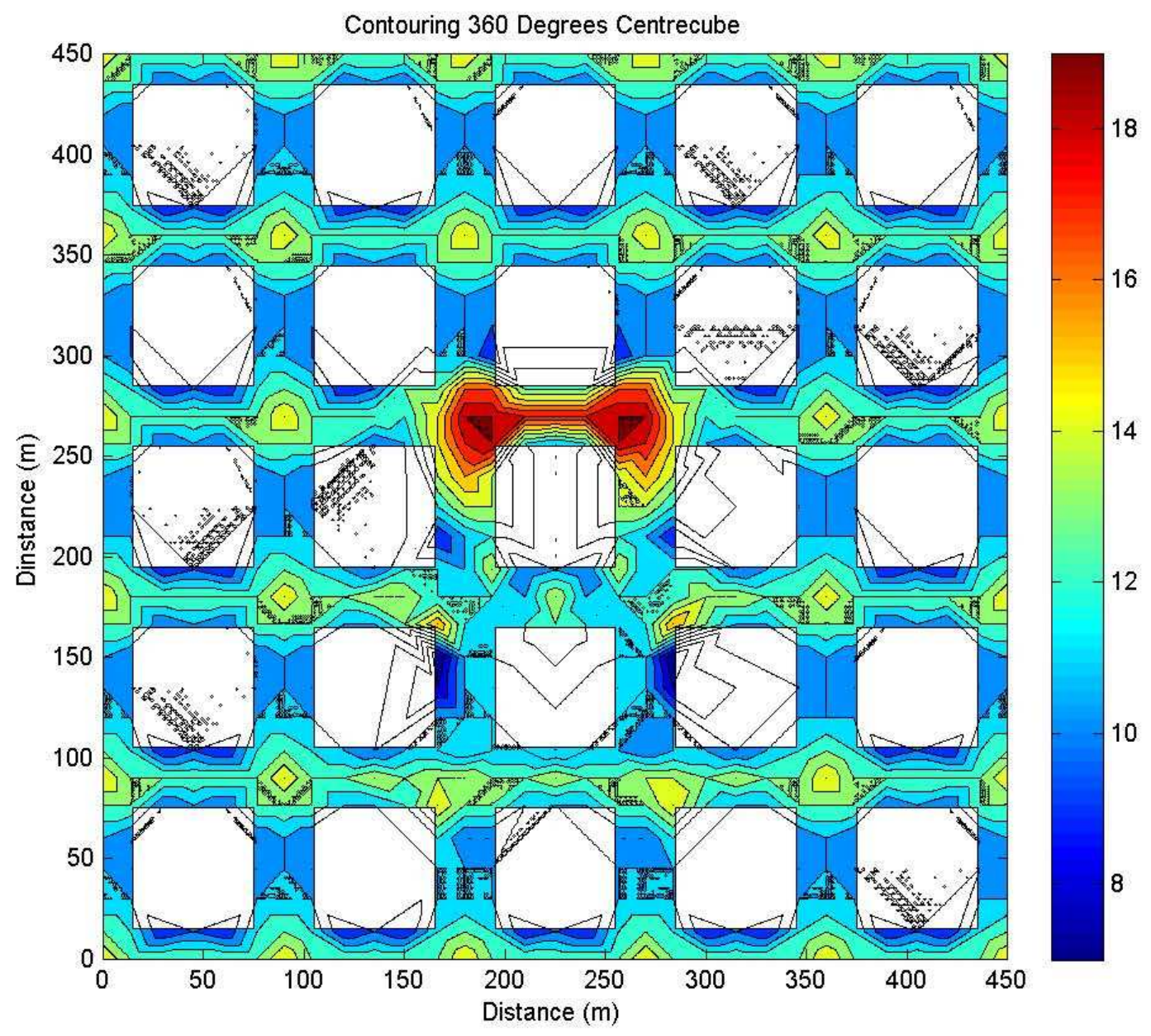

Figure 19: Interpolation investigation using "linear" option. 


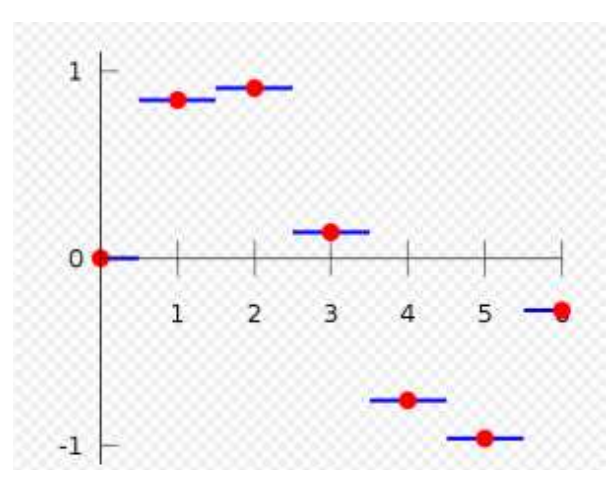

Figure 20: Nearest neighbour interpolation.

The nearest option uses nearest neighbour interpolation. Each area is defined by halving the distance between the existing measurement and the adjacent wind speed measurements. This area is then associated with the wind speed measurement and coloured accordingly. The graph to the left indicates how nearest neighbour interpolation works on a two dimensional plane. When nearest interpolation was used within the contouring script (Figure 21) to generate an image, not surprisingly the output did not resemble wind related contouring. Nearest interpolation was not ideal for this research.

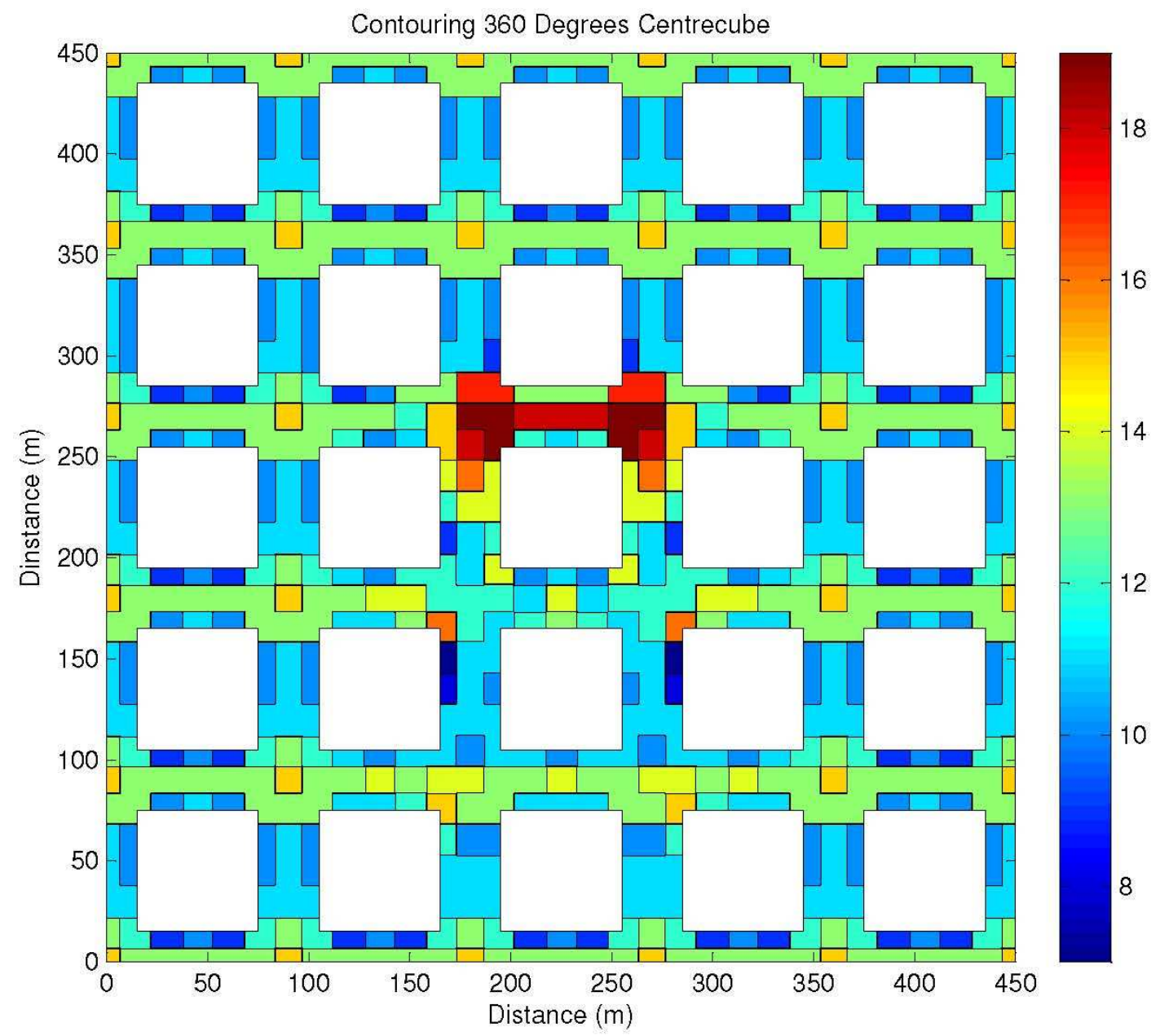

Figure 21: Interpolation investigation using "nearest" option. 


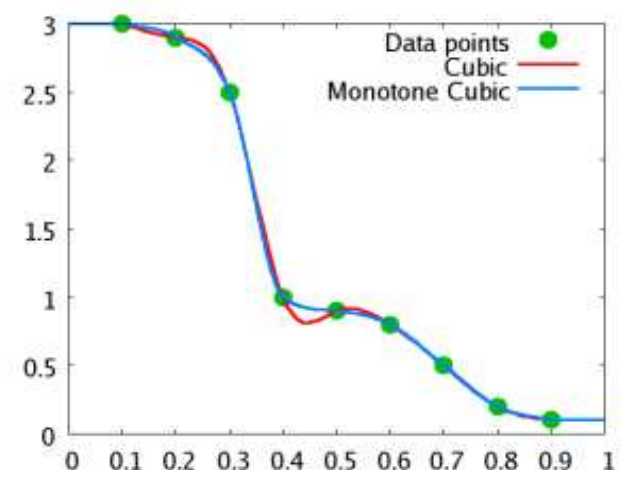

Figure 22: Cubic interpolation.
Cubic interpolation is a method of interpolation that uses mathematical formulae to fit a curve through the various data points. This produces a significant level of smoothing between the points and therefore provides a level of continuity. The contours produced as a result of this form of interpolation are smooth. However, there are still large areas with uneven edges. Figure 23 below shows an example of Cubic interpolation used in the script.

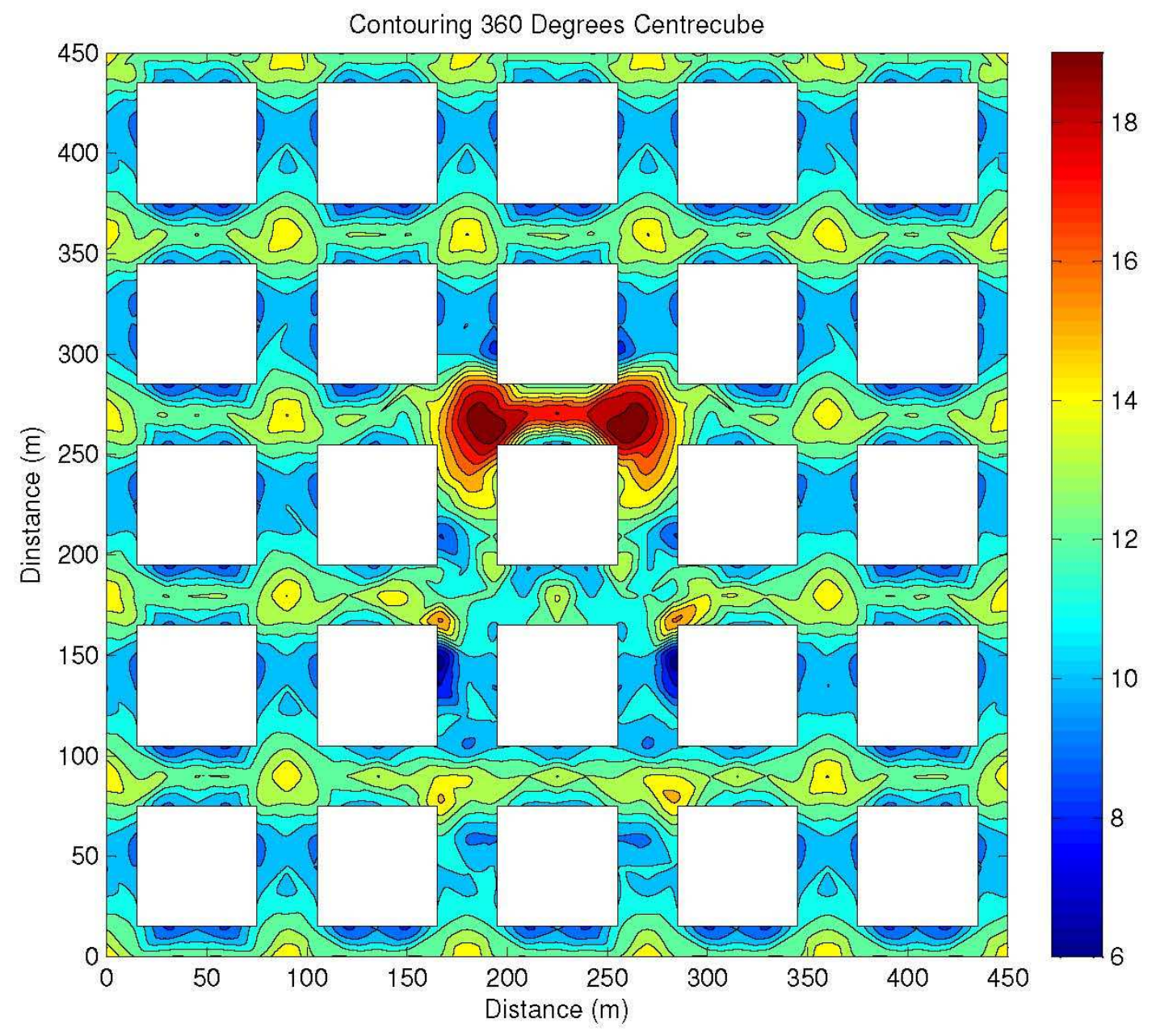

Figure 23: Interpolation investigation using "cubic" option. 


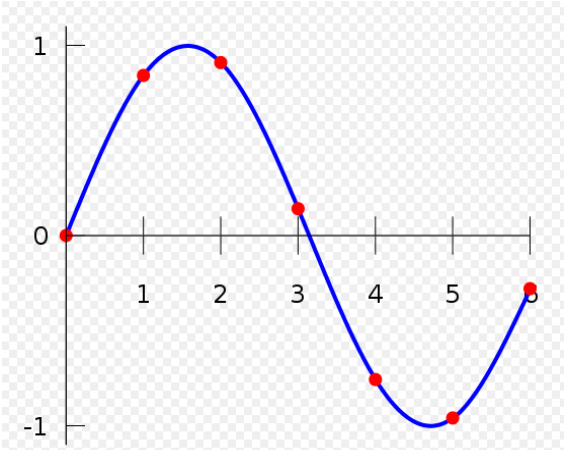

Figure 24: Spline interpolation.
The final method of interpolation available for use was the V4 option. This is a form of spline interpolation specific to MATLAB. Spline interpolation is similar in concept to polynomial interpolation, however the overall output is much smoother due to the number of different functions used. Different polynomial pieces are placed between points to ensure a smooth line, and thus a spline is drawn. This form of interpolation presented the most smoothly drawn contours. These contours were an ideal

mathematical representation of contours produced as a result of flow visualisation testing.

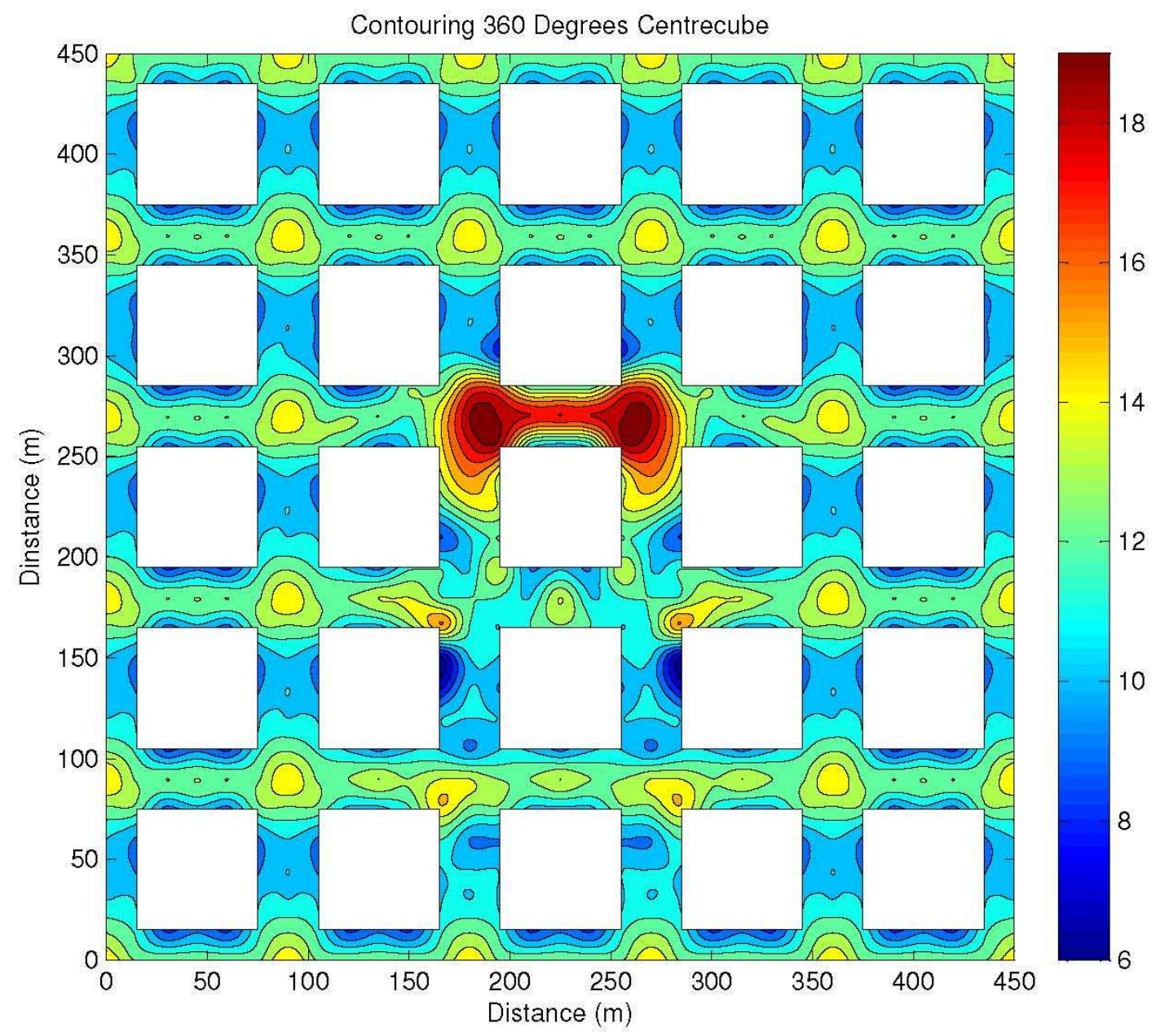

Figure 25: Interpolation investigation using "V4" option. 
After investigating of the different interpolation methods available, it became apparent that the MATLAB specific "V4" interpolation was the most ideal representation of wind flow around buildings. The smooth lines provide a visually appealing image. However, in the raw state shown above (see Figure 25) there are still areas that would need development to improve appearance. 


\subsection{FURTHER ANALYSIS OF THE SCRIPT}

Upon reviewing the results of the interpolation method investigation there still appeared to be two primary issues that would need development in order to ensure a high quality output was produced. Issues now raised in the output contour image were as follows:

- Very small spot locations of contouring produced in the V4 output were not particularly representative of the wide measurement area; and

- $\quad$ Intervals in the colour bar do not correspond with individual wind speeds.

There was an issue with the V4 interpolation method where comparatively high point wind speeds were being illustrated as a tiny point on the contour diagram. High wind speeds around a simple scenario such as this are often occurring in a small area as opposed to a single point. Each measurement is representative of a single point and is therefore relying heavily on the interpolation methods to generate a grid of pseudo measurements in order for contours to be drawn. In an attempt to improve the accuracy of the eventual output, each measurement point was made effective over a small radius. This was done by manually generating eight pseudo measurements around each point at a radius of $1 \mathrm{~m}$. The script was modified to achieve this and as a result the contours shown in Figure 26 were drawn.

Upon assessing Figure 26 it would appear that increasing the effective measurement area of each point had a negative effect on the contouring function. It was hoped that the defined radii would merge into one another and interpolated areas of a similar nature. However, as these points were defined manually this was not done and the resultant contours resembled that of the nearest interpolation method. The time taken to generate contours was increased significantly from a few minutes to close to an hour. This was due to the large number of points having to be processed. Essentially this form of manual pseudo point measurement was deemed unacceptable and the script was modified accordingly. 


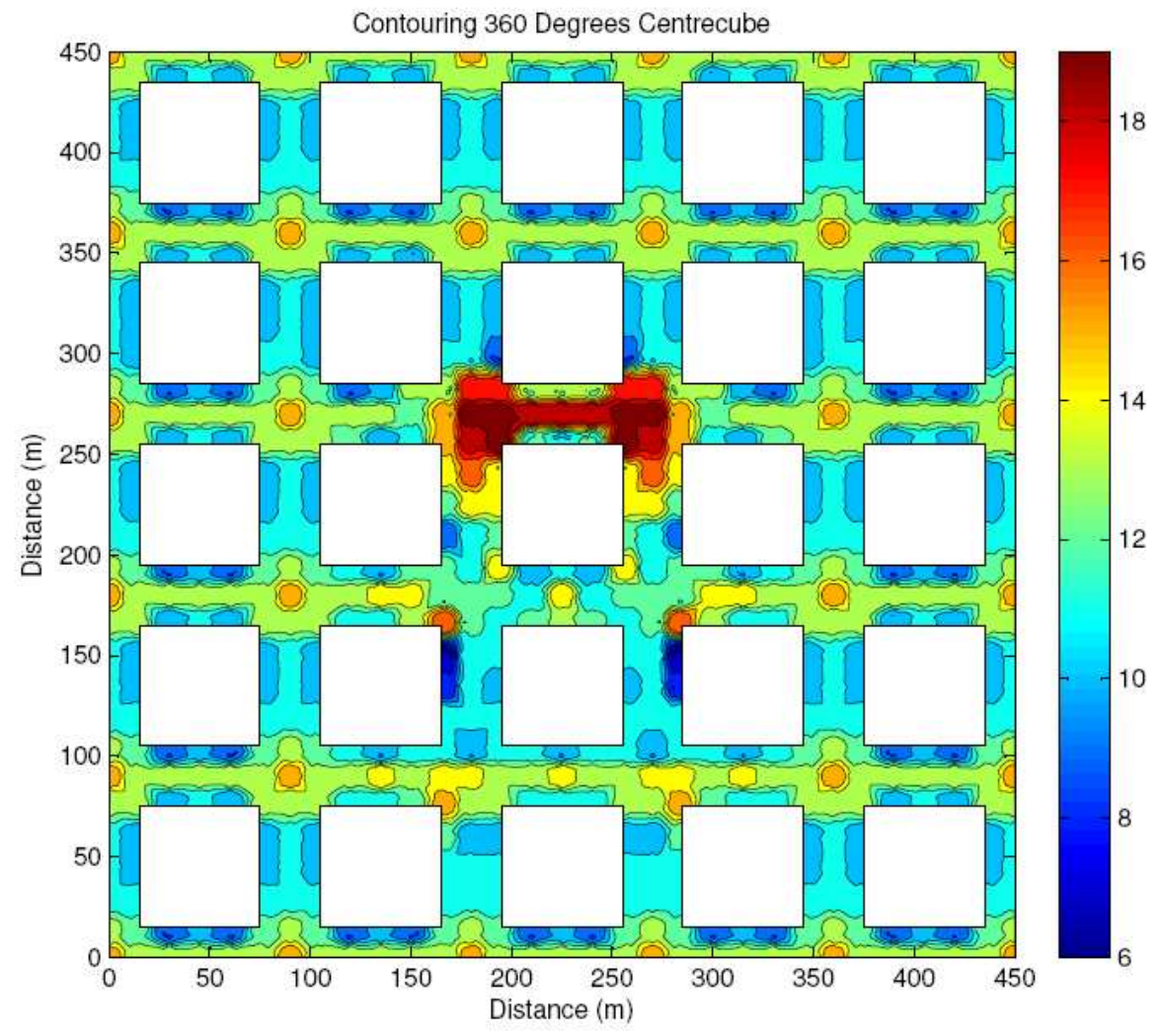

Figure 26: Resultant image with pseudo measurements generated for each point at a $1 \mathrm{~m}$ radius.

The solution to fix the colour bar intervals simply involved determining contouring intervals of $1 \mathrm{~m} / \mathrm{s}$ and ensuring that these intervals associate with the pre-determined colours in the colour bar script. The colour bar now associated directly to the contours produced and there are no additional colours to confuse readers. In defining this option the aforementioned problem with contour distance was consequently solved. It became apparent upon doing this that the contouring function was attempting to draw contours at a larger than needed number of levels yet only displaying the levels that were defined in the script. 


\subsection{SCRIPT DESIGN CONCLUSIONS}

Through a gradual process of define problem, then research and design a solution an effective script was designed to convert measured point wind speed data into mathematically generated contours. The script has been designed to ensure as much future potential as possible. By keeping the patches and colour bar design separate to the contouring script there is potential to develop the scripting further for use in commercial wind studies. The MATLAB specific form of spline interpolation titled V4 was deemed to be the most representative of wind generated contouring when compared to all other options available. The pseudo wind speed measurements generated with this form of interpolation appeared consistent and smooth which provides the end user with an easily understandable representation of wind generated contouring.

The contours produced as a result of erosion testing have served as a visual basis for replication. Due to the difficulty in determining relevant measured wind speeds from flow visualisation testing, the contouring script has not been designed to replicate a flow visualisation study. The purpose of this script is to achieve a similar visual quality of output. This has been done by outlining the primary benefits and assessing how competently the contouring script replicates these aspects. The following section will break down various aerodynamic flow patterns that are evident in flow visualisation contour diagrams and assess how well the contouring script assesses these aspects. 


\section{CHAPTER FIVE: ASSESSMENT OF THE CONTOURING SCRIPT OUTPUT}

The contouring system that has been developed had to be assessed to determine how different wind flow characteristics are visualised within the output contour image. Prominent wind flow characteristics such as downwash, the corner effect and turbulent wakes should be easily identifiable in the resultant contour image. Common wind flow characteristics were initially defined. As a basis for comparison, a contour diagram produced as a result of erosion testing was analysed to identify how these common flow characteristics were presented. Lastly, a contour image generated in MATLAB was analysed to identify how each of the three common flow characteristics were represented.

\subsection{AERODYNAMIC FLOW PATTERNS}

The regular array of buildings provided many benefits when compared to using an actual commercial wind environment study. The wind flow characteristics in a dense urban environment are highly complex and erratic, hence the need for simulations of the pedestrian wind environment surrounding a new development. Simplifying the building configuration to a $5 \times 5$ array of uniformly distributed half cubes greatly simplifies the wind flow patterns. An array of buildings such as this produces predictable flow patterns that can be easily compared to fundamental flow characteristics associated with building aerodynamics. Predominant and therefore easily identifiable aerodynamic flow such as downwash, the corner effect and turbulent wakes will be identified and assessed on a visual basis. Assessing the contouring script in a simple scenario such as this gives an understanding of how it could work in a commercial wind study. Further testing of more complex scenarios would be required to fully assess the reliability of mathematically generated contours in a number of complex scenarios. 
5.1.1 DOWNWASH

Downwash is a phenomenon in which wind strikes the face of a building and gets drawn down to pedestrian level. Wind is drawn downward as it typically follows the path of least resistance. The fast flowing air moving above a building produces a positive pressure. A large proportion of the wind travels downward towards a zone of negative pressure. The higher the building, the larger the pressure difference is, and thus the effect of downwash is accentuated. Downwash is easily identifiable in both

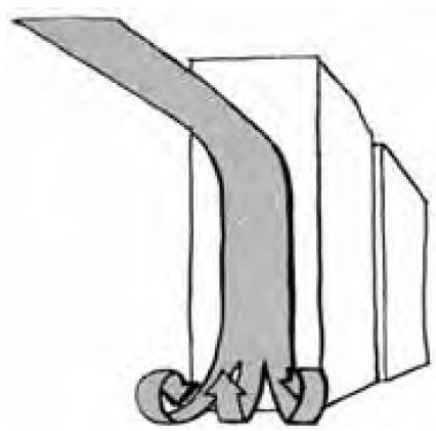

Figure 27: Downwash effect. common forms of aerodynamic simulation because it occurs solely on the windward face of a building. Increased wind speeds will be noticed at pedestrian level directly below this face of the building. Erosion tests have a tendency to over exaggerate the effects caused by downwash. Comparisons between erosion testing and measured wind velocities indicate that erosion materials have a lower threshold speed when the wind direction is perpendicular to the erosion surface as opposed to parallel to it. This would indicate that point wind speed measurements such as hot film anemometry could present a much more accurate image of areas where downwash is occurring.

\subsubsection{CORNER EFFECT}

As wind strikes the windward face of a building there is typically a highly pressurised zone created at the base. This concentration of wind naturally flows from this newly created high pressure zone to the surrounding low pressurised sheltered zones located around the sides of the building and to the rear. The areas in which this transition is occurring are rather small, thus, there is a high concentration of high speed wind in a rather localised environment which is known as the corner effect. This phenomenon is easily identifiable in both point wind speed measurements and flow

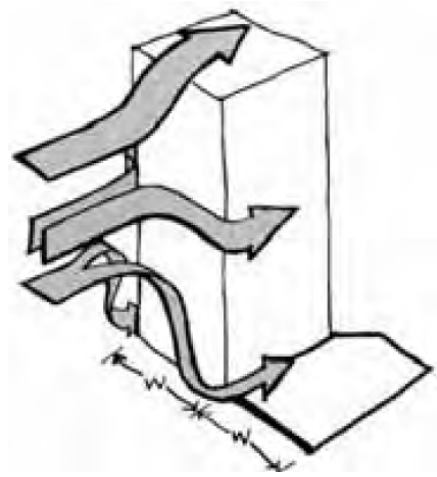

Figure 28: Locations prone to the corner effect. visualisation studies. As with downwash the locations in which the corner effect will occur are known. 
Further, the measured wind speeds where this phenomenon is occurring should be higher on the windward corners as opposed to the leeward corners. Facts such as this will be used to gauge the effectiveness of the contouring script. The corner effect can cause some of the highest recorded wind speeds through wind tunnel testing and as a result it is the primary cause of discomfort for pedestrians.

5.1.3 TURBULENT WAKE

The turbulent wake effect is another identifiable effect within both area and point wind speed measurements. It essentially refers to the increase in wind velocities and turbulence downwind from buildings. As with most building related aerodynamic flows this effect is accentuated by buildings of an increasing height. Flow visualisation tests show this effect as the eroded pattern located downwind from the building. Although it is more difficult to identify in point wind speed measurements, there will be

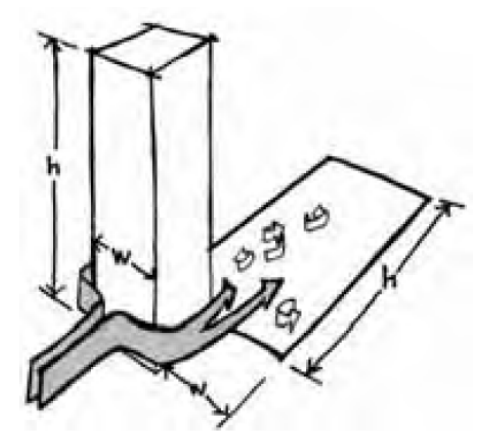

Figure 29: Turbulent wake effect. higher recorded wind speeds in the turbulent wake of a tall building than in a region of buildings with a uniformly distributed height. It is this region of increased wind speeds that will be identified through a series of point wind speed measurements, and therefore the contouring program will depict this area. Flow visualisation may present an accentuated depiction of this turbulent wake as turbulent wind flow (i.e. rapidly varying wind directions) can promote erosion more rapidly than steady high wind speeds. Point wind speed measurements from a hot film anemometer are sampled around 200 times per second. However, none of these samples can detect the wind direction. A rapid change in wind direction with no fluctuation in speed is an exceptionally uncomfortable situation for a pedestrian. This could go unnoticed during point wind speed measurements. However, since neither point wind speed measurements nor flow visualisation techniques can record rapid fluctuations in wind direction, point wind speed measurements are likely to be a more accurate measurement technique, as the actual wind speeds are recorded. 


\subsection{IDENTIFYING WIND FLOW PATTERNS}

Contour diagrams produced as a result of erosion studies have been used in aerodynamic assessments for a number of years. One New Zealand facility solely uses them to conduct aerodynamic assessments of new developments. Identifying flow patterns such as downwash, the corner effect and turbulent wakes can be difficult in these images due to the highly complex flow patterns that are generated in a densely populated urban environment. However, upon assessing a large number of these images, patterns soon become evident. In a much more simplified scenario, such as the 5 by 5 grid of half cubes assessed in this thesis, these flow patterns are easily identifiable.

An aerodynamic assessment using flow visualisation will compare the contouring diagram for a new development against that of the existing development for the same wind direction. Areas showing differences in erosion level will be noted. It is these aforementioned aerodynamic flow patterns that will cause the greatest fluctuations in erosion level. Therefore, the developed contouring script must enable the user to easily identify areas in which these flow patterns are occurring. Currently, area assessments in which different stages of erosion are compared could be influenced by a number of conditions such as: vertical wind flow, erosion material thickness, and model surface. These conditions can greatly impact the outcome of such a test and render it inaccurate. The contouring system used in this thesis uses actual measured wind speeds to generate contours. These contours can therefore provide the end user with an image from which actual wind speed measurements can be taken. This provides an opportunity to visually compare wind speeds as opposed to stages of erosion. Figure 30 shows a typical contour diagram produced as a result of a flow visualisation test. Areas of interest, such as downwash, have been indicated in red. Areas in which the corner effect is occurring are indicated in black. Areas where there is a turbulent wake evident are indicated in white. 


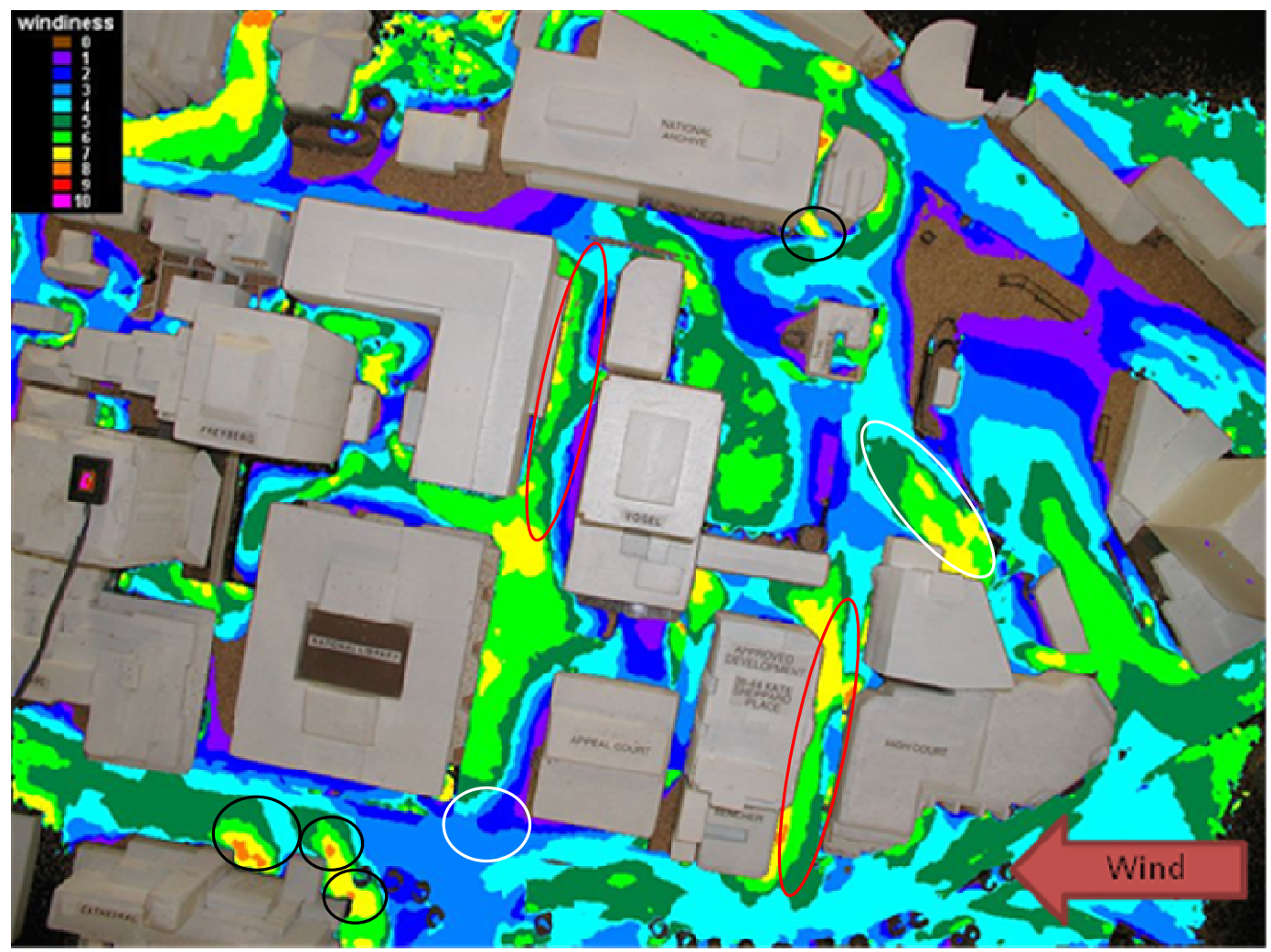

Figure 30: Example of a contour diagram produced as a result of bran erosion testing. Areas of interest that have been noted are: downwash (red); corner effect (black) and turbulent wake (white).

The contour diagram produced as a result of the script is shown in

Figure 30. Although it is for a much simpler scenario than that of the flow visualisation contouring diagram shown in Figure 32, the areas in which aerodynamic flow patterns are occurring are highly visible.

Figure 32 is for a simple building configuration consisting of 24 half cubes and one central cube. As is expected, there is an area of

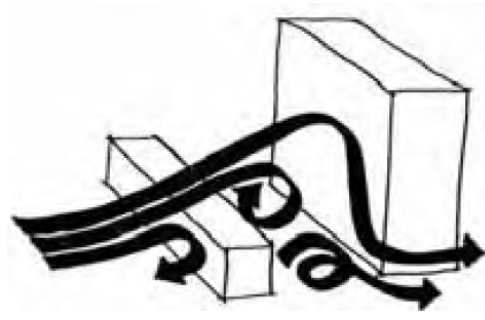

Figure 31: Flow patterns of wind between low and high buildings. downwash present near the front of the building (shown in red). This

is caused by the interaction between low and high buildings as shown in Figure 31 . As a result of this interaction, the two windward corners on the central cube are subject to the corner effect. The windward corners are expected to have a much larger wind speed than the leeward corners because of the downwash increasing the overall wind speeds, which in turn increases the pressure differential between the windward face and the more sheltered edges of the building. When the corner effects around the central cube in Figure 32 are assessed, it is evident that the windward corners are subject to much higher wind speeds than that of 
the leeward corners (shown in black). This is known as the wake effect. The wake effect is also present in Figure 32 and as a result is affecting the wind environment downwind of the central cube for a comparatively larger area. The wind speeds produced as a result of this effect are lower than that recorded from both the downwash and the corner effect. However, the wake effect is occurring over a much larger area. As mentioned above the wake effect is difficult to quantify as typically it does not result in dramatically large differences in wind speed. The wind in the downwind wake of a tall building is highly turbulent, and thus the wind changes directions frequently. This produces a highly uncomfortable environment for pedestrians. Hot film anemometers do not distinguish between wind directions. Therefore, a $180^{\circ}$ change in wind direction may only register as a small change in wind speed. Small changes in speed are not often taken into consideration when making recommendations. However, when viewing a reasonable density of points in a contouring diagram as shown in Figure 32, in which a small change has occurred downwind of the central cube, the wake effect becomes fairly obvious (shown in white). The differences can be seen by comparing the contouring in the streets near the edges of the building that have buildings of a uniform height and the highlighted areas. This turbulent area would be an uncomfortable area for pedestrians to inhabit. Single point wind speeds may result in this being overlooked and flow visualisation testing may over-exaggerate this due to erosion materials being prone to erosion in turbulent winds.

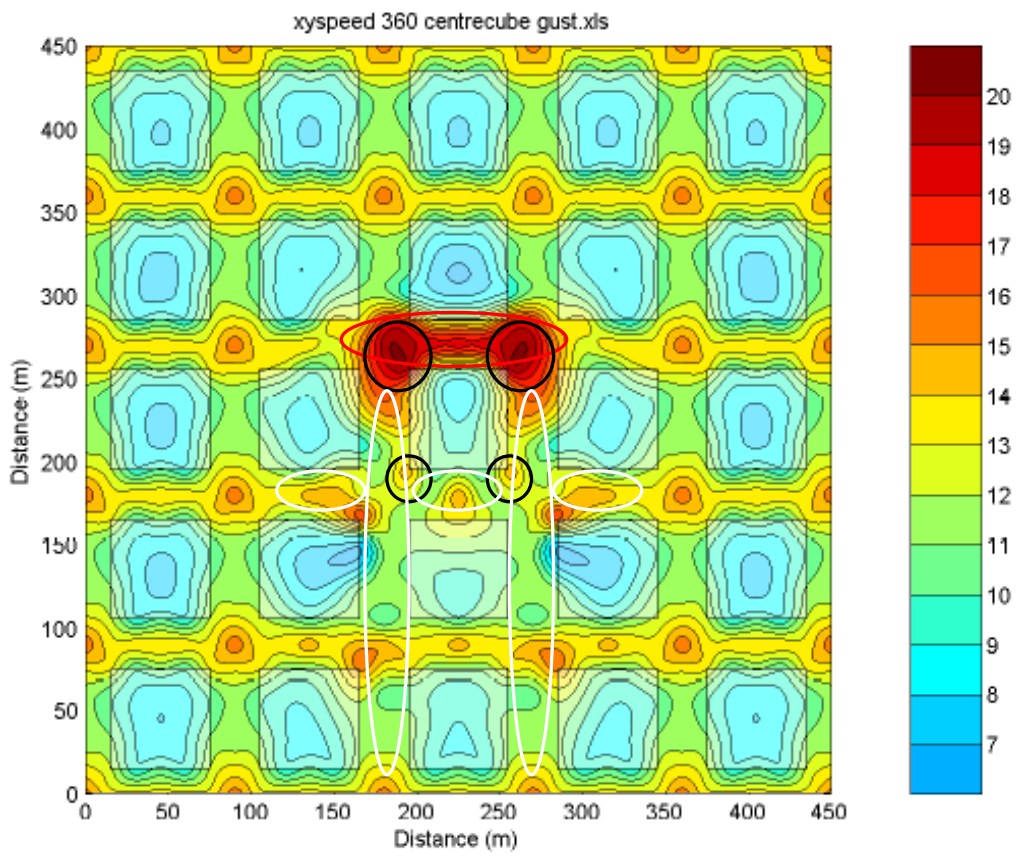

Figure 32: Contour diagram produced as a result of the developed contouring script. Areas of interest that have been noted are: downwash (red); corner effect (black) and turbulent wake (white). 
An important point to emphasise is the fact that the contouring diagrams produced as a result of point wind speed measurements and the designed MATLAB script will not be directly compared to that of contour diagrams produced through erosion testing. The potential inaccuracies in erosion testing are numerous. Not only can wind speeds not be inferred from erosion patterns but erosion patterns, cannot be compared between boundary layer wind tunnels. A system such as the contouring script has the potential to allow different wind laboratories to compare results. Wind speed measurements could be normalised between tests and combined to improve efficiency and accuracy. This technique has the potential to obtain the same quality of output (i.e. an area assessment producing contours that can be completed in a reasonable amount of time) with the added benefit of being able to infer actual wind speeds directly from the contour image. It is common knowledge that people are more responsive to visual outputs as opposed to columns of data. Therefore, combining the benefits of both a contouring diagram and columns of data into one easily understandable graph seems logical.

The contouring system that has been developed has been assessed to determine how different wind flow characteristics are visualised within the contouring program. Prominent wind flow characteristics such as downwash, the corner effect and turbulent wakes are easily identifiable in the resultant contour image. Downwashes have greatly increased the wind speeds along the windward side of the building. The windward corners are subject to much higher wind speeds than the leeward corners which is consistent with the corner effect. Finally, the turbulent wake extends downwind from the building a significant distance. It is less obvious than downwash or the corner effect but still identifiable. The generated contours visualised aerodynamic flow patterns in a fairly similar way to the contours produced as a result of erosion testing. 


\section{CHAPTER SIX: POINT REMOVAL STUDY}

In order to determine the practicality of using a method such as this, a reasonable number of points must be used to draw the contours. Reasonable can be defined as a contour diagram that is produced in around the same (or less) time taken to conduct a current pedestrian level wind analysis (both point and area methods). A pedestrian wind analysis measures the pedestrian's comfort and safety. Therefore, width of the human body is assumed to be the minimum distance between point measurements as the pedestrian's perception of wind conditions is not going to change within this distance. The maximum density of points can therefore be assumed to be at shoulder width in scale. However, when this is scaled down to the size of a wind tunnel scale model it soon becomes evident that this number of measurements is not possible. Around 100 measurements would be required to cover an area in the order of 5 meters by 5 meters. Each measurement would take a minimum of one minute to sample accurately with a hot film anemometer. Therefore, simply measuring the aforementioned $5 \mathrm{~m}$ by $5 \mathrm{~m}$ grid would take close to two hours (including calibrations) for each wind direction. It is fairly evident that this density of point measurements would be highly expensive to test which makes it highly impractical. Determining a minimum density of measurement locations while still maintaining accuracy in the contour diagram is the next step in achieving a practical use for this method.

In order to asses this further the data used throughout the script development was further analysed. These measurements are taken at $\approx 15 \mathrm{~m}$ intervals in a regular grid. Measurements are taken at $1.5 \mathrm{~m}$ (in scale) away from the buildings and in the centre of the street. After reviewing the contour diagrams produced for this rather simple array of buildings, it would appear that a density of points such as this is sufficient to produce relatively accurate contours. However, even at this resolution there are still 72 measurements in the area directly surrounding the existing development. This poses initial questions regarding the practicality of this resolution of points. To ensure this method can be used in a practical sense, this number of points would have to be reduced.

A study was done with the results acquired from the script development process to determine the minimum number of points required to retain a reliable output. To do this, measurement points were removed at random. The reliability of the output was determined by counting the number of areas above $16 \mathrm{~m} / \mathrm{s}$ (the 
most common high wind speed recorded in multiple locations) and calculating the percentage reduction of these high wind speed areas as points are removed. If the number of locations in which the wind speed exceeded $16 \mathrm{~m} / \mathrm{s}$ were relatively consistent (e.g. $\pm 20 \%$ ) the test could be assumed to have remained reasonable reliable. The ideal goal would be to achieve a reasonable set of contours for a building evaluation in less time than it would take to conduct both a flow visualisation test and a point wind speed study combined. This was done by progressively removing points until the contouring became inaccurate. Initially one in every four points was removed, followed by removing one point in every three and finally every second point. The results from this study are shown in Figure 33, Figure 34, and Figure 35 below:

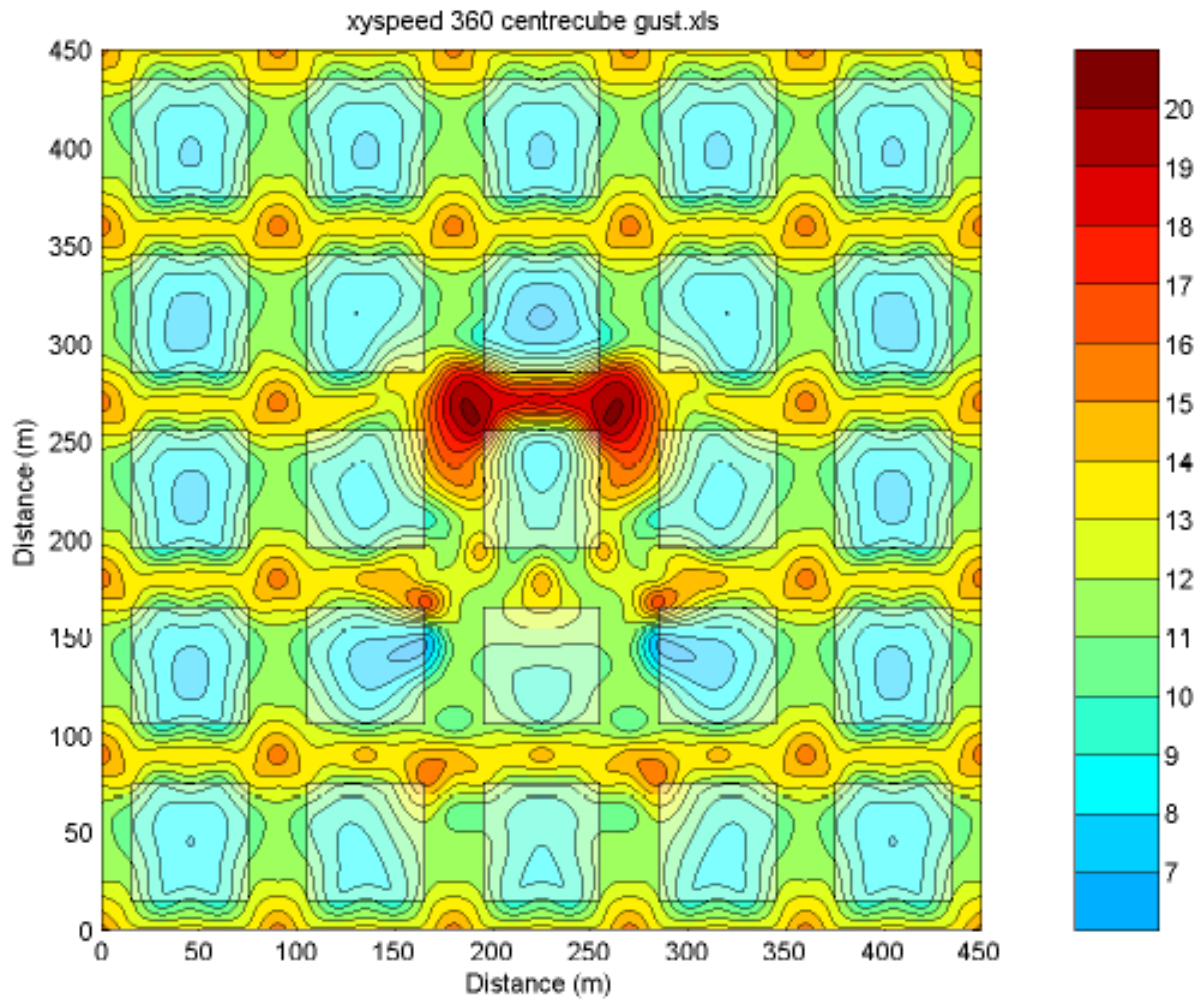

Figure 33: Original image with all points at $15 \mathrm{~m}$ intervals. 


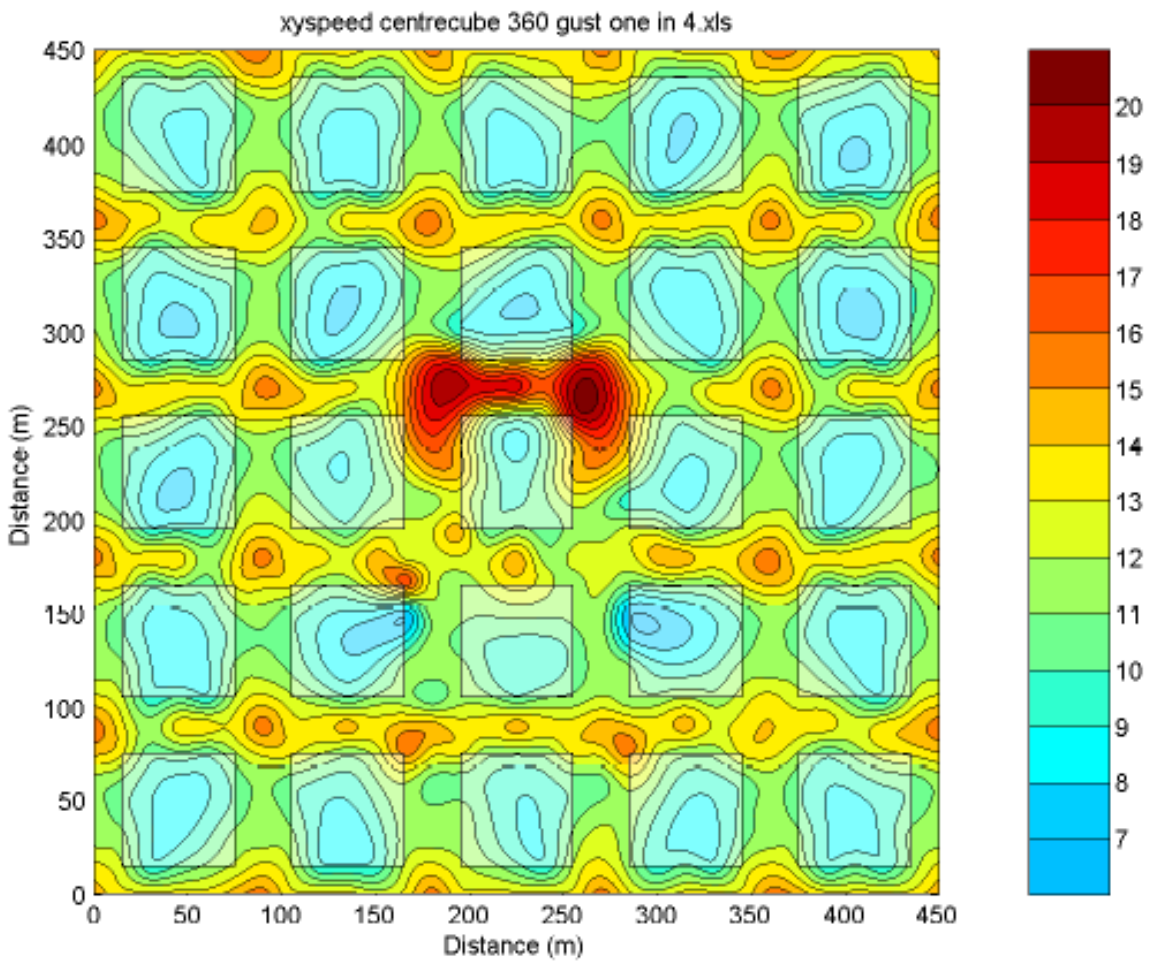

Figure 34: One four in measurement points removed.

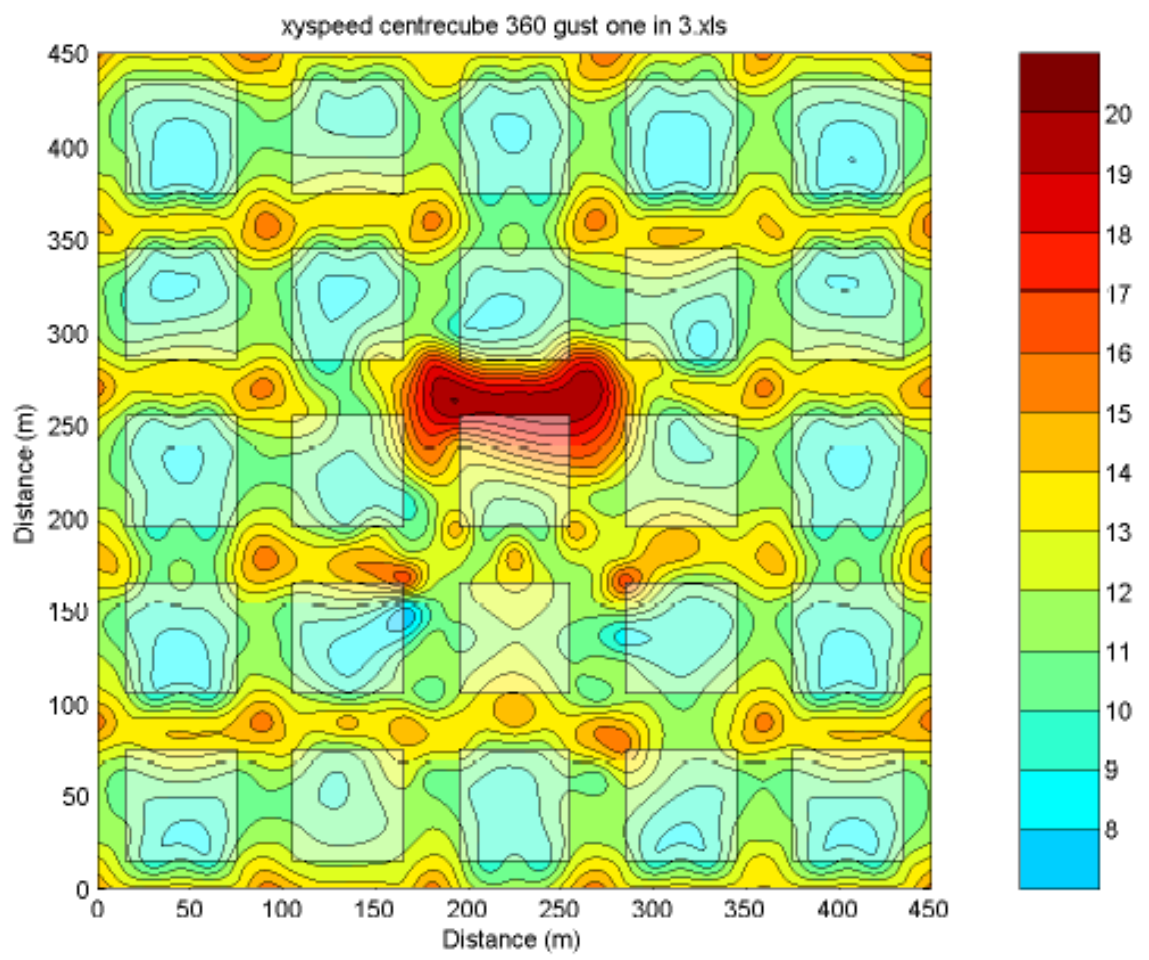

Figure 35: One in every three measurement points removed. 


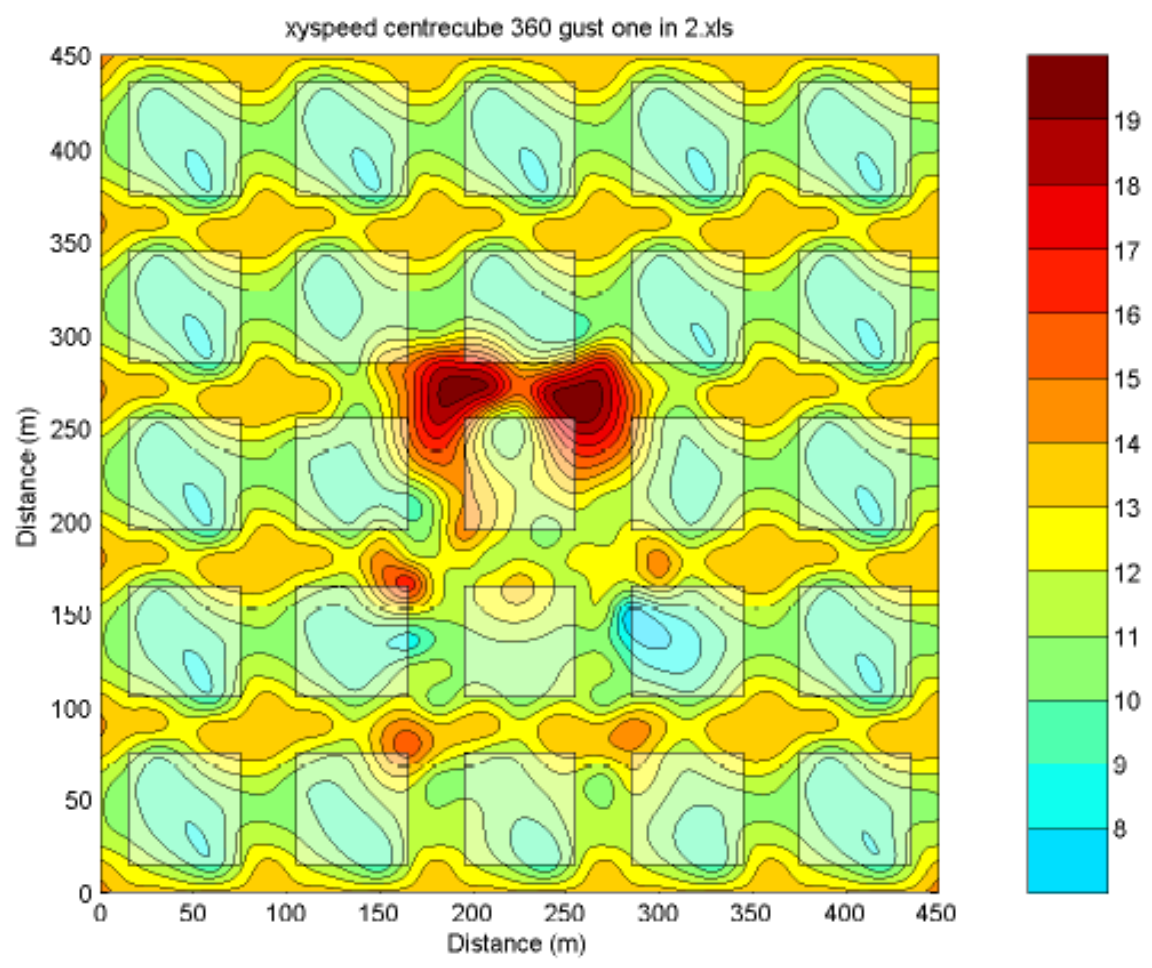

Figure 36: Every second measurement point removed.

Upon an initial review of the data removal study it became evident that a reasonable level of point density would be required to ensure a reliable contour image is produced. The initial contour image that was created from a point resolution of $15 \mathrm{~m} \times 15 \mathrm{~m}$ generated a total of 42 areas above $16 \mathrm{~m} / \mathrm{s}$ (orange). This would be taken as the base set of data, and as the contours are of a reasonable quality, for now it will be assumed to be a "best case scenario". A "reasonable level of accuracy" will be defined as a contour image where fewer points have been measured when compared the initial test, however, the number of areas above $16 \mathrm{~m} / \mathrm{s}$ remain reasonable consistent (e.g. $\pm 20 \%)$.

Removing one point in four resulted in a total of 41 areas above $16 \mathrm{~m} / \mathrm{s}$ being recorded. This is an overall reduction of accuracy of around $2.5 \%$ which is very much acceptable. There was only minor skewing of the contours, however all expected wind flow characteristics were identified. Compared with the initial contouring image there is very little change. 
Removing one point in three resulted in a total of 40 areas above $16 \mathrm{~m} / \mathrm{s}$ being recorded. This is an overall reduction of accuracy of around 5\% which again is very acceptable. There was some skewing of the data and a minor reduction in symmetry due to the uneven recording locations. All expected wind flow characteristics were identified.

Removing every second point effectively doubles the distance between measurement points from $15 \mathrm{~m}$ to $30 \mathrm{~m}$. This resulted in a significant reduction of points recorded above $16 \mathrm{~m} / \mathrm{s}$ from 42 to around 7 which results in a loss of accuracy or around $83 \%$. Although there is a significant reduction in the amount of high speed areas, the predictable flow patterns are still evident. Halving the amount of testing points will result in a reduction of precision measurement, however the overall image is still relatively the same. This provides the opportunity to divide the testing area into sections and allocate various areas a different density of points directly proportional to the vicinity of the new development.

Creating adaptive grids of measurement point locations would be the most cost effective method of testing an area. Regularly spacing measurements around the site is the most practical method as solely measuring potentially problematic areas is likely to skew the results. By creating adaptive grids of measurement locations different zones would be associated with different densities of points. Areas in the direct vicinity of the development, i.e. one block surrounding the development would have a high density of points. This would increase the accuracy of the contours. Problematic areas of increased wind speed are therefore likely to be identified and accurately quantified. Areas further away from the development could have a proportionally lower density of measurement points, as the development is less likely to impact these areas.

To further this concept, a database of measurement points and recorded speeds could be created. In time there would be an accurate recording of wind speeds, turbulence intensities etc. for predominant wind directions at specified locations around an entire model's surface. This could be done at a resolution of grid points of around $30 \mathrm{~m}$. A database such as this would require a significant investment of time initially. Testing could be done at times when there are few wind tunnel studies to be conducted, thus, optimising wind tunnel use. When the database is complete and a new development is to be tested, the model can easily be set up and only a small area around the development and downwind in the turbulent wake would need to be tested. Problematic areas could be identified through assessing the initial low resolution image, and retested 
accordingly. This has the potential to greatly reduce the amount of time taken to conduct a wind tunnel study as the majority of the data will be stored digitally. These databases could be compared and normalised between wind tunnel testing laboratories and tests could be compared between wind tunnels. There is a potential to reduce testing time and cost by dividing wind directions or testing points between wind tunnels and combining data.

The previous chapter identified areas of importance around a development site. Predominant areas of concern are directly in front of the building (to identify changes in downwash) the corners directly surrounding the site (to identify the changes in the corner effect) and directly downwind of the building (to identify changes in the turbulent wake). The streets and buildings directly surrounding the site are of primary importance as these are more prone to large changes in wind speed due to their close vicinity to the building modifications. Research thus far has indicated that increasing the resolution of points tested in these areas would provide a greater level of accuracy to identify likely changes. Figure 37 is an example of drastically reducing the number of points required for testing but retaining a reasonable level of accuracy in the primary areas of concern.

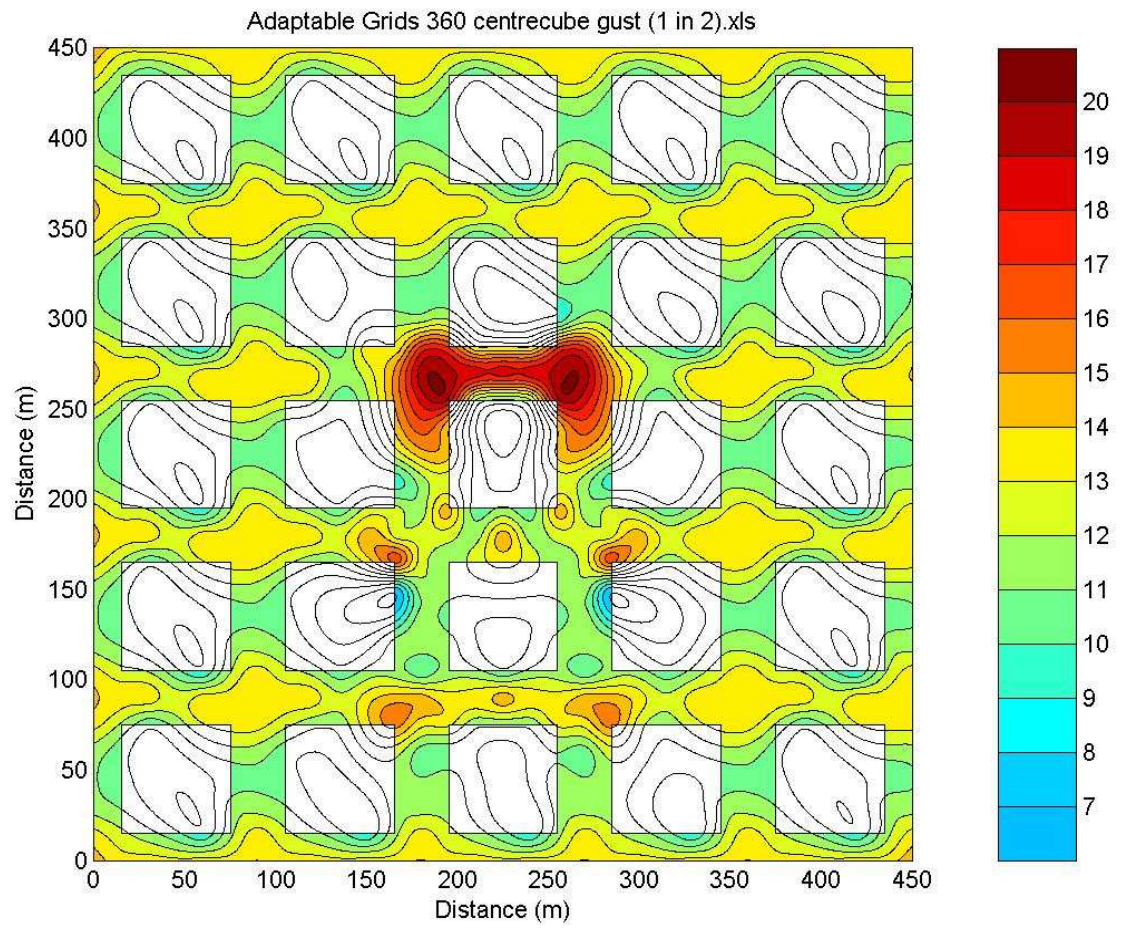

Figure 37: Retaining a high level of accuracy around the site (15m grid) while reducing surrounding areas to $30 \mathrm{~m}$ grid. 


\section{CHAPTER SEVEN: SIMULATED BUILDING SCENARIOS}

This chapter will discuss the contour diagrams produced as an output of the script. There were a total of three building configurations analysed. Each configuration was tested for $360^{\circ}$ and $45^{\circ}$ wind direction. Both gust and mean wind speeds were tested. This resulted in a total of 12 contour diagrams produced. The contour diagrams were assessed individually to ensure predictable flow patterns such as downwash, the corner effect and a turbulent wake were occurring in the appropriate areas. Only gust speeds will be shown throughout this section as mean wind speeds depict a similar image with comparatively lower wind speeds. Contour diagrams for mean wind speeds are included in Appendix Three.

Figure 38 and Figure 39 have been created for a uniform grid of half cubes assessing the gust wind speed across this space. Initially obvious is the uniform flow of wind. The flow is symmetrical and the recorded gust wind speeds have a maximum of $15 \mathrm{~m} / \mathrm{s}$. Wind flow characteristics in these images are very similar to that of the mean wind speeds (see Appendix Three). Figure 38 is set up to show the wind flow for a wind direction of $360^{\circ}$. The highest recorded gust wind speeds for this image are recorded in the centre of the streets as these are the most open to wind speeds, specifically, in the centre of intersections and in front of and behind buildings. Intersections are the meeting point for the winds travelling down the street and wind moving perpendicular to the main flow across the face of the building. The wind being drawn down from above building height is meeting wind travelling perpendicular to the flow causing a high speed point of convergence. Figure 39 is for a uniform grid of half cubes with a wind direction of $45^{\circ}$. As with the $360^{\circ}$ contour diagram, the high recorded wind speeds are in the centre of the streets; with the highest recorded wind speeds located on the windward corner of the building. This is predominantly a product of the corner effect mixing with wind flowing down the open streets. 


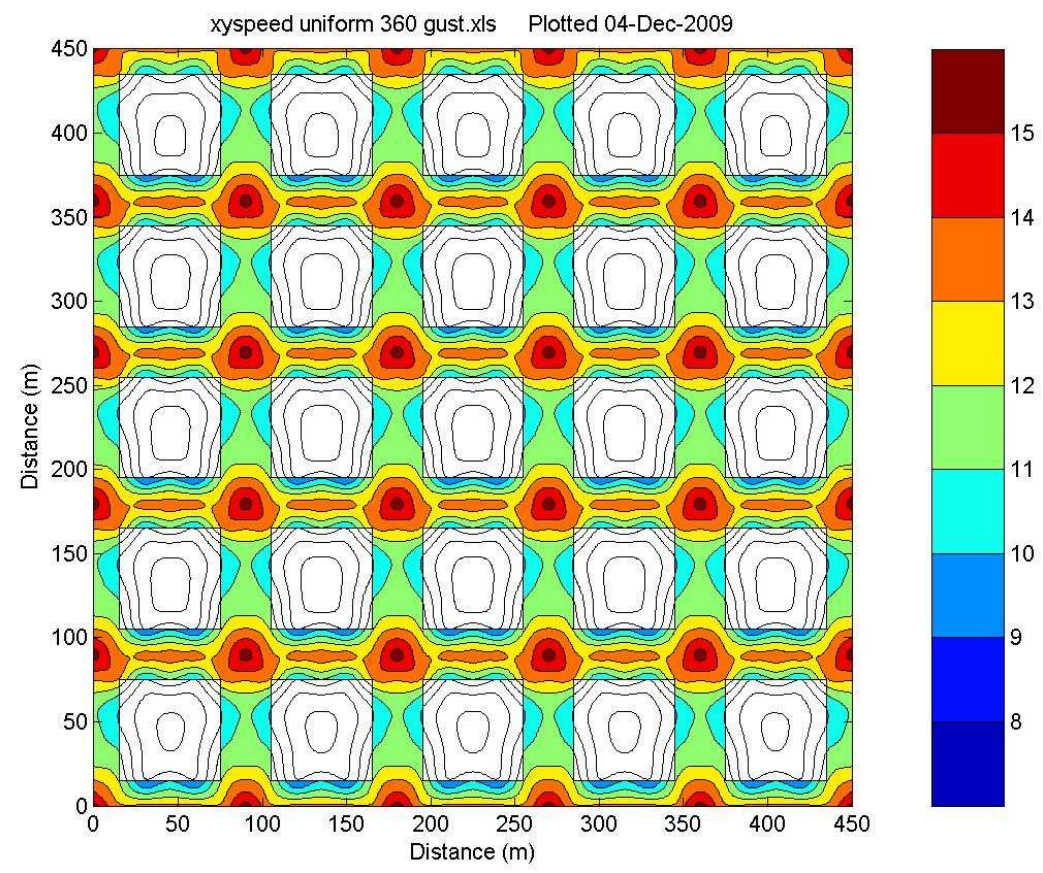

Figure 38: Contour diagram produced with a uniform distribution of buildings for gust wind speeds at a direction of $360^{\circ}$.

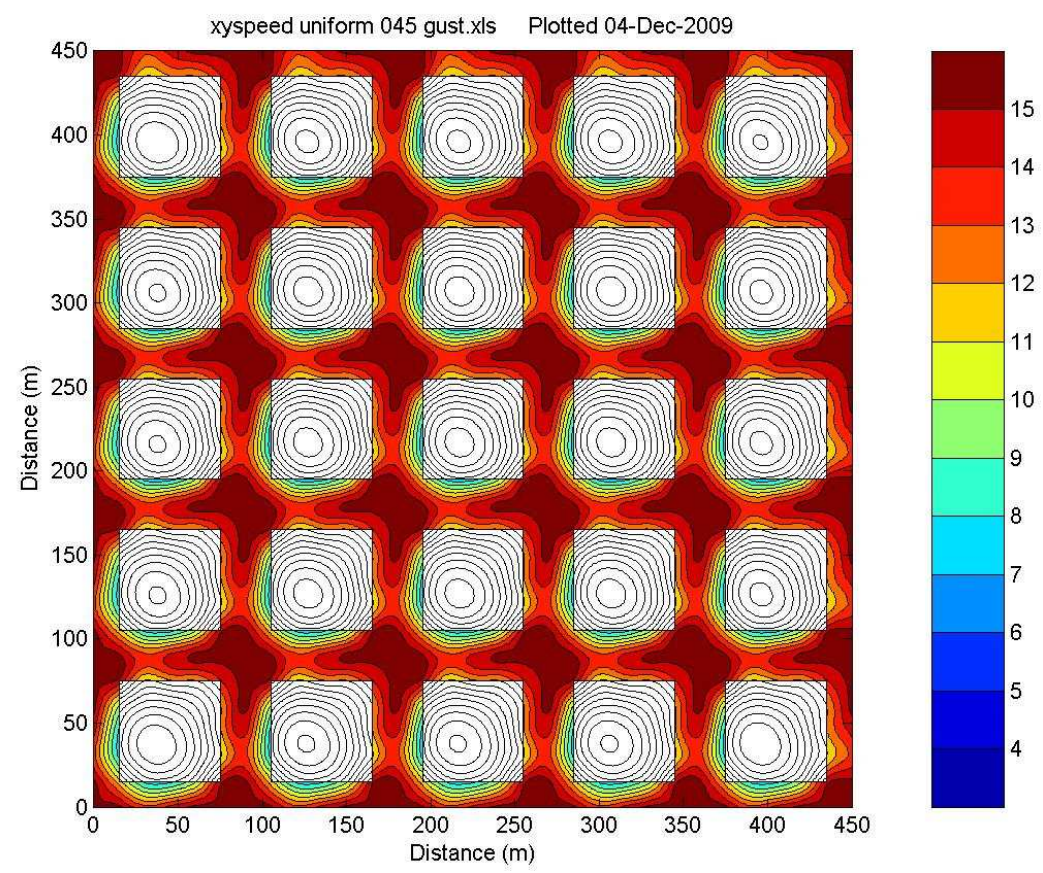

Figure 39: Contour diagram generated with a uniform distribution of buildings for gust wind speeds at a direction of $45^{\circ}$. 
The impact of removing the central half cube and replacing it with a full cube becomes evident when the data is visualised through the contouring script. Figure 40 and Figure 41 depict the effects of a central cube building configuration for two different wind directions. Figure 40 shows how the wind behaves around the buildings when flowing from a $360^{\circ}$ wind direction. It is initially obvious from viewing the images that the windward face of the building is subject to downwash. This is due to the uniform height of the buildings directly upwind which are half as tall as the cube. The windward face of the building is thus exposed, trapping the high altitude winds and drawing them to ground level. The increase in wind speed in front of the building creates a large pressure differential between the windward face and the adjacent corners of the buildings. This large pressure differential forces the wind around the windward corners of the building. Evidence of the corner effect is obvious in the resultant contour image (Figure 40). Gust wind speeds at these windward corners have increased from around $11 \mathrm{~m} / \mathrm{s}$ to $20 \mathrm{~m} / \mathrm{s}$. These are significant increases in wind speeds. More importantly, however, the contouring script is not only depicting them accurately, but the change in wind speeds can be quantified. When comparing a contour diagram produced as a result of flow visualisation tests there will be an increase in erosion, however, this increase is merely measured by changes in erosion levels as opposed to changes in actual measured wind speeds. The leeward corners are also subject to an increase in wind speeds. Both leeward corners of the central building have a gust wind speed increase of $2 \mathrm{~m} / \mathrm{s}$. There is also a fairly obvious change in the wind speeds downwind from the central cube. When comparing images for the central cube and the uniform half cubes the turbulent wake becomes obvious. This is caused by wind flowing around the central cube, which increases the amount of turbulence and consequently the wind speeds downwind from the building.

Figure 41 depicts the gust wind speeds for a wind direction of $45^{\circ}$. Initially obvious is the large area affected by the turbulent wake. Wind is striking the windward corner and being drawn down to street level across the windward faces. As this wind reaches the outside edges of the cubic building a large pressure differential is created, and, the wind is thus accelerated to around $20 \mathrm{~m} / \mathrm{s}$. Initially with the grid of half cubes, the wind speeds around this corner were $15 \mathrm{~m} / \mathrm{s}$. Once this flow has been accelerated around the outside corners it is then funnelled through the two streets on the leeward side of the building being accelerated further from the 


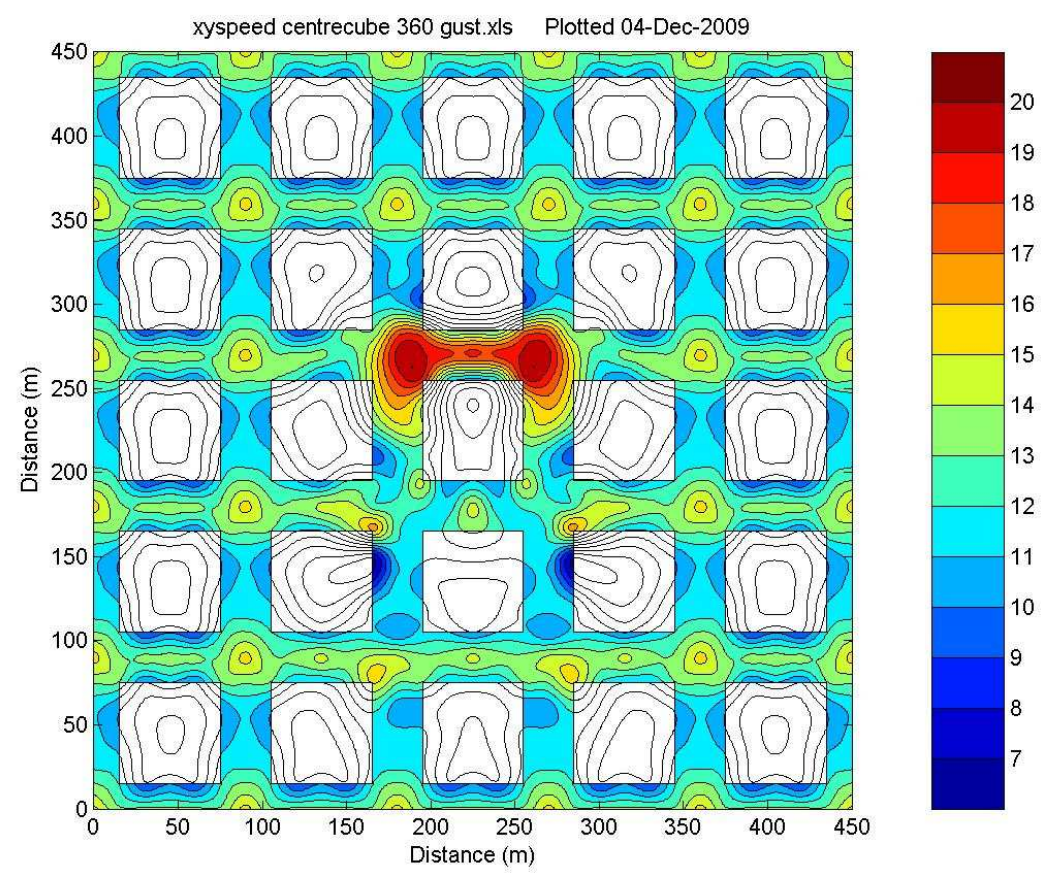

Figure 40: Contour diagram produced with a uniform distribution of buildings replacing the central half cube with a full cube, for gust wind speeds at a direction of $360^{\circ}$.

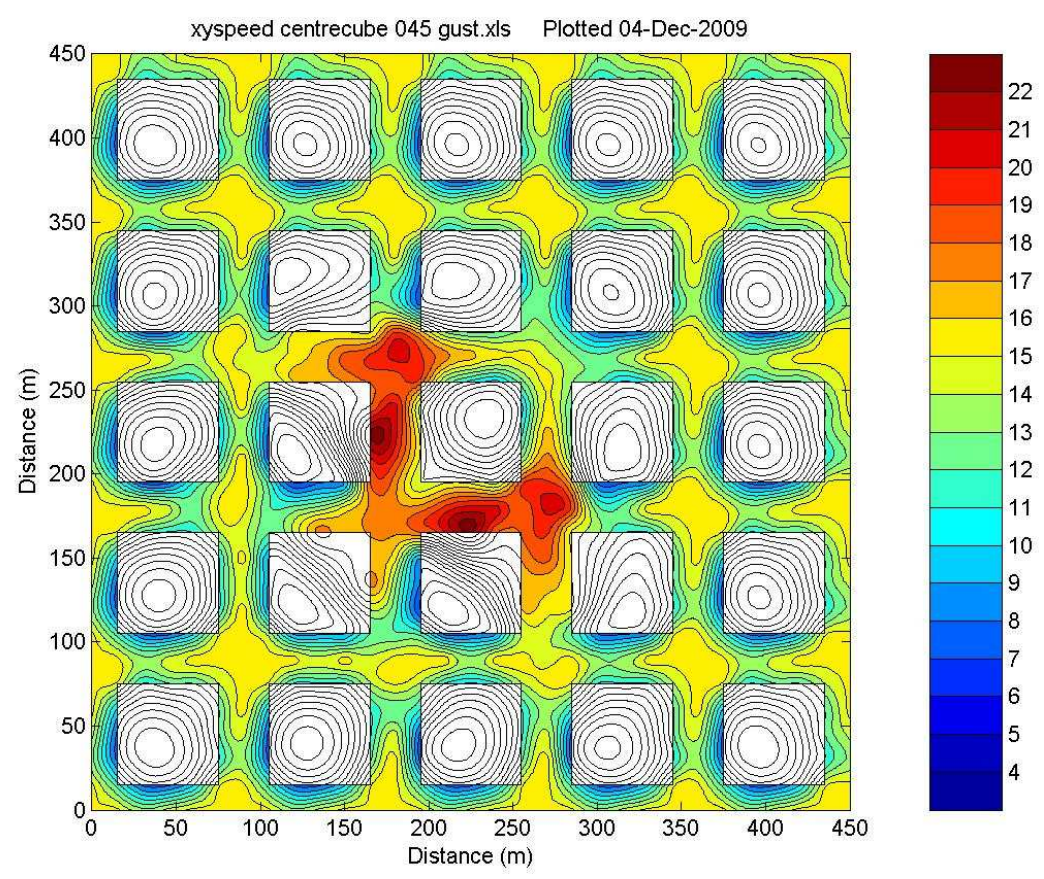

Figure 41: Contour diagram produced with a uniform distribution of buildings replacing the central half cube with a full cube, for gust wind speeds at a direction of $45^{\circ}$. 
corners to $22 \mathrm{~m} / \mathrm{s}$. Finally these two flows converge on the leeward corner of the building producing a large turbulent wake that significantly increases the wind speeds (from $15 \mathrm{~m} / \mathrm{s}$ to $19 \mathrm{~m} / \mathrm{s}$ ) on the building directly downwind from the cubic structure. The turbulent wake affects 9 buildings in total including the cubic building. By visualising the data through contouring affects on the surrounding environment due to the turbulent wake are much easier to identify and therefore mitigation measures can be undertaken.

Figure 42 and Figure 43 represent the final building configuration tested. This building configuration represented the regular array of half cubes with the central half cube replaced by a $240 \mathrm{~m}$ tall tower. The tall tower consisted of a half cube $30 \mathrm{~m}$ tall with a podium, and a $30 \mathrm{~m} \times 30 \mathrm{~m} \times 210 \mathrm{~m}$ tall tower added to the half cube. This presented two separate surfaces to produce contouring diagrams for. Firstly, the model surface similar to that of the previous contour diagrams, secondly, the podium surface above pedestrian height. Additional measurements were taken on the podium to measure wind speeds above pedestrian height. This led to complications with the contouring script as it was only designed to measure contours on a single plane. However, although this issue proved problematic with the podium wind speeds it did not invalidate the accuracy of the contours produced at pedestrian height. The downwashes produced by wind travel down the tall tower which is then drawn to street level over the podium creating an increase in gust wind speeds of around $6 \mathrm{~m} / \mathrm{s}$ directly in front of the building (see Figure 42). The central cube structure produced a large amount of downwind solely on the windward face of the structure. With the tall tower, this downwash was accentuated and occurred from the windward face along the side streets of the building and continued to run down the streets parallel with the $360^{\circ}$ wind direction. Consequently, the windward corners were subject to large accelerations in wind speed due to the corner effect. The main difference between the tall tower and the central cube structure was the length and overall increase in the leeward turbulent wake. The turbulent wake extended for two blocks similar to that of the cubic structure. However, the changes in wind speeds throughout this turbulent wake were much larger. 


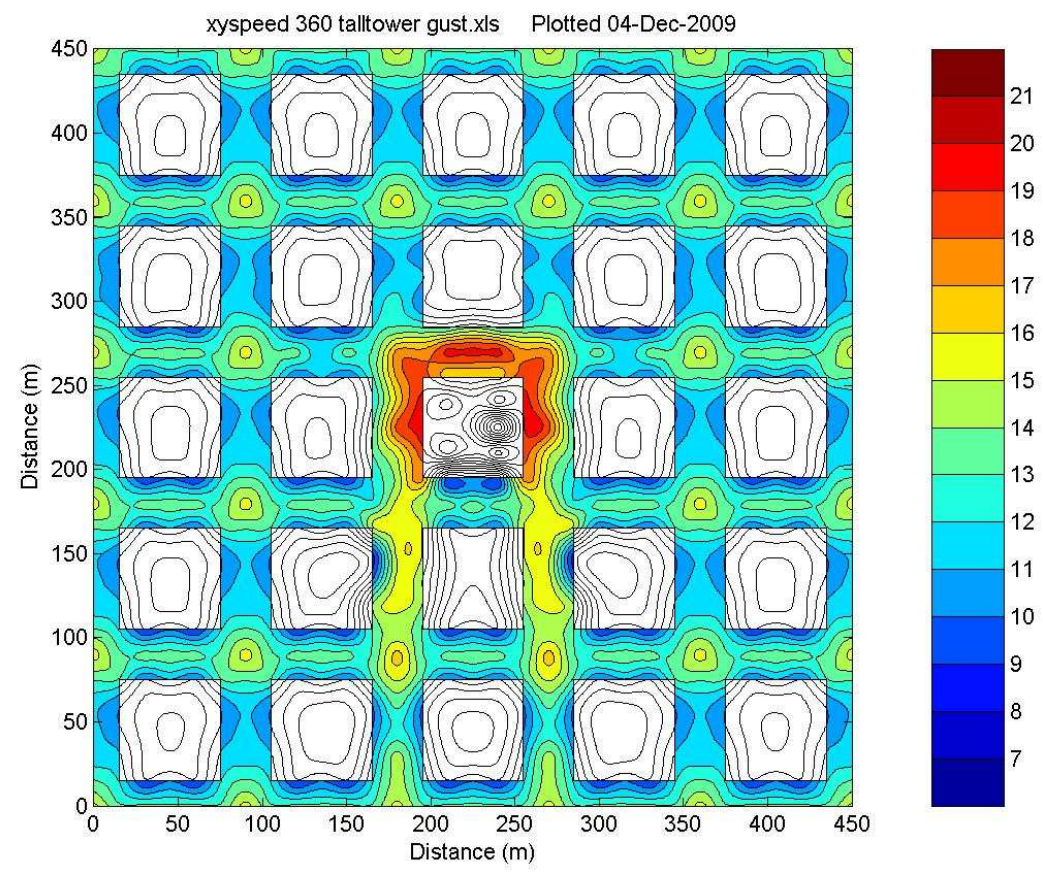

Figure 42: Contour diagram produced with a uniform distribution of buildings replacing the central half cube with a tall tower, for gust wind speeds at a direction of $360^{\circ}$.

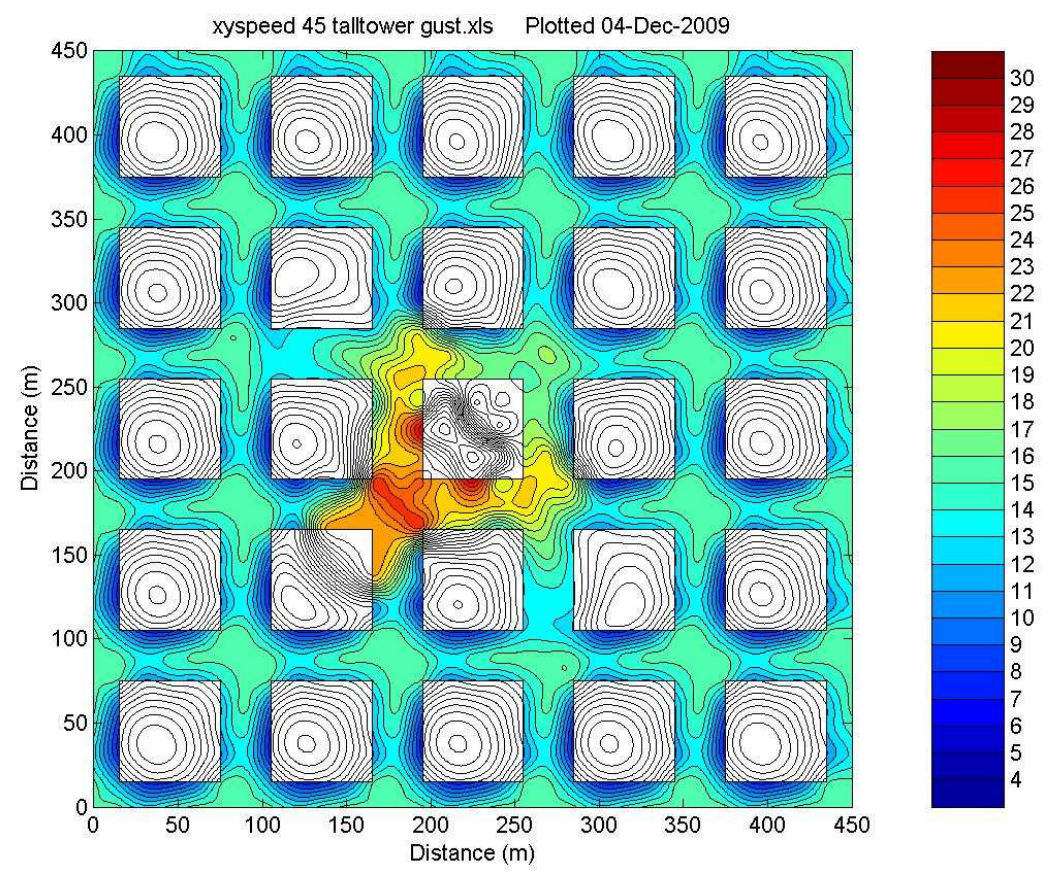

Figure 43: Contour diagram produced with a uniform distribution of buildings replacing the central half cube with a tall tower, for gust wind speeds at a direction of $45^{\circ}$. 
Figure 43 depicts the same $240 m$ tall tower with a podium base amongst a uniform grid of buildings with a $45^{\circ}$ degree wind direction. The turbulent wake which occurred across three blocks horizontally and extended downward three blocks from the central cubic building, was much more confined with the tall tower. This is due to a combination of the slender tower, building orientation ( $45^{\circ}$ to the wind flow) and the podium. The turbulent wake merely occurred in the streets directly downwind adjacent to the main building. The wind speeds in the centre of the street directly downwind from the building where the wind travelling around either side of the building is converging generated some exceptionally high wind speeds of around $27 \mathrm{~m} / \mathrm{s}$. Although, there are isolated patches of extremely high wind speeds, this contour image shows the effectiveness of the podium design combined with a tall slender tower. 


\subsection{DETERMINING CHANGES IN WIND SPEED}

The six different contour images in the previous section show, that through measuring a regular grid of reasonably spaced wind speeds, it is possible to achieve a contour image of pedestrian level wind speeds. Flow patterns and predictably problematic areas are easily identified and further mitigation could be done to achieve the required reductions in pedestrian level wind speed. However, manually comparing the two contouring images is a laborious task often resulting in the user missing small changes in wind speeds that would have been picked up by comparing measured wind speeds on a spread sheet. To aid this process a simple system was designed to compare the base measurements with the modified structure.

This was done by matching co-ordinates of measured wind speeds from either building configuration and calculating the change in wind speed. With relative ease the user can merely sort the data by co-ordinates in Excel and subtract the existing set of wind speeds from the newly generated wind speeds. An Excel macro was used to streamline this process. Essentially, the macro would read in the existing file of the same title, order the points initially by $x$ co-ordinates, then by $y$ co-ordinates, and subtract the first column from the second column. The data was then exported to a separate spreadsheet. This included the first two columns from both spreadsheets, including the $\mathrm{x}$ and $\mathrm{y}$ data. The third column added now contained the difference in wind speed between the existing and new building configurations.

Figure 44 depicts the change in wind speed between the grid of uniform half cubes and the full cube for gust wind speeds from a wind direction of $360^{\circ}$. Initially obvious is the size of the area affected by the change in building height. The area affected ranges one block either side of the central cube and 2 blocks downstream. The area with the largest change in wind speed is directly in front of the building where the downwash, where an increase of $6 \mathrm{~m} / \mathrm{s}$ was recorded. This wind is being accelerated around the windward corners due to the change in pressure between these two faces of the building. Due to this corner effect, there are substantial increases in wind speed throughout this area. Increases of 4-5m/s are occurring around these windward corners. The focus so far has been on increases in wind speed. It is important to note that there is also large areas in which the wind speed is being reduced. Areas directly behind the building away from the leeward 
corners are subject to reductions in wind speed of around $2 \mathrm{~m} / \mathrm{s}$. There are more areas in which the wind speed has been reduced further downwind of the central cube along the adjacent streets.

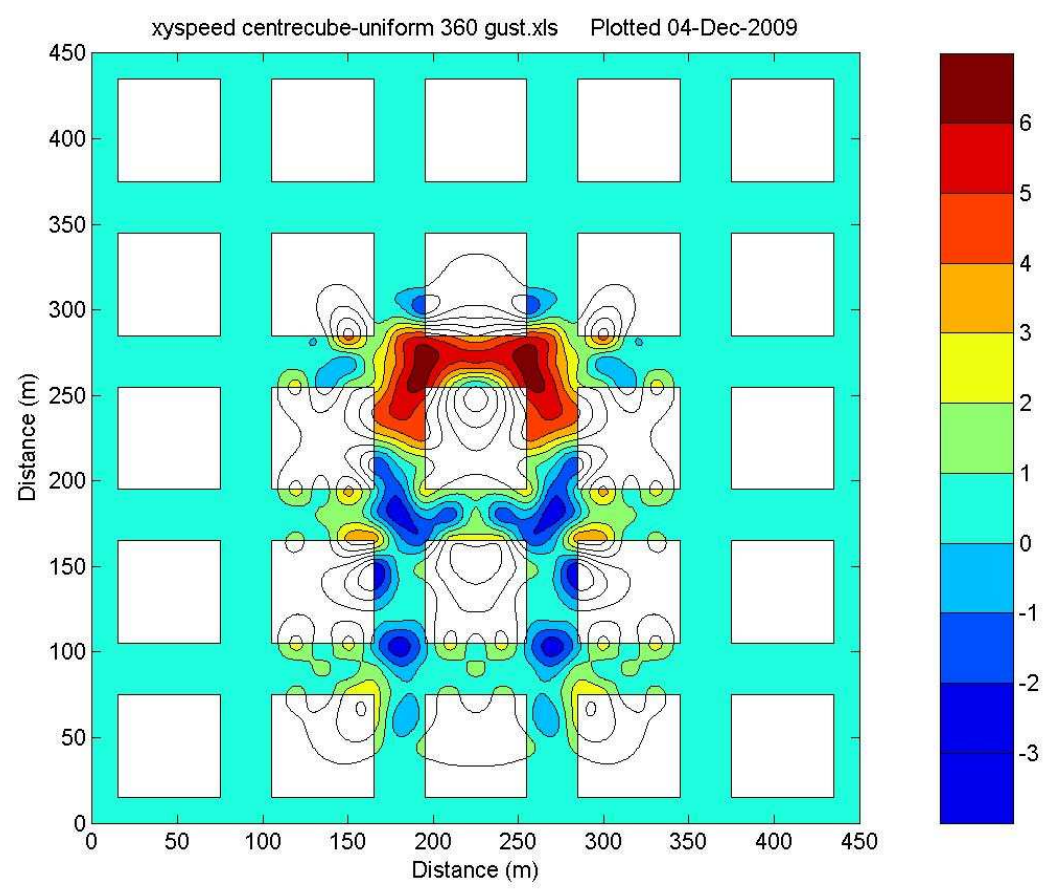

Figure 44: Change in wind speed between a grid of uniform half cubes and a central full cube, $360^{\circ}$ wind direction.

Figure 45 depicts the change in wind speed between the grid of uniform half cubes and the full cube for gust wind speeds from a wind direction of $45^{\circ}$. The first point of note is the sheer size of the area impacted by the increase in height of the building. The wake extends upwind one block and outwards at a 45 degree angle to affect 15 blocks in total. There are large increases in wind speed $(10 \mathrm{~m} / \mathrm{s})$ primarily behind the central building where wind travelling around the outside corners meets the adjacent buildings on the leeward side of the cube. Large increases in wind speeds also occur along the streets that run parallel with the windward faces of the building. Wind is deflected along the windward faces of the building and funnelled along these streets. There are also large areas in which the wind speed is reduced. Areas in which the wind speeds are reduced exceed that in which the wind speeds are increased. There are large areas in which the wind speeds have been reduced by as much as $2 \mathrm{~m} / \mathrm{s}$. 


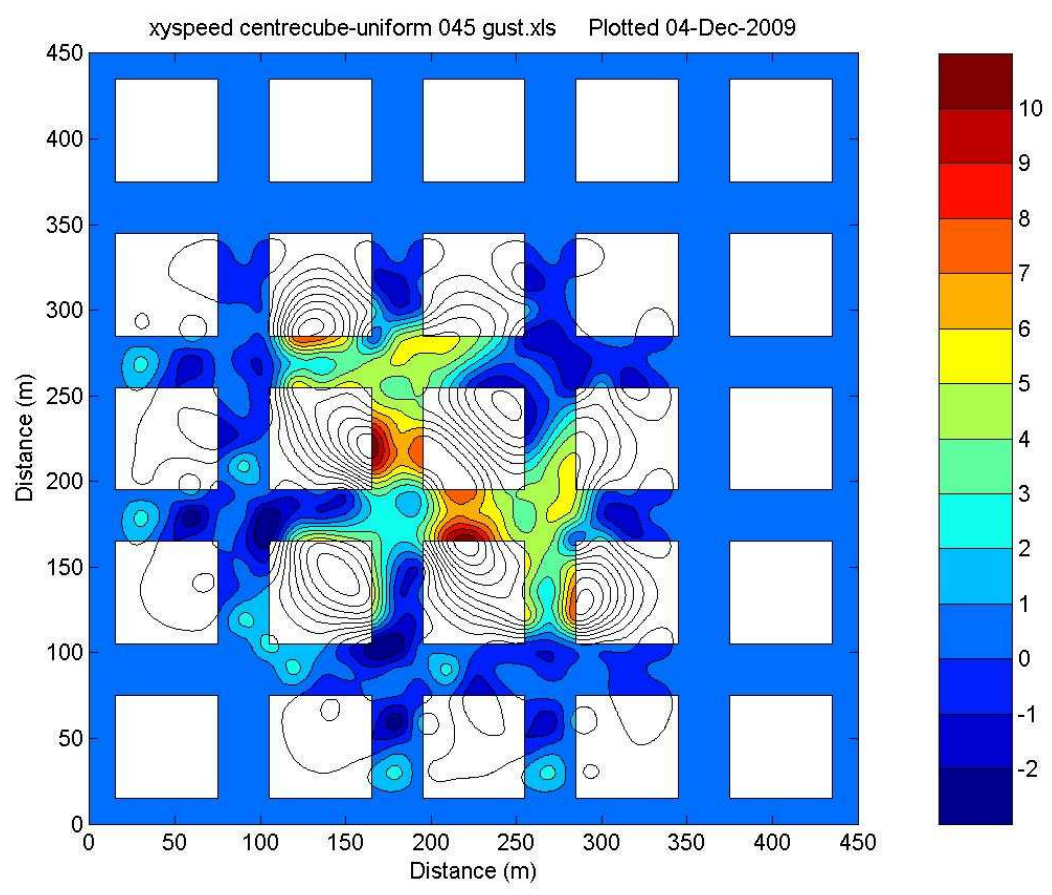

Figure 45: Change in wind speed between a grid of uniform half cubes and a central full cube, $45^{\circ}$ wind direction.

One concern with the initial contour diagrams was the inability to fix wind speeds to individual colours. Typically, gust wind speeds are considerably different than mean wind speeds. Gust speeds have a tendency to have large discrepancies in the ranges of data between building configurations within a single test. The result is a much larger array of colours required to convey the increased number of contour levels being drawn. Initially MATLAB would assign random colours to any wind speed and the resultant contour images were not comparable to one another at all. This was remedied to some extent by fixing the colour scale. An initial remedy was to ensure the same colour range was applied to the data in each contour diagram. However the different ranges of data made the contour images difficult to compare. The $360^{\circ}$ wind direction uniform grid of half cubes had a range of gust wind speeds of $9 \mathrm{~m} / \mathrm{s}$, where, the same configuration with a central cube had a range of $15 \mathrm{~m} / \mathrm{s}$. This made direct comparisons between building configurations rather difficult as the same wind speeds were associated to different colours. Calculating the difference in wind speed between the two building configurations and generating a contour diagram of this change the difference in the colours of contour levels is an attempt to rectify this issue. 


\section{CHAPTER EIGHT: CASE STUDY}

In order to determine the effectiveness of the contouring script a practical example was simulated. This study used an existing wind tunnel study that had been completed for a building in the central business district of Wellington, New Zealand. An existing wind tunnel study with a reasonable number of wind speed measurements was chosen. No additional wind speed measurements were taken as this would increase the amount of additional time that would need to be taken to complete this form of study. If successful a "reasonable" number of points could be defined as no more than what would be required in a typical wind tunnel point measurement study. It could therefore be used as a way of visualising the existing wind speed measurements and removing the need to conduct an erosion study to generate an area measurement.

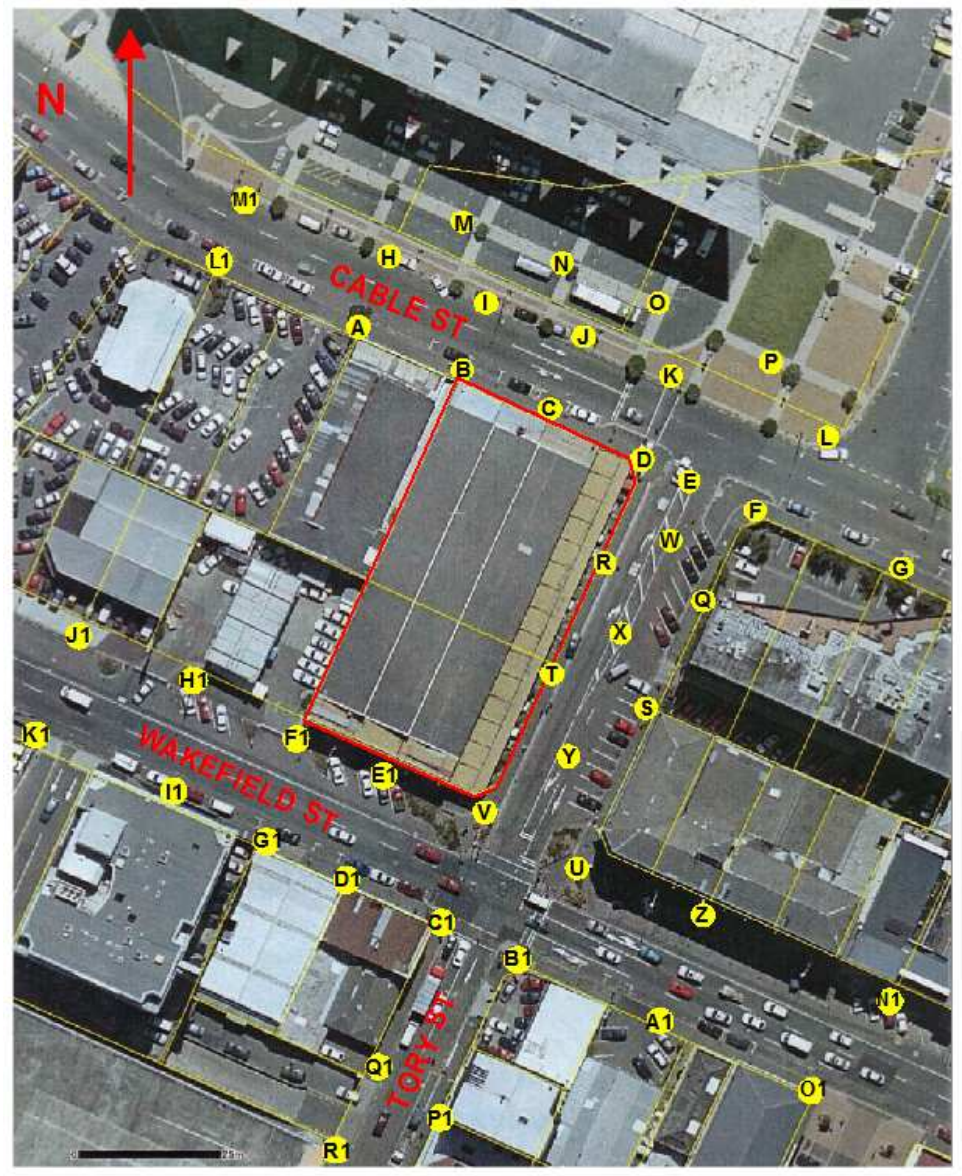

Figure 46: Image depicting the measurement point locations used in the case study contour diagram. 
There were a total of 44 measurements taken in total over an area of $180 \mathrm{~m}$ by $180 \mathrm{~m}$. Measurements were taken at the corners of buildings, entranceways, the centre of some streets, and at fairly regular intervals along the footpaths on either side of the road (see Figure 46). The contour diagrams prepared throughout this research had a total of 736 measurements over an area of $450 \mathrm{~m} \times 450 \mathrm{~m}$. Although there are considerably less measurements in this case study, the aim is not to assess the accuracy of the contouring script, but to assess the plausibility of using the contouring script in a practical situation. This would ensure that measurements could be inputted in irregular arrays. Further programming additions that would be needed in order to use this script for commercial wind studies, could also be identified.

To begin, the area had to be defined and allocated a mesh of co-ordinates to which the point measurement locations could be added. To get an accurate image with geographical co-ordinates Google Earth was used. An area containing the site in question was uploaded to Google SketchUp as the base layer. Within SketchUp the base could be manipulated to resemble the image used in the aerodynamic assessment report. The lower left hand corner of the image was then moved to the origin of the axis and became point $(0,0)$. Wind speed measurement points were then located on this image. Typical wind speed measurement procedures dictate wind speed measurements are to be taken $1.5 \mathrm{~m}$ from the edge of a building and otherwise in the centre of the streets ${ }^{57}$. If a point fell outside this, the point locations were interpreted as best as possible from the provided image. The measurement tool within Google SketchUp allowed $x$ and $y$ co-ordinates to be determined from the image with relative ease. These were then inputted into an Excel spreadsheet in a similar fashion to the previously analysed uniform grids of measurements. These co-ordinates were then associated with the recorded gust wind speeds. The end result was a three columned Excel spreadsheet with 44 locations in which there was co-ordinate matched with a gust wind speed ( $x, y$, speed).

MATLAB was then used to analyse the Excel file and generate a set of contours. For this study the patches that were used throughout the prior simulations were removed. The external patch file could be modified to contain patches of the buildings contained in this test. However, this is a laborious process that would not be ideal for commercial wind studies. An aerial photograph of the surrounding buildings would be overlaid onto

\footnotetext{
57 Jamieson, N. (2004). Wind tunnel study of the proposed P\&O development, Wellington, Central Laboratories Report, 05-529A28.
} 
the contouring image. This would produce an image that could potentially be used for a commercial wind study. Although the addition of an image post-contouring is not an ideal way in which to incorporate an aerial photograph of the surrounding area, the eventual result will parallel that of the patches, and known buildings will be much easier to identify. No modifications were made to the primary MATLAB script to ensure irregular input locations could be used to generate contours.

The data removal study identified a reasonable minimum distance between measurement points. The initial distance between measurement points was $15 \mathrm{~m}$. When this was increased to $30 \mathrm{~m}$ the contouring became too inaccurate. Measurements are typically taken at a higher resolution around the site in question and become more spread out the further away from the site they are taken. The distance between measurement points is around $15 \mathrm{~m}$ adjacent to the site in question and around $40 \mathrm{~m}$ at the perimeter of the testing area.

Figure 47 is an image of the contours produced as a result of running the script with 44 comparatively irregularly located data points. The resulting contours were a good visualisation of the measured wind speeds. Although not particularly accurate, the contours show areas of high wind speed as opposed to areas of low wind speed.

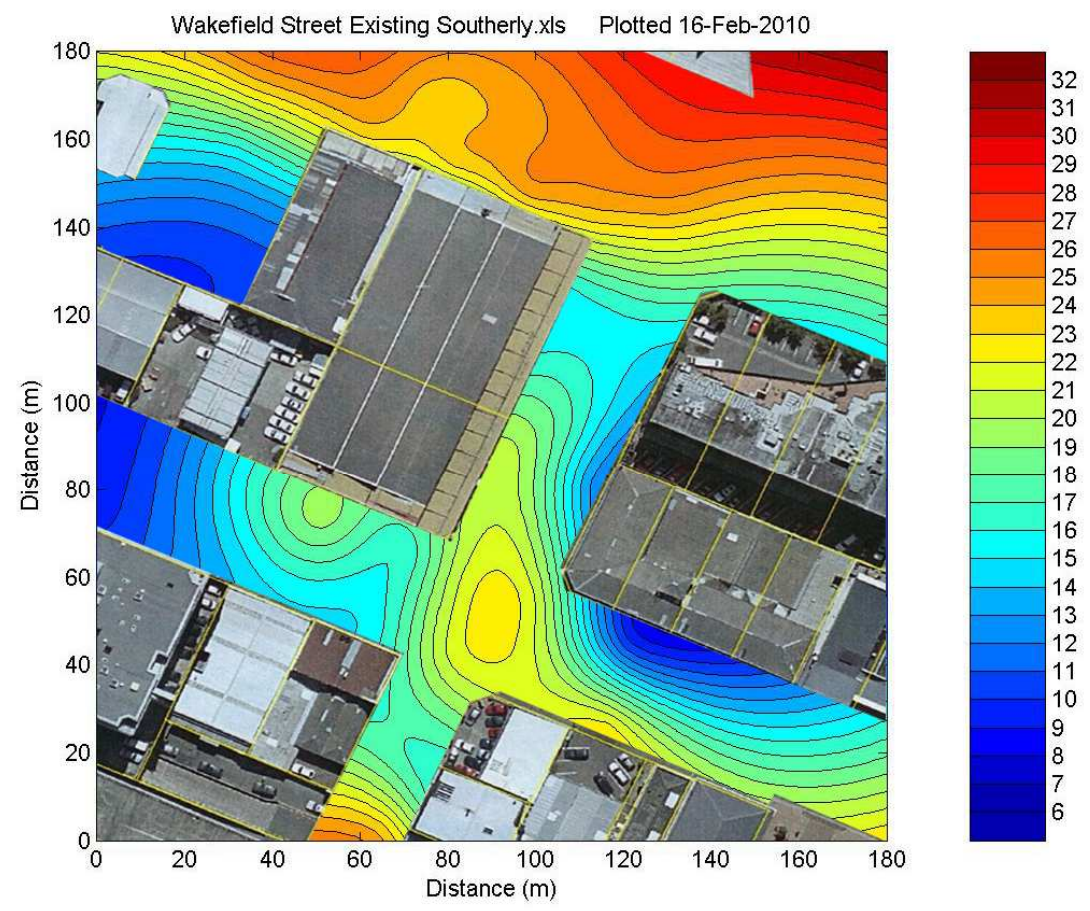

Figure 47: Contours produced for the case study with the existing building configuration. Google Earth snapshot overlaid. 


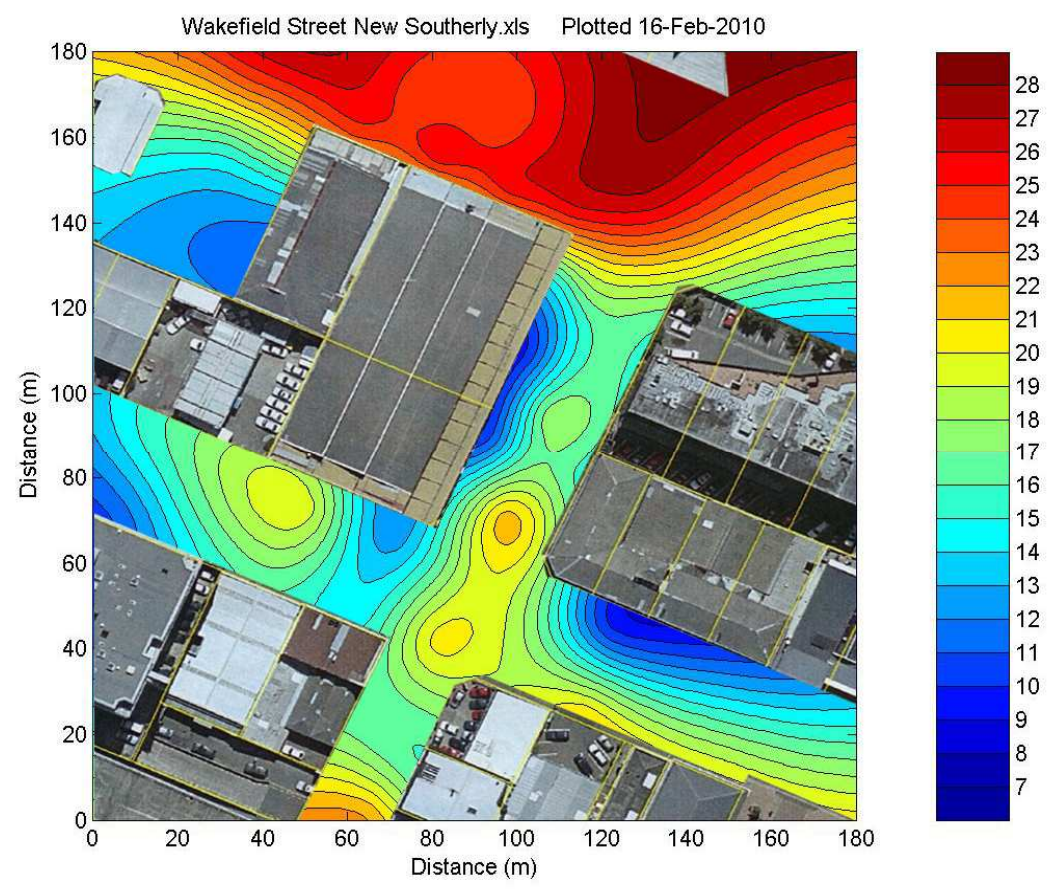

Figure 48: Contours produced for the case study with the new building configuration. Google Earth snapshot overlaid.

When comparing contours from Figure 48 with the contours in Figure 47, there are increases in wind speeds on the right hand side of the street directly adjacent to the site in question. The left hand side of the street directly beside the site in question is subject to reductions in wind speed of around $6 \mathrm{~m} / \mathrm{s}$. By presenting wind speed data in this manner, wind speeds are able to be drawn directly from the contours generated. However, the reader is still presented with the "spot-the-difference" type problem. Areas in which there is a small change in wind speed may go unnoticed. To further illustrate the benefits of this type of data presentation, one further contour diagram was produced to show changes in wind speeds. Figure 49 shows an example of this type of output. At a glance this image enables the reader to identify areas in which changes in wind speed are occurring. These changes are able to be easily quantified through the display of numerical data. An image such as this is a great improvement upon the current presentation of wind speed measurements. It provides a unison between the benefits of both flow visualisation and wind speed measurement presentation techniques. 


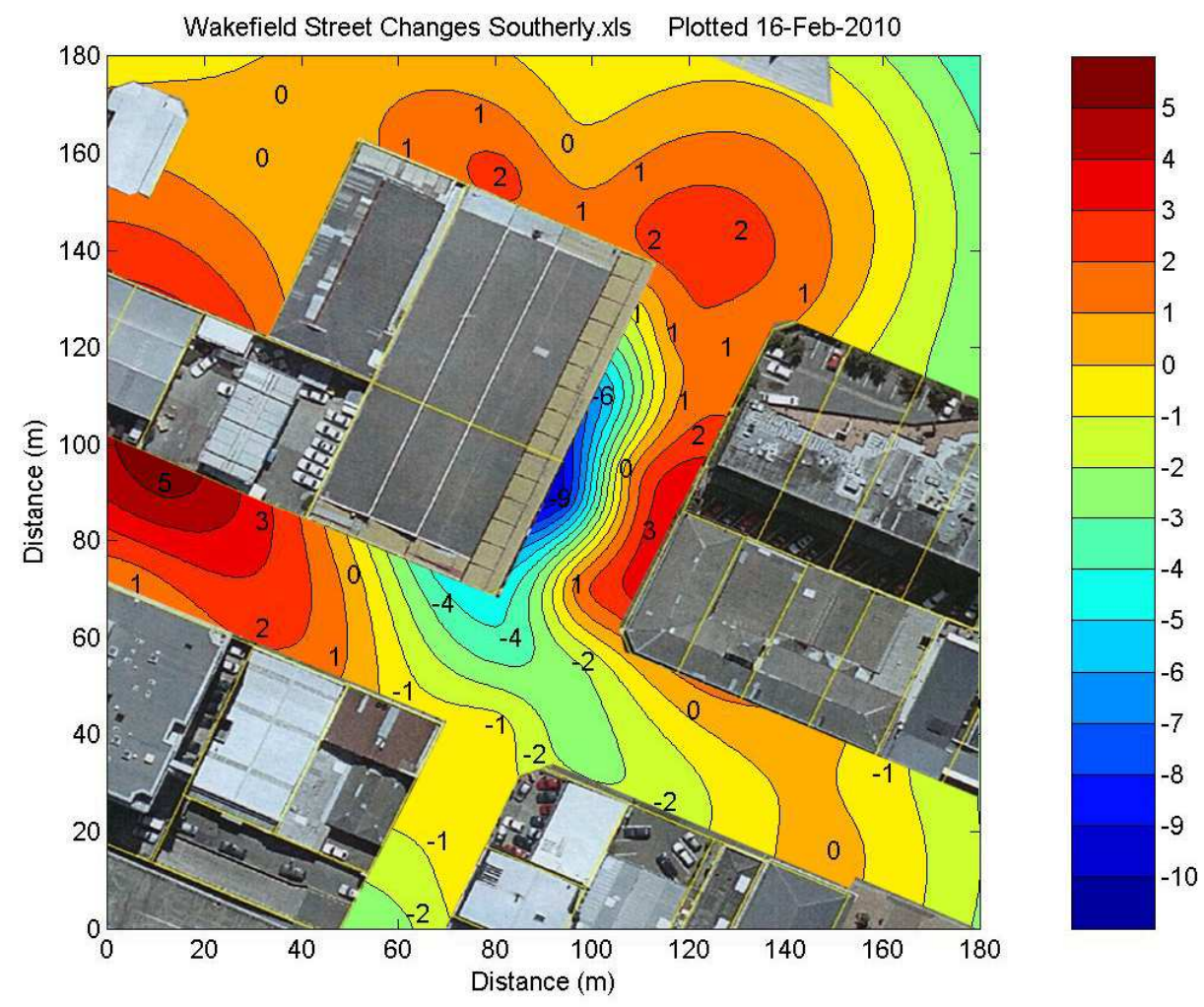

Figure 49: The difference between the existing and new wind speeds. Speeds have been added to the image to improve usability. Google Earth snapshot overlaid 


\section{CHAPTER NINE: CONCLUSIONS}

This research has shown that it is possible to produce an area measurement from a reasonable number of point wind speed measurements. A reasonable number of point wind speed measurements has been identified as a distance between measurement intervals of $15 \mathrm{~m}$ (in scale). Although, the distance between measurements can be increased, this will proportionately reduce the accuracy of the resultant contours. Mathematically generated contours have the potential to reduce the time taken to conduct a commercial pedestrian level wind analysis by negating the need for an erosion study. Interpolation methods were used to generate pseudo measurements between measured wind speeds, thus significantly reducing the total number of point wind speed measurements from pedestrian shoulder width $(\approx 0.5 \mathrm{~m})$ to around $15 \mathrm{~m}$ in scale. A measurement resolution of $15 \mathrm{~m}$ allows an adequate number of points for potentially problematic wind flow characteristics to be identified. Area measurement presentation methods consist primarily of contour images $^{58}$. Therefore, these were seen as the most efficient method of displaying area measurement data. Contour images allow the end user of the data to quickly associate measured wind speeds with locations around the site. Furthermore, changes in wind speeds can be isolated and presented in a single contour image. There is no longer a need to visually identify changes in comparative windiness between the results of two flow visualisation contour images.

An existing study in which a regular grid of point wind speed measurements were taken around a series of building configurations was used as the base data for contour generation. This data was used as opposed to designing a series of wind tunnel tests from scratch as the research was focused around the potential to generate an area measurement from a reasonable number of point wind speed measurements. The study completed at the Opus Central Laboratories simulated a series of different building configurations to determine the effect of architectural detailing on local wind speeds. Each building configuration had a number of point wind speeds measured at roughly $15 \mathrm{~m}$ intervals around the reference (or central) building. The configurations were chosen to assess the impact of introducing a building of increasing height on an area in which buildings have a relatively uniform height.

${ }^{58}$ Refer to Chapter 3.1: Data Presentation 
The accuracy of the contours was assessed by using a series of simple building scenarios. The building scenarios tested had predictable wind flow patterns that are easy to identify and assess. Flow patterns such as downwash and the corner effect are easily identifiable and were prominent in the resultant contours. The uniformly distributed grid of half cubes produced sets of contours that were uniformly distributed across the contour graph. Replacing the central half cube with a full cube produces significant downwash which in turn accelerates wind around the two windward corners (corner effect). The corner effect was accentuated when the buildings were orientated at 45 degrees to the oncoming wind. These are predictable flow patterns that are expected with the introduction of such a building. The tall building configuration greatly increased the impact of both the downwash and corner effect around the development site. The turbulent wake caused by the building was also increased significantly to that of the cube and half cube building configuration. These changes in contours were strong indications that the contouring script was working efficiently. To further the effectiveness of the contouring script images were produced to show the change in wind speed over the testing area. This allows the end user of the data to assess one contour image for each wind direction as opposed to attempting to visually identify and quantify changes in wind speed across two contour images.

A minimum density of points was then determined through a point removal study. The absolute minimum point density of pedestrian shoulder width was deemed impractical for commercial application. The $15 \mathrm{~m}$ (scale) density used in the architectural detailing paper ${ }^{59}$ produced accurate contouring for a simple building configuration. Therefore, this resolution can be assumed to be a more practical starting resolution. To identify the absolute minimum density of measurements required before the contours became too inaccurate for flow patterns to be identified, points were removed systematically from the data. One in every four points were initially removed, then one in three points, and finally every second point was removed. The primary contour image that was created from a point resolution of $15 \mathrm{~m} \times 15 \mathrm{~m}$ generated a total of 42 areas above $16 \mathrm{~m} / \mathrm{s}$ (orange). This would be taken as the base set of data and as the contours are of a reasonable quality for now it will be assumed to be a "best case scenario". A "reasonable level of accuracy" will be defined as a contour image where fewer points have been measured when compared to the initial test, however, the

\footnotetext{
59 Jamieson, N., Carpenter, P., Cenek, P. D. (1992). The Effect of Architectural Detailing on Pedestrian Level Wind Speeds. Journal of wind engineering and industrial aerodynamics. 41-44, 2301-2312.
} 
number of areas above $16 \mathrm{~m} / \mathrm{s}$ remain reasonably consistent. Removing one point in four resulted in a total of 41 areas above $16 \mathrm{~m} / \mathrm{s}$ being recorded. This is an overall reduction of accuracy of around $2.5 \%$ which is very much acceptable. Removing one point in three resulted in a total of 40 areas above $16 \mathrm{~m} / \mathrm{s}$ being recorded. This produced an overall reduction of accuracy of around 5\%. All expected wind flow characteristics were identified in these two contour images. Removing every second point effectively doubles the distance between measurement points from $15 \mathrm{~m}$ to $30 \mathrm{~m}$. This resulted in a significant reduction of points recorded above $16 \mathrm{~m} / \mathrm{s}$ from 42 to around 7 which results in a loss of accuracy or around $83 \%$. Although there is a significant reduction in the amount of high speed areas, the predictable flow patterns are still evident.

The results from the point removal study indicate that the most effective method of generating an area measurement from a series of point wind speed measurements would be through adaptive measurement grid sizes. By creating adaptive grids of measurement locations different zones would be associated with different densities of points. Areas in the direct vicinity of the development, i.e. one block surrounding the development, would have a high density of points ( $\leq 15 \mathrm{~m}$ resolution). This would increase the accuracy of the contours, therefore problematic areas of increased wind speed are likely to be identified and accurately quantified. Areas further away from the development could have a proportionally lower density of measurement points ( $\approx 30 \mathrm{~m}$ resolution) as the development is less likely to impact these areas. In this manner the predictable flow patterns are still identified while the time taken to complete the test is not impractical.

The resulting contour system was then assessed on a case study development to determine the further script additions required to potentially implement the program for commercial use. A commercial case study was selected from the Victoria University of Wellington archives. The study contained 44 point wind speed measurements. Google Earth was used to associate each measurement point with $\mathrm{x}$ and y co-ordinates relative to an origin located at the lower left hand corner of the supplied point measurement location diagram. This study was done to assess the potential of implementing the contouring script into current measurement techniques requiring no extra time or cost to set up. This would also enable the script to be tested with irregularly located points, as opposed to the fairly regular array used in the initial building configurations. The contours produced as a result of this study were of a lower resolution than that of the simple building studies. This is indicative of the much lower number of points. However, the contours still 
gave a good indication of flow patterns and areas in which the wind speeds had changed as a result of the new development. Ultimately a higher resolution of points would be required to produce a commercially applicable area measurement, but as an overall indication or presentation of measured wind speeds, this contour image could potentially be an improvement on current presentation techniques.

Overall a contouring script has been developed that can produce an area measurement from a reasonable number of point wind speed measurements. The resolution of the output contours in any case is directly proportional to the number of point wind speed measurements. A larger number of point wind speed measurements generated a much higher level of reliability in the contours. Combined with mathematical interpolation a measurement point resolution of around $15 \mathrm{~m}$ (in scale) is sufficient to identify potentially problematic wind flow characteristics. The distance between measurements can be increased to around $30 \mathrm{~m}$ (in scale) in areas that are unlikely to be impacted by the development, thus reducing the total time required to conduct simulations. 


\section{CHAPTER TEN: FUTURE RESEARCH}

A number of issues arose during development of the script that were unable to be rectified in the allocated time. The output contour diagrams that were generated were accurate enough to identify potentially problematic wind flow characteristics. An overall indication of wind speeds, locations and local field flows was able to be depicted. MATLAB is not solely created for the purpose of architectural aerodynamics. To adapt a script through MATLAB to interpolate contours around buildings with a more defined level of accuracy is a difficult task. The contours produced through this script are an example of how it is possible to produce an area measurement of a pedestrian wind environment based upon a reasonable minimum number of point wind speed measurements. Using interpolation methods pseudo points were generated around the measured points to provide a continuous surface of wind speeds measurements.

The primary issue that would need to be resolved before this contouring system could be implemented in commercial studies would be to ensure the interpolation engine could allow for buildings to be placed onto the contouring surface. Without significant improvements in the programming, MATLAB is only able to contour on one continuous surface. When the surface is broken in any way problems arise with the connections between the interpolated curves. The calculations require the surface to be continuous. Pedestrian level was represented as a single continuous two dimensional plane. Attempts were made to remove portions of the contours where the buildings were located. However, these empty areas resulted in skewing of the contours.

The addition of buildings into the contouring simulation could potentially negate the need to draw patches where the buildings are in fact located. Through completing the case study it became obvious that such tools as Google Earth could be exploited to ensure geographical accuracy in the contouring. As patches have little relevance to the actual contouring, process these could be removed all together and images of the buildings could be placed into the contouring output. Aerial photographs and images from Google Earth are already commonly used throughout wind tunnel reports. These images are used to orientate and familiarise the reader with the site in question. The report writer will already be in possession of an image of the development site. This could be then used as part of the contouring diagram either by placing the buildings on 
top of the contours produced through an image manipulating program such as Adobe Photoshop or by including such a mechanism in a purpose build contouring program. A script could easily automatically identify the surrounding streets, remove them from the image, scale the image appropriately, and use the image as a background for the contouring to be laid upon.

A script or program could be developed to incorporate the interpolation power of MATLAB with a simplistic interface for defining the buildings and manipulating the outputs. The internal interpolation calculations that work with the contouring function would need to be manipulated to allow flexibility in the surface plane. A GUI would be the most notable improvement to increase usability. The script based system that is presently being used to generate contours requires an individual who is competent in MATLAB (or programming language) to operate effectively. Through the implementation of a GUI to control the various functions, a larger proportion of people could easily be instructed on how to generate contours. A GUI could greatly streamline the co-ordinate input system. An image of the model surface to be tested could be inputted and scaled appropriately. The data for simulation could then be "drawn" atop of the image to define the building/point locations. The measurement points could take on a "point and click" approach, as opposed to calculating co-ordinates and inputting them into an Excel spreadsheet alongside the measured wind speeds. Wind speeds could be recorded directly into the program eliminating the possibility of human error in manually inputting the wind speed data.

The measurement of downwash by vertically orientated hot film anemometers would present an interesting study. The differences in results between horizontally and vertically orientated hot film anemometers could identify reasons for the over erosion of bran during area assessments. Finally, there is more work needed in the assessment of how various aerodynamic effects are assessed between different testing methods. Throughout this research three were considered: downwash, corner effect and turbulent wake. Future work may also consider air flow over podiums, porous car parks, building corner modifications, wind breaks and internal alleyways. 


\section{REFERENCES CITED}

- $\quad$ ANSYS Inc. (n.d.). ANSYS FLUENT Flow Modeling Software. Retrieved March 09, 2010, from ANSYS: http://www.ansys.com/products/fluid-dynamics/fluent/

- $\quad$ Arens, E., (1982). On Considering Pedestrian Winds During Building Design, International Workshop on Wind Tunnel Modelling and Techniques in Civil Engineering Applications, Maryland, USA, 8-26.

- Aynsley, R. M. et al., (1974). Effects of Airflow on Human Comfort, Building Science, 9, 91-94.

- $\quad$ Aynsley, R. M. et al., (1977). Architectural Aerodynamics: Environmental Wind Flows Around Buildings, Applied Science Publishers, London.

- $\quad$ Baigrie, B., (1996). Picturing Knowledge: Historical and Philosophical Problems Concerning the Use of Art in Science, University of Toronto Press, Toronto.

- $\quad$ Beranek, W.J., Van Koten, H., (1979) Visual Techniques for the Determination of Wind Environments, Journal of Wind Engineering and Industrial Aerodynamics (4) 295-306.

- Blocken B, Carmeliet J., (2004). Pedestrian wind environment around buildings: Literature review and practical examples. Journal of Thermal Envelope and Building Science. 28(2): 107-159.

- $\quad$ Bottema, M., (1993). Wind climate and urban geometry, Ph.D. thesis, FAGO, Technical University of Eindhoven.

- $\quad$ Carter, L., (1947). An experiment on the design of tables and graphs used for presenting numerical data. Journal of Applied Psychology, 31, 640-650.

- Cook, N. J. (1985) The Designer's Guide to Wind Loading of building Structures, Part 1, Buttersworths, London.

- Cook, N. J. (1985) The Designer's Guide to Wind Loading of building Structures, Part 2, Buttersworths, London.

- Deaves, D., Harris, R., (1978). A Mathematical Model of the Structure of Strong Winds, CIRIA Report 76.

- Deaves, D., Harris, R., (1982). A note on the use of asymptotic similarity theory in neutral atmospheric boundary layers, Atmospheric Environment. 16, 1889-1893.

- Durgin, F., (1991). Pedestrian level wind studies at the Wright Brothers facility. Journal of Wind Engineering and Industrial Aerodynamics, 41-44, 2253-2264.

- Durgin, F., (1997). Pedestrian level wind criteria using the equivalent average. Journal of Wind Engineering and Industrial Aerodynamics, 66, 215-226. 
- Dwyer, F., (1976). The effect of IQ level on the instructional effectiveness of black and white and colour illustrations. Audio Visual Communications Review. 24, 49-62.

- Eaddy, M., (1998), Pedestrian Level Wind Measurement using Computer Image Processing, Department of Mechanical Engineering, University of Auckland.

- $\quad$ Eaddy, M., Flay, R., (1998). Image processing applied to pedestrian level wind investigations, IPENZ Transactions. 25, 37-45.

- Flay, R., (1991). Pedestrian-level wind investigations using cork grain erosion techniques. Report ME G 91-02, University of Auckland.

- Greenan, B,. (2001). MATLAB Central: colorbarf. Retrieved March 11, 2010, from MATLAB Central: http://www.mathworks.com/matlabcentral/fileexchange/1135-colorbarf

- Jackson, P. S., (1975). Testing the Aerodynamics of Buildings, NZIA Journal, (February).

- Jackson, P. S., (1978). The evaluation of windy environments, Building and Environment, 13, 251-260.

- Jamieson, N., (2004). Wind tunnel study of the proposed P\&O development, Wellington, Central Laboratories Report, 05-529A28.

- Jamieson, N., (2005). Wind tunnel study of a proposed development for 233-245 Wakefield Street, Central Laboratories Report, 04-529871.

- Jamieson, N., Carpenter, P., Cenek, P. D. (1992). The Effect of Architectural Detailing on Pedestrian Level Wind Speeds. Journal of wind engineering and industrial aerodynamics. 41-44, 2301-2312.

- Kirkup, L., (1994). Experimental Methods: An Introduction to the Analysis and Presentation of Data, John Wiley \& Sons, Queensland, Australia.

- Lawson, T. (2001). Building Aerodynamics. London, England. Imperial College Press.

- $\quad$ Livesey, F., Inculet, N., Isyumov, A., Davenport, A., (1990). A Sour Technique for the Evaluation of Pedestrian Level Wind Environment. Journal of Wing Engineering and Industrial Aerodynamics.(36) 779-789.

- $\quad$ Livesey, F., Morrish, D., Mikitiuk, M., Isyumov, N., (1992). Enhanced Scout Tests to Evaluate Pedestrian Level Winds. Journal of Wind Engineering and Industrial Aerodynamics. (41-44) 22652276.

- Murakami, S., Uehara, K., Deguchi, K. (1980). Wind effects on pedestrians: new criteria based on outdoor observation of over (2000) persons, In: Cermak (Ed.) (1980), Proceedings of the 5th International Conference on Wind Engineering, Fort Collins, Colorado, pp. 277-288.

- $\quad$ Penwarden, A., (1972). Wind environment around Tall Buildings, Building Research Station, Watford.

- Penwarden, A. D. and Wise, A. F. E. (1975) Wind Environment around Tall Buildings, E7, Building Research Establishment, Watford.

- Reynolds, L., Simmonds, D., (1981). Presentation of Data in Science, Martinus Nijhoff Publishers, London. 
- Sexton, D., (1968). Building Aerodynamics, Building Research Station, Watford.

- Soligo M., Irwin P., Williams C., Schuyler G., (1998). A comprehensive assessment of pedestrian comfort including thermal effects. Journal of wind engineering and industrial aerodynamics. 77\&78, 753-766.

- $\quad$ Stathopoulos, T., (2002). The Numerical Wind Tunnel for Industrial Aerodynamics: Real or Virtual in the New Millennium? Wind \& Structures, 5, 193-208.

- Task Committee on Outdoor Human Comfort of the Aerodynamic Committee of the American Society of Civil Engineers, 'ASCE Outdoor Human Comfort and its Assessment: State of the Art', American Society of Civil Engineers, Virginia, 2004.

- The Mathworks (n.d.). MATLAB 7.10 - Product Description. Retrieved March 8, 2010, from The Mathworks: http://www.mathworks.com/products/matlab/description1.html

- Virtualwind Inc. (n.d.). Value to Users. Retrieved March 8, 2010, from Virtualwind: http://www.virtualwind.com/about-virtualwind-20/42-value-to-users

- $\quad \mathrm{Vu}$ T, Takashi A, Manabu I, Steve A., (1995) Characteristics of wind field in a street canyon. Journal of wind engineering and industrial aerodynamics 57, 63-80.

- Wellington City Council, (1984). Wind: A Design Guide for the Wellington City Centre, Town Planning Department, Wellington City Council, Wellington.

- Wellington City Council, (1984). Wellington City Proposed District Plan: Central Area Design Guide, Town Planning Department, Wellington City Council, Wellington.

- Wellington City Council, (2007). Change 48: Central Area Review. Retrieved January 1, 2010, from Wellington City Council:

http://www.wellington.govt.nz/plans/district/planchanges/pdfs/change48/change48-pcdchap13.pdf

- Wise, A. F. E. (1971) Wind Effects due to Groups of Buildings, Phil. Trans. Roy. Soc., 269, (A), 469-485. 


\section{ADDITIONAL REFERENCES}

- $\quad$ Ahuja, R., Dalui, S., Gupta, V., (2006). Unpleasant Pedestrian Wind Conditions Around Buildings. Asian Journal of Civil Engineering (Building and Housing). 7. 147-154.

- $\quad$ Cochran, L., (2004). Design Features to Change and/or Ameliorate Pedestrian Wind Conditions. Structures 2004 - Building On The Past: Securing The Future. 1-8.

- Grey, N., (2006). Visualization in MATLAB. Retrieved June 8, 2009, from School of Mathematics, University of Manchester: http://www.maths.manchester.ac.uk/ ngray/teaching/mt1242/Handouts/Handout04.pdf

- Jones, P., Alexander, D., Burnett, J., (2004). Pedestrian Wind Environment Around High-Rise Residential Buildings in Hong Kong. Indoor Built Environment. 13. 259-269.

- Kataryna, K., (2004). Wind speed at pedestrian level in a residential building complex. Plea 2004 - The 21th Conference on Passive and Low Energy Architecture. Eindhoven, The Netherlands.

- Malyarenko, A., (2003). Graphics in MATLAB. Retrieved July 23, 2009, from Mälardalen University: https://kurswebbplats.mdh.se/mt1370/mt1370-2003-2004-lecture01.pdf

- $\quad$ MATLAB Inc., (2009). MATLAB Graphics, The Mathworks Inc., Natick, United states of America.

- Mitchell, T., (2001). MATLAB Graphics Help, Retrieved June 8, 2009, from Joint Institute for the Study of the Atmosphere and Ocean: http://jisao.washington.edu/computer_helps/MATLAB_graphics.html

- Neuman, E., (n.d.). Tutorial 2: Programming in MATLAB, Retrieved June 8, 2009, from Department of Mathematics Southern Illinois University: www.math.siu.edu/matlab/tutorial2.pdf

- $\quad$ Pawlowicz, R., (2009). M_Map: A mapping package for MATLAB. Retrieved June 27, 2009, from Earth and Ocean Sciences: http://www.eos.ubc.ca/ rich/map.html

- Pumphrey, H., (2005). An Introduction to matplotlib. Retrieved June 8, 2009, from School of GeoSciences: http://xweb.geos.ed.ac.uk/ hcp/notes_python.pdf 


\section{APPENDICES}

\section{APPENDIX ONE: PUBLIC SPACES}

Public spaces listed in Wellington City district plan section 16.3.6.4.

Source:

Wellington City Council, (2007). Change 48: Central Area Review. Retrieved January 1, 2010, from Wellington City Council:http://www.wellington.govt.nz/plans/district/planchanges/pdfs/change48/change48-pcdchap13.pdf

\begin{tabular}{|c|c|}
\hline Public Space & $\begin{array}{l}\text { Time period to be calculated using New Zealand } \\
\text { Standard Time at either of the equinoxes (i.e. } 21 \\
\text { March or } 23 \text { September) }\end{array}$ \\
\hline $\begin{array}{cl}\text { Pedestrian malls: } \\
\bullet \quad \text { Cuba Mall, Cuba Street } \\
\bullet \quad \text { Manners Mall, Manners Street }\end{array}$ & $\begin{array}{c}12: 00 \text { noon to } 2: 00 \mathrm{pm} \\
1: 30 \mathrm{pm} \text { to } 3: 00 \mathrm{pm}\end{array}$ \\
\hline $\begin{array}{ll}\text { Parks and squares: } \\
\text { - } & \text { Civic Square, Civic Centre } \\
\text { - } & \text { Midland Park, Lambton Quay } \\
\text { - } & \text { Cobblestone Park, Vivian Street } \\
\text { - } & \text { Glover Park, Ghuznee Street } \\
\text { - } & \text { Te Aro Park, Manners/Dixon Streets } \\
\text { - } & \text { 'Clock Park' Southeast corner Courtenay } \\
\text { - Place/ Taranaki Street intersection } & \text { Denton Park, Bond/Lombard Streets }\end{array}$ & $\begin{array}{c}12 \text { noon to } 2: 00 \mathrm{pm} \\
" ~ " \\
" ~ " \\
" ~ " \\
" ~ " ~ " \\
12: 30 \mathrm{pm} \text { to } 2: 00 \mathrm{pm}\end{array}$ \\
\hline $\begin{array}{l}\text { Lambton Harbour Area: } \\
\text { - Frank Kitts Park } \\
\text { - Kumutoto Plaza, North Queens Wharf } \\
\text { - Taranaki Street Wharf lagoon area } \\
\text { - Post Office Square, Customhouse/Jervois } \\
\text { Quays }\end{array}$ & $\begin{array}{l}10: 00 \mathrm{am} \text { to } 4: 00 \mathrm{pm} \\
12 \text { noon to } 2: 00 \mathrm{pm} \\
12 \text { noon to } 2: 00 \mathrm{pm} \\
12 \text { noon to } 1: 30 \mathrm{pm}\end{array}$ \\
\hline
\end{tabular}


APPENDIX TWO: MEAN SPEED CONTOUR DIAGRAMS

Contour Diagrams generated for mean wind speeds not included in Chapter 7.

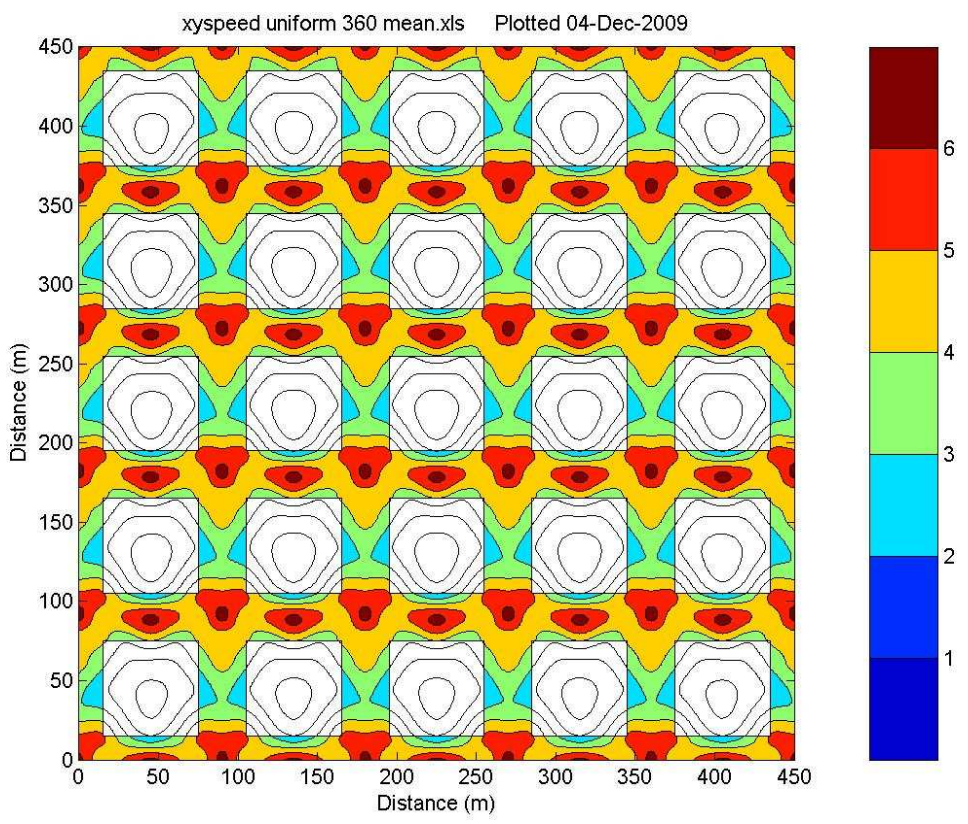

Figure 50: Contour diagram produced with a uniform distribution of buildings for mean wind speeds at a direction of $360^{\circ}$.

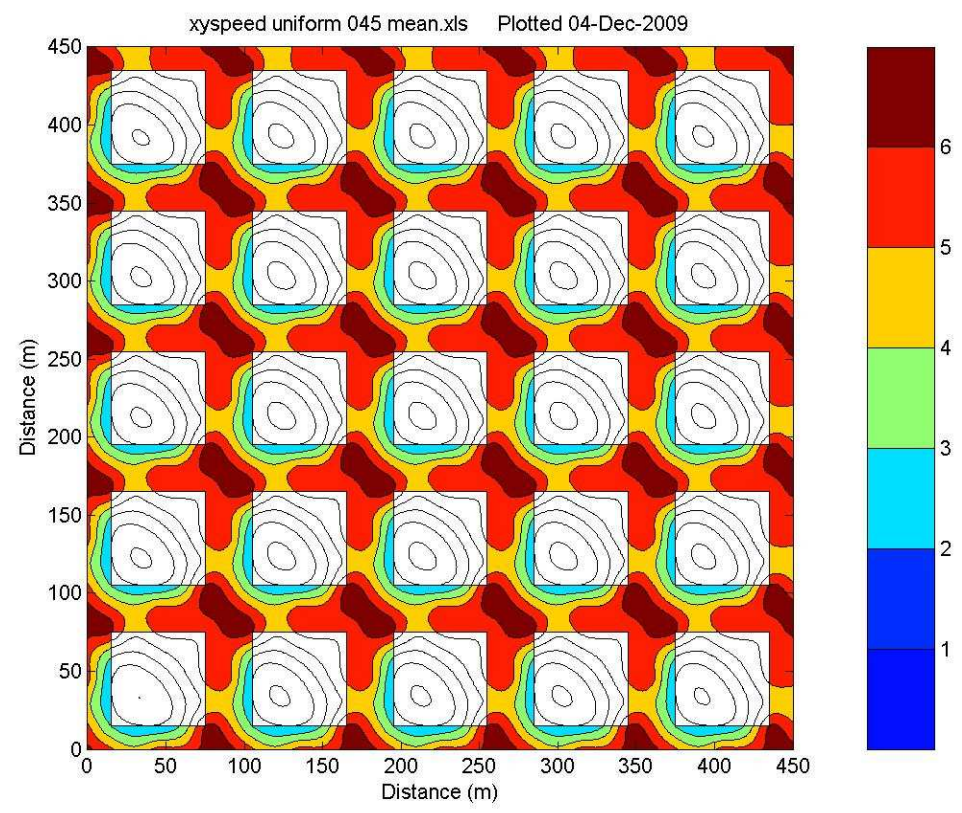

Figure 51: Contour diagram generated with a uniform distribution of buildings for mean wind speeds at a direction of $45^{\circ}$. 


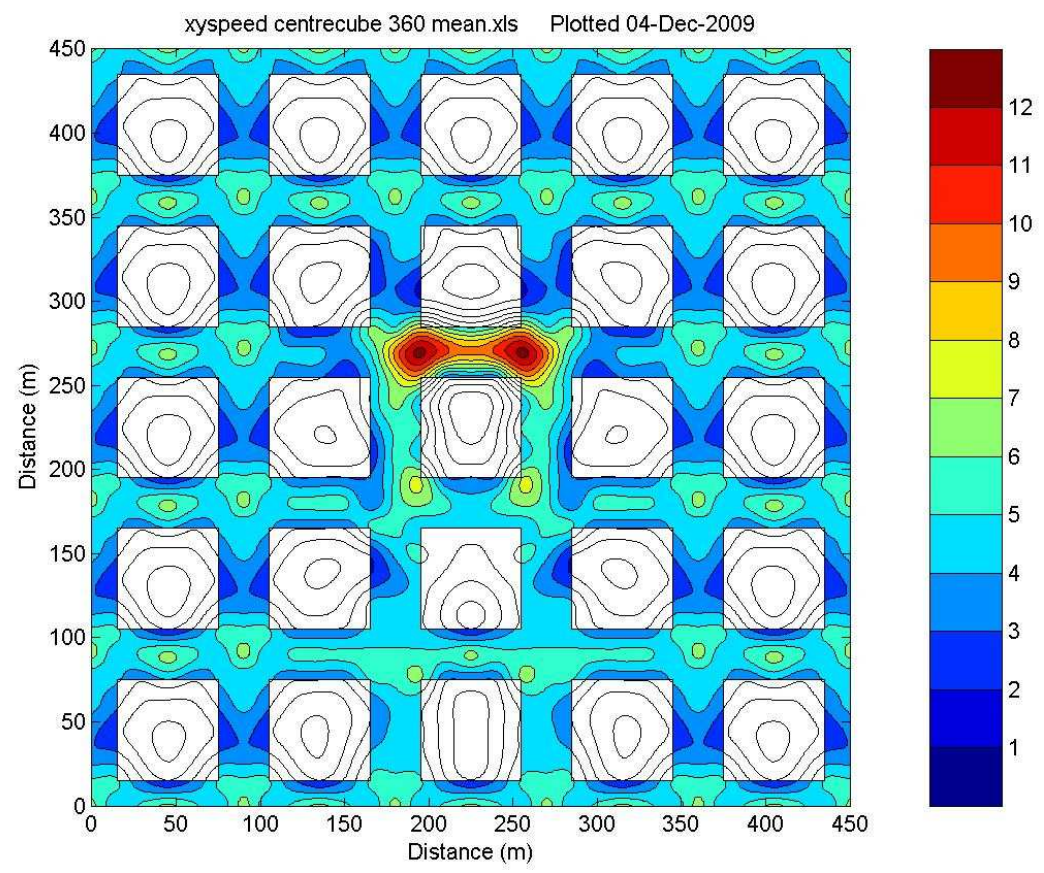

Figure 52: Contour diagram produced with a uniform distribution of buildings replacing the central half cube with a full cube, for mean wind speeds at a direction of $360^{\circ}$.

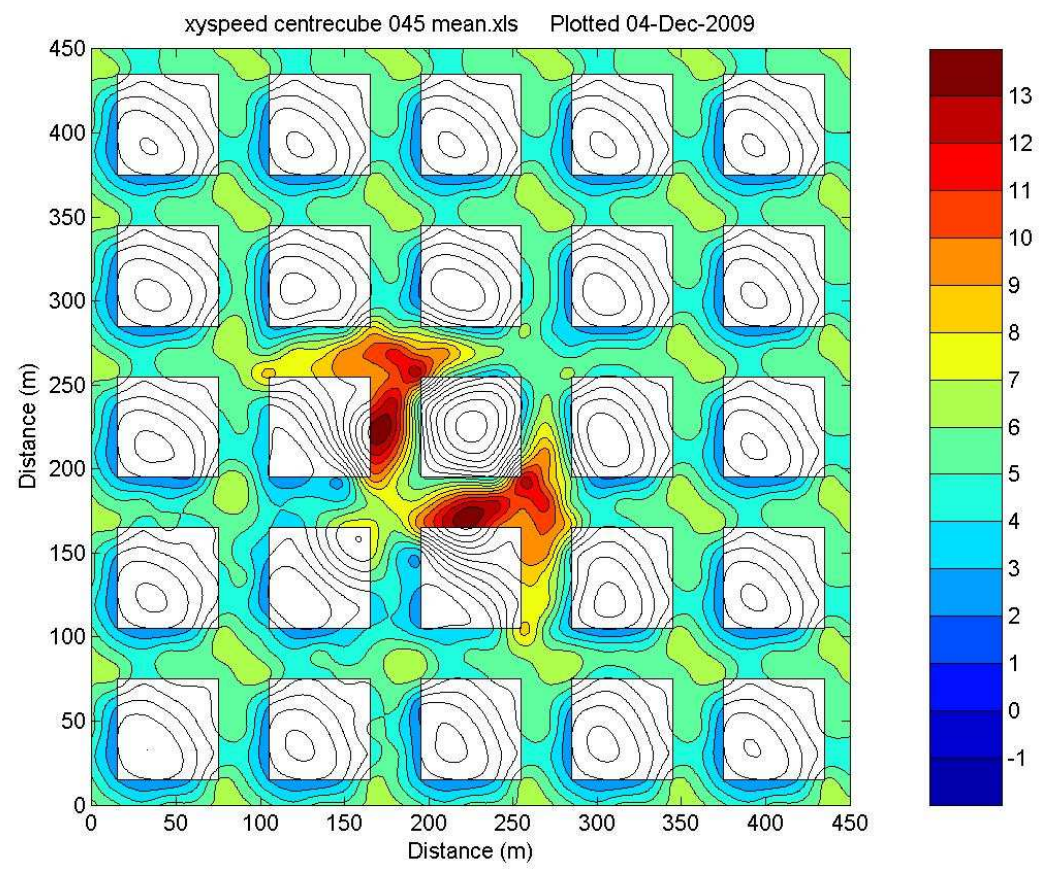

Figure 53: Contour diagram produced with a uniform distribution of buildings replacing the central half cube with a full cube, for mean wind speeds at a direction of $45^{\circ}$. 


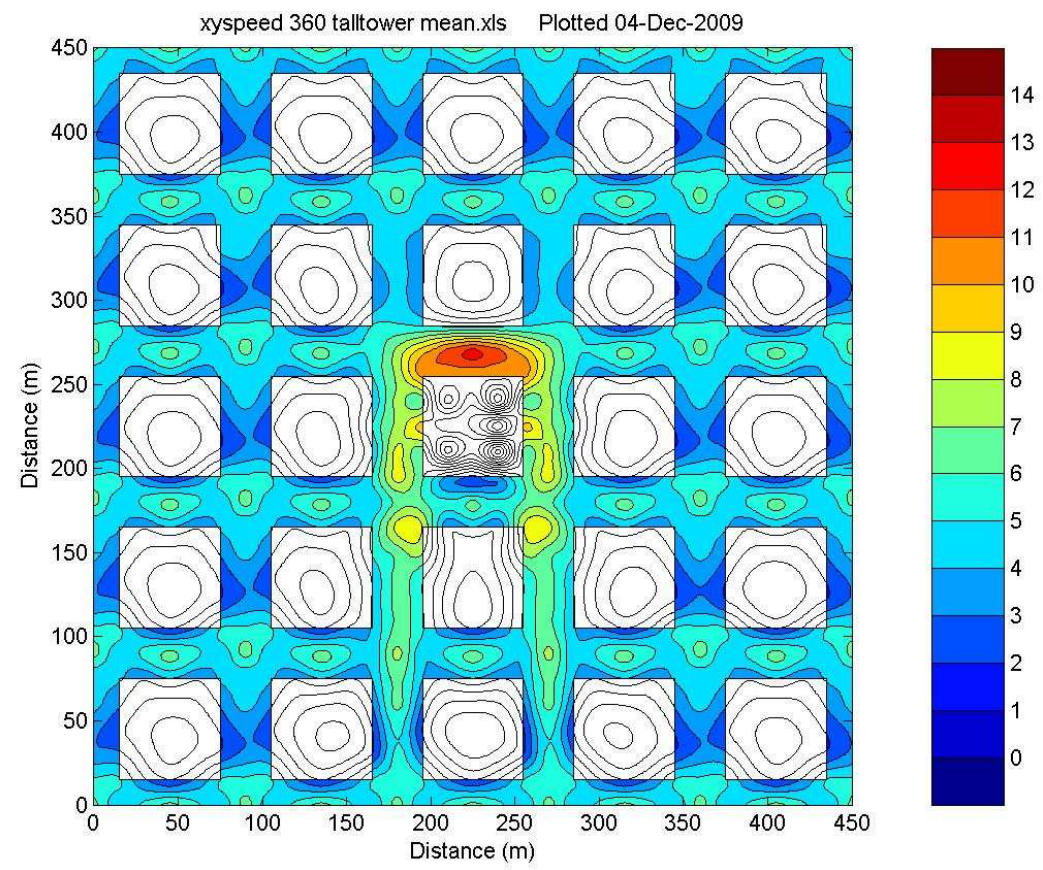

Figure 54: Contour diagram produced with a uniform distribution of buildings replacing the central half cube with a tall tower, for mean wind speeds at a direction of $360^{\circ}$.

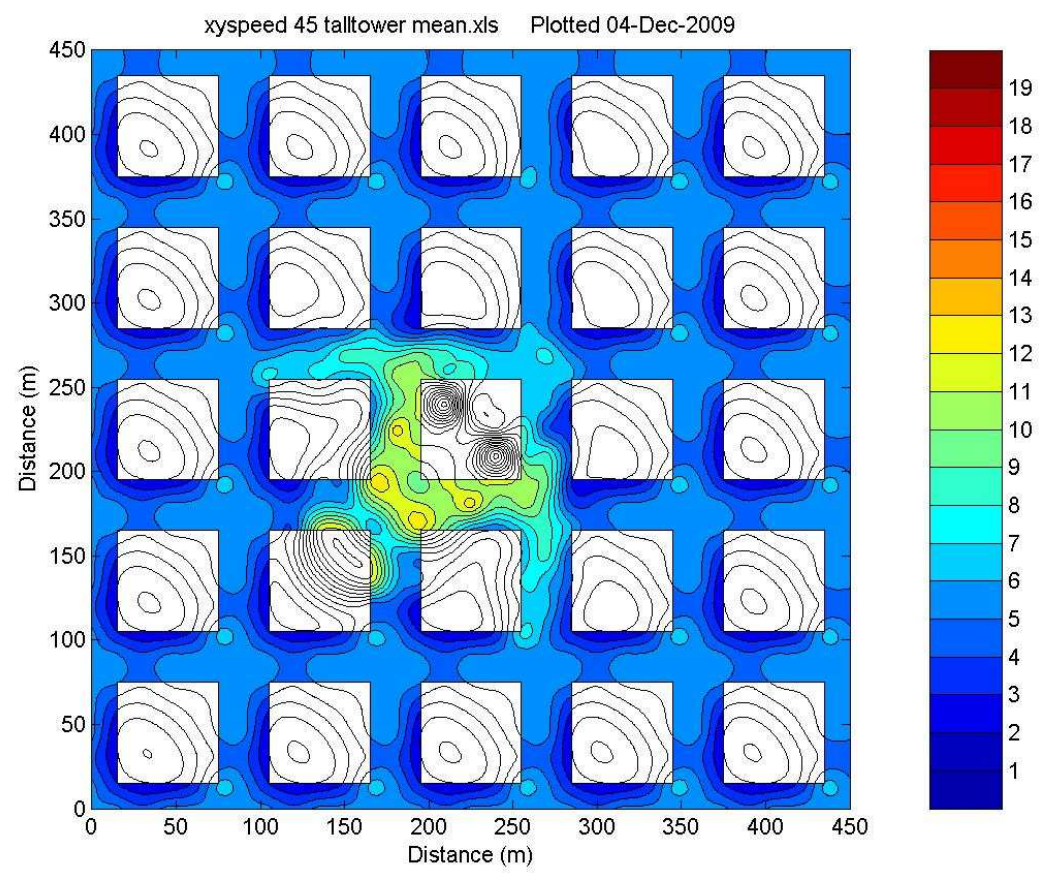

Figure 55: Contour diagram produced with a uniform distribution of buildings replacing the central half cube with a tall tower, for mean wind speeds at a direction of $45^{\circ}$. 
APPENDIX THREE: MEAN CHANGE IN WIND SPEED CONTOUR DIAGRAMS

Surplus change in wind speed diagrams not included within Chapter 7.1
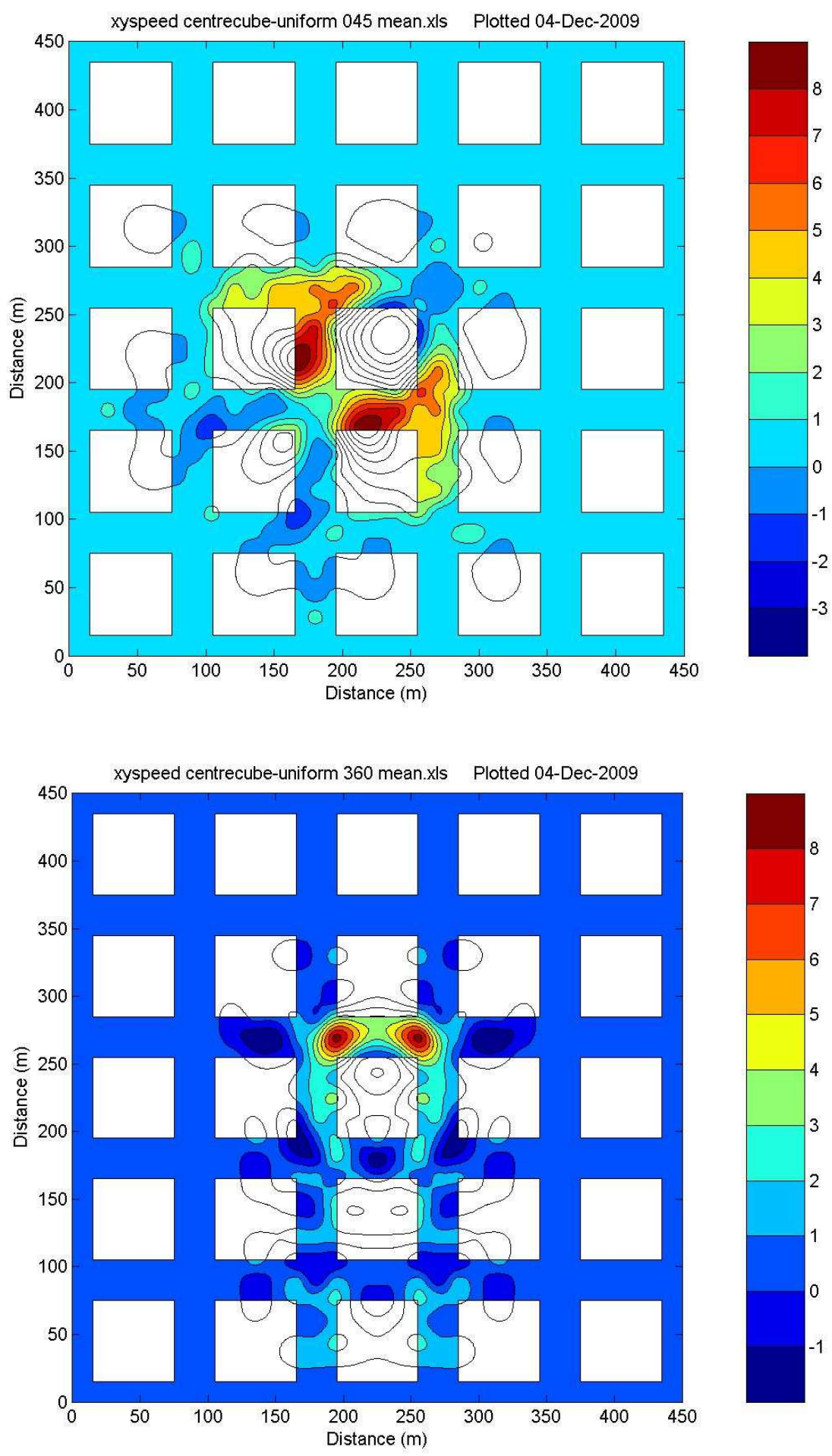


\section{APPENDIX FOUR: MATLAB SCRIPTS}

MATLAB SCRIPTS the following are the actual scripts used in MATLAB to generate contours. Listed in chronological order they illustrate the progression and development of the script.

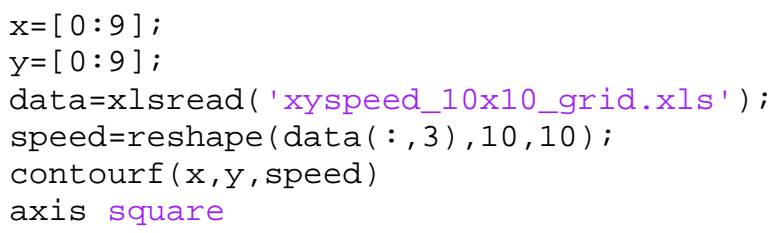

CONTOURING A LARGE GRID OF DATA

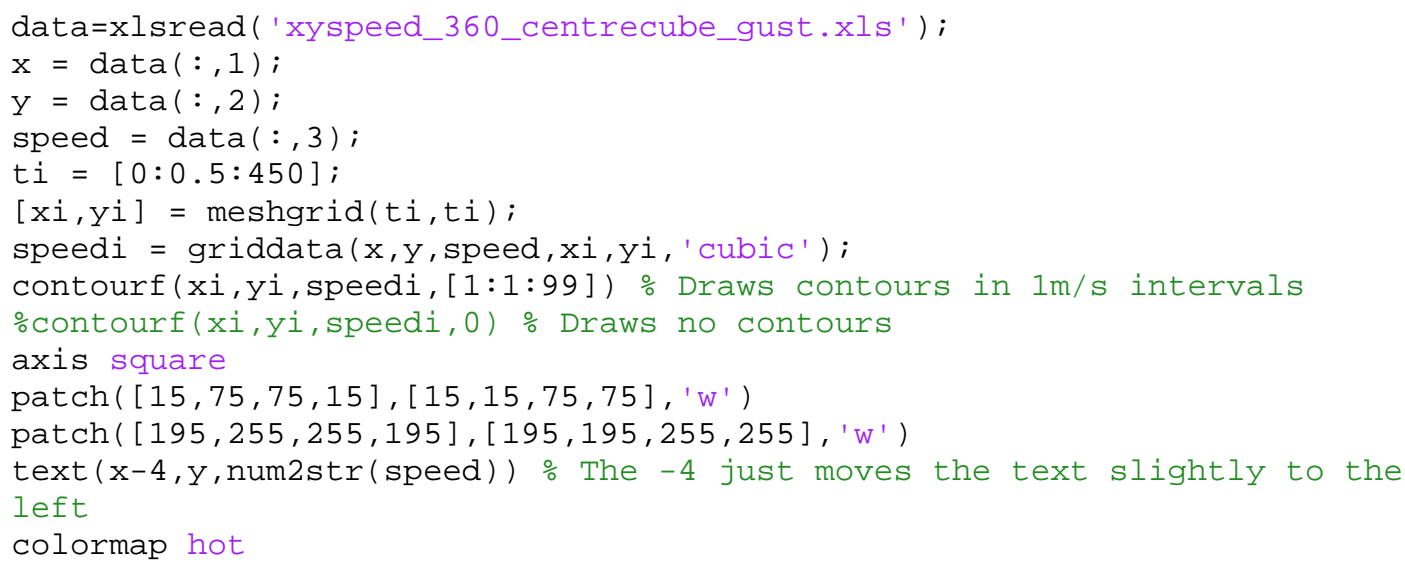


CONTOURING X,Y,SPEED WITH PATCHES

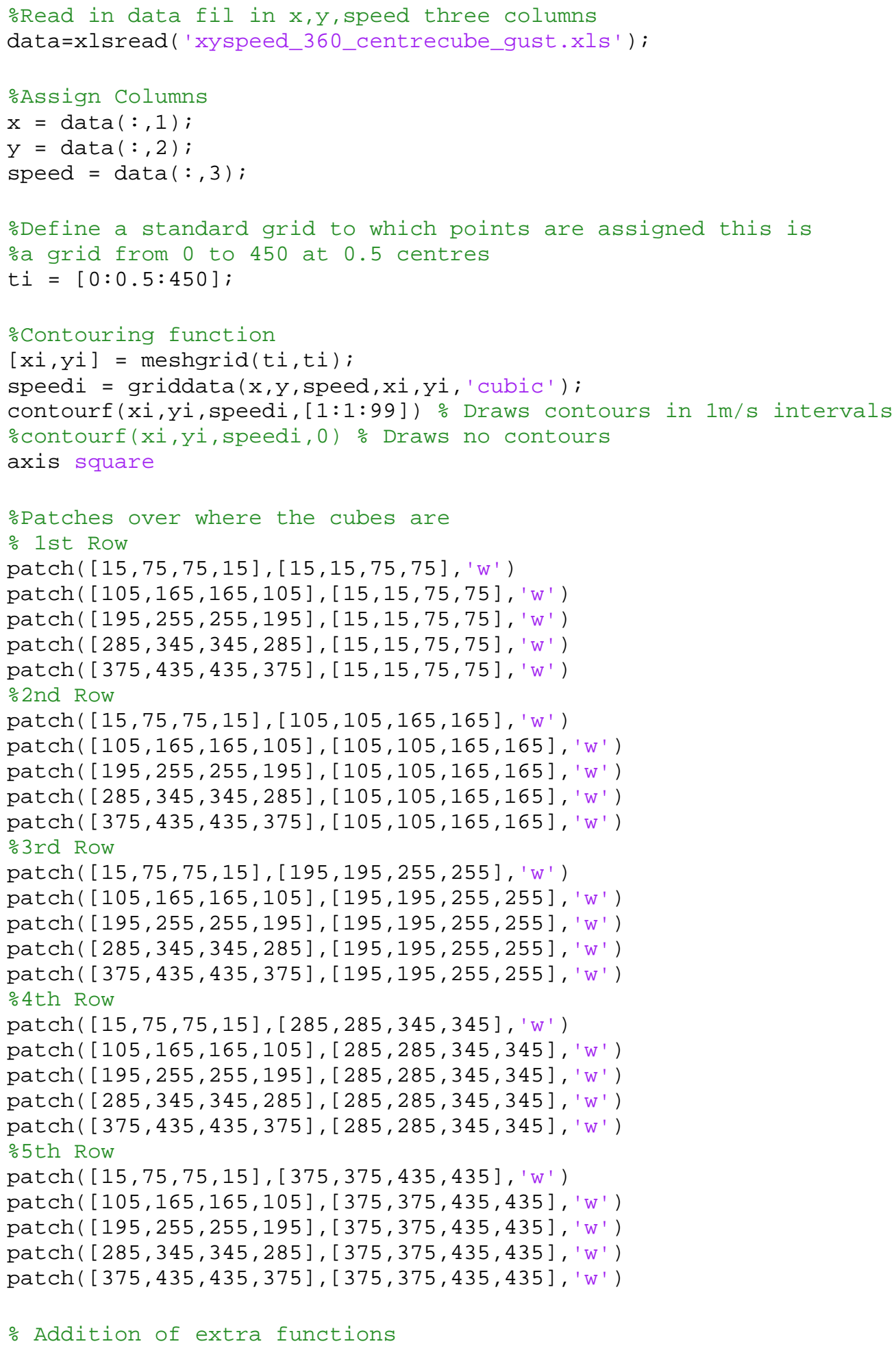


otext ( $\mathrm{x}-4, \mathrm{y}$, num2str(speed)) \% The -4 just moves the text slightly to the left

colormap jet

colorbar

xlabel ('Distance (m)')

ylabel ('Distance (m)')

title('Contouring 360 Degrees Centrecube') 
CONTOURING WITH PSEUDO MEASUREMENTS MANUALLY ADDED

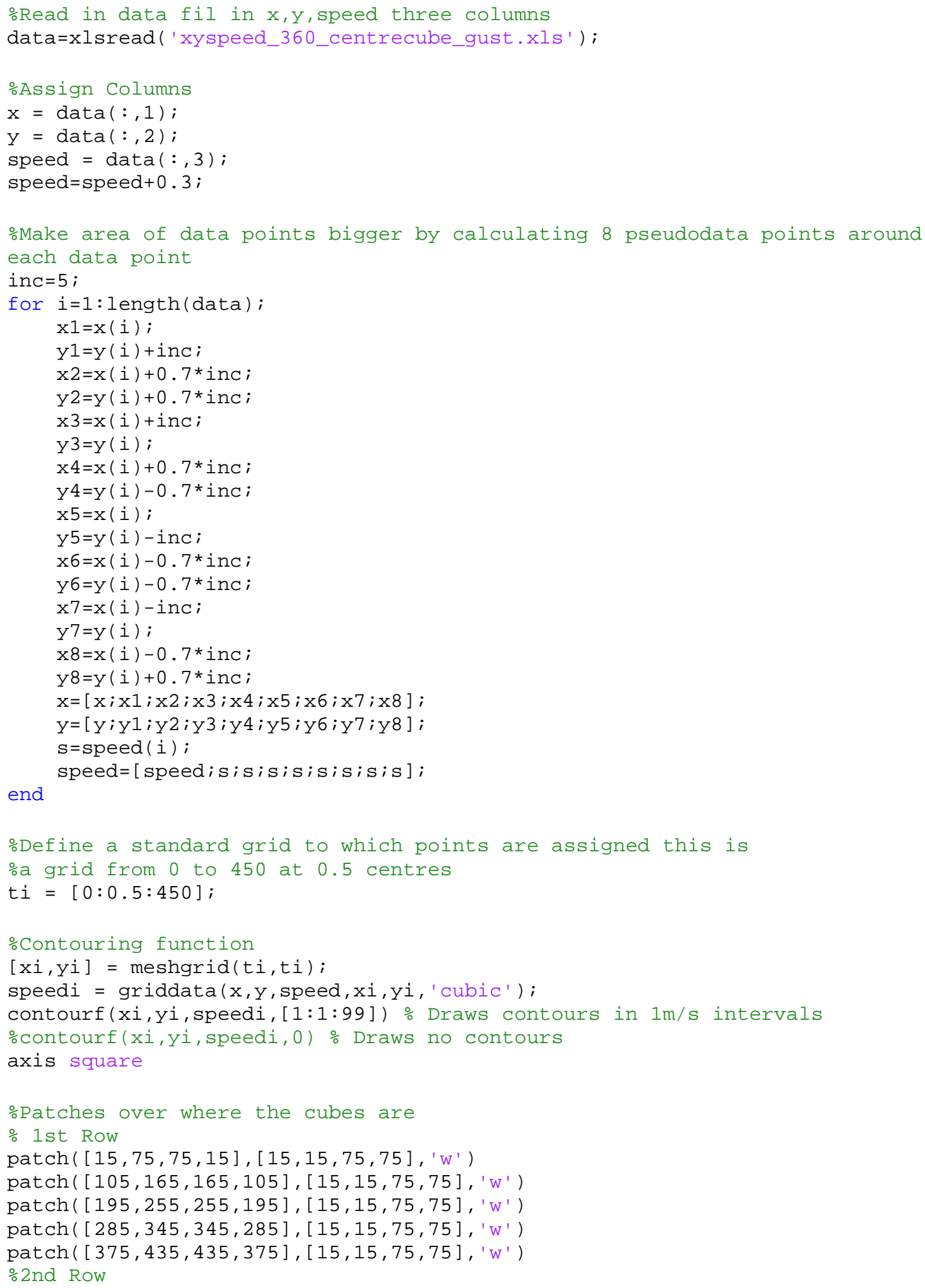




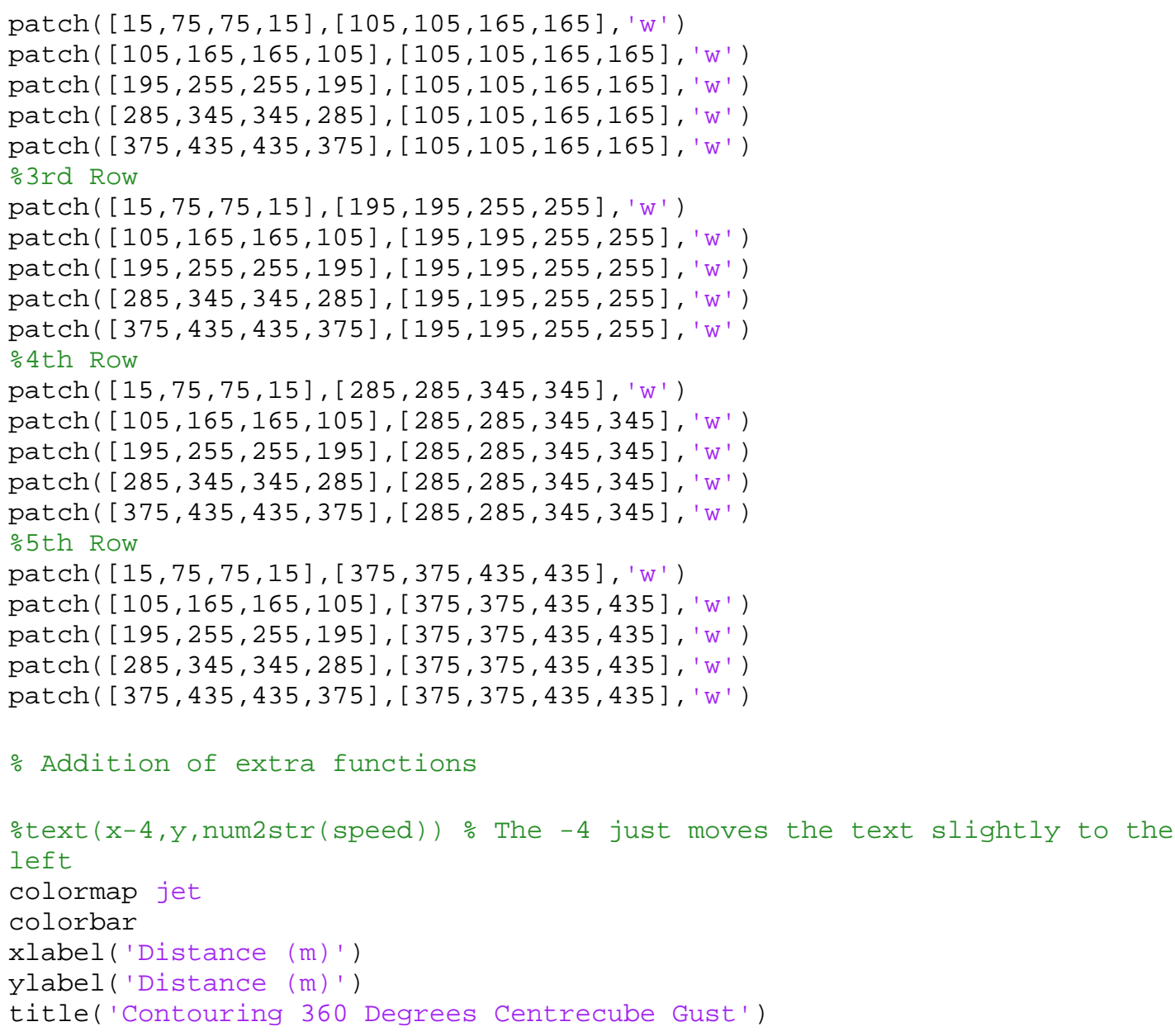




\section{ANALYSING MULTIPLE INLUT FILES AUTOMATICALLY}

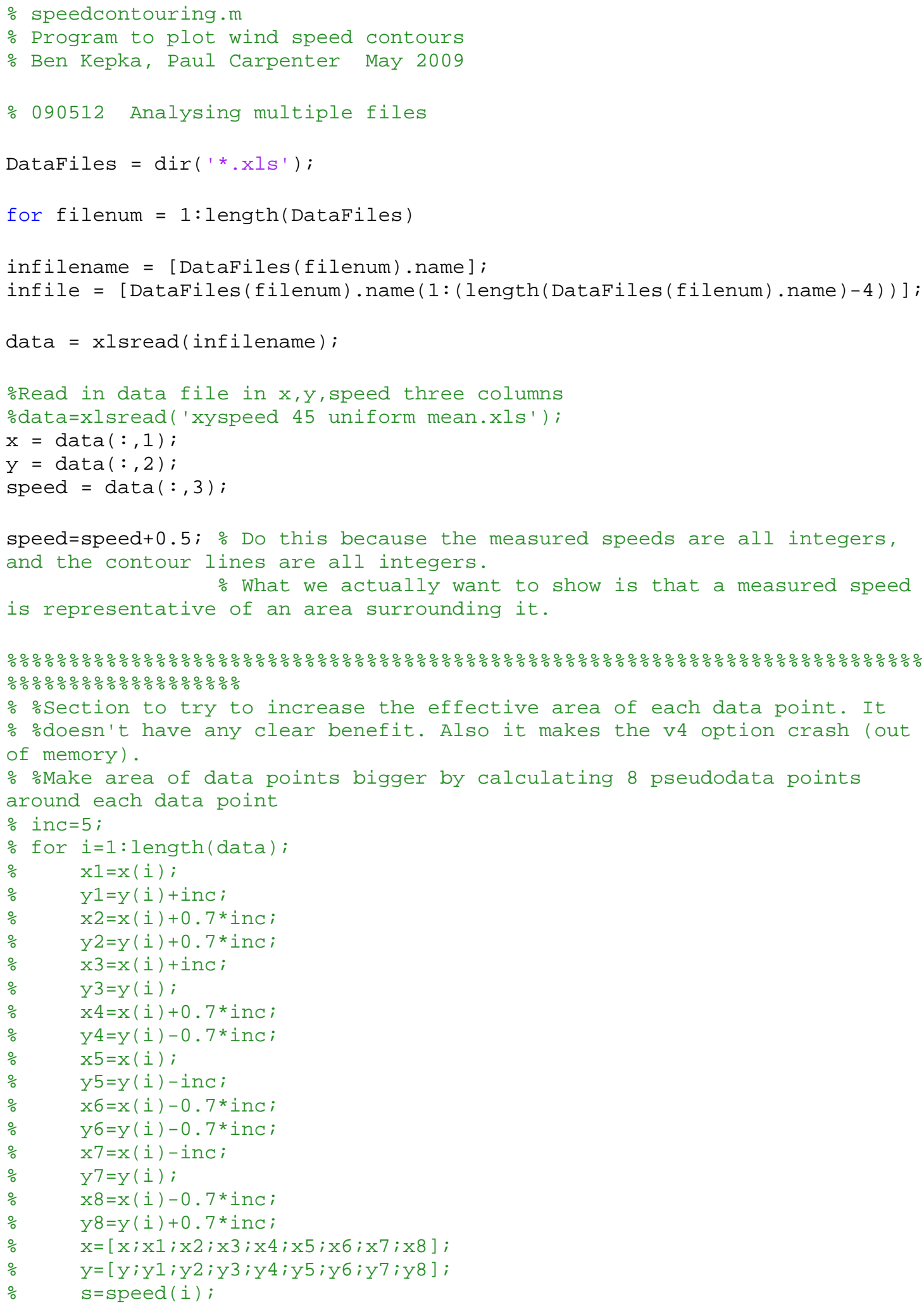




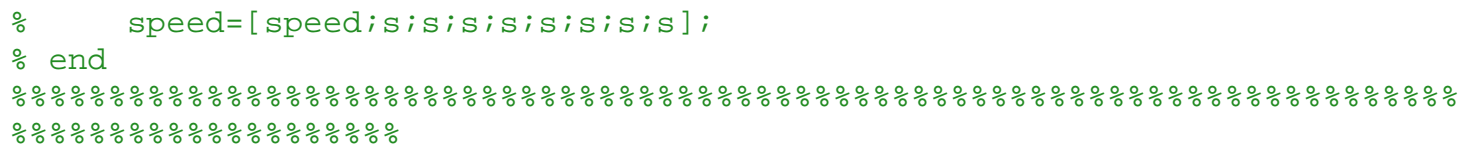




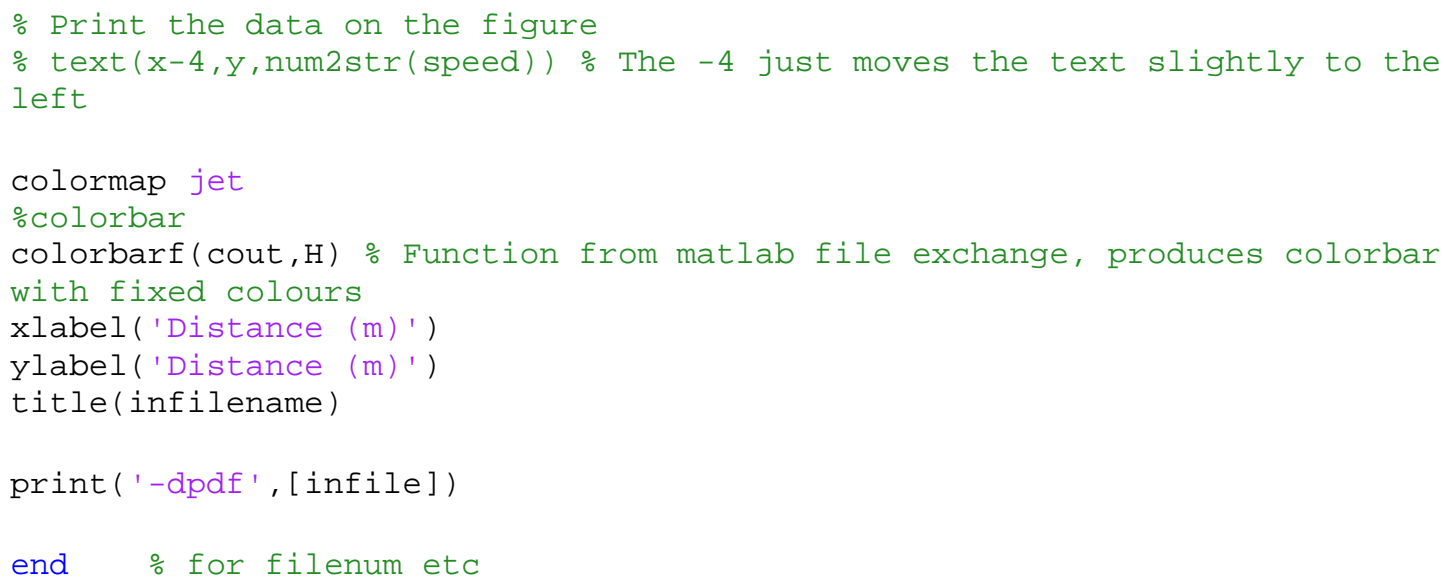


COLORBARF SCRIPT

This script was obtained form the MATLAB file exchange.

Source: http://www.mathworks.com/matlabcentral/fileexchange/1135-colorbarf

\section{Retrieved: 29 May 2009}

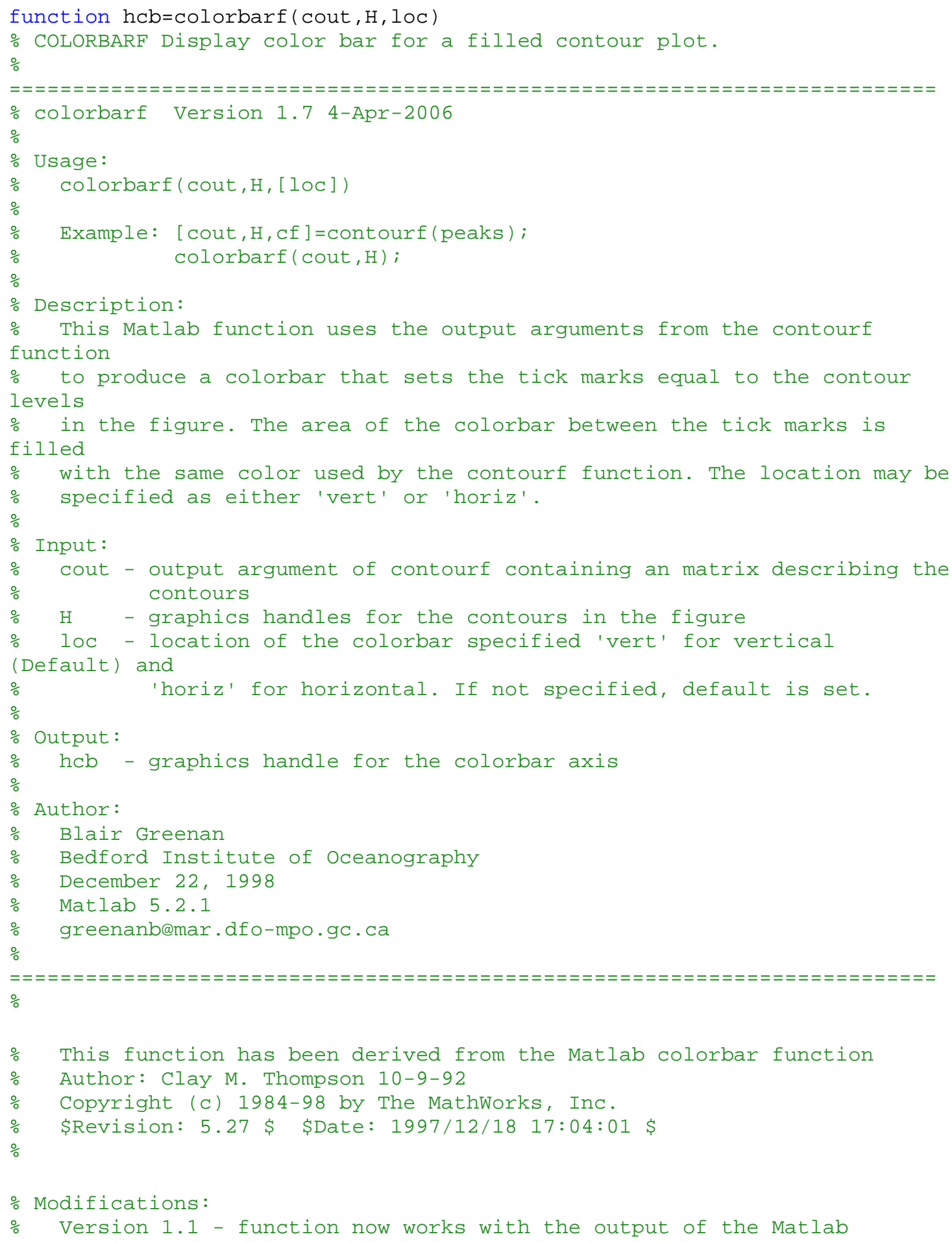




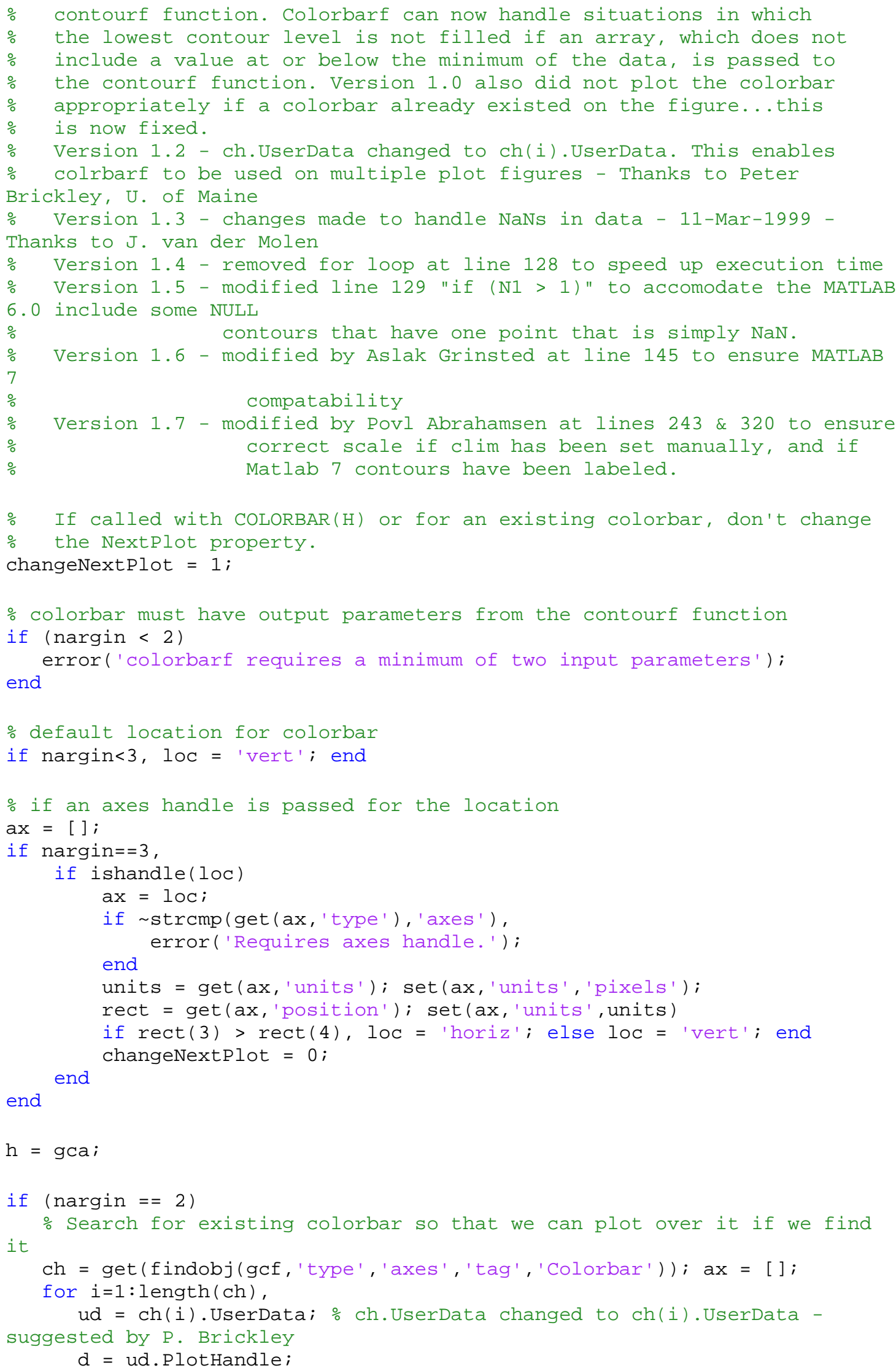




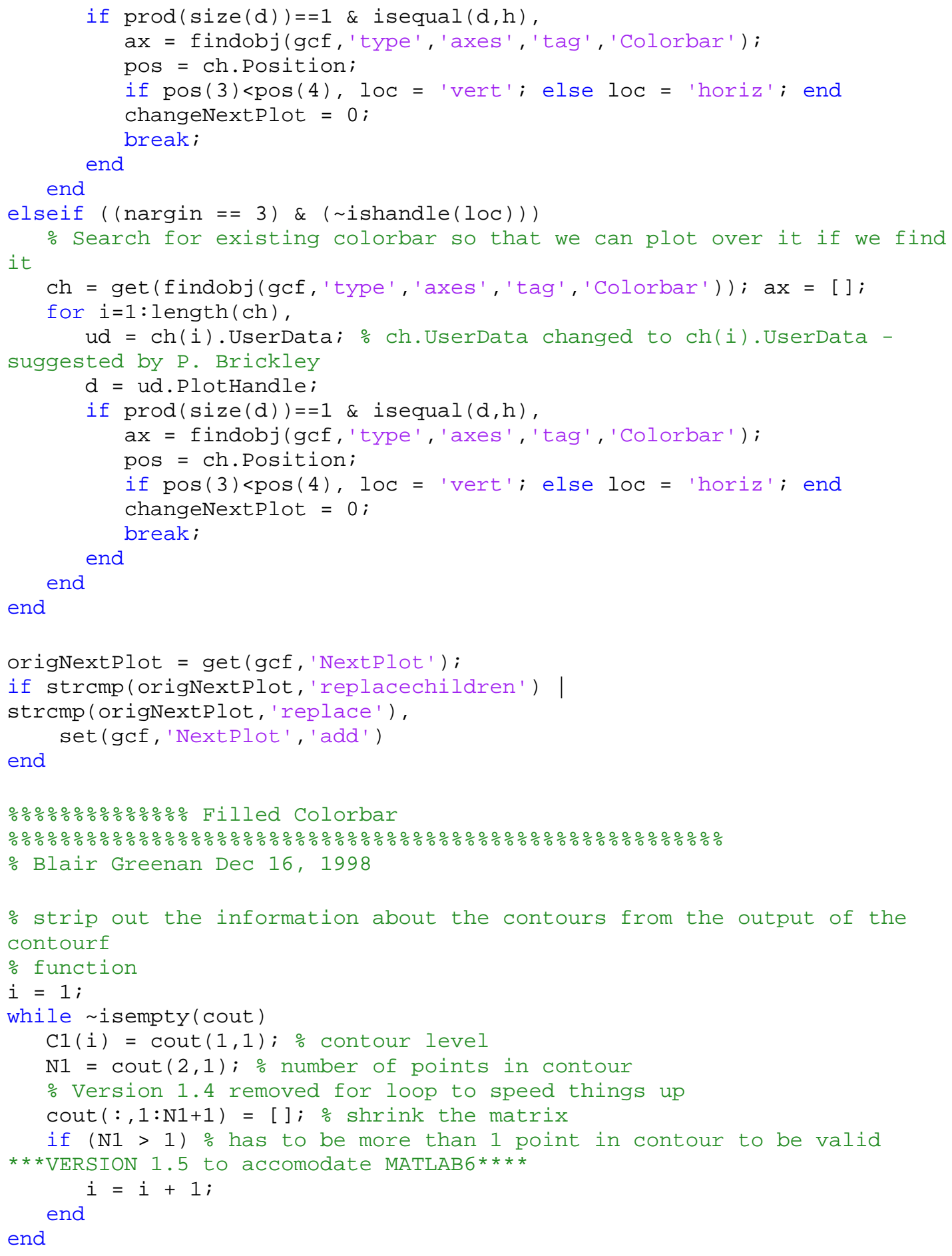


H=findobj (H, 'type', 'patch'); 으의 1.7 fixed by Povl Abrahamsen so it works with labeled contours, too.

end

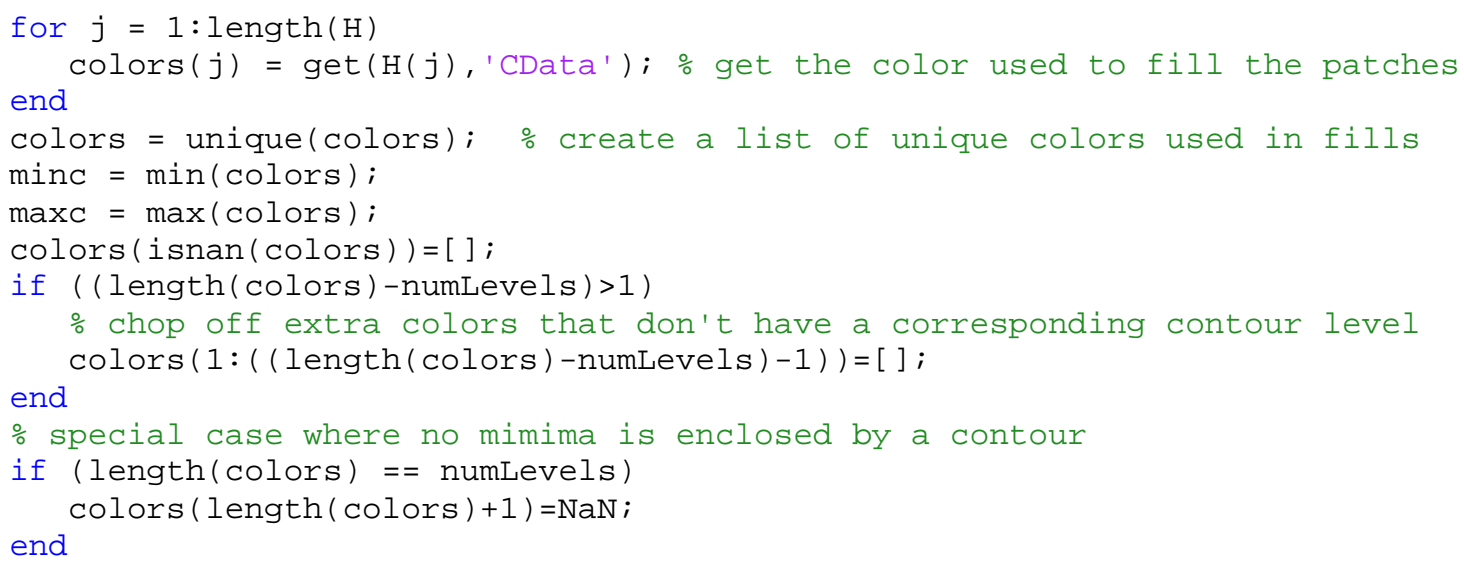




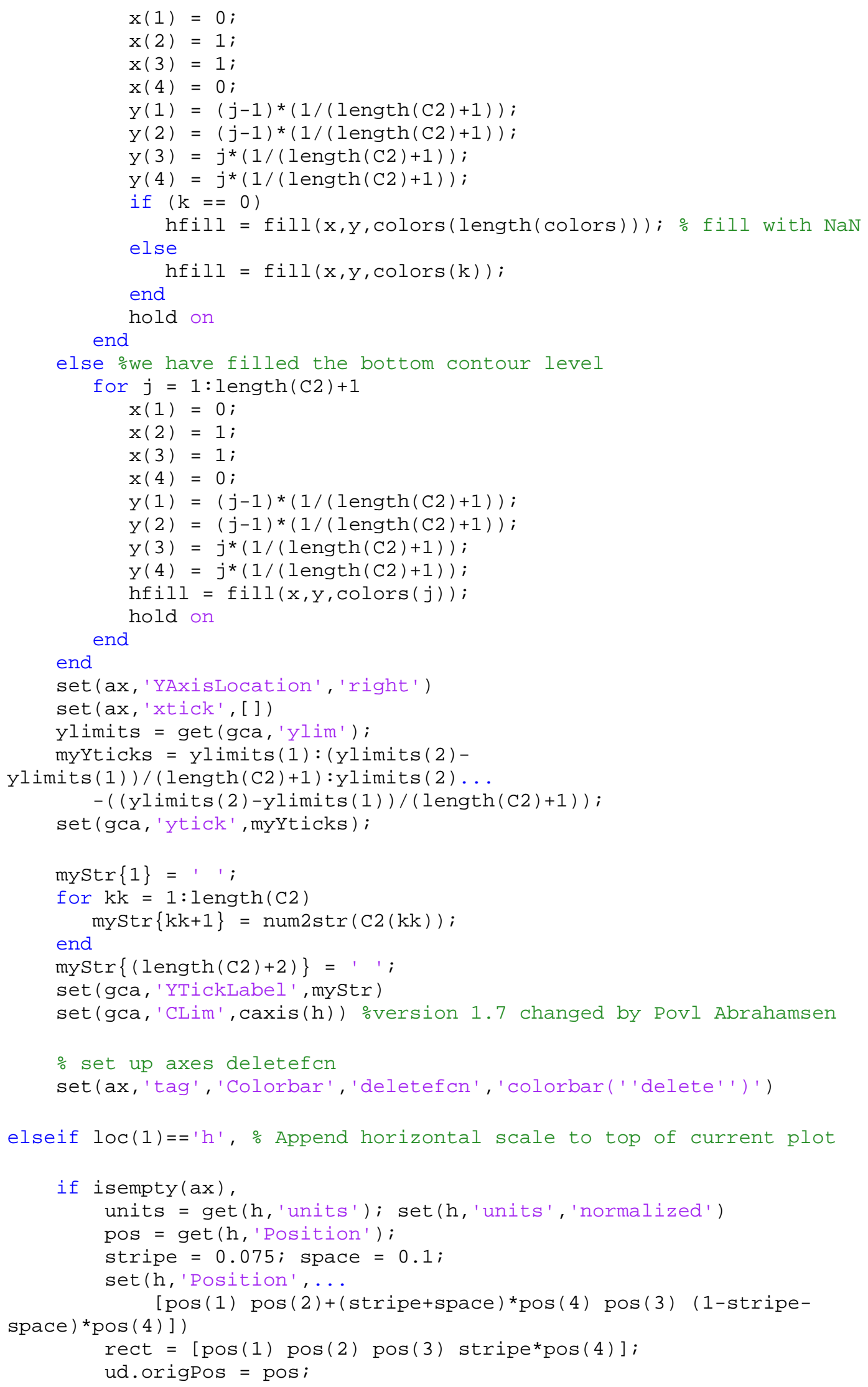




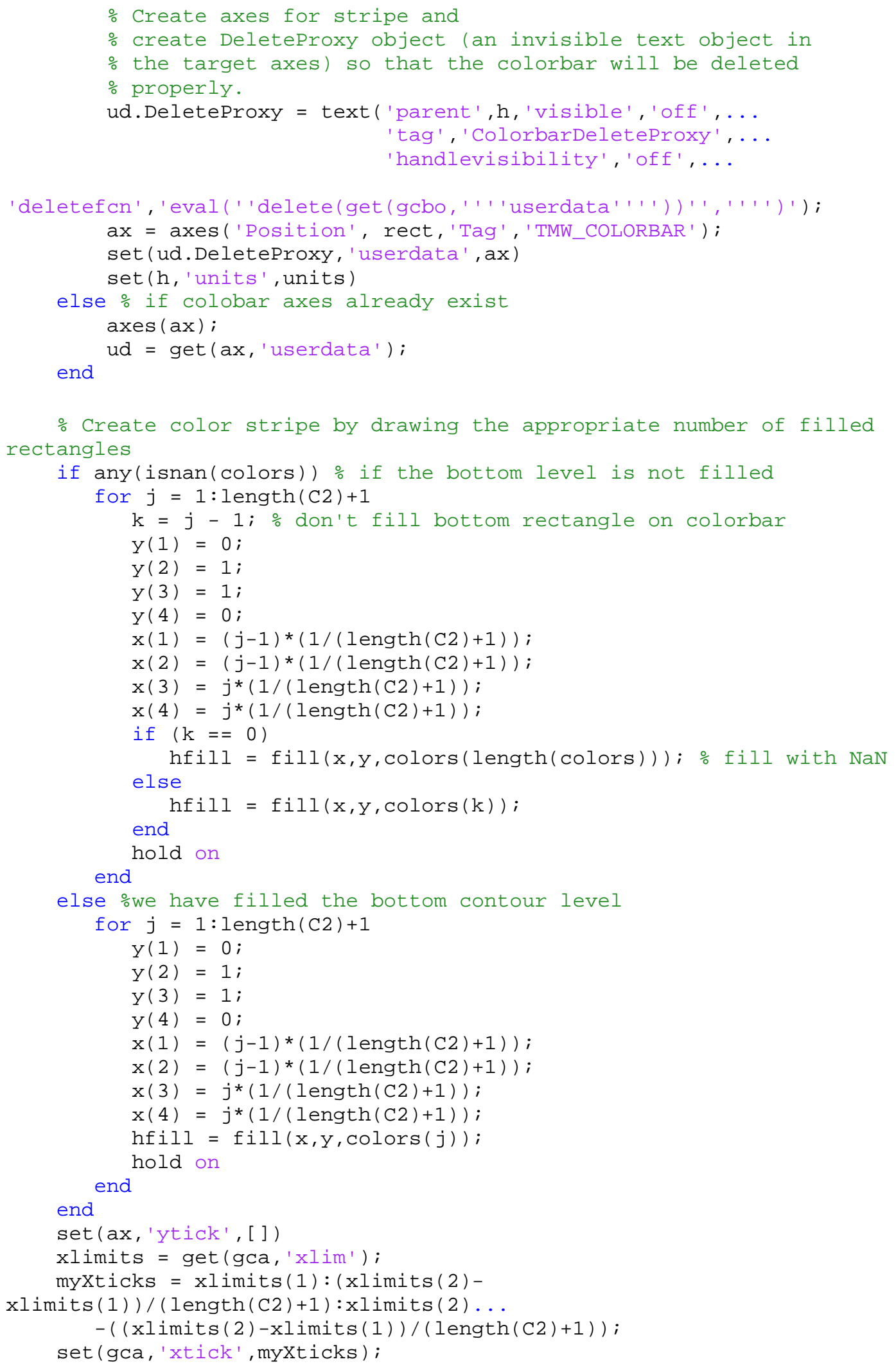




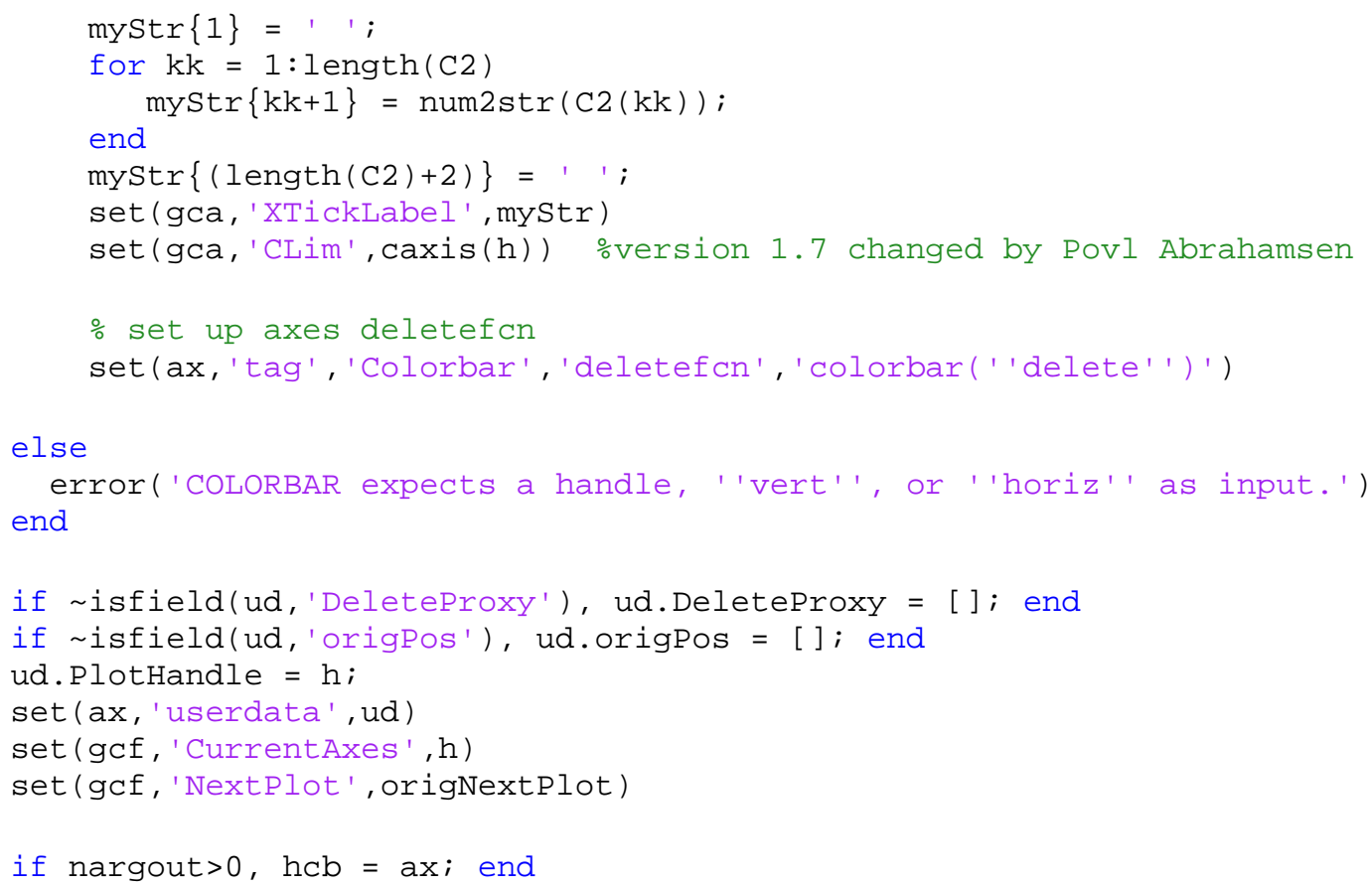




\section{ADDTITION OF EXTERNAL PATCH DATA}

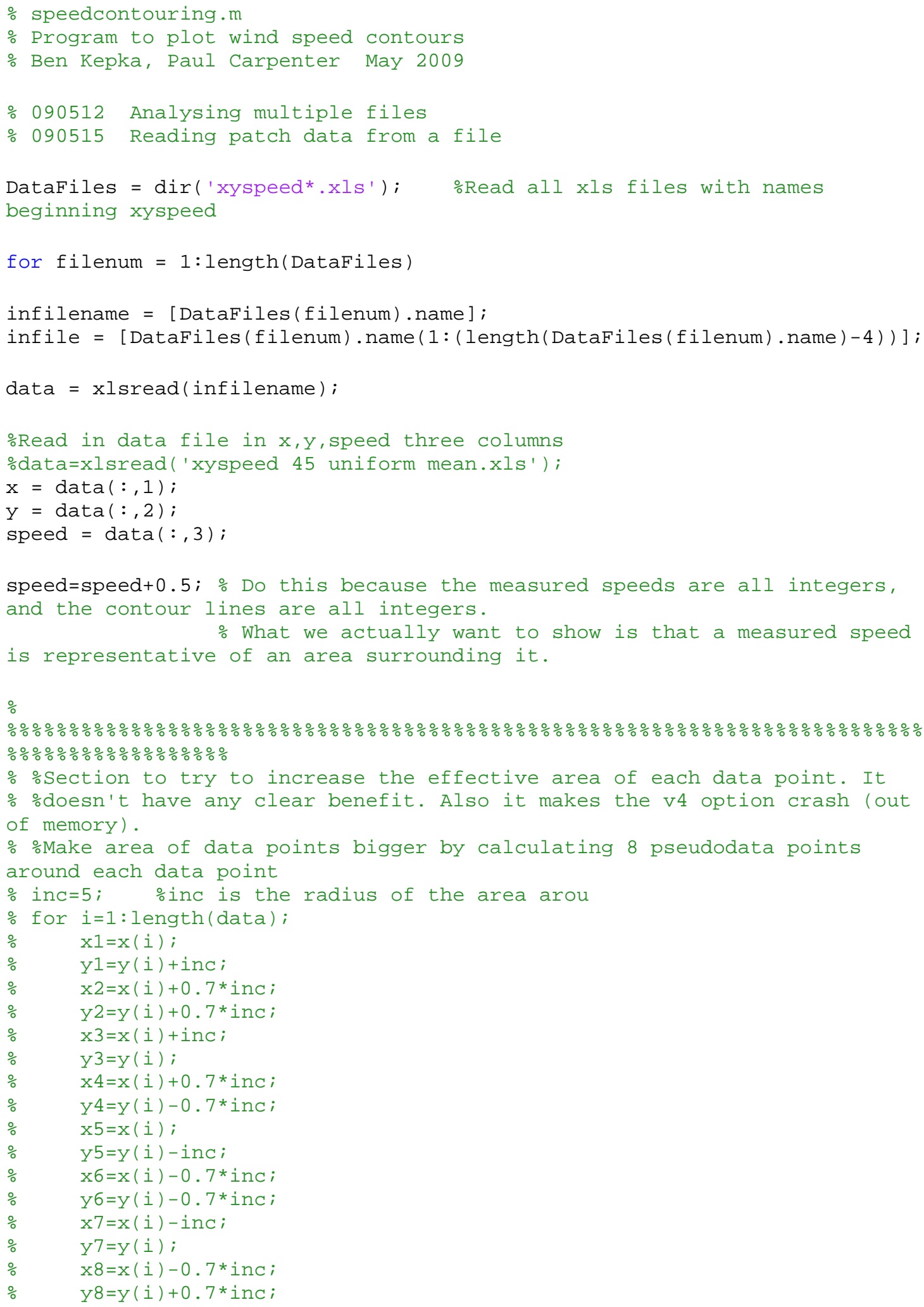




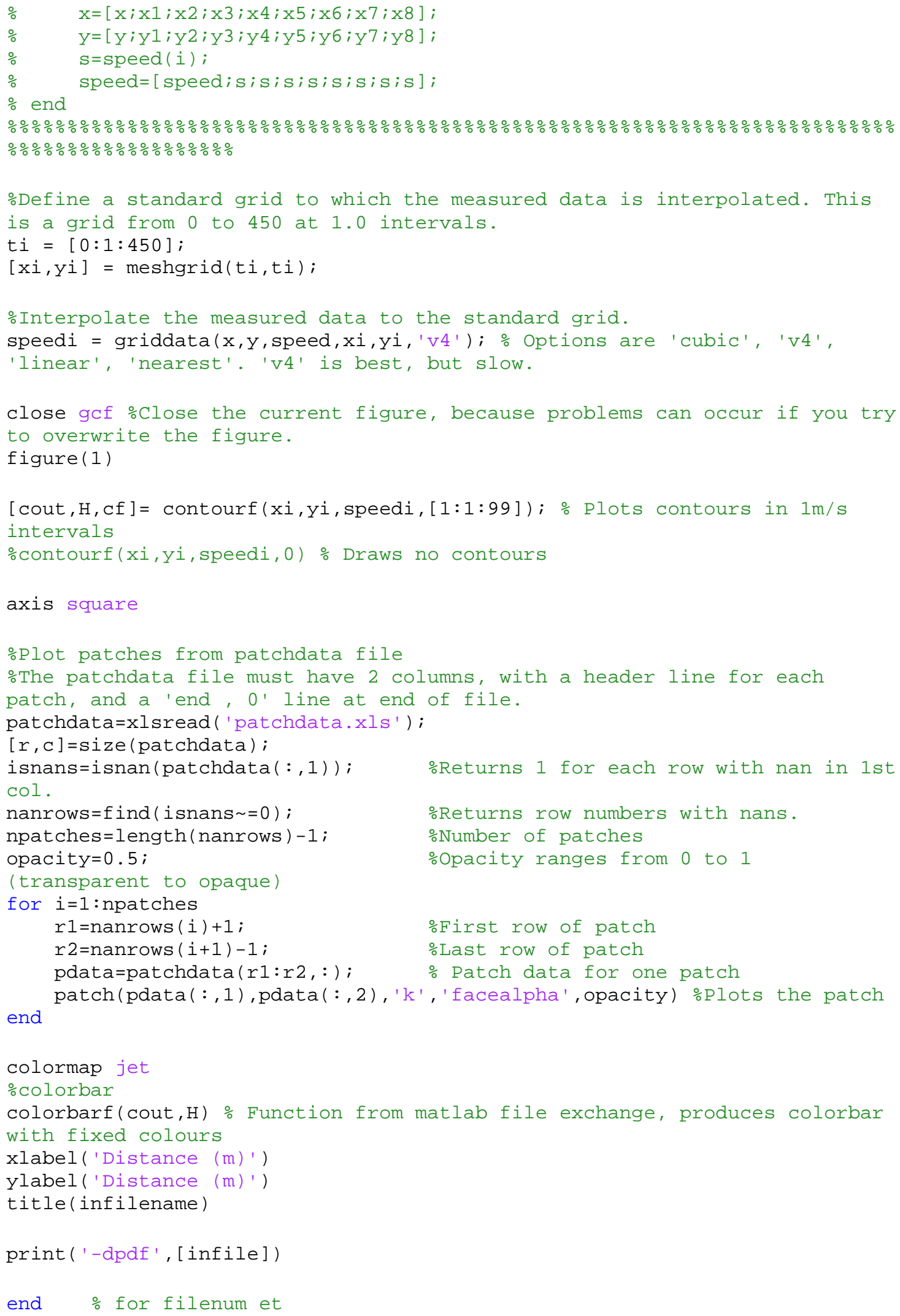


REFINEMENT OF THE EXTERNAL PATCHING

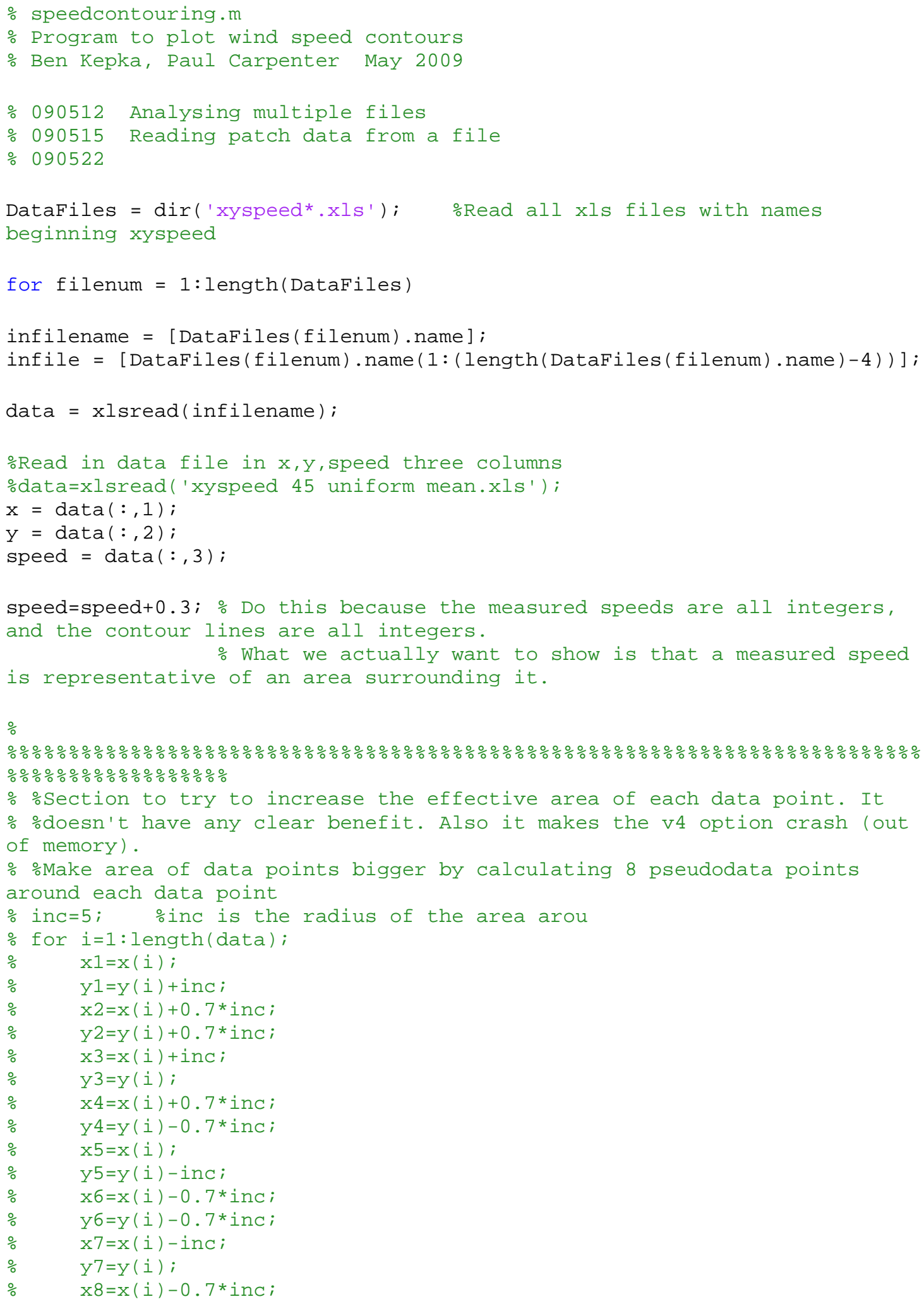




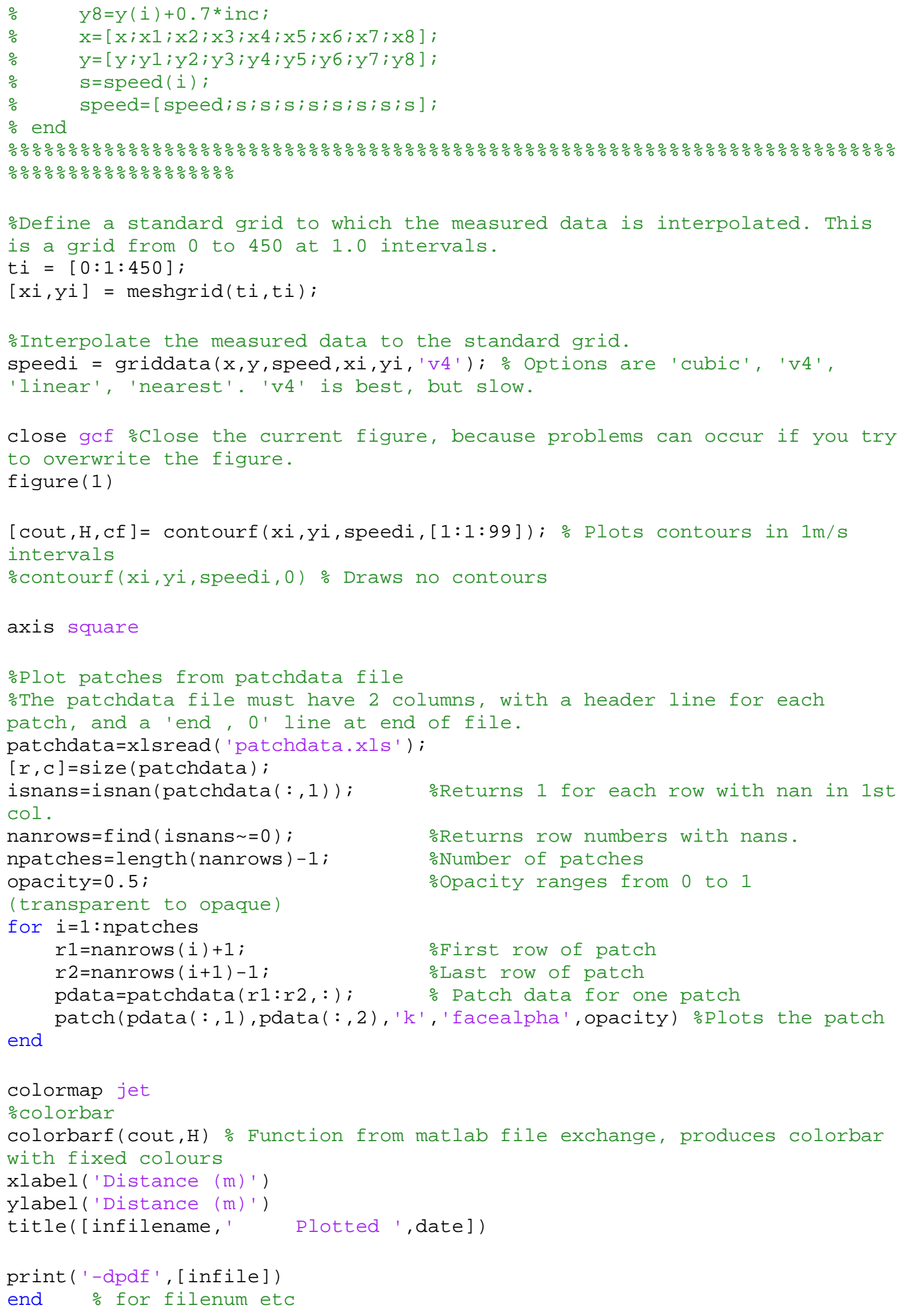


FINAL CONTOURING SCRIPT

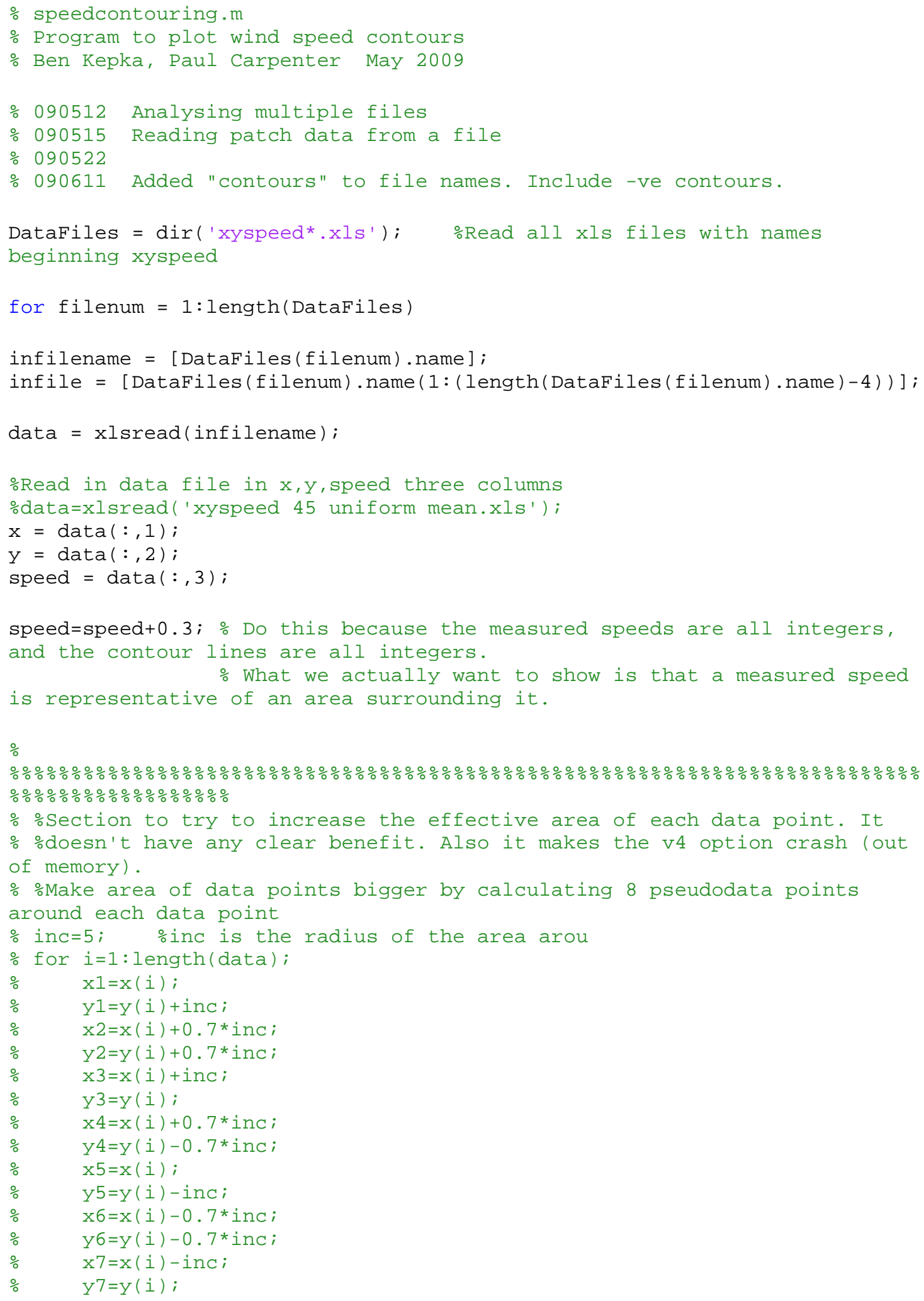




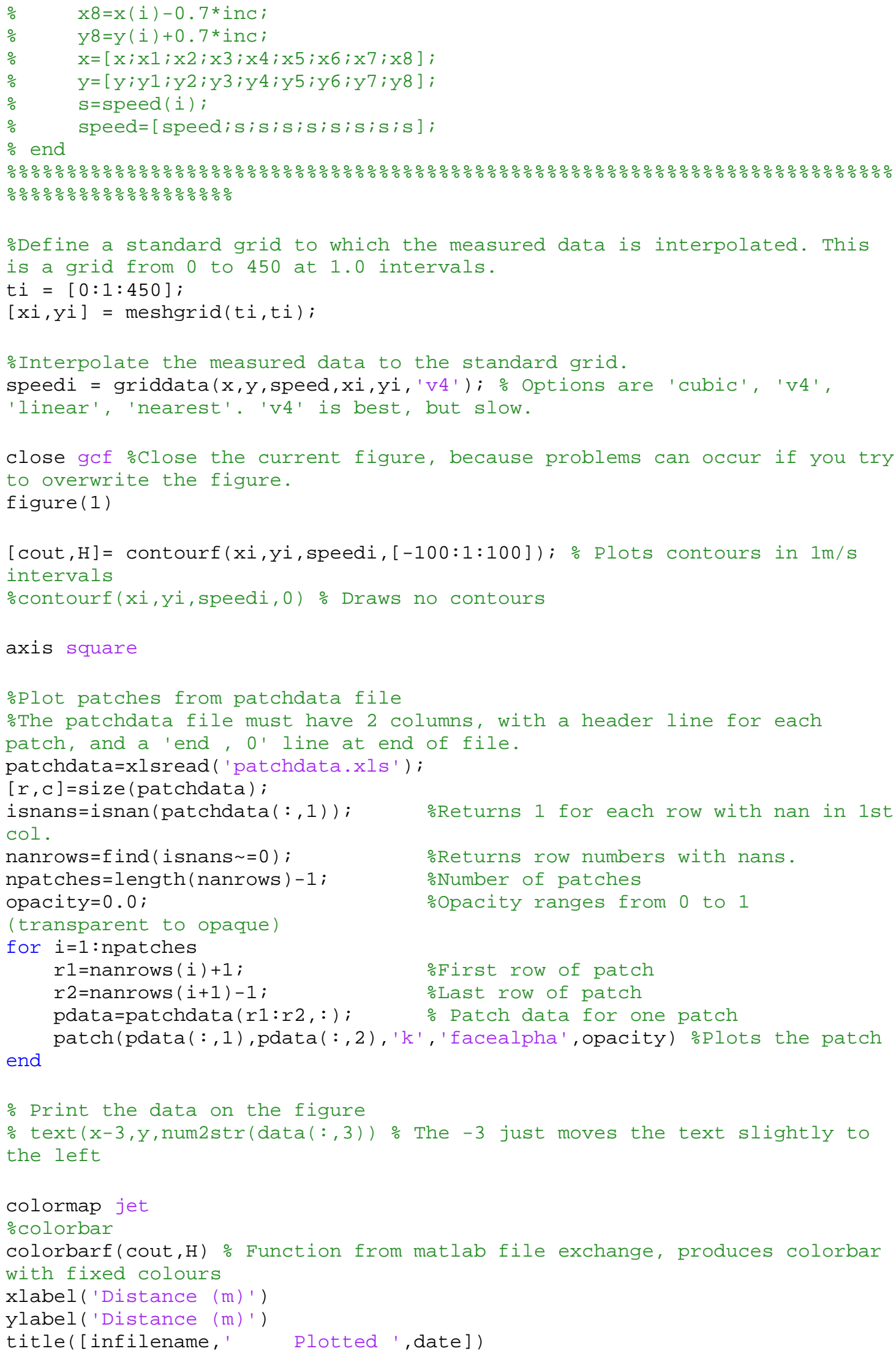


print('-dpdf', [infile, ' contours'])

end $\%$ for filenum etc 

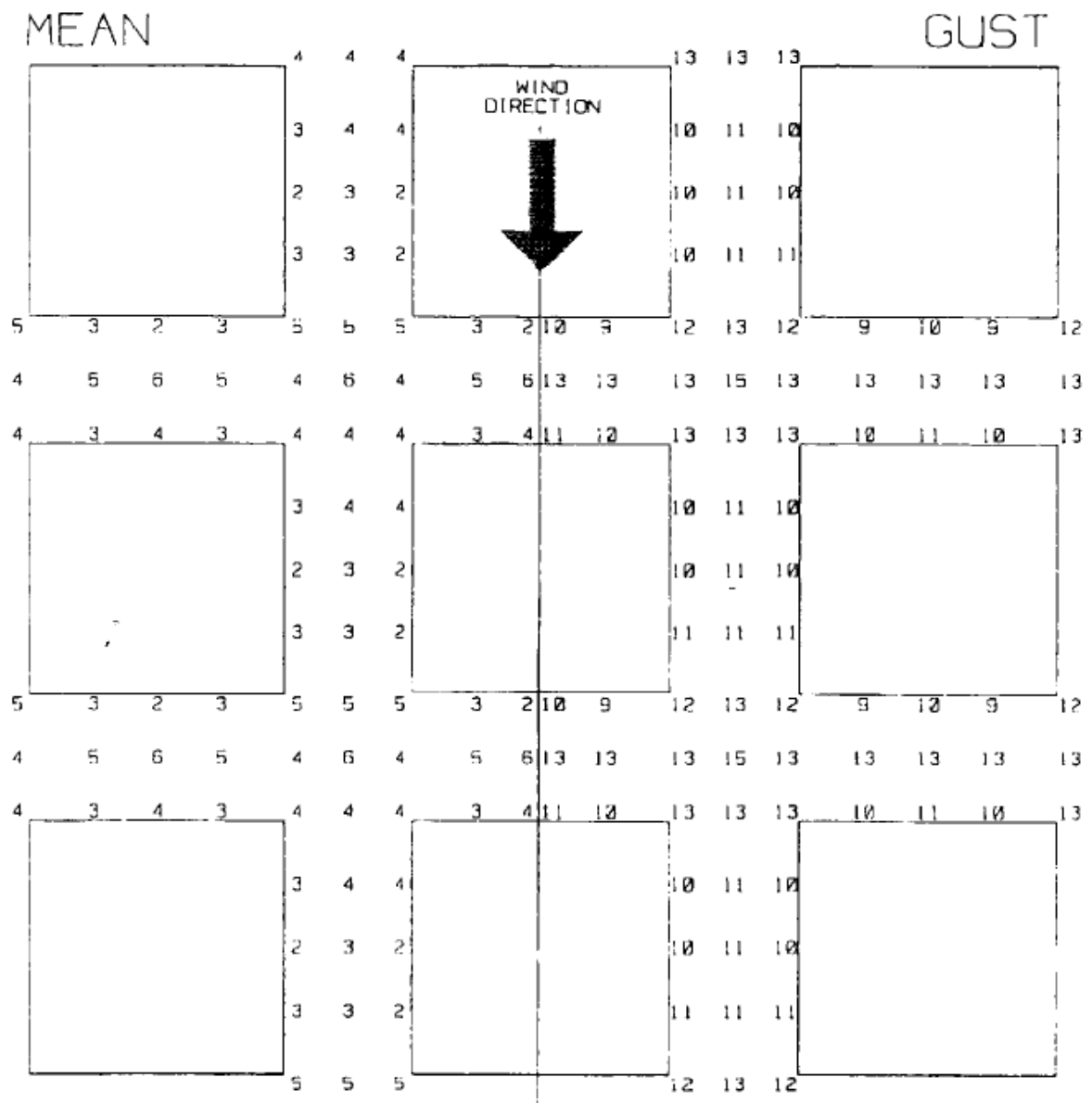

1011
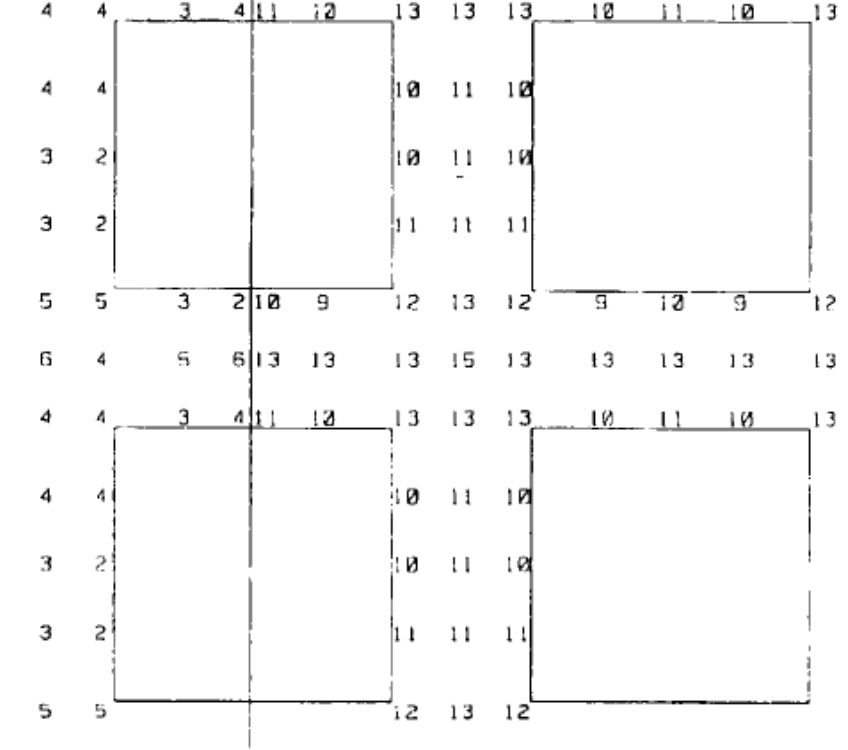

Figure 56: Original data for uniform city block configuration $360^{\circ}$ wind direction. Source: Jamieson et. al. (1992) 


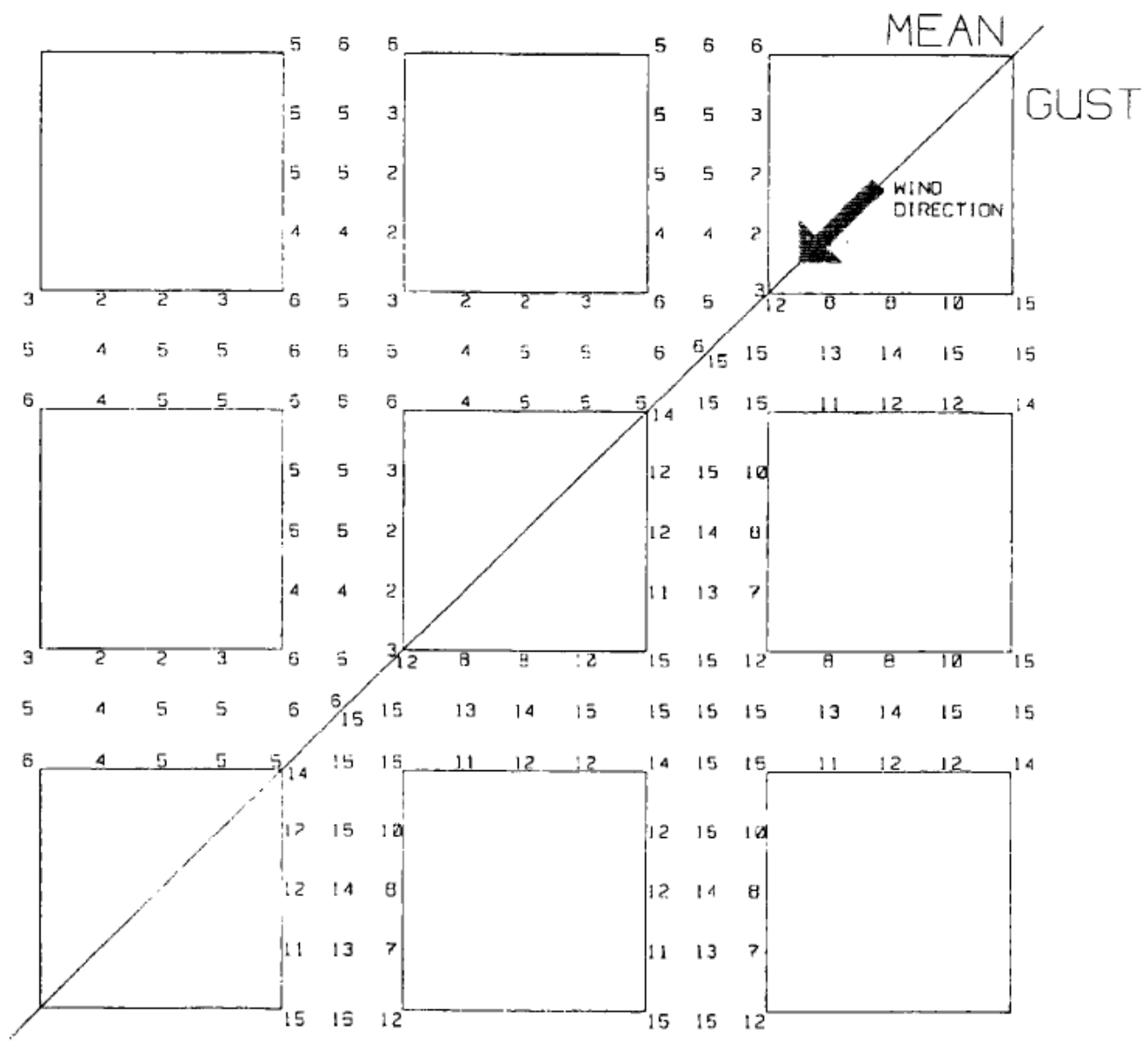

Figure 57: Original data for uniform city block configuration $45^{\circ}$ wind direction. Source: Jamieson et. al. (1992) 

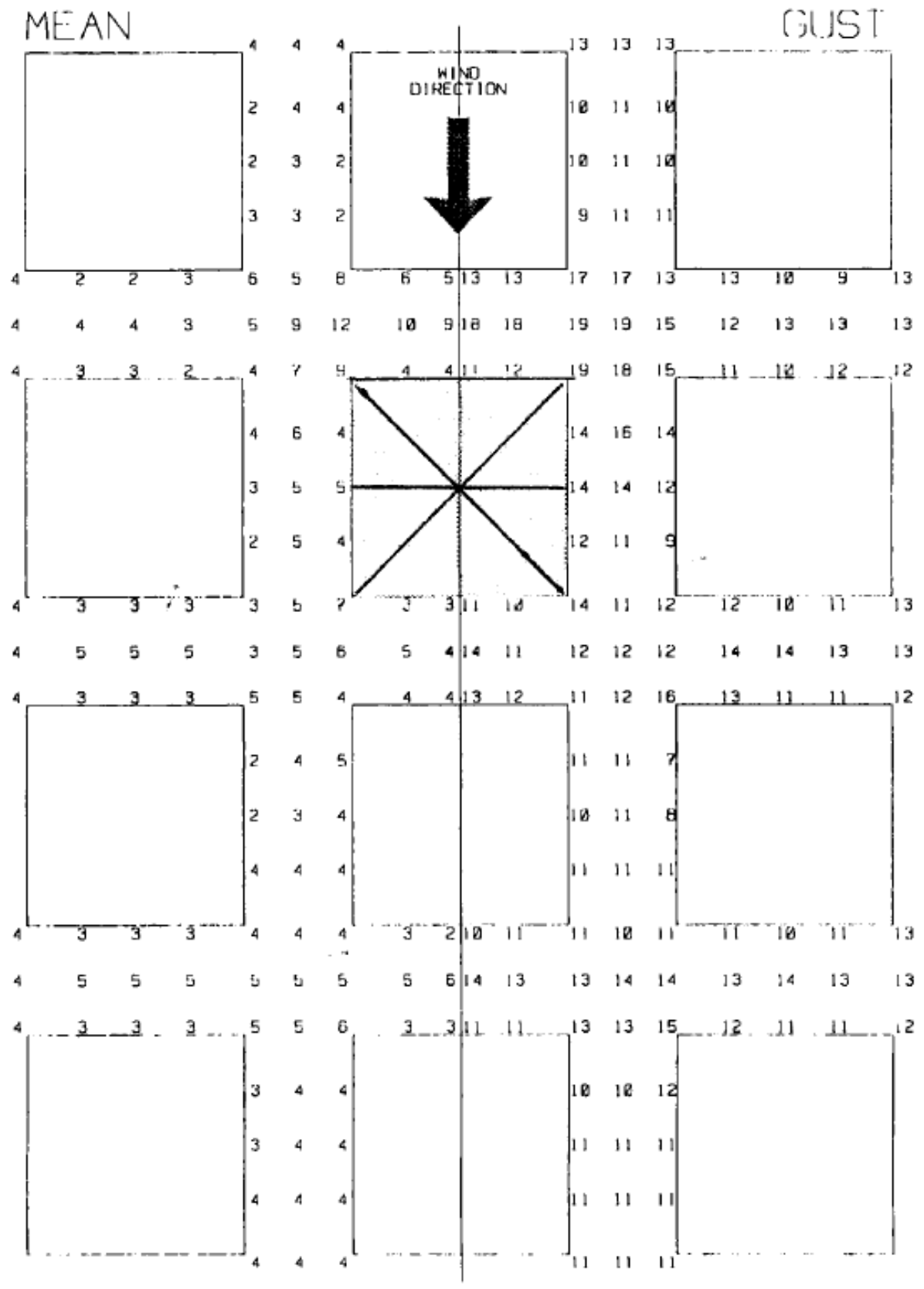

Figure 58: Original data for central cube configuration $360^{\circ}$ wind direction. Source: Jamieson et. al. (1992) 


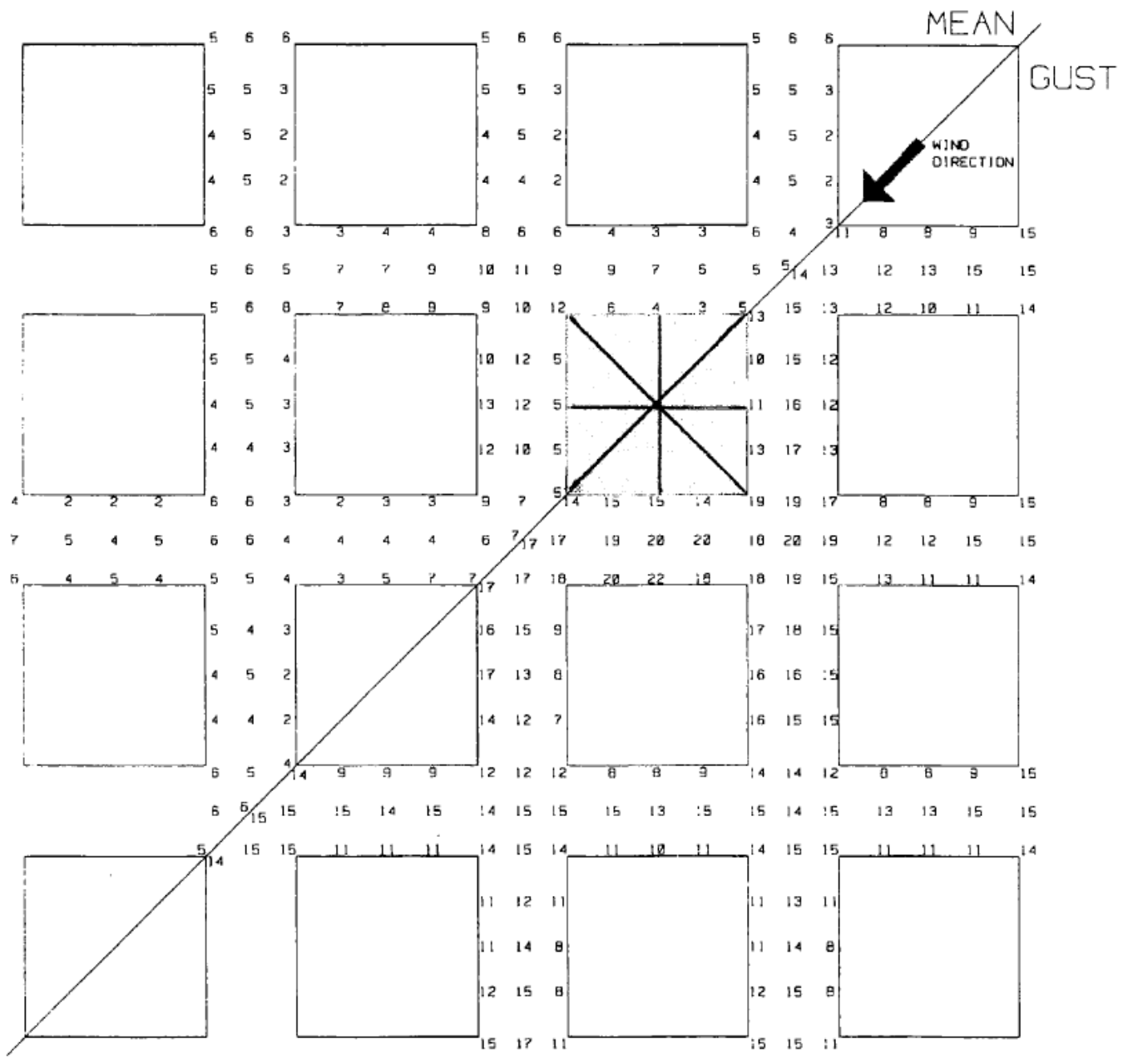

Figure 59: Original data for central cube configuration $45^{\circ}$ wind direction. Source: Jamieson et. al. (1992) 
TALL TOWER CONFIGURATION

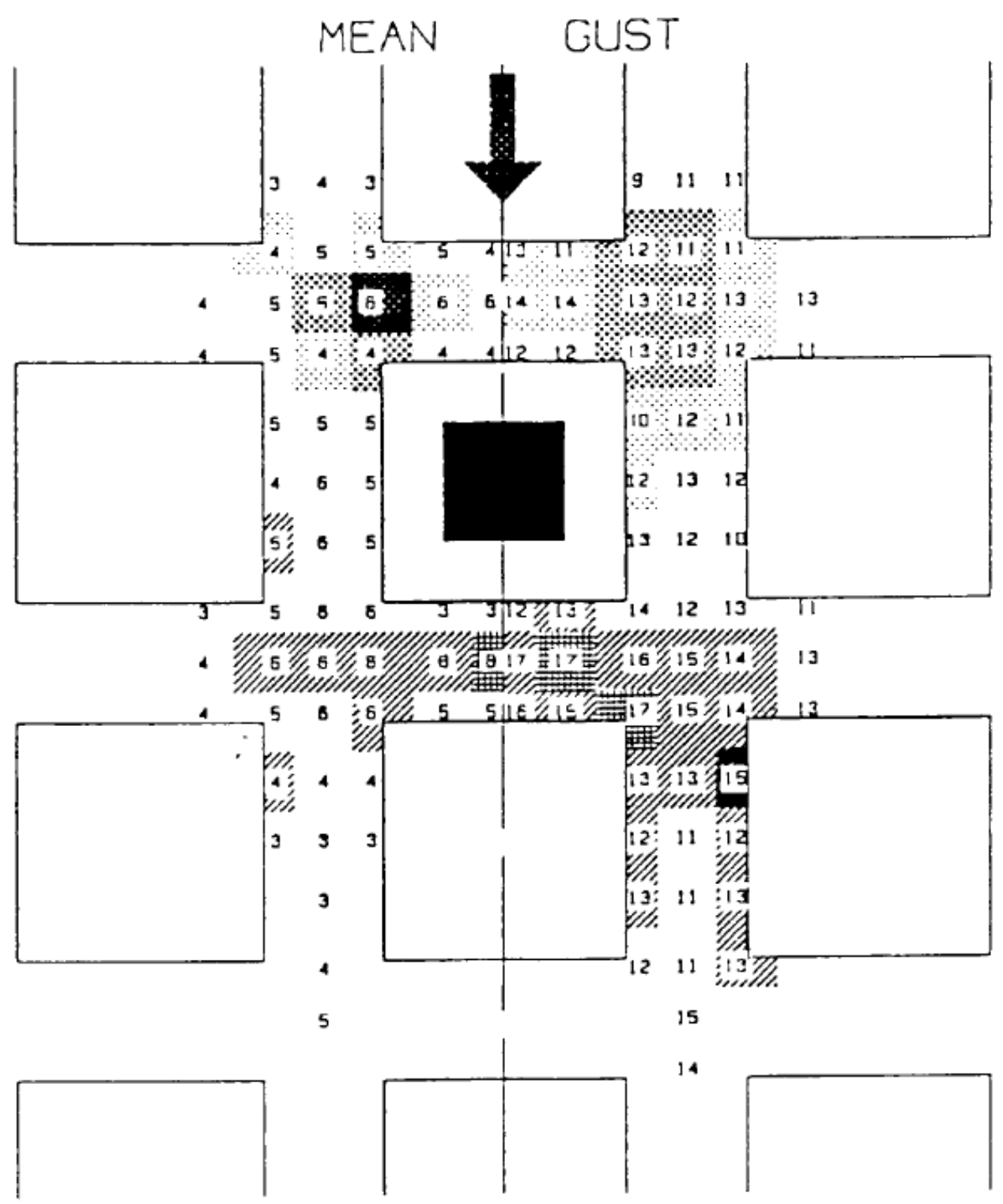

Figure 60: Original data for central tall tower $360^{\circ}$ wind direction. Indicating change from uniform city blocks. Source: Jamieson et. al. (1992) 


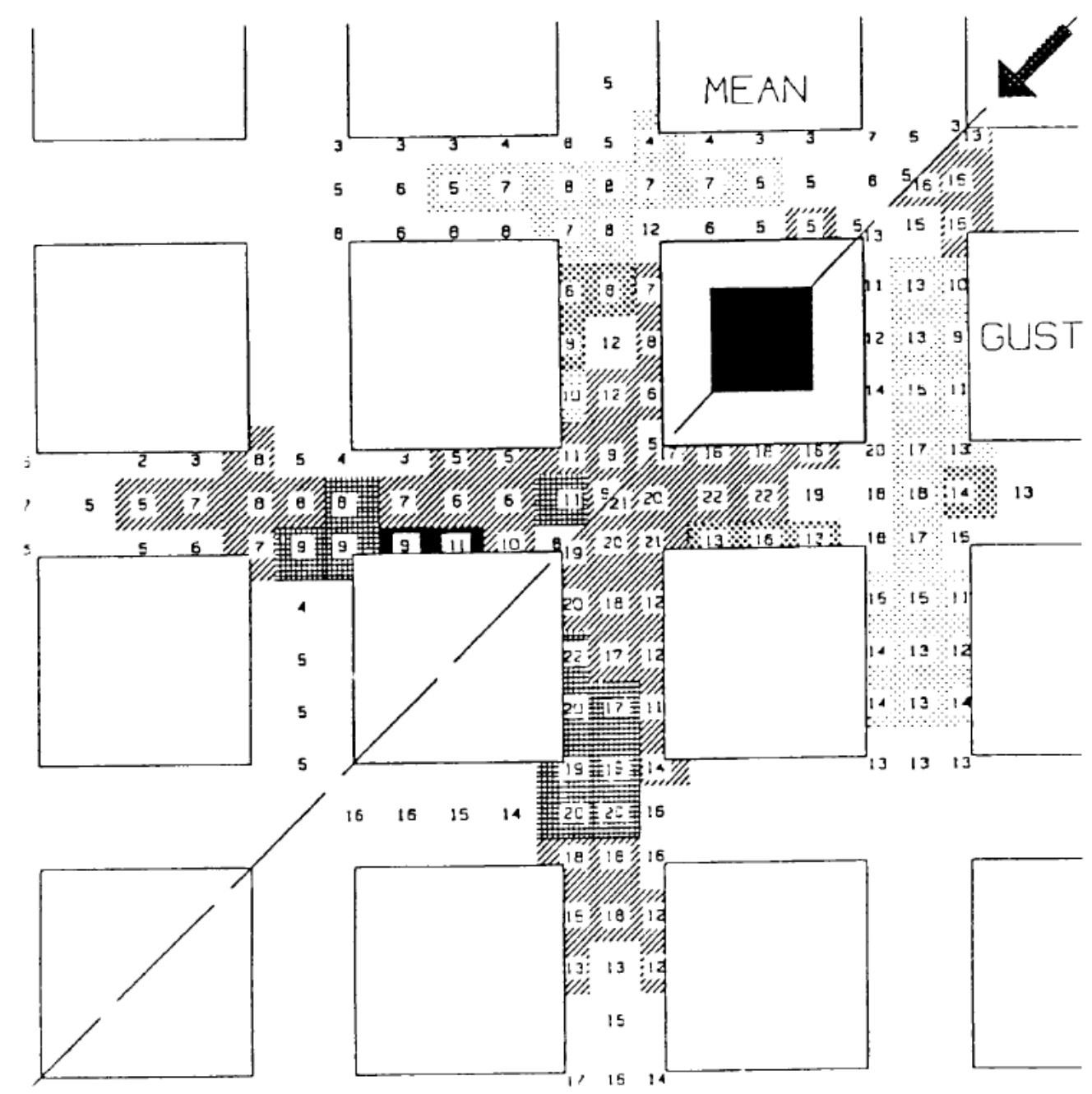

Figure 61: Original data for central tall tower $45^{\circ}$ wind direction. Indicating change from uniform city blocks. Source: Jamieson et. al. (1992) 
A calibration study was conducted on the $22^{\text {nd }}$ of October 2008 . This study used a $200 \mathrm{~mm}$ by $200 \mathrm{~mm}$ reference cube in the Opus Central Laboratories open circuit wind tunnel. Measurements were taken at 6 locations around the reference cube. Figure 62 below depicts these measurement locations.

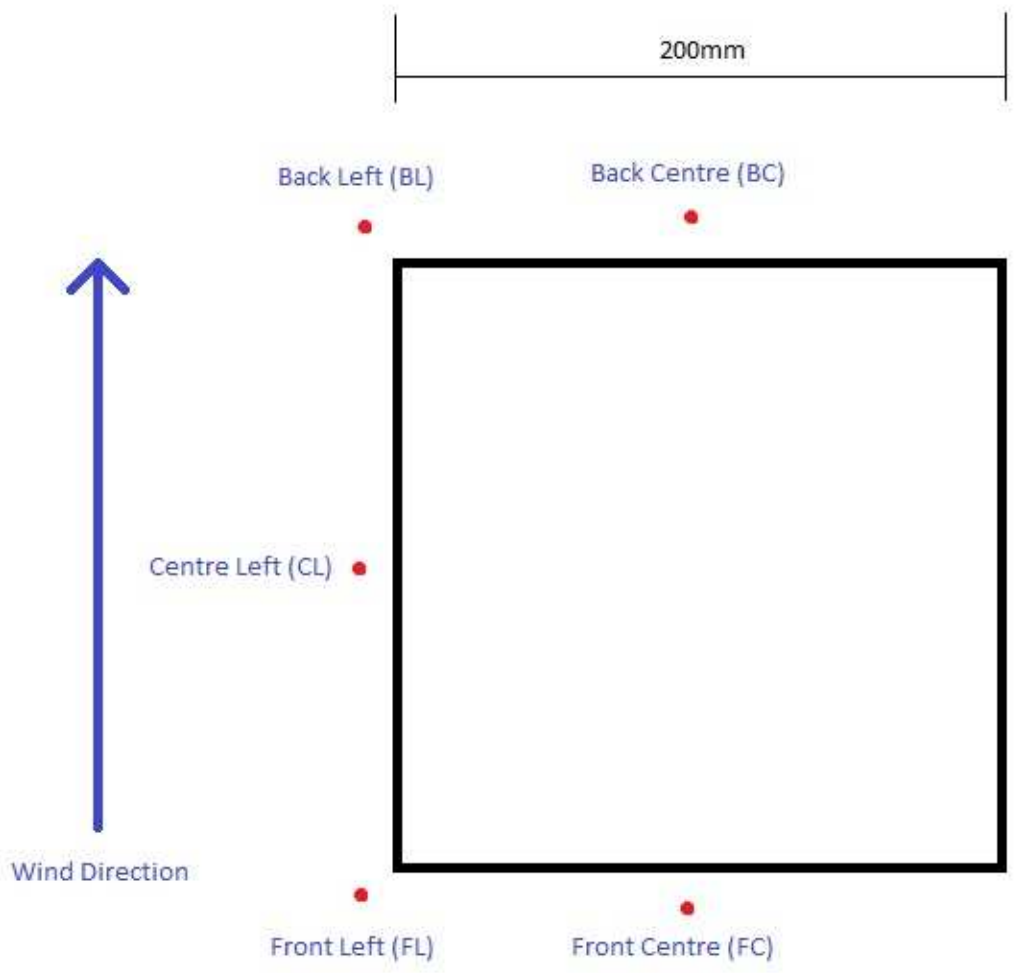

Figure 62: Measurement locations around the reference cube.

Measurements were taken at a distance of $7 \mathrm{~mm}$ from the cube in the 6 different locations. The aim of this study was to determine the difference in wind speed recorded with the hot film anemometer in a vertical orientation and with it in a horizontal orientation.

Upon assessing the results it was discovered that there was a difference in the measured wind speeds with the two different hot film anemometer orientations. The vertically orientated hot film anemometer measured higher wind speeds in areas where the wind flow was predominantly horizontal. These locations were: back 
centre, back left, centre left and front left. The horizontally orientated hot film measured a higher wind speed only at the front center location (where downwash is to be expected). An analysis of these results is shown in

Figure 63 below.

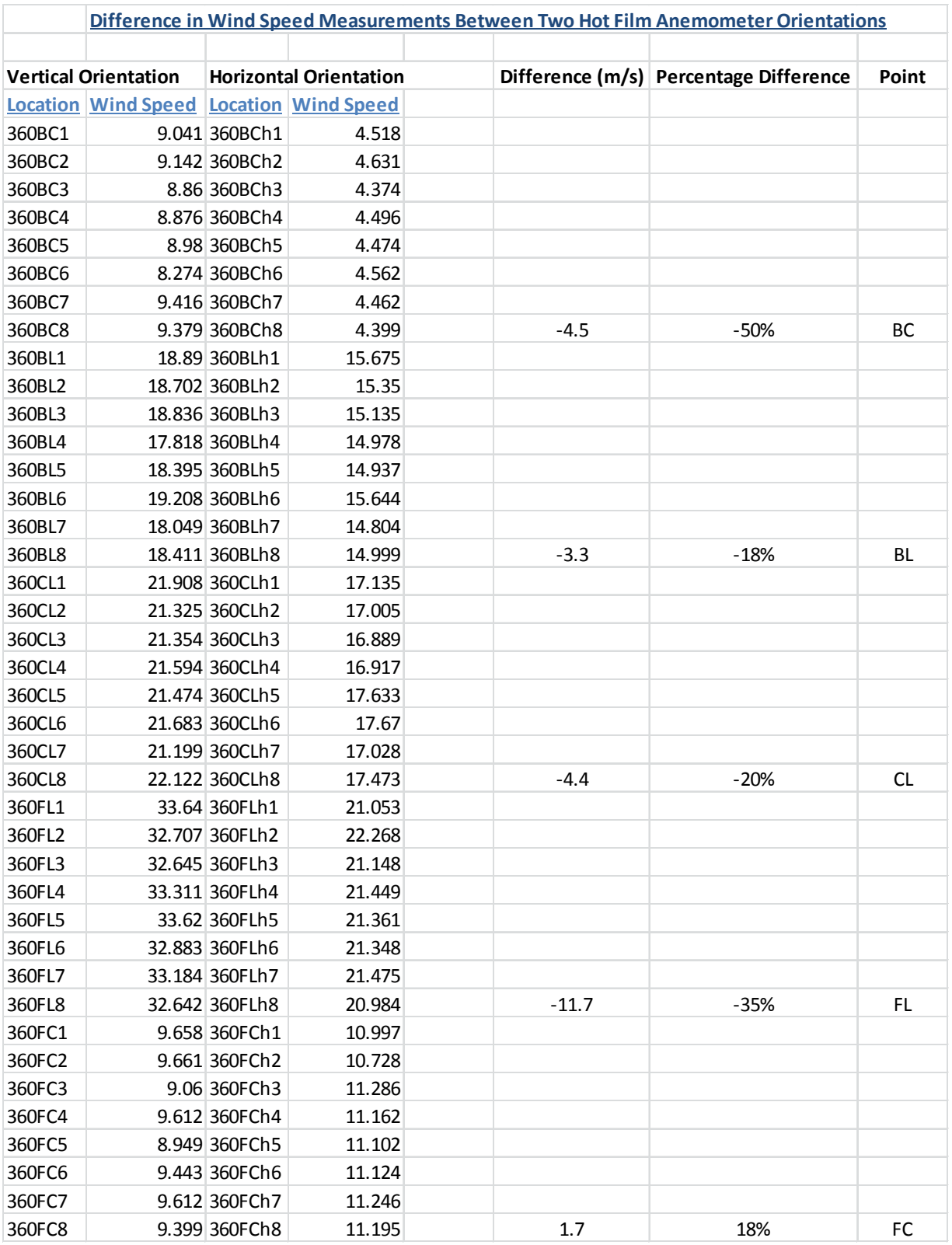

Figure 63: Analysis of the hot film orientation study. 
The percentage difference in measured wind speed ranged from 18 to $50 \%$. The vertically orientated hot film anemometer measured higher wind speeds in all locations in which horizontal wind flow was predominant. The horizontally orientated anemometer recorded much lower wind speeds for all of these locations. At the front centre location the horizontally orientated anemometer measured an $18 \%$ higher wind speed than the vertically orientated anemometer. When compared to the variations in measured wind speeds in all other locations $18 \%$ was the lowest variation. This suggests that a vertically orientated hot film anemometer will quantify horizontal wind flows more consistently than a horizontally orientated anemometer. Changing the orientation from vertical to horizontal will only result in a slightly increased measure of wind speed in areas of down wash. This indicates that a vertically orientated hot film anemometer will quantify horizontal wind flows accurately while providing a reasonably accurate measure of the vertical wind flow. Since it is the horizontal component of the wind velocity vector that most greatly affects pedestrian comfort and safety, a hot film anemometer should be vertically orientated to quantify this most accurately. 


\begin{tabular}{|c|c|c|c|c|c|c|c|c|c|c|c|c|c|c|}
\hline \multicolumn{15}{|c|}{ Filename: C:|Wind Tunnel Data\Wind Tunnel Calibration\Cal\Repeatability\DANTEC_repeatability_360.etb } \\
\hline \multicolumn{15}{|c|}{ Project Number: Calibration } \\
\hline \multicolumn{15}{|c|}{ Project Name: } \\
\hline \multicolumn{15}{|c|}{ Operator: Ben } \\
\hline \multicolumn{15}{|c|}{ Comments: Repeatability measurements on } \\
\hline \multicolumn{15}{|c|}{ Wind Direction: 360} \\
\hline \multicolumn{15}{|c|}{ Propeller Constant: 0.000} \\
\hline \multicolumn{15}{|c|}{ Propeller Coefficient: 8.000} \\
\hline Filter cu & -off frequen & ency: $1 \mathrm{~Hz}$ & & & & & & & & & & & & \\
\hline Scan rate & : $1000 \mathrm{~Hz}$ & & & & & & & & & & & & & \\
\hline Oversam & pling Rate: 2 & & & & & & & & & & & & & \\
\hline Channel & 1 Lineariser & r On Coeffic & icients: 0.0 & 0000000.76 & 693903.239 & 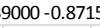 & 15300.8959 & & & & & & & \\
\hline Hot Wire & Slope: 1.050 & & & & & & & & & & & & & \\
\hline Hot Wire & Intercept: 0 & 0.0011 & & & & & & & & & & & & \\
\hline Hot Wire & Std. Error: 0 & 0.0003 & & & & & & & & & & & & \\
\hline a, Vmod & I/Vref: 0.80 & & & & & & & & & & & & & \\
\hline Design V & ind Speed: 2 & $: 21.0 \mathrm{~m} / \mathrm{s}$ & & & & & & & & & & & & \\
\hline Label & Mean & StdDev & Min & Max & EstMax & CalMax & EffGust & RefMean & RefStDv & Ref $\mathrm{m} / \mathrm{s}$ & Duratn & Temp & Type & Time \\
\hline *****En & Of Header* & $\mathrm{r}^{* * * * *}(\mathrm{Hot}$ & twire $\mathrm{V} 3.00$ & , August 20 & $000)$ & & & & & & & & & \\
\hline ref25 & 25.956 & 2.943 & 11.538 & 36.813 & 37.536 & 36.844 & 41.394 & 0.72 & 0.016 & 5.76 & 60 & 12.1 & 1 & $22 / 10 / 20087: 35$ \\
\hline $360 \mathrm{BC} 1$ & 3.049 & 1.953 & 0.205 & 19.513 & 17.101 & 10.274 & 9.041 & 1.415 & 0.026 & 11.32 & 60 & 11.9 & 1 & $22 / 10 / 20087: 39$ \\
\hline $360 \mathrm{BC} 2$ & 2.99 & 2.021 & 0.129 & 16.998 & 15.508 & 10.469 & 9.142 & 1.413 & 0.026 & 11.304 & 60 & 12 & 1 & $22 / 10 / 20087: 41$ \\
\hline 360BC3 & 3.011 & 1.902 & 0.232 & 19.432 & 17.122 & 10.049 & 8.86 & 1.411 & 0.025 & 11.288 & 60 & 12 & 1 & $22 / 10 / 20087: 44$ \\
\hline $360 B C 4$ & 3.05 & 1.889 & 0.227 & 13.933 & 14.084 & 10.038 & 8.876 & 1.412 & 0.025 & 11.296 & 60 & 12 & 1 & $22 / 10 / 20087: 45$ \\
\hline $360 \mathrm{BC} 5$ & 3.118 & 1.895 & 0.239 & 15.371 & 15.75 & 10.129 & 8.98 & 1.411 & 0.025 & 11.288 & 60 & 12.1 & 1 & $22 / 10 / 20087: 48$ \\
\hline $360 \mathrm{BC} 6$ & 2.836 & 1.764 & 0.244 & 16.53 & 14.861 & 9.364 & 8.274 & 1.414 & 0.026 & 11.312 & 60 & 12.1 & 1 & $22 / 10 / 20087: 50$ \\
\hline $360 \mathrm{BC} 7$ & 3.162 & 2.04 & 0.225 & 19.656 & 16.709 & 10.711 & 9.416 & 1.41 & 0.025 & 11.28 & 60 & 12.2 & 1 & $22 / 10 / 20087: 51$ \\
\hline $360 \mathrm{BC} 8$ & 3.246 & 1.984 & 0.243 & 15.445 & 16.043 & 10.587 & 9.379 & 1.417 & 0.026 & 11.336 & 60 & 12.2 & 1 & $22 / 10 / 20087: 54$ \\
\hline 360BL1 & 7.142 & 3.694 & 0.391 & 25.723 & 24.921 & 20.811 & 18.89 & 1.412 & 0.025 & 11.296 & 60 & 12.2 & 1 & $22 / 10 / 20087: 56$ \\
\hline 360BL2 & 6.862 & 3.762 & 0.383 & 28.834 & 28.251 & 20.782 & 18.702 & 1.413 & 0.025 & 11.304 & 60 & 12.3 & 1 & $22 / 10 / 20087: 58$ \\
\hline 360BL3 & 7.081 & 3.704 & 0.417 & 26.297 & 27.346 & 20.786 & 18.836 & 1.412 & 0.025 & 11.296 & 60 & 12.3 & 1 & $22 / 10 / 20087: 59$ \\
\hline 360BL4 & 6.689 & 3.509 & 0.419 & 25.421 & 24.829 & 19.671 & 17.818 & 1.414 & 0.025 & 11.312 & 60 & 12.3 & 1 & $22 / 10 / 20088: 01$ \\
\hline 360BL5 & 6.869 & 3.64 & 0.395 & 26.232 & 24.813 & 20.339 & 18.395 & 1.413 & 0.025 & 11.304 & 60 & 12.3 & 1 & $22 / 10 / 20088: 02$ \\
\hline 360BL6 & 7.128 & 3.824 & 0.515 & 24.648 & 26.862 & 21.276 & 19.208 & 1.411 & 0.025 & 11.288 & 60 & 12.3 & 1 & $22 / 10 / 20088: 03$ \\
\hline 360BL7 & 6.711 & 3.587 & 0.381 & 25.915 & 26.61 & 19.982 & 18.049 & 1.413 & 0.025 & 11.304 & 60 & 12.3 & 1 & $22 / 10 / 20088: 05$ \\
\hline 360BL8 & 6.881 & 3.64 & 0.456 & 30.253 & 29.733 & 20.351 & 18.411 & 1.413 & 0.025 & 11.304 & 60 & 12.3 & 1 & $22 / 10 / 20088: 06$ \\
\hline $360 \mathrm{CL} 1$ & 8.121 & 4.366 & 0.417 & 35.9 & 30.405 & 24.274 & 21.908 & 1.415 & 0.025 & 11.32 & 60 & 12.3 & 1 & $22 / 10 / 20088: 08$ \\
\hline $360 C L 2$ & 7.917 & 4.244 & 0.476 & 28.557 & 28.188 & 23.619 & 21.325 & 1.411 & 0.025 & 11.288 & 60 & 12.4 & 1 & $22 / 10 / 20088: 09$ \\
\hline $360 \mathrm{CL} 3$ & 7.875 & 4.276 & 0.486 & 28.298 & 30.865 & 23.695 & 21.354 & 1.411 & 0.025 & 11.288 & 60 & 12.4 & 1 & $22 / 10 / 20088: 12$ \\
\hline $360 C L 4$ & 7.957 & 4.327 & 0.531 & 29.107 & 30.288 & 23.967 & 21.594 & 1.415 & 0.025 & 11.32 & 60 & 12.4 & 1 & $22 / 10 / 20088: 14$ \\
\hline $360 C L 5$ & 7.785 & 4.367 & 0.516 & 30.359 & 30.332 & 23.942 & 21.474 & 1.41 & 0.025 & 11.28 & 60 & 12.4 & 1 & $22 / 10 / 20088: 16$ \\
\hline $360 \mathrm{CL} 6$ & 7.945 & 4.367 & 0.555 & 29.899 & 29.52 & 24.104 & 21.683 & 1.409 & 0.026 & 11.272 & 60 & 12.4 & 1 & $22 / 10 / 20088: 17$ \\
\hline $360 \mathrm{CL} 7$ & 7.825 & 4.241 & 0.527 & 28.022 & 28.176 & 23.517 & 21.199 & 1.412 & 0.025 & 11.296 & 60 & 12.5 & 1 & $22 / 10 / 20088: 18$ \\
\hline $360 C L 8$ & 8.152 & 4.433 & 0.381 & 34.364 & 31.844 & 24.552 & 22.122 & 1.41 & 0.025 & 11.28 & 60 & 12.5 & 1 & $22 / 10 / 20088: 19$ \\
\hline 360FL1 & 18.704 & 3.587 & 2.914 & 37.11 & 35.65 & 31.975 & 33.64 & 1.414 & 0.025 & 11.312 & 60 & 12.5 & 1 & $22 / 10 / 20088: 21$ \\
\hline $360 F L 2$ & 18.264 & 3.448 & 1.927 & 34.88 & 35.623 & 31.021 & 32.707 & 1.409 & 0.025 & 11.272 & 60 & 12.5 & 1 & $22 / 10 / 20088: 22$ \\
\hline $360 F L 3$ & 18.245 & 3.433 & 1.734 & 35.453 & 36.598 & 30.948 & 32.645 & 1.411 & 0.026 & 11.288 & 60 & 12.5 & 1 & $22 / 10 / 20088: 25$ \\
\hline $360 F L 4$ & 18.283 & 3.67 & 1.687 & 36.002 & 35.933 & 31.864 & 33.311 & 1.409 & 0.025 & 11.272 & 60 & 12.6 & 1 & $22 / 10 / 20088: 28$ \\
\hline $360 F L 5$ & 18.44 & 3.711 & 1.868 & 35.389 & 36.361 & 32.17 & 33.62 & 1.415 & 0.026 & 11.32 & 60 & 12.6 & 1 & $22 / 10 / 20088: 30$ \\
\hline $360 F L 6$ & 18.277 & 3.509 & 1.839 & 36.285 & 36.036 & 31.26 & 32.883 & 1.411 & 0.026 & 11.288 & 60 & 12.6 & 1 & $22 / 10 / 20088: 31$ \\
\hline $360 F L 7$ & 18.206 & 3.66 & 1.796 & 35.142 & 35.006 & 31.748 & 33.184 & 1.412 & 0.026 & 11.296 & 60 & 12.6 & 1 & $22 / 10 / 20088: 34$ \\
\hline 360FL8 & 18.136 & 3.487 & 2.393 & 32.87 & 33.643 & 31.037 & 32.642 & 1.414 & 0.026 & 11.312 & 60 & 12.6 & 1 & $22 / 10 / 20088: 35$ \\
\hline $360 \mathrm{FC} 1$ & 3.282 & 2.074 & 0.28 & 17.744 & 17.7 & 10.955 & 9.658 & 1.414 & 0.026 & 11.312 & 60 & 12.6 & 1 & $22 / 10 / 20088: 36$ \\
\hline $360 \mathrm{FC} 2$ & 3.258 & 2.087 & 0.27 & 19.104 & 17.982 & 10.979 & 9.661 & 1.415 & 0.025 & 11.32 & 60 & 12.6 & 1 & $22 / 10 / 20088: 38$ \\
\hline 360FC3 & 3.123 & 1.923 & 0.278 & 15.583 & 16.044 & 10.238 & 9.06 & 1.412 & 0.026 & 11.296 & 60 & 12.6 & 1 & $22 / 10 / 20088: 39$ \\
\hline $360 \mathrm{FC} 4$ & 3.267 & 2.063 & 0.344 & 17.61 & 17.745 & 10.902 & 9.612 & 1.411 & 0.026 & 11.288 & 60 & 12.6 & 1 & $22 / 10 / 20088: 40$ \\
\hline $360 \mathrm{FC5}$ & 3.044 & 1.92 & 0.288 & 19.388 & 16.742 & 10.148 & 8.949 & 1.414 & 0.026 & 11.312 & 60 & 12.6 & 1 & $22 / 10 / 20088: 41$ \\
\hline $360 \mathrm{FC6}$ & 3.222 & 2.021 & 0.3 & 17.948 & 17.29 & 10.699 & 9.443 & 1.415 & 0.025 & 11.32 & 60 & 12.6 & 1 & $22 / 10 / 20088: 42$ \\
\hline $360 F C 7$ & 3.262 & 2.066 & 0.315 & 16.897 & 15.918 & 10.906 & 9.612 & 1.411 & 0.025 & 11.288 & 60 & 12.7 & 1 & $22 / 10 / 20088: 45$ \\
\hline $360 \mathrm{FC} 8$ & 3.17 & 2.03 & 0.314 & 19.739 & 16.63 & 10.68 & 9.399 & 1.414 & 0.025 & 11.312 & 60 & 12.7 & 1 & $22 / 10 / 20088: 46$ \\
\hline ref25 & 26.066 & 2.905 & 12.791 & 37.502 & 38.321 & 36.813 & 41.437 & 0.72 & 0.016 & 5.76 & 60 & 12.8 & 1 & $22 / 10 / 20088: 55$ \\
\hline calo & Inf & Inf & $-\operatorname{lnf}$ & Inf & Inf & Inf & Inf & 0 & 0.001 & 0 & 10 & 15.4 & 2 & $22 / 10 / 20087: 29$ \\
\hline cal50 & 26.217 & 3.196 & 11.649 & 37.887 & 37.22 & 38.043 & 42.392 & 1.41 & 0.026 & 11.28 & 60 & 11.9 & 2 & $22 / 10 / 20087: 30$ \\
\hline cal50 & 26.323 & 3.177 & 8.793 & 37.582 & 37.519 & 38.077 & 42.479 & 1.411 & 0.026 & 11.288 & 60 & 11.8 & 2 & $22 / 10 / 20087: 32$ \\
\hline calo & $-\operatorname{Inf}$ & Inf & $-\operatorname{Inf}$ & Inf & Inf & $\mathrm{NaN}$ & $\mathrm{NaN}$ & 0 & 0.001 & 0 & 10 & 14.3 & 2 & $22 / 10 / 20088: 50$ \\
\hline cal50 & 26.273 & 3.114 & 13.267 & 38.424 & 39.16 & 37.794 & 42.251 & 1.413 & 0.025 & 11.304 & 60 & 12.7 & 2 & $22 / 10 / 20088: 53$ \\
\hline cal50 & 26.187 & 3.172 & 11.199 & 37.753 & 38.287 & 37.925 & 42.291 & 1.414 & 0.025 & 11.312 & 60 & 12.6 & 2 & $22 / 10 / 20088: 54$ \\
\hline
\end{tabular}

Figure 64: Raw data for wind speeds taken around a reference cube with a vertically orientated anemometer. 
Filename: C:\Wind Tunnel Data\Wind Tunnel Calibration\Cal\Repeatability\DANTEC_repeatability_360_horizontal.etb Project Number: Calibration

Project Name:

Operator: Ben

Comments: Horizontal Hot Film Orientation

Wind Direction: 360

Propeller Constant: 0.000

Propeller Coefficient: 8.000

Filter cut-off frequency: $1 \mathrm{~Hz}$

Scan rate: $1000 \mathrm{~Hz}$

Oversampling Rate: 20

Channel 1 Lineariser On Coefficients: $0.0000000 .7693903 .239000-0.8715300 .895940$

Hot Wire Slope: 1.0381

Hot Wire Intercept: 0.0029

Hot Wire Std. Error: 0.0047

a, Vmodel/Vref: 0.800

Design Wind Speed: $21.0 \mathrm{~m} / \mathrm{s}$

Label Mean StdDev Min Max EstMax CalMax EffGust RefMean RefStDv Ref m/s Duratn Temp Type Time *****End Of Header***** (Hotwire V3.00, August 2000)

\begin{tabular}{|l|r|r|r|r|r|r|r|r|r|r|r|r|r|r|}
\hline ref25 & 26.004 & 3.028 & 13.836 & 39.865 & 39.146 & 37.206 & 41.677 & 0.72 & 0.016 & 5.76 & 60 & 11.1 & 1 & $23 / 10 / 20087: 34$ \\
\hline
\end{tabular}

\begin{tabular}{|l|r|r|r|r|r|r|r|r|r|r|r|r|r|r|r|}
\hline 360BCh1 & 1.625 & 0.925 & 0.13 & 9.677 & 9.43 & 5.049 & 4.518 & 1.41 & 0.025 & 11.28 & 60 & 10.9 & 1 & $23 / 10 / 20087: 39$ \\
\hline
\end{tabular}

\begin{tabular}{|l|l|l|l|l|l|l|l|l|l|l|l|l|l|l|}
\hline 360BCh2 & 1.658 & 0.952 & 0.175 & 10.975 & 10.179 & 5.181 & 4.631 & 1.413 & 0.025 & 11.304 & 60 & 10.9 & 1 & $23 / 10 / 20087: 41$ \\
\hline
\end{tabular}

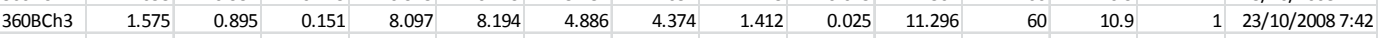

\begin{tabular}{|l|r|r|r|r|r|r|r|r|r|r|r|r|r|r|r|}
\hline $360 \mathrm{BCh} 4$ & 1.604 & 0.927 & 0.154 & 9.917 & 9.751 & 5.035 & 4.496 & 1.414 & 0.025 & 11.312 & 60 & 11 & 1 & $23 / 10 / 20087: 43$ \\
\hline
\end{tabular}

\begin{tabular}{|l|r|r|r|r|r|r|r|r|r|r|r|r|r|r|}
\hline 360BCh5 & 1.63 & 0.906 & 0.181 & 9.435 & 9.515 & 4.982 & 4.474 & 1.41 & 0.025 & 11.28 & 60 & 11 & 1 & $23 / 10 / 20087: 45$ \\
\hline
\end{tabular}

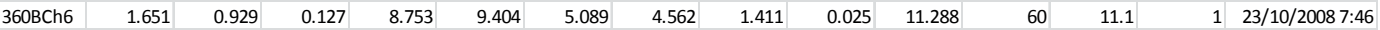

\begin{tabular}{|l|l|l|l|l|l|l|l|l|l|l|l|l|l|l|}
\hline $360 \mathrm{BCh} 7$ & 1.617 & 0.908 & 0.166 & 9.216 & 8.832 & 4.975 & 4.462 & 1.411 & 0.025 & 11.288 & 60 & 11.1 & 1 & $23 / 10 / 20087: 48$ \\
\hline
\end{tabular}

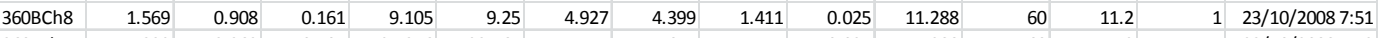

\begin{tabular}{|l|l|l|l|l|l|l|l|l|l|l|l|l|l|l|}
\hline 360BLh1 & 5.332 & 3.363 & 0.405 & 24.376 & 23.765 & 17.774 & 15.675 & 1.411 & 0.025 & 11.288 & 60 & 11.2 & 1 & $23 / 10 / 20087: 52$ \\
\hline
\end{tabular}

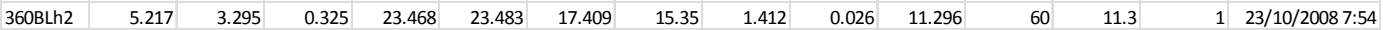

\begin{tabular}{|r|r|r|r|r|r|r|r|r|r|r|r|r|r|r|r|r|r|}
\hline 360BLh3 & 5.037 & 3.302 & 0.441 & 22.966 & 24.212 & 17.256 & 15.135 & 1.411 & 0.025 & 11.288 & 60 & 11.3 & 1 & $23 / 10 / 20087: 56$ \\
\hline
\end{tabular}

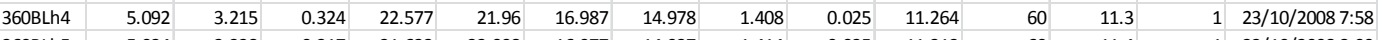

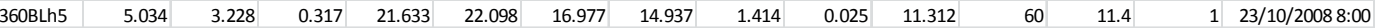

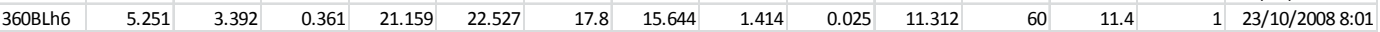

\begin{tabular}{|l|r|r|r|r|r|r|r|r|r|r|r|r|r|r|r|r|}
\hline 360 BLh7 & 5 & 3.194 & 0.328 & 21.445 & 22.265 & 16.817 & 14.804 & 1.412 & 0.026 & 11.296 & 60 & 11.4 & 1 & $23 / 10 / 20088: 02$ \\
\hline
\end{tabular}

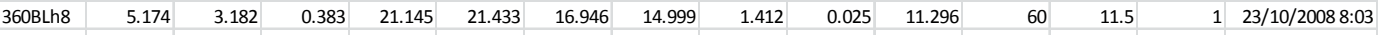

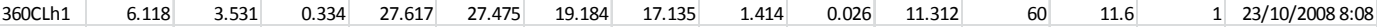

\begin{tabular}{|l|r|r|r|r|r|r|r|r|r|r|r|r|r|r|r|}
\hline 360CLh2 & 6.07 & 3.505 & 0.321 & 24.676 & 25.901 & 19.039 & 17.005 & 1.41 & 0.025 & 11.28 & 60 & 11.6 & 1 & $23 / 10 / 20088: 09$ \\
\hline
\end{tabular}

\begin{tabular}{|l|r|r|r|r|r|r|r|r|r|r|r|r|r|r|r|r|r|}
\hline 360 CLh3 & 6.073 & 3.459 & 0.394 & 26.805 & 24.104 & 18.873 & 16.889 & 1.406 & 0.025 & 11.248 & 60 & 11.6 & 1 & $23 / 10 / 20088: 12$ \\
\hline
\end{tabular}

\begin{tabular}{|l|l|l|l|l|l|l|l|l|l|l|l|l|l|l|}
\hline 360CLh4 & 6.041 & 3.486 & 0.355 & 28.106 & 24.531 & 18.939 & 16.917 & 1.41 & 0.025 & 11.28 & 60 & 11.6 & 1 & $23 / 10 / 2008$ \\
\hline
\end{tabular}

\begin{tabular}{|l|l|l|l|l|l|l|l|l|l|l|l|l|l|l|}
\hline 360 LLh5 & 6.279 & 3.642 & 0.346 & 30.908 & 27.073 & 19.756 & 17.633 & 1.414 & 0.025 & 11.312 & 60 & 11.7 & 1 & $23 / 10 / 2008$ \\
\hline
\end{tabular}

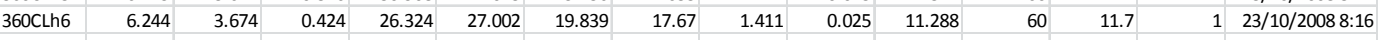

\begin{tabular}{|l|l|l|l|l|l|l|l|l|l|l|l|l|l|l|}
\hline 360CLh7 & 6.107 & 3.495 & 0.429 & 23.782 & 23.787 & 19.04 & 17.028 & 1.412 & 0.025 & 11.296 & 60 & 11.7 & 1 & $23 / 10 / 20088: 18$ \\
\hline
\end{tabular}

\begin{tabular}{|l|l|l|l|l|l|l|l|l|l|l|l|l|l|l|}
\hline 360 CLh8 & 6.165 & 3.638 & 0.275 & 28.294 & 27.393 & 19.625 & 17.473 & 1.411 & 0.026 & 11.288 & 60 & 11.7 & 1 & $23 / 10 / 20088: 20$ \\
\hline
\end{tabular}

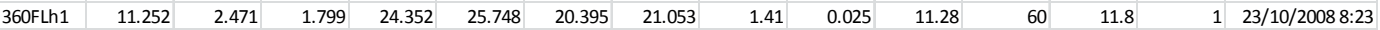

\begin{tabular}{|l|r|r|r|r|r|r|r|r|r|r|r|r|r|r|r|r|}
\hline 360FLh2 & 11.755 & 2.687 & 1.614 & 31.231 & 27.442 & 21.698 & 22.268 & 1.407 & 0.025 & 11.256 & 60 & 11.8 & 1 & $23 / 10 / 20088: 24$ \\
\hline
\end{tabular}

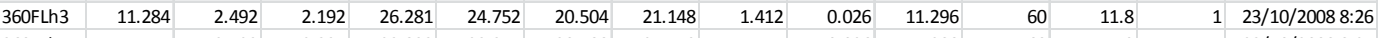

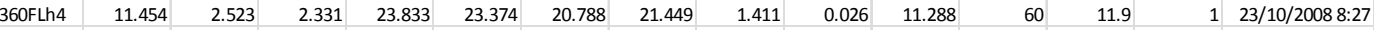

\begin{tabular}{|l|l|l|l|l|l|l|l|l|l|l|l|l|l|l|}
\hline $360 F L h 5$ & 11.391 & 2.52 & 2.022 & 25.51 & 23.842 & 20.716 & 21.361 & 1.411 & 0.025 & 11.288 & 60 & 11.9 & 1 & $23 / 10 / 20088: 29$ \\
\hline
\end{tabular}

\begin{tabular}{|l|r|r|r|r|r|r|r|r|r|r|r|r|r|r|r|r|}
\hline 360FLh6 & 11.397 & 2.512 & 1.968 & 25.299 & 24.642 & 20.692 & 21.348 & 1.41 & 0.025 & 11.28 & 60 & 11.9 & 1 & $23 / 10 / 20088: 30$ \\
\hline
\end{tabular}

\begin{tabular}{|l|r|r|r|r|r|r|r|r|r|r|r|r|r|r|}
\hline 360FLh7 & 11.44 & 2.539 & 2.411 & 24.486 & 23.704 & 20.836 & 21.475 & 1.407 & 0.025 & 11.256 & 60 & 11.9 & 1 & $23 / 10 / 20088: 31$ \\
\hline
\end{tabular}

\begin{tabular}{|l|l|l|l|l|l|l|l|l|l|l|l|l|l|l|}
\hline 360FLh8 & 11.174 & 2.484 & 1.817 & 23.261 & 25.016 & 20.365 & 20.984 & 1.411 & 0.026 & 11.288 & 60 & 12 & 1 & $23 / 10 / 2008$ \\
\hline
\end{tabular}

\begin{tabular}{|l|l|l|l|l|l|l|l|l|l|l|l|r|r|}
\hline 360FCh1 & 4.132 & 2.163 & 0.281 & 18.052 & 17.536 & 12.137 & 10.997 & 1.406 & 0.025 & 11.248 & 60 & 12 & $123 / 10 / 20088: 34$ \\
\hline
\end{tabular}

\begin{tabular}{|l|r|r|r|r|r|r|r|r|r|r|r|r|r|r|r|r|}
\hline 360 FCh2 & 4.003 & 2.125 & 0.309 & 16.085 & 16.612 & 11.865 & 10.728 & 1.409 & 0.025 & 11.272 & 60 & 12 & 1 & $23 / 10 / 20088: 35$ \\
\hline
\end{tabular}

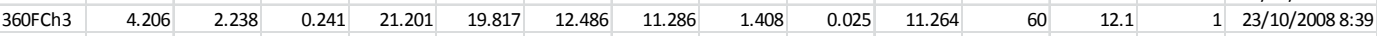

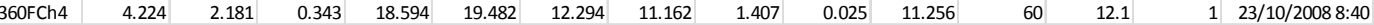

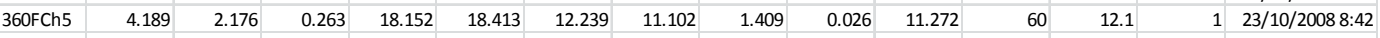

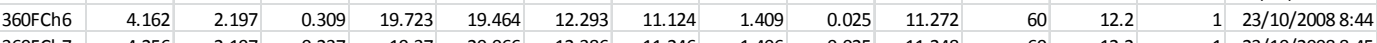

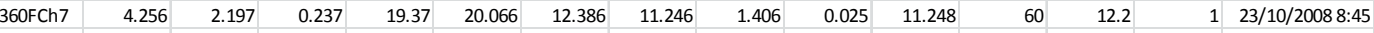

\begin{tabular}{|l|l|l|l|l|l|l|l|l|l|l|l|l|l|l|}
\hline $360 F C h 8$ & 4.27 & 2.171 & 0.322 & 16.502 & 17.316 & 12.302 & 11.195 & 1.406 & 0.025 & 11.248 & 60 & 12.2 & 1 & $23 / 10 / 2008$ \\
\hline
\end{tabular}

\begin{tabular}{|l|l|l|l|l|l|l|l|r|r|r|r|r|r|r|}
\hline cal0 & Inf & $\mathrm{NaN}$ & $-\operatorname{lnf}$ & $\mathrm{Inf}$ & $\mathrm{Inf}$ & $\mathrm{NaN}$ & $\mathrm{NaN}$ & 0 & 0 & 0 & 10 & 14.7 & 1 & $23 / 10 / 20088: 54$ \\
\hline
\end{tabular}

\begin{tabular}{|l|r|r|r|r|r|r|r|r|r|r|r|r|r|r|}
\hline ref25 & 25.502 & 3.084 & 10.606 & 36.854 & 36.684 & 36.911 & 41.17 & 0.718 & 0.016 & 5.744 & 60 & 12.4 & 1 & $23 / 10 / 20089: 01$ \\
\hline
\end{tabular}

\begin{tabular}{|l|l|l|l|l|l|l|l|l|l|l|l|l|l|l|}
\hline $360 F C i 1$ & 3.604 & 1.919 & 0.287 & 17.571 & 17.496 & 10.704 & 9.674 & 1.411 & 0.025 & 11.288 & 60 & 12.5 & 1 & $23 / 10 / 20089: 58$ \\
\hline
\end{tabular}

\begin{tabular}{|l|r|r|r|r|r|r|r|r|r|r|r|r|r|r|}
\hline $360 F C i 2$ & 3.577 & 1.93 & 0.299 & 18.47 & 19.265 & 10.72 & 9.67 & 1.408 & 0.025 & 11.264 & 60 & 12.5 & 1 & $23 / 10 / 20089: 59$ \\
\hline
\end{tabular}

\begin{tabular}{|l|l|l|l|l|l|l|l|l|l|l|l|l|l|l|}
\hline $360 \mathrm{FCi} 3$ & 3.678 & 1.936 & 0.304 & 16.598 & 17.069 & 10.842 & 9.816 & 1.411 & 0.026 & 11.288 & 60 & 12.5 & $123 / 10 / 200810: 00$ \\
\hline
\end{tabular}

\begin{tabular}{|l|r|r|r|r|r|r|r|r|r|r|r|r|r|}
\hline $360 F C i 4$ & 3.625 & 1.9 & 0.323 & 15.893 & 17.764 & 10.655 & 9.652 & 1.411 & 0.026 & 11.288 & 60 & 12.6 & $123 / 10 / 200810: 02$ \\
\hline
\end{tabular}

\begin{tabular}{|l|r|r|r|r|r|r|r|r|r|r|r|r|r|}
\hline $360 \mathrm{FCi} 5$ & 3.56 & 1.903 & 0.349 & 17.438 & 17.16 & 10.602 & 9.577 & 1.412 & 0.025 & 11.296 & 60 & 12.6 & $123 / 10 / 200810: 03$ \\
\hline
\end{tabular}

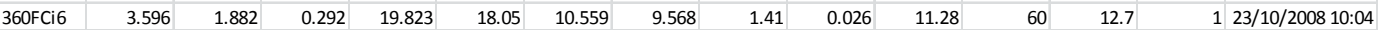

\begin{tabular}{|l|r|r|r|r|r|r|r|r|r|r|r|r|r|r|r|r|}
\hline $360 F C i 7$ & 3.604 & 1.87 & 0.321 & 16.602 & 16.454 & 10.523 & 9.547 & 1.408 & 0.026 & 11.264 & 60 & 12.7 & $123 / 10 / 200810: 05$ \\
\hline
\end{tabular}

\begin{tabular}{|l|r|r|r|r|r|r|r|r|r|r|r|r|r|r|}
\hline $360 F C i 8$ & 3.717 & 1.943 & 0.323 & 18.643 & 17.264 & 10.907 & 9.885 & 1.411 & 0.026 & 11.288 & 60 & 12.7 & 1 & $23 / 10 / 200810: 06$ \\
\hline
\end{tabular}

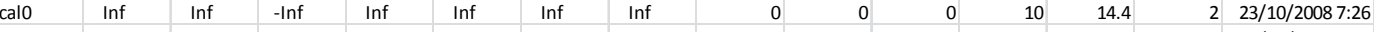

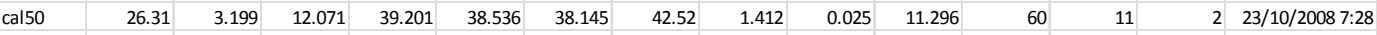

\begin{tabular}{|l|r|r|r|r|r|r|r|r|r|r|r|r|r|r|r|}
\hline cal50 & 26.354 & 3.235 & 13.184 & 40.012 & 38.398 & 38.324 & 42.672 & 1.416 & 0.026 & 11.328 & 60 & 10.8 & $23 / 10 / 20087: 30$ \\
\hline cal50 & 25.944 & 3.252 & 13.92 & 39.005 & 39.453 & 37.977 & 42.182 & 1.415 & 0.026 & 11.32 & 60 & 12.2 & 2 & $23 / 10 / 20088: 57$ \\
\hline
\end{tabular}

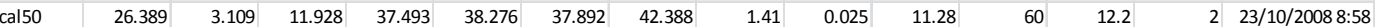

Figure 65: Raw data for wind speeds taken around a reference cube with a horizontally orientated anemometer 